\title{
Influence of Aggregate Characteristics on Concrete Performance
}
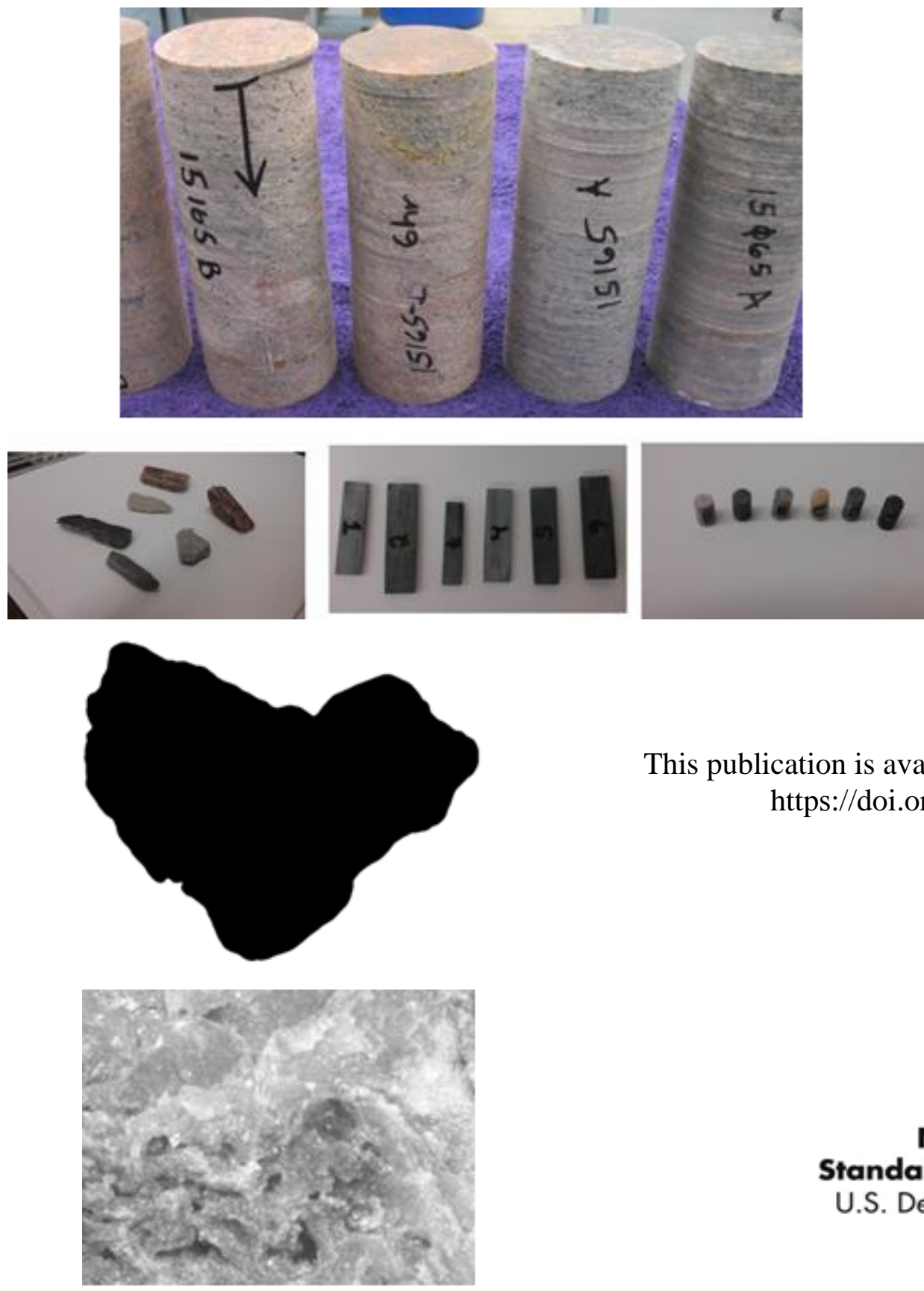

Dale P. Bentz Joshua Arnold Michael J. Boisclair Scott Z. Jones Paul Rothfeld Paul E. Stutzman Jussara Tanesi Mengesha Beyene Haejin Kim Jose Muñoz Ahmad Ardani

This publication is available free of charge from: https://doi.org/10.6028/NIST.TN.1963

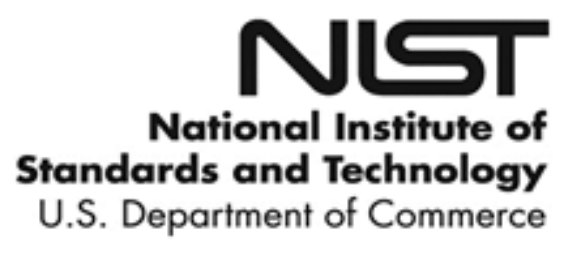

National Institute of Standards and Technology .S. Departmer 



\title{
NIST Technical Note 1963
}

\section{Influence of Aggregate Characteristics on Concrete Performance}

\author{
Dale P. Bentz \\ Joshua Arnold \\ Michael J. Boisclair \\ Scott Z. Jones \\ Paul Rothfeld \\ Paul E. Stutzman \\ Materials and Structural Systems Division \\ Engineering Laboratory \\ Jussara Tanesi \\ Mengesha Beyene \\ Haejin Kim \\ Jose Muñoz \\ SES Group and Associates
}

Ahmad Ardani

Federal Highway Administration

This publication is available free of charge from: https://doi.org/10.6028/NIST.TN.1963

May 2017

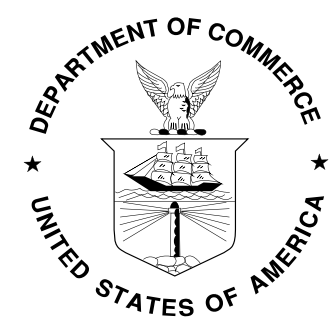

U.S. Department of Commerce

Wilbur L. Ross, Jr., Secretary

National Institute of Standards and Technology Kent Rochford, Acting NIST Director and Under Secretary of Commerce for Standards and Technology 
Certain commercial entities, equipment, or materials may be identified in this document in order to describe an experimental procedure or concept adequately. Such identification is not intended to imply recommendation or endorsement by the National Institute of Standards and Technology, nor is it intended to imply that the entities, materials, or equipment are necessarily the best available for the purpose.

National Institute of Standards and Technology Technical Note 1963

Natl. Inst. Stand. Technol. Tech. Note 1963, 109 pages (May 2017) CODEN: NTNOEF

This publication is available free of charge from:

https://doi.org/10.6028/NIST.TN.1963 


\begin{abstract}
While the influence of paste properties on concrete performance has been extensively studied and in many cases reduced to quantitative relationships (e.g., Abram's law), that between aggregate characteristics and concrete performance has not been investigated in detail. Based on previous research that demonstrated significant strength differences for two similar concrete mixtures, one prepared with limestone aggregates and the other with siliceous gravel, a joint study between the National Institute of Standards and Technology (NIST) and the Federal Highway Administration (FHWA) was initiated to explore in detail the influence of aggregate source, mineralogy, and material properties on concrete performance. Eleven aggregates of differing mineralogy were identified and obtained both for bulk characterization and for incorporation into two concrete mixtures. The first concrete mixture was based on a $100 \%$ ordinary Type I/II portland cement (OPC), while the second consisted of a ternary 60:30:10 volumetric blend of this cement with $30 \%$ of a Class $\mathrm{C}$ fly ash and $10 \%$ of a fine limestone powder. This latter sustainable mixture had exhibited exemplary performance in a previous study. Aggregates were characterized with respect to mechanical and thermomechanical properties, geometrical characteristics, and surface energies. For the prepared concretes, mechanical, thermomechanical, and electrical properties were measured at different ages out to $91 \mathrm{~d}$ and microstructural examinations were conducted to examine the interfaces between aggregates and cement paste. Concrete performance varied widely amongst the different aggregates, with the (range/average) ratio for 28-d compressive strength being 0.32 for the OPC concretes and 0.37 for those based on the ternary blend binder. With the exceptions of relating concrete modulus to aggregate modulus and concrete coefficient of thermal expansion (CTE) to aggregate CTE, weak correlations were generally obtained between a single aggregate characteristic and concrete performance properties. Models to predict 28-d compressive strength based on the aggregates' CTE (and aggregate absorption in the case of the ternary blend mixtures) provided predictions with a relative standard error (standard error/mean) of about $7 \%$. It is suggested that aggregate and binder characteristics control the bond between aggregates and paste. Then, for most properties, concrete performance is primarily controlled by the level of this bonding, a characteristic that was only assessed in an indirect manner in the present study. Research using non-linear ultrasonic measurements to better assess this bonding in specimens remaining from the present study is currently underway.
\end{abstract}

Keywords: Aggregate mineralogy; aggregate shape; aggregate texture; bond; coefficient of thermal expansion (CTE); interfacial transition zone (ITZ); modulus; strength. 


\section{TABLE OF CONTENTS}

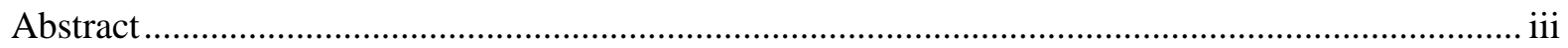

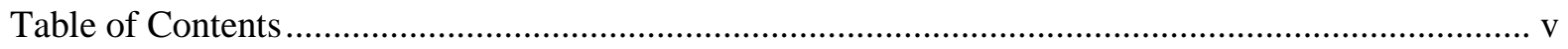

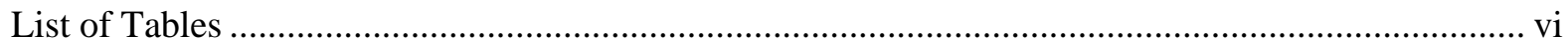

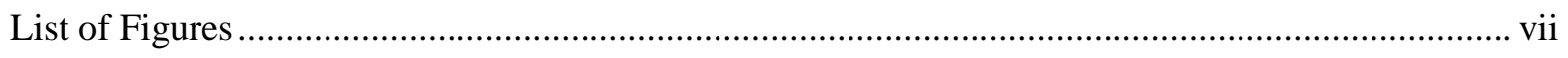

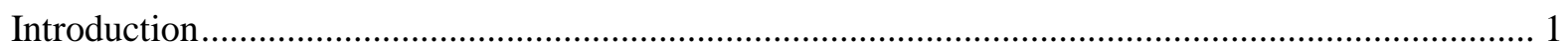

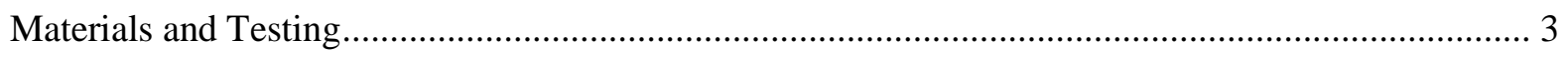

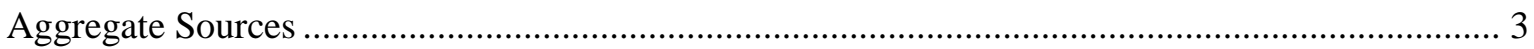

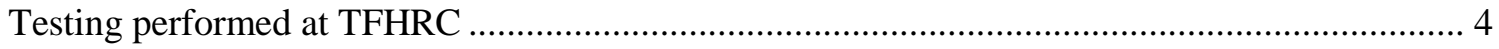

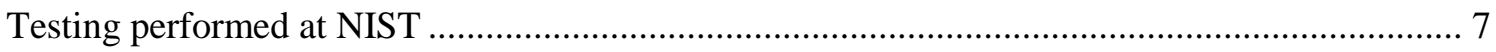

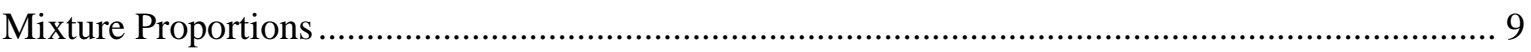

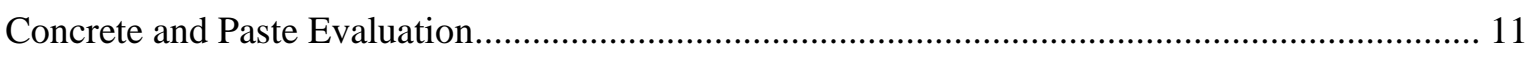

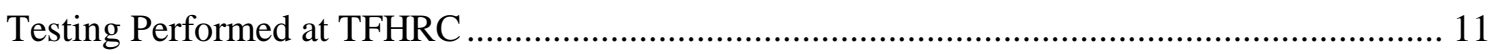

Testing performed at NIST (SEM Preparation and Analysis) ............................................... 12

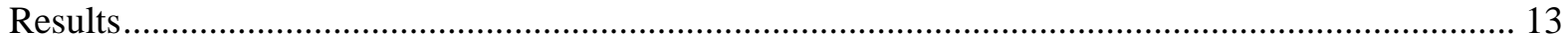

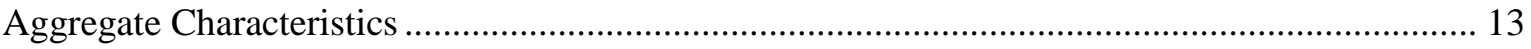

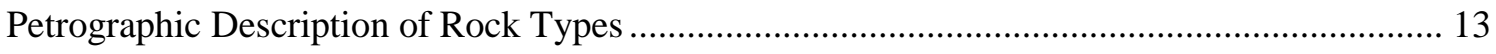

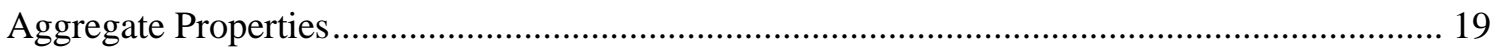

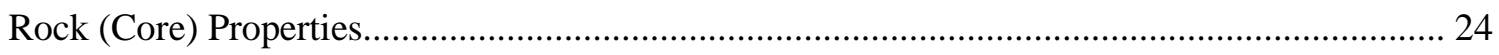

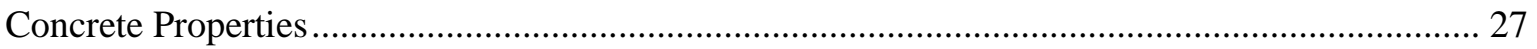

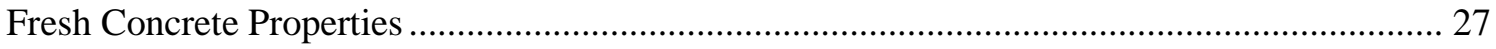

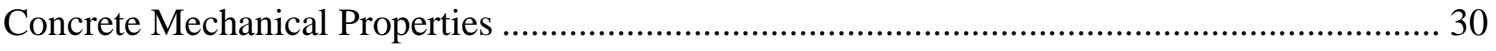

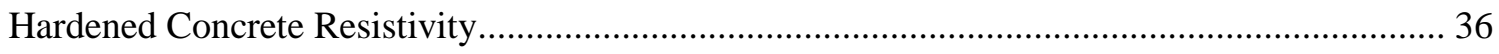

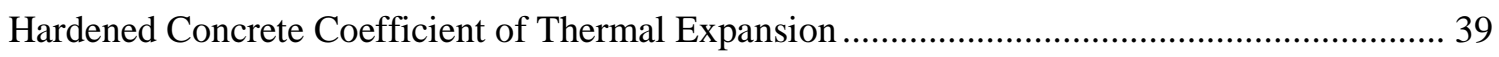

Concrete Mechanical Properties in Relation to Aggregate Characteristics ................................... 42

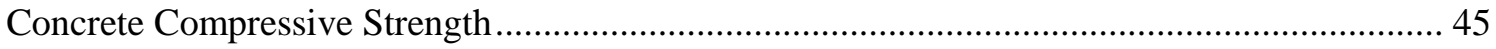

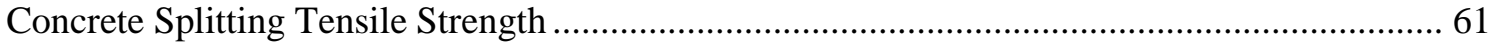

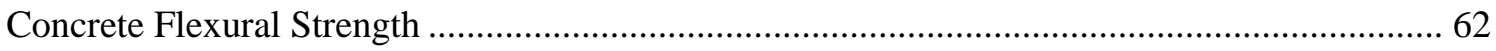

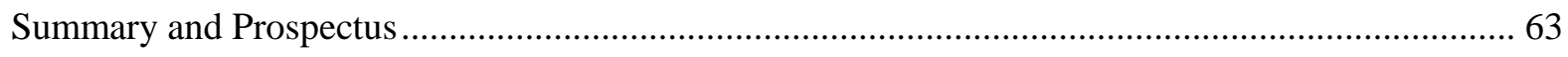

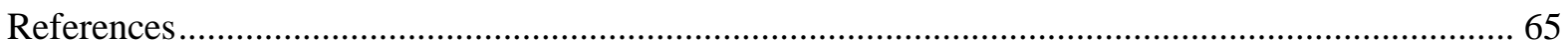

Appendix A. Aggregate Reactivity as Assessed by Isothermal Calorimetry and ICP-AES Analysis . 70

Appendix B. Plots of 28-d Compressive Strength vs. Individual Aggregate Characteristics .............. 75

Appendix C. Representative SEM Images from Concrete Mixtures ................................................. 78

Appendix D. X-ray Diffraction Scans of Selected Aggregates.......................................................... 94 


\section{LIST OF TABLES}

Table 1. List of aggregate quarry locations and rock types for the present study..................................... 3

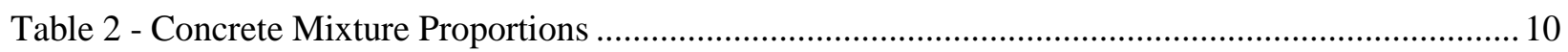

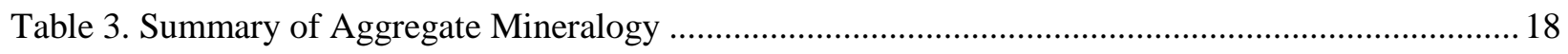

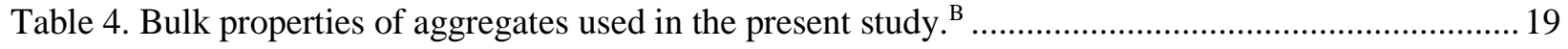

Table 5. AIMS characteristics of aggregates used in the present study (Coarse/Coarse + Fine). ${ }^{\mathrm{C}, \mathrm{D}}$...........20

Table 6. Surface energies, modulus, and CTE of aggregates used in the present study.........................21

Table 7. Density, static modulus of elasticity, compressive and tensile strengths, and CTE of rock cores ${ }^{\mathrm{G}}$

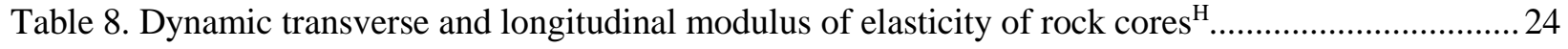

Table 9. Mechanical Properties of OPC Concrete, Mortar, and Paste Mixtures.........................................31

Table 10. Mechanical Properties of Ternary Blend Concrete, Mortar, and Paste Mixtures ....................... 32

Table 11. 28-d and 91-d Electrical Resistivities of the Hardened Concretes............................................ 36

Table 12. Measured CTE for the OPC and Ternary Blend Concretes, Mortars, and Pastes.......................39

Table 13. Fitting of OPC concrete mechanical properties to linear model based on aggregate CTE........59 


\section{LIST OF FigURES}

Figure 1. Measured concrete compressive strength as a function of the measured cumulative heat release (per unit volume of water) used to establish a strength-heat release linear relationship (dashed line, $\mathrm{R}^{2}=0.91$ ) [20]. Purdue regression line was taken from [21].

Figure 2. U.S. map showing the locations of the aggregate sources used in the present study. Labels are per TFHRC petrography designations for aggregate types from Table 1.Characterization of Aggregates ........ 3

Figure 3. Cores taken from the same quarry but different large-sized quarried rocks. (a) Marble; (b) Granitic gneiss and (c) Granite (two pictures).

Figure 4. Specimen geometries for testing of surface energy (left), elastic modulus (center), and CTE (right) at NIST.

Figure 5. Measured net expansion $\left(0^{\circ} \mathrm{C}\right.$ to $\left.100{ }^{\circ} \mathrm{C}\right)$ vs. initial length for the two NIST standard reference materials $[43,44]$. Note that the intercepts for the best-fit lines for the two materials are nearly identical, as would be expected (representing the equipment expansion). For replicate measurements on either material, the average $\mathrm{CoV}$ in the net expansion was $0.40 \%$. ... 8

Figure 6. Thin section photomicrographs: (a) diabase, (b) dolomite, (c) relatively fine-grained argillaceous dolomite, (d) relatively uniformly textured dolomitic limestone, (e) limestone with locally recrystallized calcite, (f) fine-grained and dense micritic limestone, (g) granite, (h) granitic gneiss, (i) siliceous gravel, (j) marble fracture surface $(\mathrm{k})$ marble showing twin lamellae, (l) meta-basalt, (m) quartzite, (n) sandstone and major constituents of sand (chert is shown by yellow arrows and quartzite by red arrows): (o) mixture of mainly quartz with lesser amounts of chert, (p) mainly quartz with lesser amounts of quartzite, (q) quartz and quartzite and (r) chert particles .17

Figure 7. Angularity pictures of representative particles retained on the $19.0 \mathrm{~mm}$ sieve. (a) Diabase, (b) Dolomite, (c) Dolomitic limestone, (d) High absorption limestone, (e) Micritic limestone, (f) Granite, (g) Granitic gneiss, (h) Siliceous gravel, (i) Marble, (j) Meta-basalt and (k) Quartzite \& Sandstone. (l) Angularity picture of representative sand particle retained on a $4.75 \mathrm{~mm}$ sieve.

Figure 8. Texture pictures of representative particles retained on the $19.0 \mathrm{~mm}$ sieve. (a) Diabase, (b) Dolomite, (c) Dolomitic limestone, (d) High absorption limestone, (e) Micritic limestone, (f) Granite, (g) Granitic gneiss, (h) Siliceous gravel, (i) Marble, (j) Meta-basalt and (k) Quartzite \& Sandstone..............23

Figure 9. Correlation of measured rock properties. Dashed line in (c) indicates line of equality. Average $\mathrm{CoV}$ can be found in Tables 7 and 8 . .25

Figure 10. Correlation between aggregate tests and tests on rock cores. (a) aggregate dynamic modulus carried out at NIST and either transverse dynamic modulus or static modulus carried out on rock cores at TFHRC. Dashed line indicates line of equality. (b) apparent specific gravity carried out on aggregates and compressive strength carried out on rock cores. (c) aggregate CTE versus rock core CTE. Average CoV can be found in Tables 7 and 8 .

Figure 11. Semi-adiabatic temperature rise (normalized temperatures per initial temperature) plots for the OPC (top) and ternary blend (bottom) concrete mixtures...... 28

Figure 12. Fresh concrete electrical resistance (impedance) plots for the OPC (top) and ternary blend (bottom) concrete mixtures. 
Figure 13. Later age compressive strength vs. 1-d compressive strength for the OPC and ternary blend concretes. Average $\mathrm{CoV}$ can be found in Tables 9 and 10 .

Figure 14. 28-d compressive strength of ternary blend concretes vs. corresponding OPC concrete. Average CoV can be found in Tables 9 and 10. Blue line is fit to all the data, while red line is fit to the seven indicated aggregates, omitting high absorption limestone and three limestones (including marble). Black dashed line indicates a one-to-one correspondence.

Figure 15. Isothermal calorimetry of aggregates in OPC or ternary pore solution. Cumulative heat over time of (a) marble; (b) micritic limestone and (c) high absorption limestone. 34

Figure 16. 28-d and 91-d splitting tensile strength vs. compressive strength. Recommended ACI coefficient is 0.56 (instead of 0.62) [65]. Linear relation shown in box is for 28-d data for both ternary and OPC mixtures. Average $\mathrm{CoV}$ can be found in Tables 9 and 10. 34

Figure 17. Modulus of rupture vs. compressive strength at $28 \mathrm{~d}$ and $91 \mathrm{~d}$ for the 22 concrete mixtures. Average $\mathrm{CoV}$ can be found in Tables 9 and 10. 35

Figure 18. Electrical resistivity and qualitative chloride penetrability classification as per AASHTO T358 [59]. Average CoV can be found in Table 11. 37

Figure 19. Measured electrical resistivity vs. compressive strength for the OPC and ternary blend concretes at ages of $28 \mathrm{~d}$ and $91 \mathrm{~d}$. Average CoV can be found in Tables 9, 10, and 11. .38

Figure 20. Concrete CTE vs. aggregate CTE for the OPC and ternary blend concrete mixtures. Average $\mathrm{CoV}$ can be found in Tables 6 and 12. Model lines correspond to a simple additive model, assuming aggregate and mortar volume fractions of 0.39 and 0.58 . Dashed lines indicate best linear fits. 40

Figure 21. Concrete CTE vs. rock core CTE for the OPC and ternary blend concrete mixtures. Average $\mathrm{CoV}$ can be found in Tables 7 and 12 . 41

Figure 22. Concrete 28-d and 91-d elastic modulus vs. aggregate elastic modulus for all the aggregates. Fitted lines include all the data at a given age, except for the siliceous gravel and meta-basalt. Average CoV can be found Tables 6,9 , and 10 .

Figure 23. (a) Ratio of aggregate and paste moduli of elasticity at $28 \mathrm{~d}$ and $91 \mathrm{~d}$, (b) effect of $\mathrm{E}_{\mathrm{agg}} / \mathrm{E}_{\text {paste }}$ on compressive strength of OPC mixtures at $7 \mathrm{~d}, 28 \mathrm{~d}$, and $91 \mathrm{~d}$ and (c) effect of $\mathrm{E}_{\text {agg }} / \mathrm{E}_{\text {paste }}$ on compressive strength of ternary blend mixtures at $7 \mathrm{~d}, 28 \mathrm{~d}$, and $91 \mathrm{~d}$. Average CoV can be found in Tables 9 and 10.47

Figure 24. Cumulative heat over time of diabase and quartzite $\&$ sandstone aggregates in OPC pore solution. Information on uncertainty is provided at the bottom of page 4 . 47

Figure 25. (a) Transmitted light thin section photomicrographs of weakly metamorphosed sandstone. The darker laminations appear developed parallel to the bedding plane (shown by dashed lines). Length of field of view is $1 \mathrm{~mm}$. (b) Stereo-photomicrographs showing example of dominant fracture patterns (both through and around coarse aggregates) in the 28-d cylinders. Length of field of view is $61 \mathrm{~mm}$. .48

Figure 26. Cumulative heat over time of carbonate aggregates in (a) OPC pore solution and (b) ternary pore solution.

Figure 27. Stereo-photomicrographs showing examples of dominant fracture patterns, after compressive strength testing. Yellow arrows indicate fracture around aggregate, green indicate socket of aggregate (aggregate was completely detached from paste) and red indicate fracture through the aggregate. Scale shown at the corner is in $0.25 \mathrm{~mm}$ increments. Underscore values indicate testing ages of $1 \mathrm{~d}, 7 \mathrm{~d}, 28 \mathrm{~d}$, or 
$91 \mathrm{~d}$ of mixtures containing: (a) micritic limestone, (b) high absorption limestone, (c) granite and (d) siliceous gravel.

Figure 28. Thin section photomicrographs showing of high absorption limestone concrete samples tested at different ages (a) OPC mixture tested at $1 \mathrm{~d}$. Locally discontinuous cracks/gaps at the ITZ (b) ternary mixture tested at $1 \mathrm{~d}$. Extensive areas with gaps between aggregate and paste, (c) OPC mixture tested at 28 d. Locally discontinuous cracks/gaps at the ITZ (d) ternary mixture tested at $28 \mathrm{~d}$. Gaps/cracks at the ITZ, (e) OPC mixture tested at $91 \mathrm{~d}$. Good bond between aggregate and paste, (f) ternary mixture tested at $91 \mathrm{~d}$. Gaps/cracks still present at ITZ. Gaps/Cracks at ITZ are circled in yellow or indicated by arrows...........52

Figure 29. Stereo-photomicrographs of samples, showing fractures surfaces through the aggregate. Scale shown at the corner is in $0.25 \mathrm{~mm}$ increments: (a) dolomitic limestone ternary mixture tested at $91 \mathrm{~d}$ and (b) and (c) micritic limestone OPC mixture and ternary mixtures, respectively, tested at $28 \mathrm{~d}$. (d) Transmitted light thin section photomicrographs of argillaceous dolomitic limestone containing thin darker lamination. Length of field of view in image (d) is $1 \mathrm{~mm}$. .53

Figure 30. Stereo-photomicrographs showing fracture surfaces of granite mixtures tested at $91 \mathrm{~d}$ (a) OPC mixture (failure through the aggregate), (b) ternary mixture (failure around the aggregate), (c) ternary mixture (failure around and through the aggregate) and (d) zoom in of image in (c). Scale shown at the corners in images (a), (b), and (c) is in $0.25 \mathrm{~mm}$ increments. .54

Figure 31. Relation between rock compressive strength and concrete compressive strength. .54

Figure 32. Stereo-photomicrographs of samples tested at $91 \mathrm{~d}$ : (a) meta-basalt OPC mixture with failure through the aggregate, (b) meta-basalt OPC mixture with failure around the aggregate and lack of bond and (c) meta-basalt ternary mixture with failure around the aggregate and lack of bond. Scale shown at the corner is in $0.25 \mathrm{~mm}$ increments. .55

Figure 33. Cumulative heat over time of siliceous gravel in OPC pore solution or ternary pore solution. 55 Figure 34. Stereo-photomicrographs of granitic gneiss samples tested at $91 \mathrm{~d}$ (a) OPC mixture and (b) ternary mixture. Scale shown at the corner is in $0.25 \mathrm{~mm}$ increments. .56

Figure 35. 28-d compressive strength vs. CTE for the OPC concrete mixtures. Dotted blue line indicates best linear fit for all the data. Dashed grey line indicates best linear fit when siliceous gravel data (lower right point) is excluded from the analysis. Error bars indicate one standard deviation for two cylinders broken from each mixture. $\mathrm{CoV}$ for CTE can be found in Testing section on page 8 . .58

Figure 36. Predicted 28-d compressive strength vs. measured values for the ternary blend concrete mixtures. The dashed line indicates what would be a one-to-one relationship between measured and predicted values.

Figure 37. Photographs of OPC beam specimens tested for flexural strength at $28 \mathrm{~d}$ (left) and $91 \mathrm{~d}$ (right), respectively. (a) and (b) with marble aggregate, (c) and (d) with dolomitic limestone aggregate... 62

Figure 38. Ion concentrations in solutions exposed to aggregates over time. Charts on the left show all the OPC mixtures tested, while charts on the right show only the carbonate aggregates exposed to OPC solutions. Error bars indicate one standard deviation for three replicate specimens. .71

Figure 39. Ion concentrations in OPC and ternary solutions that have been exposed to aggregates over time. Error bars indicate one standard deviation for three replicate specimens. .72 
Figure 40. Cumulative heat over time of aggregates in OPC pore solution (a) carbonate aggregates and (b) non-carbonate aggregates.

Figure 41. Cumulative heat over time of aggregates in ternary pore solution (a) carbonate aggregates and (b) non-carbonate aggregates.

Figure 42. 28-d compressive strength vs. aggregate coefficient of thermal expansion (CTE) of the 11 aggregates for the OPC and ternary blend concretes. 75

Figure 43. 28-d compressive strength vs. absorption of the 11 aggregates for the OPC and ternary blend concretes. 75

Figure 44. 28-d compressive strength vs. aggregate elastic modulus of the 11 aggregates for the OPC and ternary blend concretes. 76

Figure 45. 28-d compressive strength vs. specific gravity of the 11 aggregates for the OPC and ternary blend concretes. Standard errors are 4.06 MPa and 3.81 MPa for OPC and ternary blends, respectively. 76 Figure 46. 28-d compressive strength vs. aggregate surface energy, dispersive (left) and polar (right) components, for the OPC and ternary blend concretes. Standard errors for linear fits in the case of dispersive surface energy are 3.73 MPa and 4.1 MPa for the OPC and ternary blends, respectively..... .77

Figure 47. 28-d compressive strength vs. CAAT (left) and Texture (right) parameters from the AIMS analysis of each of the 11 aggregates for the OPC and ternary blend concretes....................................... 77

Figure 48. BE image for siliceous gravel concrete prepared with OPC . ............................................... 78

Figure 49. Ca-Si-Al RGB pseudo-color image for OPC siliceous gravel concrete. .................................79

Figure 50. BE image for siliceous gravel concrete prepared with the ternary blend............................... 80

Figure 51. Ca-Si-Al RGB pseudo-color image for ternary blend siliceous gravel concrete......................81

Figure 52. BE image for dolomitic limestone concrete prepared with OPC .......................................... 82

Figure 53. Ca-Si-Al RGB pseudo-color image for OPC dolomitic limestone concrete. ...........................83

Figure 54. BE image for dolomitic limestone concrete prepared with the ternary blend. ........................ 84

Figure 55. Ca-Si-Al RGB pseudo-color image for ternary blend dolomitic limestone concrete................85

Figure 56. BE image for meta-basalt concrete prepared with OPC ....................................................... 86

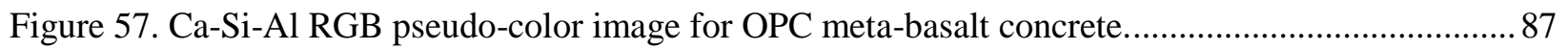

Figure 58. BE image for meta-basalt concrete prepared with the ternary blend..................................... 88

Figure 59. Ca-Si-Al RGB pseudo-color image for ternary blend meta-basalt concrete. ........................... 89

Figure 60. BE image for high absorption limestone concrete prepared with OPC..................................90

Figure 61. Ca-Si-Al RGB pseudo-color image for OPC high absorption limestone concrete....................91

Figure 62. BE image for high absorption limestone concrete prepared with the ternary blend.................92

Figure 63. Ca-Si-Al RGB pseudo-color image for ternary blend high absorption limestone concrete...... 93 


\section{INTRODUCTION}

Control and enhancement of the properties of concrete have been two longstanding concerns of the construction community. Performance of concrete mixtures is often specified/guaranteed in a prescriptive fashion by selecting specific combinations of cement (type), supplementary cementitious materials (SCMs such as fly ash and blast furnace slag), and chemical admixtures (high range water reducing agents, air entrainers, etc.). While some attention is paid to aggregate gradation to assure proper flow and avoid segregation issues, generally less consideration is given to the mineralogy of the (coarse) aggregates, as designers are often limited to what is available locally. Still, it is well known from previous studies [1-12] that coarse aggregate type can have a significant impact on properties and performance of concrete. This impact depends on the microstructure of the interfacial transition zone that is formed between coarse aggregates and the surrounding mortar [10, 13-16], and particularly on the level of bond established between these two. This bond can be influenced by both physical (roughness, shape, angularity) and chemical (reactivity) attributes of the aggregates $[4,5,17,18]$.

The impetus for the present study was a previous comparison of compressive strengths obtained for similar concretes prepared with either a siliceous-based gravel or a limestone coarse aggregate [19]. When strength was plotted against cumulative heat release (as measured via isothermal calorimetry) as shown in Figure 1, straight line relationships were obtained for both concretes, but at a similar heat release (degree of hydration), the strengths of the mixtures prepared with limestone were consistently and significantly higher than those of the concretes prepared with the siliceous aggregates (gravel). The current study extends this comparison to encompass aggregates obtained from 11 different quarries located throughout the U.S. and used to prepare concretes based on two binders: one is a $100 \%$ ordinary portland cement (OPC) concrete and the other is a ternary blend of $60 \%$ cement, $30 \%$ Class C fly ash, and $10 \%$ fine limestone powder on a volume basis.

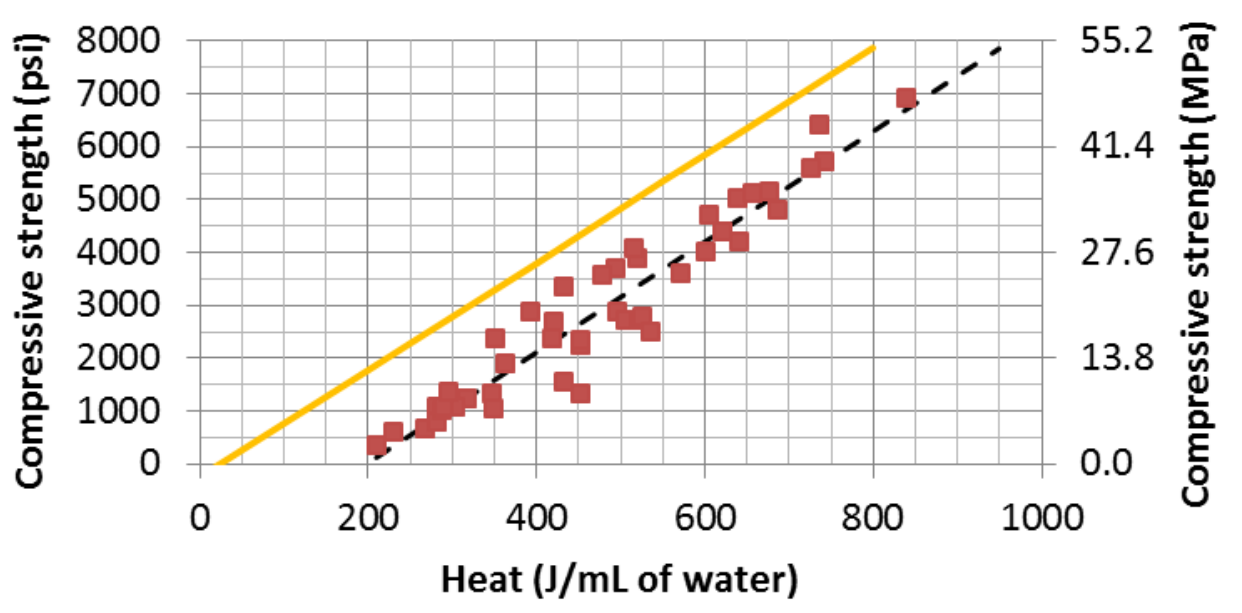

- FHWA concrete - gravel aggregate

_- Purdue concrete - limestone aggregate

Figure 1. Measured concrete compressive strength as a function of the measured cumulative heat release (per unit volume of water) used to establish a strength-heat release linear relationship (dashed line, $\mathrm{R}^{2}=0.91$ ) [20]. Purdue regression line was taken from [21]. 
Previous evaluation of the influence of aggregates on concrete properties has been limited to only a few aggregate properties and has never included so many different aggregate mineralogies [2,5,10,12,22-27], as in the current study. This study is a collaboration between the National Institute of Standards and Technology (NIST) and the Turner Fairbank Highway Research Center (TFHRC) and presents an extensive characterization of these 11 sources of aggregates (ten crushed stones and one gravel) aimed to provide the basis for a better understanding of which aggregate properties play a role in the concrete's mechanical performance. 


\section{MATERIALS AND TESTING}

\section{Aggregate Sources}

Eleven different aggregates were obtained from quarries located throughout the U.S., with the major concentration being on the east coast, and particularly in the MD-VA corridor. Table 1 summarizes the aggregate types per the petrographic analysis performed at TFHRC, while a map showing the quarry locations is provided in Figure 2.

Table 1. List of aggregate quarry locations and rock types for the present study.

\begin{tabular}{cc}
\hline Quarry Location & Aggregate Type (TFHRC petrography) \\
\hline Leesburg, VA & Diabase \\
Wappinger Falls, NY & Dolomite \\
West Lafayette, IN & Dolomitic limestone \\
Ottawa, KS & High absorption limestone \\
Harrisonburg, VA & Micritic limestone \\
Morrison, CO & Granite \\
North Garden, VA & Granitic gneiss \\
Waldorf, MD & Siliceous gravel \\
Harpers Ferry, WV & Marble* \\
Charlottesville, VA & Metabasalt ${ }^{* *}$ \\
Hillsville, VA & Quartzite \& Sandstone \\
\hline${ }^{*}$ Sometimes called Blue Stone or Limestone. Thin sections show it is a dolomitic marble. \\
${ }^{* *}$ Sometimes called Green Stone or Basalt. Thin sections show it is a meta-basalt. \\
\hline
\end{tabular}

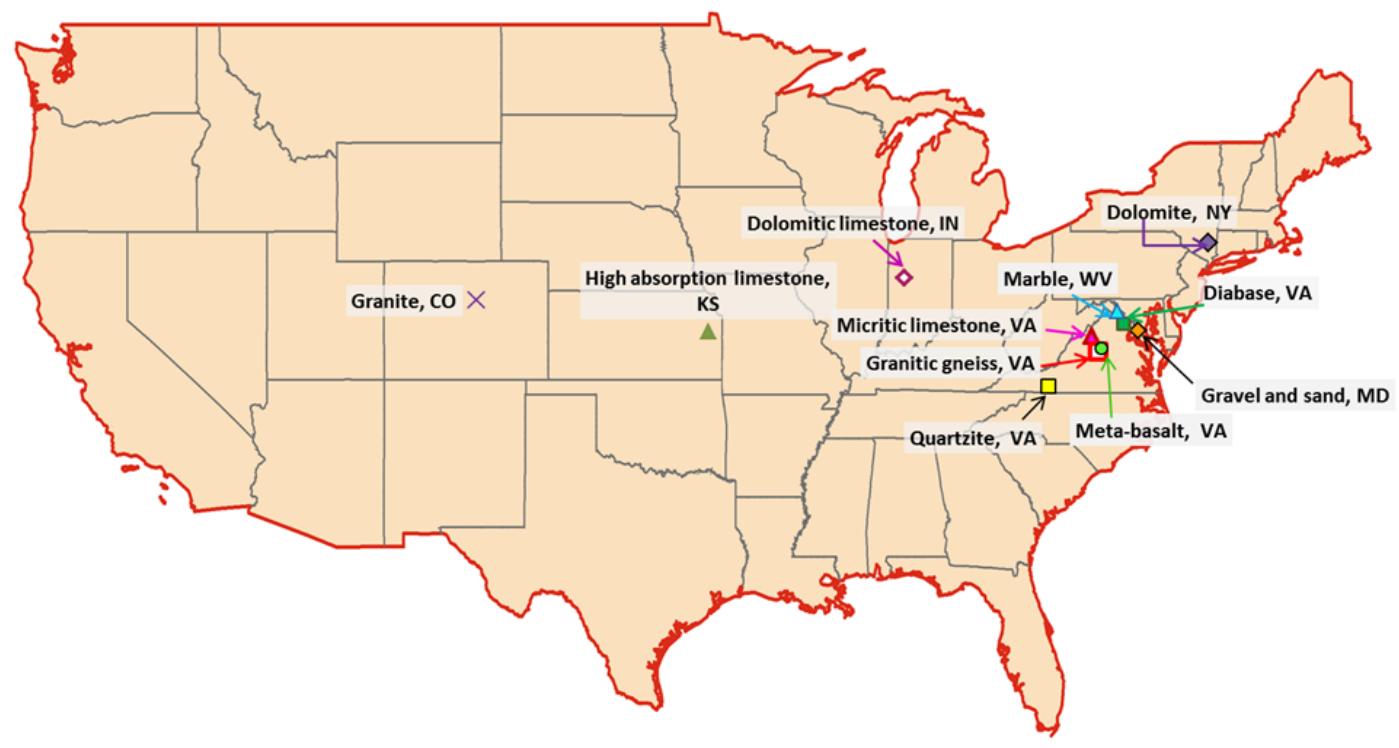

Aggregate Sources

Figure 2. U.S. map showing the locations of the aggregate sources used in the present study. Labels are per TFHRC petrography designations for aggregate types from Table 1. 


\section{Characterization of Aggregates}

\section{TESTING PERFORMED AT TFHRC}

Aggregates were characterized with respect to unit weight (ASTM C29-09), specific gravity, and absorption (ASTM C127-12) characteristics following the standard ASTM procedures [28,29]. They were further characterized with respect to their shape and texture using the aggregate imaging analysis system (AIMS2, a second generation of AIMS) originally developed by Masad [30,31] and in accordance with AASHTO TP81-12 [32]. Per the definitions provided in AASHTO TP81-12 [32], angularity relates to the variations at the particle boundary that influence the overall shape, while sphericity refers to the overall three-dimensional shape. In addition, texture is described as the relative smoothness/roughness of the surface features and the CAAT is a combined angularity and texture value that is computed as 10 times the texture + one half of the angularity [30].

The AIMS2 system uses a digital camera mounted to a variable magnification microscope, providing a maximum field of view of $53.7 \mathrm{~mm} \times 71.6 \mathrm{~mm}(0.044 \mathrm{~mm}$ per pixel) down to a field of view of $4 \mathrm{~mm} \times 5.4 \mathrm{~mm}(0.0033 \mathrm{~mm}$ per pixel). Backlighting is used to capture particle silhouettes for angularity analysis, while oblique top lighting is used to capture surface features in black and white images for texture analysis. The two-dimensional angularity images are also used to capture the overall particle dimensions along the major (longest) and minor (shortest) axes. The third particle dimension is established by the position of the focal plane determined while capturing the texture image at the surface of the particle. The gradient vector and wavelet analysis methods are used to quantify angularity and surface texture, respectively [30,31].

Petrographic examination of the coarse aggregates was performed in accordance with a modified form of ASTM C295 [33]. Representative coarse aggregate particles were selected from each coarse aggregate supply. The samples were then placed into separate rubber molds and embedded in epoxy resin. After hardening of the epoxy, each embedded sample was cut with a low-speed, diamond-rimmed saw, finely ground, and placed on a glass microscope slide using epoxy. The thickness of the mounted samples was reduced to approximately $20 \mu \mathrm{m}$ to $30 \mu \mathrm{m}$. The resulting thin sections were studied using a polarizedlight (petrographic) microscope at magnifications up to 400X to identify each aggregate type and their mineralogical composition.

In addition, the chemical interaction between selected coarse aggregates and the two cementitious binders was inferred by isothermal calorimetry (ASTM C1679 [34]) and inductively coupled plasma atomic emission spectroscopy (ICP-AES). Synthetic pore solution was created using a procedure adapted from Tasong et al. [3] and Lawrence [35]. First, $75 \mathrm{~g}$ of cementitious materials (OPC or ternary blend) were gradually added to $300 \mathrm{~mL}$ of deionized water and stirred in a sealed container for about $2 \mathrm{~h}$. Then, the resultant solution was filtered through a $10 \mu \mathrm{m}$ filter.

Each aggregate to be evaluated was crushed to pass through a sieve with $200 \mu \mathrm{m}$ openings. A $10-\mathrm{g}$ sample of the aggregate was thoroughly mixed with $40 \mathrm{~mL}$ of solution and brought to $25^{\circ} \mathrm{C} \pm 2{ }^{\circ} \mathrm{C}$ before isothermal calorimetry testing. Two samples per mixture were tested, with masses of $7.0 \mathrm{~g} \pm 0.5 \mathrm{~g}$. Isothermal calorimetry was carried out at $25{ }^{\circ} \mathrm{C}$ for $7 \mathrm{~d}$ and measured heat flows and cumulative heat release were normalized by the mass of the solution. Previously, the average absolute difference between replicate specimens of hydrating cement paste has been reported as $2.5 \times 10^{-5} \mathrm{~W} / \mathrm{g}$ (cement) for measurements conducted between $1 \mathrm{~h}$ and $7 \mathrm{~d}$ after mixing [19].

The same sample preparation described above (synthetic pore solution with aggregates) was also used for ICP-AES testing. Samples were kept at laboratory conditions and daily manually agitated until the 
ages of testing of $7 \mathrm{~d}$ and $28 \mathrm{~d}$, and then filtered through a $1 \mu \mathrm{m}$ filter. The liquid fraction was vacuum filtered and diluted by a known volume and then the elemental (ion) concentration was determined by ICP-AES. The accuracy of each set of measurements was controlled by calibrating the ICP-AES and running a check standard at the beginning and the end of each batch of analyses. Three replicates were tested at each age for selected mixtures: OPC mixtures with dolomitic limestone, micritic limestone, quartzite \& sandstone, marble, meta-basalt or siliceous gravel and ternary blends with dolomitic limestone or quartzite \& sandstone. Samples containing only OPC solution and ternary blend solution were tested as soon as they were prepared to obtain their respective baselines.

For selected sources (granitic gneiss, diabase, dolomitic limestone, micritic limestone, marble, meta-basalt, and granite), cores were obtained from large-sized quarried rocks (boulder size) to directly assess the rocks' mechanical properties, as well as their coefficient of thermal expansion (CTE). In some cases, although the large-sized quarried rocks were obtained from the same source, they were visually different (Figure 3), implying that the crushed aggregates were often a mixture of different rocks.

The large-sized quarried rocks had an average height between $200 \mathrm{~mm}$ and $300 \mathrm{~mm}$, with masses that varied from about $35 \mathrm{~kg}$ to $70 \mathrm{~kg}$. Coring took place using a water-cooled diamond coring drill at speeds that varied from $47 \mathrm{rad} / \mathrm{s}$ to $94 \mathrm{rad} / \mathrm{s}$. The core diameter was about $70 \mathrm{~mm}$ (nominal core drill bit was $3 \mathrm{in}$., yielding a $2.75 \mathrm{in}$. core). Each core was then cut to a $177.8 \mathrm{~mm} \pm 2.5 \mathrm{~mm}$ section with a slab saw cooled with food grade mineral oil. The position of these cross cuts was chosen to minimize the number of visible cracks on the final sample. Cores used for testing complied with AASHTO T22 [36] for perpendicularity and parallelism of ends. Cores were then washed with warm soapy water to remove the mineral oil and dried in an oven at $50{ }^{\circ} \mathrm{C}$ for $16 \mathrm{~h}$ to $20 \mathrm{~h}$. Cores were subsequently saturated in tap water until they achieved the saturation criterion specified in AASHTO T336 [37].

Cores were tested for compressive strength, static elastic modulus and Poisson's ratio at room temperature in accordance with ASTM D7012 [38], for splitting tensile strength per ASTM D3967 [39] and for dynamic modulus of elasticity and dynamic modulus of rigidity per ASTM C215 [40]. Density was obtained for a dry condition by measuring the dimensions and masses of the specimens. The CTE of the cores was obtained following AASHTO T336 [37]. Two cores were tested for compressive strength, static elastic modulus and Poisson's ratio and CTE, while 3 cores were tested for splitting tensile strength. When a clear difference in large-sized quarried rocks from the same source was observed (granite and marble for example), the number of replicates was doubled, but due to a lack of cores, the splitting tensile strength was not determined. Six replicates were tested for the dynamic modulus of elasticity, with exception of the granite and marble, which had 10 and 8 replicates tested, respectively. The dynamic modulus of elasticity was determined both after the drying process and after the saturation process, described earlier. 

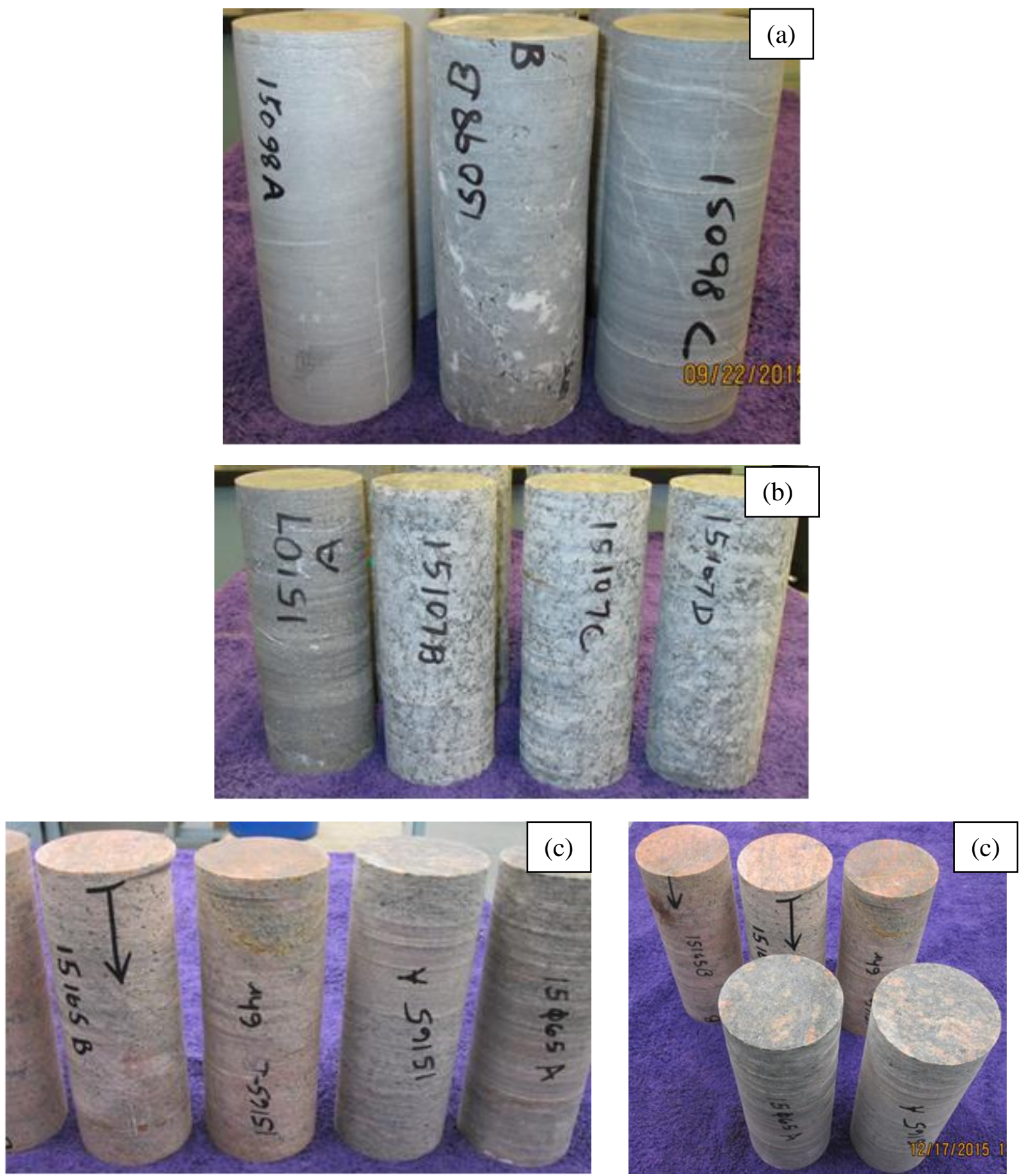

Figure 3. Cores taken from the same quarry but different large-sized quarried rocks. (a) Marble; (b) Granitic gneiss and (c) Granite (two pictures). 


\section{TESTING PERFORMED AT NIST}

For each of the aggregates, a set of samples retained on the $25-\mathrm{mm}$ sieve was obtained. Specimens were handpicked from this selection for further preparation prior to measurements of contact angle/surface energy, dynamic elastic modulus, and CTE. A subset of the specimens was first cut using a diamond-blade laboratory saw with water as the lubricant to obtain flat and smooth surfaces for the contact angle measurements. For these specimens, the cut surface was polished with 120-grit silicon carbide paper. Some of the single-cut specimens were further cut and polished to produce prismatic specimens (typically a few mm thick with a length of $20 \mathrm{~mm}$ to $40 \mathrm{~mm}$ and a width of $3 \mathrm{~mm}$ to $12 \mathrm{~mm}$ ) for the measurement of elastic modulus using sonic (frequency) techniques (ASTM C1259-14 [41]). For CTE measurements, other aggregates were cored (by wet drilling with tap water) to obtain small cylinders typically $8 \mathrm{~mm}$ to $15 \mathrm{~mm}$ in length, with a diameter of about $7.2 \mathrm{~mm}$. These cylindrical cores were subsequently polished as needed to obtain two flat and parallel faces for mounting in the differential thermo-mechanical analyzer (DTMA) that was used to obtain CTE values. Example specimen geometries for the various tests conducted at NIST are provided in Figure 4.
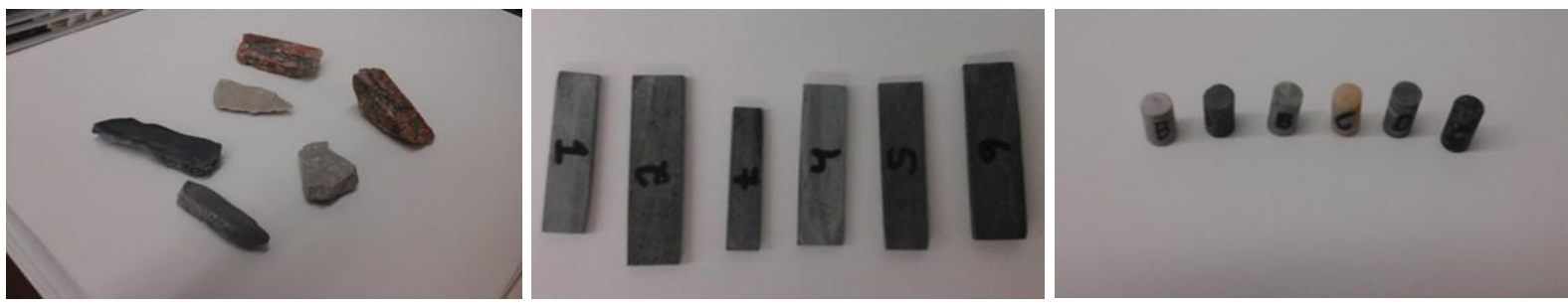

Figure 4. Specimen geometries for testing of surface energy (left), elastic modulus (center), and CTE (right) at NIST.

Contact angles were assessed using either water (polar) or diiodomethane (nonpolar) and an automated contact angle analyzer. Drop sizes of $5 \mu \mathrm{L}$ and $3 \mu \mathrm{L}$ were used for the water and diiodomethane, respectively. Aggregates were mounted to a positioning table using modeling clay, with their flat, smooth surface facing upwards. Typically, four different rock surfaces were evaluated for each aggregate, with four drops of each liquid applied per surface. Prior to the first measurement and when switching liquids, the rock surface was cleaned using ethanol and dried. Using the automated angle measurements provided by the equipment, angles were recorded immediately after contact and after $1 \mathrm{~min}$ and $2 \mathrm{~min}$. For the analysis to follow, surface energies were calculated based on the immediate readings. Angle measurements for each liquid were subsequently averaged, after discarding obvious outliers. Typical coefficients of variation $(\mathrm{CoV})$ for these measurements were on the order of $12 \%$ for both the water and the diiodomethane. To convert the average angle measurements for the two liquids to estimated polar and dispersive surface energy components, the Young-Owens-Wendt equation was employed [42]:

$$
\frac{\gamma_{L} \times(1+\cos \theta)}{2 \times \sqrt{\gamma_{L}^{D}}}=\sqrt{\frac{\gamma_{L}^{P}}{\gamma_{L}^{D}}} \times \sqrt{\gamma_{S}^{P}}+\sqrt{\gamma_{S}^{D}}
$$

where $\theta$ is the measured contact angle (average), $\gamma^{\mathrm{D}}$ and $\gamma^{\mathrm{P}}$ refer to the dispersive and polar components of the surface energy $\gamma$, respectively and the subscripts $L$ and $S$ refer to liquid and solid (aggregate). The surface energy values utilized for water (polar $-51 \mathrm{~mJ} / \mathrm{m}^{2}$, dispersive $-21.8 \mathrm{~mJ} / \mathrm{m}^{2}$ ) and diiodomethane (polar $-0 \mathrm{~mJ} / \mathrm{m}^{2}$, dispersive $-50.8 \mathrm{~mJ} / \mathrm{m}^{2}$ ) were taken from Boulange and Sterczynskia [42]. Computationally, equation (1) was first applied to the data obtained using diiodomethane to obtain the dispersive component of the aggregate surface energy. Using this computed dispersive component along 
with the measured average angle for water, equation (1) was applied a second time to obtain the corresponding polar component of the aggregate surface energy.

Modulus of elasticity measurements were performed on the aggregate prisms using the techniques detailed in ASTM C1259-14 [41]. The value reported for each prism was based on the average of 10 individual measurements (taps). Between two and eight individual prisms were evaluated for each of the 11 aggregates. For these modulus measurements, the $\mathrm{CoV}$ ranged between $1.7 \%$ and $21 \%$, with an average value for the 11 aggregates of $10 \%$.

CTE measurements were carried out using a DTMA mounted in a temperature-controlled (heating and cooling) chamber. Typically, three or four specimens of different lengths were evaluated for each aggregate. The CTE was estimated by the changes in specimen dimensions obtained when cycling back and forth between the nominal temperatures of $0{ }^{\circ} \mathrm{C}$ and $100^{\circ} \mathrm{C}$. Because the DTMA fixtures also expand/contract with temperature, it was necessary to adjust the results determined for the aggregates to eliminate this artifact, which is also a function of the specimen height. This adjustment was based on a calibration obtained using the net expansion values $\left(0{ }^{\circ} \mathrm{C}\right.$ to $\left.100{ }^{\circ} \mathrm{C}\right)$ measured for different length specimens of two NIST Standard Reference Materials (SRMs), namely SRM 731 (Borosilicate Glass) [43] and SRM 738 (Stainless Steel - AISI 446) [44] in comparison to their certified values (see Figure 5). To enable such a calibration, the original nominally $50 \mathrm{~mm}$ long SRMs were each cut into different length pieces that spanned the range of aggregate cylinder lengths and it was further assumed that each piece of each SRM would exhibit the same CTE as the value that was certified for the entire $50 \mathrm{~mm}$ length. For the investigated temperature range, the certified values computed for borosilicate glass and stainless steel are $4.91 \times 10^{-6} \mathrm{~K}^{-1}$ and $9.94 \times 10^{-6} \mathrm{~K}^{-1}$, respectively $[43,44]$. For the aggregates, the $\mathrm{CoV}$ for the computed average CTEs ranged between $1.5 \%$ and $36.7 \%$, with an average $\mathrm{CoV}$ of $18 \%$.

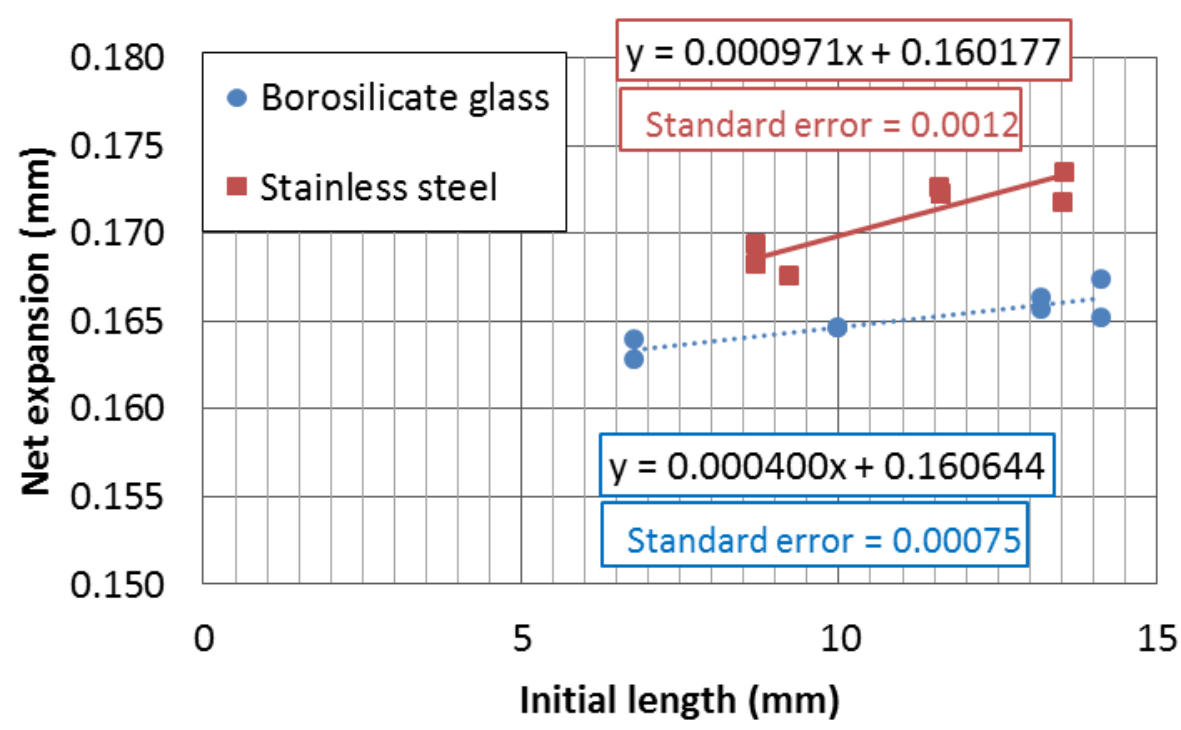

Figure 5. Measured net expansion $\left(0^{\circ} \mathrm{C}\right.$ to $\left.100{ }^{\circ} \mathrm{C}\right)$ vs. initial length for the two NIST standard reference materials $[43,44]$. Note that the intercepts for the best-fit lines for the two materials are nearly identical, as would be expected (representing the equipment expansion). For replicate measurements on either material, the average $\mathrm{CoV}$ in the net expansion was $0.40 \%$. 


\section{Mixture Proportions}

A total of 22 concrete mixtures were prepared, two each for the 11 different coarse aggregates. For each aggregate, one mixture contained a binder that was $100 \%$ ordinary portland cement (OPC) (ASTM C150 type I/II [45]), while the other was a 60:30:10 volumetric ternary blend of the same ordinary portland cement as used in the $100 \%$ OPC mixtures, an ASTM C618 Class C fly ash [46], and a limestone powder [20]. The OPC had a reported Blaine fineness of $377 \mathrm{~m}^{2} / \mathrm{kg}, 0.5 \%$ equivalent alkalis and a calculated Bogue phase composition of $54.3 \% \mathrm{C}_{3} \mathrm{~S}, 14.6 \% \mathrm{C}_{2} \mathrm{~S}, 7.3 \% \mathrm{C}_{3} \mathrm{~A}$, and $9.6 \% \mathrm{C}_{4} \mathrm{AF}$, with a reported limestone content of $3.6 \%$, all of which are mass percentages [20]. The Class C fly ash had a density of $2630 \mathrm{~kg} / \mathrm{m}^{3}$, a median particle size of $10.3 \mu \mathrm{m}$, and a total $\mathrm{CaO}$ content of $24.6 \%$ by mass, and is hydraulic [20]. A fine limestone powder with a median particle diameter of $0.7 \mu \mathrm{m}, 90 \%$ finer than $2 \mu \mathrm{m}$, and $65 \%$ finer than $1 \mu \mathrm{m}$ was also used in the ternary blends. It had a reported density of $2710 \mathrm{~kg} / \mathrm{m}^{3}$ and reported $\mathrm{CaCO}_{3}$ and $\mathrm{MgCO}_{3}$ contents of $98 \%$ and $1 \%$ by mass, respectively [20].

All coarse aggregates were sieved and recombined to keep the same gradation for all the mixtures. For the gradation chosen, the percentages successively retained on sieves of size $19 \mathrm{~mm}, 12.5 \mathrm{~mm}, 9.5 \mathrm{~mm}$, $4.75 \mathrm{~mm}$, and $2.36 \mathrm{~mm}$ were $10.8 \%, 45.1 \%, 24.5 \%, 19.0 \%$, and $0.6 \%$, respectively. Then before use, the coarse aggregates were washed to eliminate any other particles that could interfere in the results. For all concretes, the fine aggregate was a natural silica sand having a density of $2610 \mathrm{~kg} / \mathrm{m}^{3}$, water absorption of $1.1 \%$, and a fineness modulus of 2.82. The sand was used above saturated-surface-dry (SSD) conditions, while the coarse aggregates were used below SSD, except for the high absorption limestone that was soaked in water for a minimum of $48 \mathrm{~h}$ and then drained prior to mixing. The moisture content of the aggregates was determined and considered for the required amount of mixing water.

The OPC mixtures were designed based on a non-air entrained mixture with a cement content of $335 \mathrm{~kg} / \mathrm{m}^{3}$ and a $w / c=0.45$ (water content of $151 \mathrm{~kg} / \mathrm{m}^{3}$ ). A Type A-F water-reducing admixture was used and its dosage was adjusted to produce mixtures with a $25-\mathrm{mm}$ slump (representative of a typical paving concrete mixture). The coarse and fine aggregate contents were calculated per ACI 211-91 [47], except for the mixture containing siliceous gravel, as ACI 211-91 would yield a much higher volume of coarse aggregate, compared to the other mixtures. The ternary mixtures had the same proportions as their respective OPC mixture (for each individual aggregate), but the volume of the OPC was replaced by the ternary blend (Table 2). Two mortar and two paste mixtures were prepared with the same mixture proportions as the concrete, by eliminating the coarse aggregate or both aggregates for the mortar and paste, respectively. 
Table 2 - Concrete Mixture Proportions

\begin{tabular}{|c|c|c|c|c|c|c|c|c|c|}
\hline $\begin{array}{l}\text { Coarse } \\
\text { Aggregate }\end{array}$ & $\begin{array}{l}\text { Type of } \\
\text { mixture }\end{array}$ & $\begin{array}{l}\text { Cement } \\
\left(\mathrm{kg} / \mathrm{m}^{3}\right)\end{array}$ & $\begin{array}{l}\text { Fly ash } \\
\left(\mathrm{kg} / \mathrm{m}^{3}\right)\end{array}$ & $\begin{array}{c}\text { Limestone } \\
\text { powder } \\
\left(\mathrm{kg} / \mathrm{m}^{3}\right) \\
\end{array}$ & $\begin{array}{c}\text { Coarse } \\
\text { aggregate } \\
\left(\mathrm{kg} / \mathrm{m}^{3}\right) \\
\end{array}$ & $\begin{array}{l}\text { Sand } \\
\left(\mathrm{kg} / \mathrm{m}^{3}\right)\end{array}$ & $\begin{array}{l}\text { Water } \\
\left(\mathrm{kg} / \mathrm{m}^{3}\right)\end{array}$ & $\begin{array}{l}\text { Admix, } \\
\mathrm{mL} / \mathrm{kg}\end{array}$ & $w / \mathrm{cm}$ \\
\hline \multirow{2}{*}{ Diabase } & OPC & 335 & - & - & 1230 & 786 & 151 & 2.1 & 0.45 \\
\hline & Ternary & 201 & 85 & 28 & $(42.0 \%)^{A}$ & $(30.3 \%)$ & 151 & 0.2 & 0.48 \\
\hline \multirow{2}{*}{ Dolomite } & OPC & 335 & - & - & 1132 & 827 & 151 & 2.3 & 0.45 \\
\hline & Ternary & 201 & 85 & 28 & (40.4\%) & (31.9\%) & 151 & 0.4 & 0.48 \\
\hline \multirow{2}{*}{$\begin{array}{l}\text { Dolomitic } \\
\text { limestone }\end{array}$} & OPC & 335 & - & - & 1083 & 859 & 151 & 2.7 & 0.45 \\
\hline & Ternary & 201 & 85 & 28 & (39.2\%) & (33.1\%) & 151 & 1.2 & 0.48 \\
\hline \multirow{2}{*}{$\begin{array}{l}\text { High Abs. } \\
\text { limestone }\end{array}$} & OPC & 335 & - & - & 1053 & 784 & 151 & 3.1 & 0.45 \\
\hline & Ternary & 201 & 85 & 28 & $(42.0 \%)$ & $(30.3 \%)$ & 151 & 0.4 & 0.48 \\
\hline \multirow{2}{*}{$\begin{array}{l}\text { Micritic } \\
\text { limestone }\end{array}$} & OPC & 335 & - & - & 1089 & 831 & 151 & 2 & 0.45 \\
\hline & Ternary & 201 & 85 & 28 & (40.2\%) & (32.1\%) & 151 & 1.2 & 0.48 \\
\hline \multirow{2}{*}{ Granite } & OPC & 335 & - & - & 1078 & 815 & 151 & 3.1 & 0.45 \\
\hline & Ternary & 201 & 85 & 28 & $(40.8 \%)$ & (31.5 \%) & 151 & 0.8 & 0.48 \\
\hline \multirow{2}{*}{$\begin{array}{l}\text { Granitic } \\
\text { gneiss }\end{array}$} & OPC & 335 & - & - & 1118 & 830 & 151 & 2 & 0.45 \\
\hline & Ternary & 201 & 85 & 28 & $(40.3 \%)$ & $(32.0 \%)$ & 151 & 0.6 & 0.48 \\
\hline \multirow{2}{*}{$\begin{array}{l}\text { Siliceous } \\
\text { gravel }\end{array}$} & OPC & 335 & - & - & 1030 & 824 & 151 & 1.2 & 0.45 \\
\hline & Ternary & 201 & 85 & 28 & (40.5\%) & (31.8 \%) & 151 & 0 & 0.48 \\
\hline \multirow{2}{*}{ Marble } & OPC & 335 & - & - & 1203 & 791 & 151 & 2.3 & 0.45 \\
\hline & Ternary & 201 & 85 & 28 & (41.7\%) & $(30.6 \%)$ & 151 & 1 & 0.48 \\
\hline \multirow{2}{*}{$\begin{array}{l}\text { Meta- } \\
\text { basalt }\end{array}$} & OPC & 335 & - & - & 1156 & 848 & 151 & 2.9 & 0.45 \\
\hline & Ternary & 201 & 85 & 28 & (39.6\%) & (32.7\%) & 151 & 1.2 & 0.48 \\
\hline \multirow{2}{*}{$\begin{array}{l}\text { Quartzite \& } \\
\text { sandstone }\end{array}$} & OPC & 335 & - & - & 1086 & 804 & 151 & 2.3 & 0.45 \\
\hline & Ternary & 201 & 85 & 28 & (41.3\%) & $(31.0 \%)$ & 151 & 1.2 & 0.48 \\
\hline
\end{tabular}

A Numbers in parenthesis indicate the volume percentage of the coarse and fine aggregates in the mixture. 


\section{Concrete and Paste Evaluation}

\section{Testing PERFORMED AT TFHRC}

Concrete mixtures were prepared and cast per ASTM C192 [48] and temperature, slump, air content and unit weight were determined per ASTM C1064 [49], ASTM C143 [50], ASTM C231 [51], and ASTM C138 [52], respectively. Uniaxial electrical resistance of the fresh concrete was measured for the first $24 \mathrm{~h}$ by using a special attachment to connect to two screw rods inserted into the fresh concrete [53]. Semi-adiabatic calorimetry was carried out for the first $24 \mathrm{~h}$ on two $100 \mathrm{~mm}$ by $200 \mathrm{~mm}$ cylinders [54]. For this technique, for 18 concrete mixtures like the ones prepared in this study, the average maximum $\mathrm{CoV}$ between two replicate specimens from a single concrete batch has been determined to be $0.7 \%$.

Concrete cylinders were stored in a temperature-regulated bath of saturated lime water until the time of testing. Determination of concrete mechanical properties included: compressive strength (ASTM C39 [55]) and static modulus of elasticity (ASTM C469 [56]) on $100 \mathrm{~mm}$ by $200 \mathrm{~mm}$ cylinders, using unbonded caps, at ages of $1 \mathrm{~d}, 7 \mathrm{~d}, 28 \mathrm{~d}$ and $91 \mathrm{~d}$; splitting tensile strength on $100 \mathrm{~mm}$ by $200 \mathrm{~mm}$ cylinders (ASTM C496 [57]) at $28 \mathrm{~d}$ and $91 \mathrm{~d}$ and flexural strength (ASTM C78 [58]) on $100 \mathrm{~mm}$ by $100 \mathrm{~mm}$ by $355 \mathrm{~mm}$ prisms at $28 \mathrm{~d}$ and $91 \mathrm{~d}$. The number of replicates for compressive strength and modulus of elasticity was two, while for splitting tensile strength and flexural strength, three specimens were tested per age. The two paste mixtures were also cast into $100 \mathrm{~mm}$ by $200 \mathrm{~mm}$ cylinders, cured, and subsequently tested for static modulus of elasticity at $7 \mathrm{~d}, 28 \mathrm{~d}$, and $91 \mathrm{~d}$.

Surface resistance (per AASHTO T358 [59]) of the hardened concrete cylinders $(100 \mathrm{~mm} \times 200 \mathrm{~mm})$ was measured using a 4-point (Wenner) probe with a probe spacing of $38 \mathrm{~mm}$. The measured surface resistivity values were divided by the appropriate geometry correction factor (1.95) for $100 \mathrm{~mm}$ by $200 \mathrm{~mm}$ cylindrical specimens (as opposed to the probe's default geometry setting for measuring the resistivity of a large flat slab). Two replicates from each mixture were tested at ages of $28 \mathrm{~d}$ and $91 \mathrm{~d}$.

Concrete CTE was determined on $100 \mathrm{~mm}$ by $178 \mathrm{~mm}$ cylinders following AASHTO T336 [37]. Two replicates were tested per mixture at ages exceeding $100 \mathrm{~d}$, with exception of the OPC and ternary mixtures containing siliceous gravel, which were tested between $47 \mathrm{~d}$ and $49 \mathrm{~d}$.

Concrete cylinders tested in compression at $1 \mathrm{~d}, 7 \mathrm{~d}, 28 \mathrm{~d}$ and $91 \mathrm{~d}$ and prisms tested in flexure at $28 \mathrm{~d}$ and $91 \mathrm{~d}$ were visually examined and photographed. Subsequently, fractured surfaces of each broken cylinder were examined using a stereo-microscope at magnifications up to $90 \mathrm{X}$. The nature of the fracture patterns, especially the dominant fracture pattern with respect to the coarse aggregates was documented and close-up photomicrographs were taken. Paste-aggregate interface quality, as well as the bond between them, was qualitatively evaluated through stereomicroscopic examination.

Some of the concrete cylinders tested for compressive strength, especially from early ages $(1 \mathrm{~d}$ and $7 \mathrm{~d}$ ), were selected to be further examined to compare the strength behavior of OPC and ternary mixtures. Specimens containing high absorption limestone also received additional testing, since the compressive strength ratio between ternary and OPC mixtures prepared with the high absorption limestone was much lower than that from mixtures with any other aggregate. Two representative rectangular blocks were cut from an area of interest of each selected cylinder, placed on individual glass microscope slides with epoxy, and reduced to a thickness of approximately $20 \mu \mathrm{m}$. These thin sections were studied using a petrographic polarized light microscope (PLM) at magnifications up to $400 \mathrm{X}$, primarily to examine the distribution and size of the limestone fillers, as well as to evaluate the relative degree of hydration of portland cement and fly ash particles. 


\section{TESTING PERFORMED AT NIST (SEM PREPARATION AND ANALYSIS)}

Paste-aggregate interface quality, as well as the bond between them, was qualitatively evaluated through scanning electron microscopy (SEM) analysis. After compressive strength testing, (broken) concrete cylinders were sawn to form disks approximately $3 \mathrm{~mm}$ to $5 \mathrm{~mm}$ thick. Smaller specimens appropriate for SEM analysis were obtained by scoring and breaking the disks into pieces to fit into $25 \mathrm{~mm}$ diameter silicone SEM molds. Specimens were oven dried at $65^{\circ} \mathrm{C}$ for $24 \mathrm{~h}$, then subsequently placed onto a small amount of the low-viscosity LR White resin that intruded the pore space via capillary suction. After $2 \mathrm{~h}$ of intrusion, samples were fully immersed in the LR White resin and placed under a moderate vacuum to remove any remaining air voids within the sample. The resin was then oven-cured at $65^{\circ} \mathrm{C}$ for $24 \mathrm{~h}$.

Hardened resin-impregnated samples were ground flat using 120-grit silicon carbide paper. Samples were ground further using 400-, 600-, and 1200-grit silicon carbide paper. After the final grinding step, specimens were polished using a series of diamond pastes with diamond particles of nominal diameters of $9 \mu \mathrm{m}, 6 \mu \mathrm{m}, 3 \mu \mathrm{m}, 1 \mu \mathrm{m}$, and $0.25 \mu \mathrm{m}$. Upon completion of polishing, specimens were rinsed with both ethanol and acetone to remove any residual polishing compound.

Polished specimens were coated with a conductive layer of carbon using an evaporative coater in preparation for SEM imaging. Imaging settings were chosen to maximize specimen throughput, while maintaining resolution of fine-grained features. An excitation voltage of $13 \mathrm{keV}$, a probe current of approximately $2 \mathrm{nA}$, and a working distance of $13 \mathrm{~mm}$ yielded high-contrast backscattered electron (BE) images, as well as energy-dispersive X-ray (EDX) images of the major elemental constituents. BE images and the total EDX counts for each element of interest were recorded as 16-bit TIFF grayscale images. Pseudo-color images for highlighting bulk chemistry were generated using the elemental EDX images of calcium, silicon, and aluminum for the red, green, and blue color channels, respectively.

Using stage automation, BE/EDX image sets were acquired at four distinct locations along an overlapping two-by-two grid. The four sets of images were then stitched together to create a single image using the ImageJ plugin MIST [60]. Using the silicon image as a reference, the MIST algorithm determined the translations and rotations necessary to stitch the image into a single image; the stitching was then executed for the other EDX images, as well as the BE image, using the same set of translations and rotations. The result is a $1.8 \mathrm{~mm}$ by $1.4 \mathrm{~mm}$ stitched image which provides a broader view of the aggregate and interfacial transition zones (ITZ). Stitched images for selected concretes of interest are shown in Appendix C.

For a few of the aggregates, X-ray diffraction (XRD) scans over a two-theta range of $4^{\circ}$ to $75^{\circ}$ were conducted to identify crystalline components. The measured patterns for these aggregates are provided in Appendix D. 


\title{
RESULTS
}

\section{Aggregate Characteristics}

\author{
PETROGRAPHIC DESCRIPTION OF ROCK TYPES
}

\section{- Diabase:}

The diabase (Figure 6a) was a dark gray, medium-grained, somewhat dense diabase/dolerite, consisting mainly of plagioclase feldspar and pyroxene. The proportions of feldspar and pyroxene appeared to vary from particle to particle.

\section{- Dolomite:}

The dolomite exhibited slight textural and mineralogical variations: medium to coarse-grained dolomite (Figure 6b), and, what appeared to be relatively, a fine-grained dolomite (Figure 6c). This finegrained dolomite contained a fine-grained argillaceous/clayey matrix. Additionally, some aggregate particles contained relatively large (non-reactive) traces of detrital quartz grains.

\section{- Dolomitic limestone:}

This aggregate (Figure 6d) was a somewhat dense dolomitic limestone with a uniform texture (medium-grained).

\section{- High absorption limestone:}

The observed limestone particles were predominantly a micritic limestone containing sparse fossil remains (Figure 6e). However, a few slightly coarse dolomitic limestone particles, as well as argillaceous limestone particles, were observed. In some of the micritic limestone particles, the original fine-grained micrite (microcrystalline calcite) matrix appeared to have recrystallized locally into a relatively granular calcite matrix (sparite). The sparite matrix appeared to have a relatively higher inter-granular porosity than the finer and denser micrite matrix. Some of the open spaces, either in the matrix or within the fossil remains, were filled with coarser secondary calcite/sparite.

\section{- Micritic limestone:}

This aggregate was a somewhat dense, fine-grained micritic limestone (Figure 6f), with local thin intercalated layers/lamination of argillaceous limestone. The argillaceous limestone laminations were dolomitic and contained other miscellaneous materials, including dark dissolution materials, small quartz grains, and miscellaneous iron minerals.

\section{- Granite:}

The granite was composed mainly of quartz and feldspar (Figure 6g), with lesser but appreciable amounts of biotite, associated locally with some muscovite. Muscovite without association of biotite was also observed locally in some of the aggregate particles. The relative proportions of biotite and muscovite appeared to vary from particle to particle (Figure $6 \mathrm{~g}$ ).

\section{- Granitic gneiss:}

The granitic gneiss was composed mainly of quartz and feldspar with lesser amounts of biotite and muscovite and trace amounts of secondary minerals including calcite, epidote, and sericite (Figure 6h). The micaceous minerals formed a separate local band/layer in the rock. In some aggregate particles, most of the 
calcium-rich plagioclase feldspars were altered into fine-grained, sodic-rich plagioclase, epidote, muscovite, calcite, scapolite, and zeolite.

\section{- $\quad$ Siliceous gravel:}

The siliceous gravel was composed of coarse-grained quartz and quartzite-quartz crystals (Figure 6i), exhibiting undulose extinction and lobate grain boundaries, an indication that the quartz grains were strained and thus the rock can be designated as quartzite.

\section{- Marble:}

The marble (Figure 6j) exhibited a conspicuous twin lamella resulting from the deformation of the original dolomitic limestone (Figure 6k). Finer-grained portions, consisting of darker argillaceous materials and traces of strained quartz were observed locally.

\section{- Meta-basalt:}

This rock was found to be a fine to medium-grained metamorphosed basalt (meta-basalt). It consisted mainly of feldspar with some secondary minerals, including amphiboles (hornblende and actinolite) and chlorite (Figure 61). Other secondary minerals, including calcite and epidote, were also observed. The calcite occurred as veinlets, which apparently formed in the cracks and because of local alteration of the minerals associated with epidote. Some particles also contained local veinlets of recrystallized quartz and miscellaneous opaque minerals.

\section{- Quartzite \& Sandstone:}

This aggregate was a mixture of quartzite $\&$ sandstone. The quartzite consisted mainly of quartz and feldspars with traces of amphibole and mica (Figure $6 \mathrm{~m}$ ). A uniform medium-grained texture was observed. On the other hand, the sandstone consisted mainly of a combination of sand-sized quartz and feldspar clasts (Figure 6n). It also contained lesser amounts of a microcrystalline quartz, cemented in an argillaceous/clayey matrix. Traces of calcite and black miscellaneous ferruginous materials were also observed in the matrix of the rock.

\section{- Sand:}

The natural sand consisted mainly of quartz with lesser amounts of chert (Figure 6o), but also contained lesser amounts of fine and coarse-grained ferruginous sandstone, granitic rock, and feldspar, as well as quartzite/strained quartz (Figures 6p and 6q) and chert (Figure 6r).

Table 3 summarizes the major and minor mineralogy of the aggregates used in this study. 

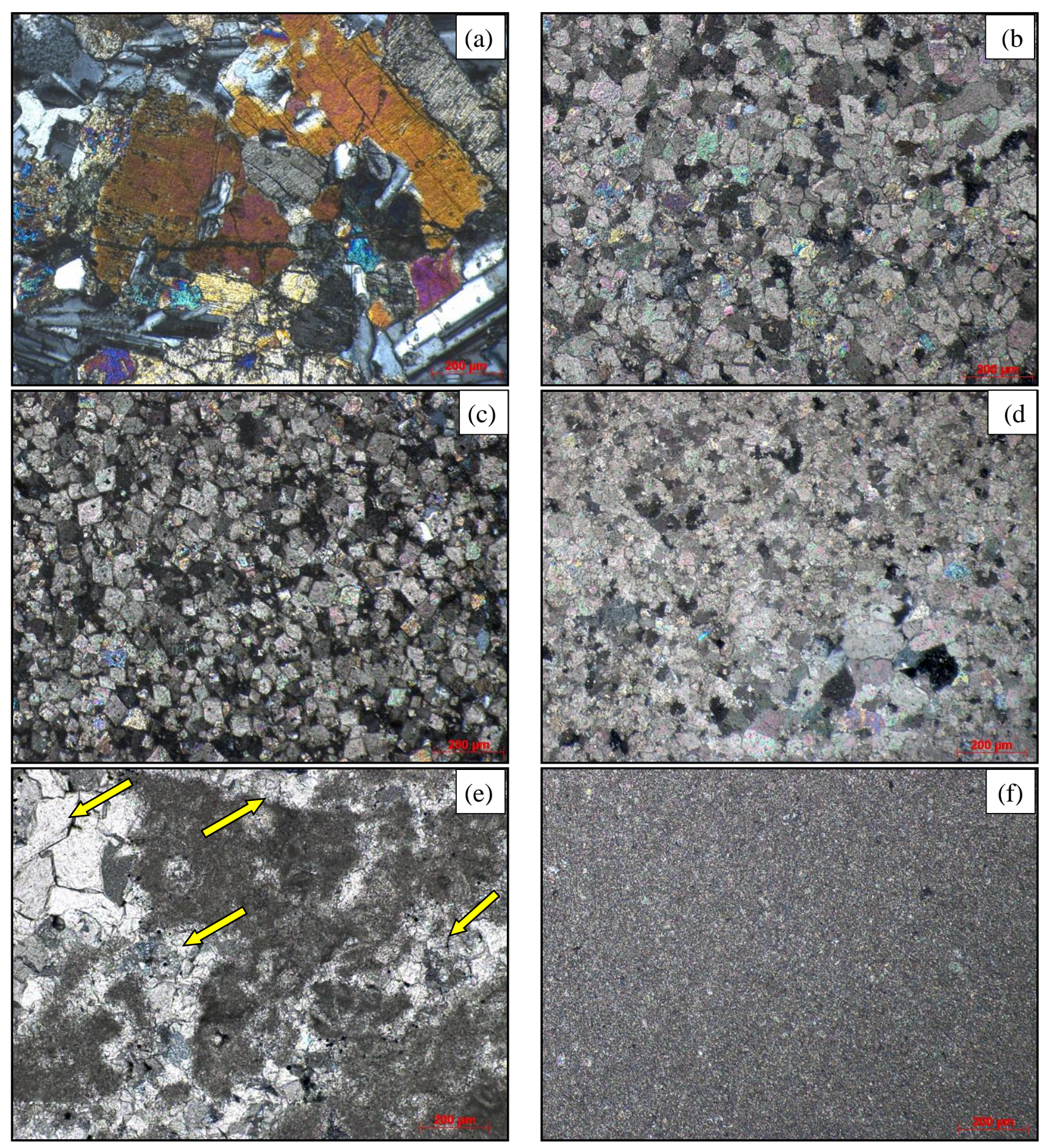

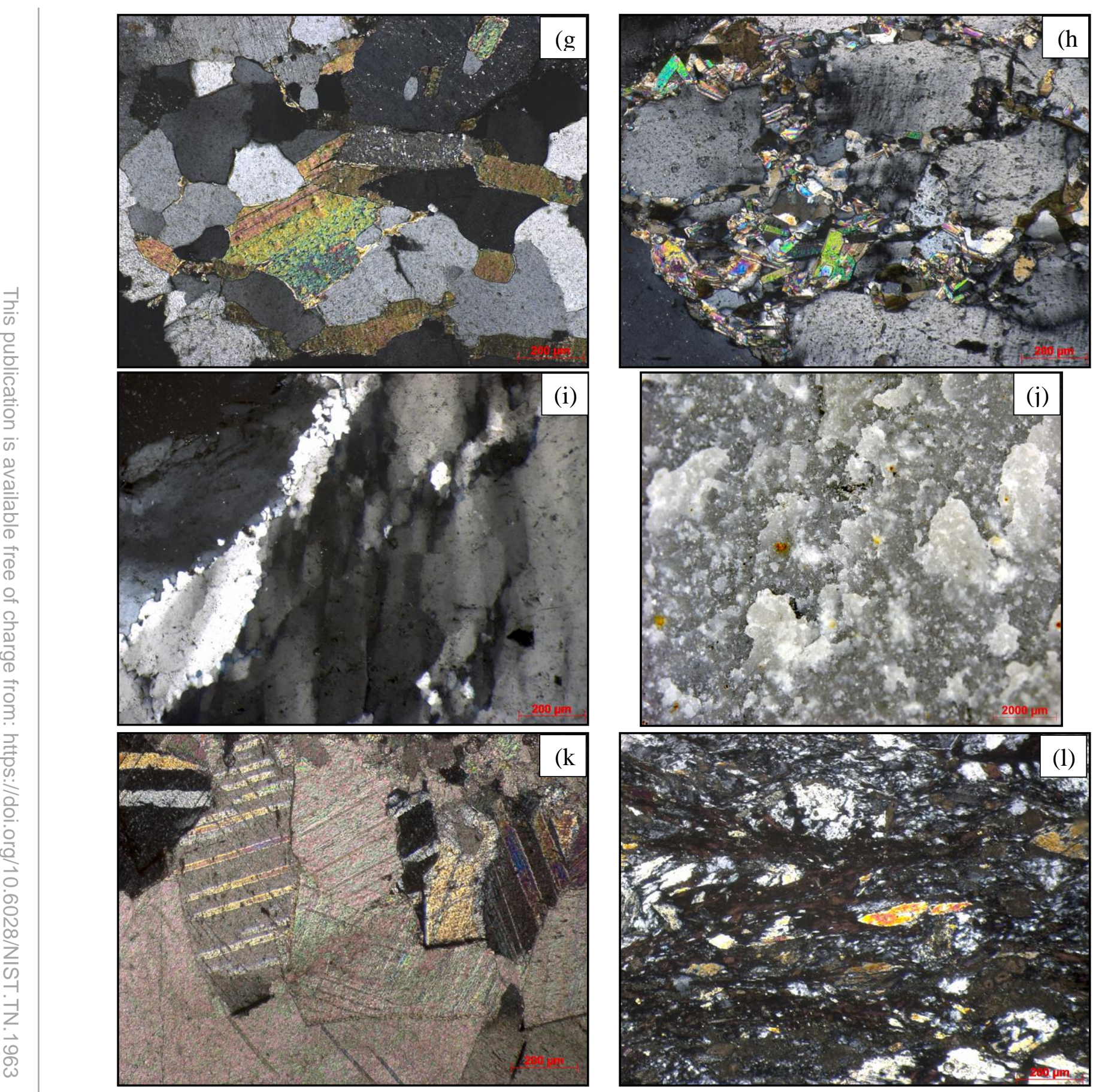

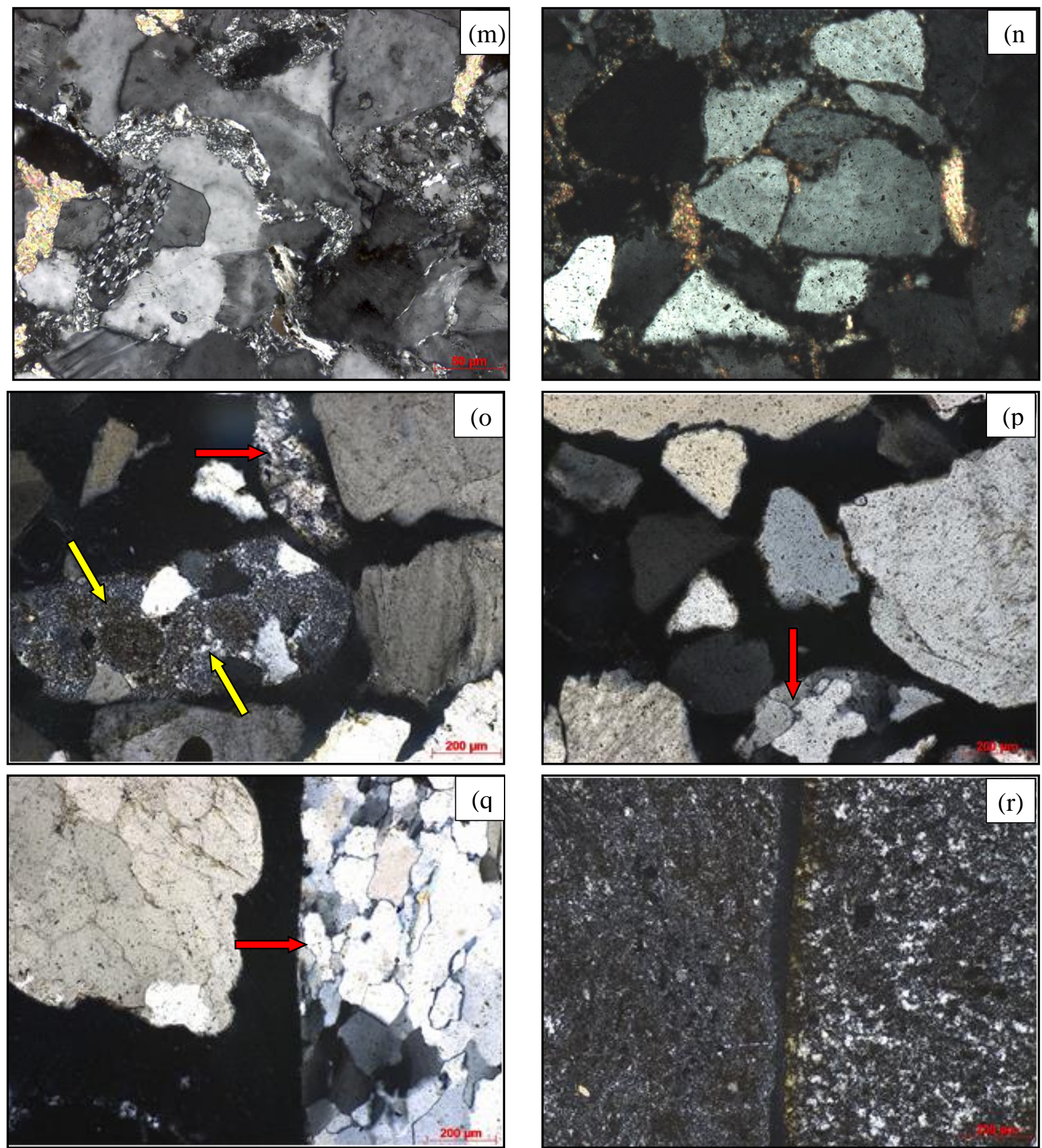

Figure 6. Thin section photomicrographs: (a) diabase, (b) dolomite, (c) relatively fine-grained argillaceous dolomite, (d) relatively uniformly textured dolomitic limestone, (e) limestone with locally recrystallized calcite, (f) fine-grained and dense micritic limestone, (g) granite, (h) granitic gneiss, (i)

siliceous gravel, (j) marble fracture surface $(\mathrm{k})$ marble showing twin lamellae, (l) meta-basalt, (m) quartzite, (n) sandstone and major constituents of sand (chert is shown by yellow arrows and quartzite by red arrows): (o) mixture of mainly quartz with lesser amounts of chert, (p) mainly quartz with lesser amounts of quartzite, (q) quartz and quartzite and (r) chert particles. 
Table 3. Summary of Aggregate Mineralogy

\begin{tabular}{|c|c|c|}
\hline Rock Type & Major minerals & Minor minerals \\
\hline Diabase $^{*}$ & Plagioclase feldspar and pyroxene & N/A \\
\hline Dolomite ${ }^{*}$ & Dolomite and calcite & $\begin{array}{l}\text { Argillaceous/clayey } \\
\text { constituents }\end{array}$ \\
\hline Dolomitic limestone $^{*}$ & Calcite & Dolomite \\
\hline $\begin{array}{l}\text { High absorption } \\
\text { limestone }\end{array}$ & Calcite & $\begin{array}{c}\text { Dolomite, argillaceous } \\
\text { materials }\end{array}$ \\
\hline Micritic limestone ${ }^{*}$ & Calcite & $\begin{array}{c}\text { Thin layers of argillaceous } \\
\text { materials, quartz }\end{array}$ \\
\hline Granite $^{*}$ & Quartz and feldspar & Biotite \\
\hline Granitic gneiss* & Quartz and feldspar & Biotite and muscovite \\
\hline $\begin{array}{l}\text { Siliceous gravel: } \\
\text { quartzite/quartz }\end{array}$ & Silica & N/A \\
\hline Marble* & Calcite & Strained quartz \\
\hline Meta-basalt ${ }^{*}$ & Feldspar & Amphibole and chlorite \\
\hline $\begin{array}{l}\text { Quartzite \& } \\
\text { Sandstone }\end{array}$ & $\begin{array}{l}\text { Quartz and feldspar } \\
\text { Sandstone also contains some } \\
\text { clayey/argillaceous matrix }\end{array}$ & $\begin{array}{l}\text { Calcite and micaceous } \\
\text { minerals }\end{array}$ \\
\hline $\begin{array}{l}\text { Sand: mainly quartz } \\
\text { with some quartzite } \& \\
\text { chert }^{* *}\end{array}$ & Silica & $\begin{array}{c}\text { Ferruginous materials in the } \\
\text { sandstone }\end{array}$ \\
\hline${ }^{*}$ Manufactured/Crushed stone & ${ }^{* *}$ Natural aggregate & N/A not applicable \\
\hline
\end{tabular}




\section{AGgRegate Properties}

The measured aggregate characteristics are summarized in Tables 4, 5, and 6 for bulk properties, shape and texture measures, and contact angle/modulus/CTE measurements, respectively. In addition to the measured average values for each aggregate, the variation amongst the aggregates, as indicated by the ratio of the range to the overall average for each property is indicated, as it was envisioned that those properties with the most variation might be good candidates for influencing the measured performance characteristics of the produced concretes. Conversely, if a property is constant across different aggregate types, the study will not be able to determine if it has any effect on concrete performance. Properties that vary most significantly in Tables 4, 5, and 6 include absorption (Table 4), texture and CAAT (Table 5), and polar surface energy, elastic modulus, and CTE (Table 6).

Table 4. Bulk properties of aggregates used in the present study. ${ }^{\mathrm{B}}$

\begin{tabular}{ccccc}
\hline Aggregate Type & $\begin{array}{c}\text { Bulk unit weight } \\
(\mathbf{o v e n ~ d r y ,} \\
\mathbf{k g / \mathbf { m } ^ { 3 } )}\end{array}$ & $\begin{array}{c}\text { Specific } \\
\text { gravity (SSD) }\end{array}$ & $\begin{array}{c}\text { Apparent } \\
\text { specific } \\
\text { gravity }\end{array}$ & $\begin{array}{c}\text { Absorption } \\
(\%)\end{array}$ \\
\hline Diabase & 1808 & 2.94 & 2.97 & 0.51 \\
Dolomite & 1665 & 2.82 & 2.84 & 0.44 \\
Dolomitic limestone & 1593 & 2.78 & 2.81 & 0.59 \\
High absorption & 1548 & 2.58 & 2.71 & 2.98 \\
limestone & 1601 & 2.72 & 2.73 & 0.33 \\
Micritic limestone & 1585 & 2.66 & 2.69 & 0.68 \\
Granite & 1645 & 2.80 & 2.83 & 0.60 \\
Granitic gneiss & 1653 & 2.57 & 2.64 & 1.67 \\
Siliceous gravel & 1769 & 2.89 & 2.91 & 0.31 \\
Marble & 1700 & 2.94 & 2.97 & 0.48 \\
Meta-basalt & 1596 & 2.65 & 2.69 & 0.87 \\
Quartzite \& Sandstone & 15.8 & 13.5 & 11.9 & 310.2 \\
Range/Average $(\%)$ & & & & \\
\hline
\end{tabular}

${ }^{\mathrm{B}}$ For bulk unit weight, specific gravity, and absorption, the average $\mathrm{CoV}$ was $0.1 \%, 0.1 \%$, and $3.4 \%$, respectively.

Figure 7 and Figure 8 provide representative images of angularity and texture, respectively, obtained by AIMS for particles retained on the $19.0 \mathrm{~mm}$ sieve. Angularity of natural sand particles retained on the $4.75 \mathrm{~mm}$ sieve is also provided. In Figure 7, the siliceous gravel appears much smoother than any of the other aggregates and this observation is quantitatively confirmed in Table 5, where the gravel exhibits the lowest texture and CAAT indices. Similarly, the images and measurements indicate that the high absorption limestone ranks second in terms of "smoothness." 
Table 5. AIMS characteristics of aggregates used in the present study (Coarse/Coarse + Fine). ${ }^{\mathrm{C}, \mathrm{D}}$

\begin{tabular}{cccccc}
\hline Aggregate Type & Form2D $^{\mathbf{E}}$ & Angularity & Texture & CAAT & Sphericity \\
\hline Diabase & $7.53 / 7.16$ & $2817 / 2658$ & $724 / 721$ & $8806 / 8773$ & $0.68 / 0.68$ \\
Dolomite & $7.66 / 7.16$ & $2858 / 2659$ & $525 / 523$ & $6680 / 6654$ & $0.58 / 0.58$ \\
Dolomitic limestone & $8.78 / 7.16$ & $3118 / 2668$ & $221 / 220$ & $3769 / 3757$ & $0.61 / 0.62$ \\
High absorption & $7.19 / 7.16$ & $2483 / 2643$ & $149 / 148$ & $2730 / 2724$ & $0.69 / 0.69$ \\
$\quad$ limestone & $7.90 / 7.16$ & $2934 / 2662$ & $645 / 642$ & $7992 / 7960$ & $0.60 / 0.60$ \\
Micritic limestone & $8.16 / 7.16$ & $2877 / 2660$ & $543 / 540$ & $7113 / 7086$ & $0.59 / 0.59$ \\
$\quad$ Granite & $7.75 / 7.16$ & $2995 / 2664$ & $606 / 603$ & $7788 / 7757$ & $0.59 / 0.60$ \\
Granitic gneiss & $7.67 / 7.16$ & $2366 / 2636$ & $112 / 111$ & $2246 / 2243$ & $0.68 / 0.69$ \\
Siliceous gravel & $8.20 / 7.16$ & $2943 / 2663$ & $441 / 440$ & $5883 / 5863$ & $0.66 / 0.66$ \\
Marble & $8.57 / 7.16$ & $3075 / 2667$ & $454 / 452$ & $6086 / 6062$ & $0.60 / 0.60$ \\
Meta-basalt & $7.33 / 7.16$ & $3029 / 2666$ & $312 / 310$ & $4632 / 4618$ & $0.60 / 0.60$ \\
Quartzite \& Sandstone & & & 142.3 & 113.2 & 16.9 \\
Range/Ave. $(\%)$ & 20.1 & 26.3 & 140 \\
for Coarse & & & & \\
\hline
\end{tabular}

${ }^{\mathrm{C}}$ Coarse/Coarse+Fine: first number indicates indices for coarse aggregate only and second number indicates indices for the coarse and fine aggregate combination.

${ }^{\mathrm{D}}$ Form2D, angularity, texture, and sphericity $\mathrm{CoV}$ were reported as $2.1 \%, 2.9 \%, 4.5 \%$, and $1.2 \%$, respectively [31].

${ }^{\mathrm{E}}$ Form2D is a measure of the flat or elongated nature of the aggregate particles. 
Table 6. Surface energies, modulus, and CTE of aggregates used in the present study.

\begin{tabular}{|c|c|c|c|c|c|}
\hline $\begin{array}{c}\text { Aggregate } \\
\text { Type }\end{array}$ & $\begin{array}{c}\text { Dispersive } \\
\text { surface } \\
\text { energy } \\
\left(\mathbf{m} \mathbf{J} / \mathbf{m}^{2}\right)\end{array}$ & $\begin{array}{c}\text { Polar } \\
\text { surface } \\
\text { energy } \\
\left(\mathbf{m J} / \mathbf{m}^{2}\right)\end{array}$ & $\begin{array}{c}\text { Total } \\
\text { surface } \\
\text { energy } \\
\left(\mathbf{m J} / \mathbf{m}^{2}\right)\end{array}$ & $\begin{array}{c}\text { Elastic } \\
\text { modulus } \\
(\mathbf{G P a})\end{array}$ & $\begin{array}{c}\mathbf{C T E} \\
\left(\mu \varepsilon /{ }^{\circ} \mathbf{C}\right)\end{array}$ \\
\hline Diabase & 36.1 & 13.3 & 49.4 & $67.6(16.6 \%)^{\mathrm{F}}$ & 4.6 \\
\hline Dolomite & 38.3 & 12.4 & 50.7 & $73.4(3.4 \%)$ & 8.0 \\
\hline $\begin{array}{l}\text { Dolomitic } \\
\text { limestone }\end{array}$ & 36.7 & 3.3 & 40.0 & $79.4(11.5 \%)$ & 8.4 \\
\hline $\begin{array}{l}\text { High } \\
\text { absorption } \\
\text { limestone }\end{array}$ & 36.6 & 7.8 & 44.4 & $44.1(14.6 \%)$ & 7.0 \\
\hline $\begin{array}{l}\text { Micritic } \\
\text { limestone }\end{array}$ & 37.2 & 2.5 & 39.7 & $71.6(12.1 \%)$ & 5.0 \\
\hline Granite & 37.8 & 11.2 & 49.0 & $54.4(9.8 \%)$ & 9.2 \\
\hline Granitic gneiss & 35.8 & 14.0 & 49.8 & $40(21.0 \%)$ & 10.5 \\
\hline $\begin{array}{c}\text { Siliceous } \\
\text { gravel }\end{array}$ & 29.1 & 11.4 & 40.5 & $97.3(4.6 \%)$ & 11.3 \\
\hline Marble & 32.5 & 9.2 & 41.7 & $102.1(4.2 \%)$ & 8.1 \\
\hline Meta-basalt & 42.3 & 19.7 & 62.0 & $92.4(9.2 \%)$ & 6.3 \\
\hline $\begin{array}{l}\text { Quartzite \& } \\
\text { Sandstone }\end{array}$ & 39.3 & 27.3 & 66.6 & $62.9(1.7 \%)$ & 10.1 \\
\hline $\begin{array}{c}\text { Range/Ave. } \\
(\%)\end{array}$ & 36.2 & 206.5 & 55.4 & 87.0 & 83.3 \\
\hline
\end{tabular}

${ }^{\mathrm{F}} \mathrm{Number}$ in parenthesis indicates $\mathrm{CoV}$ for measured elastic modulus. 

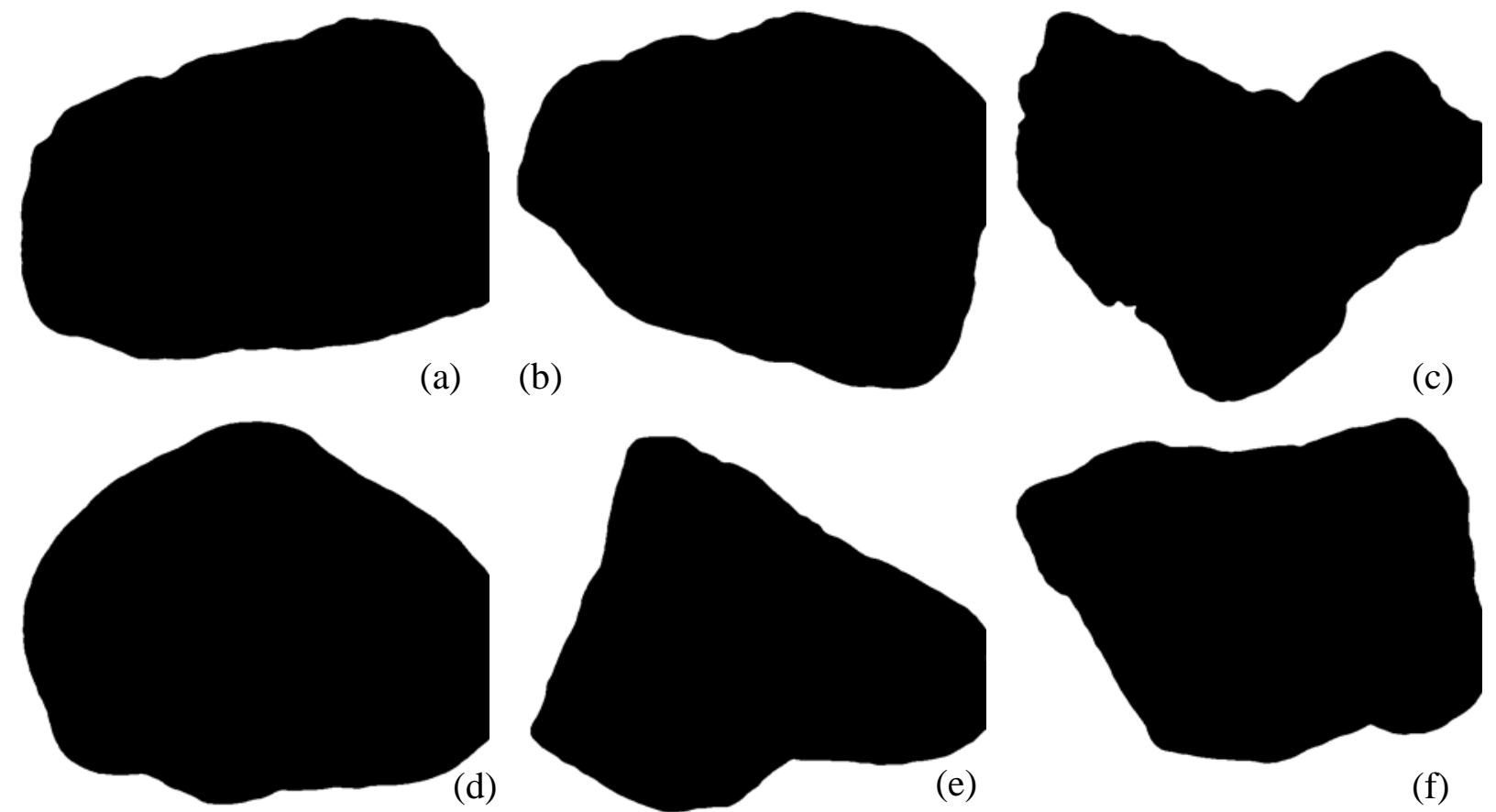

(e)

(f)
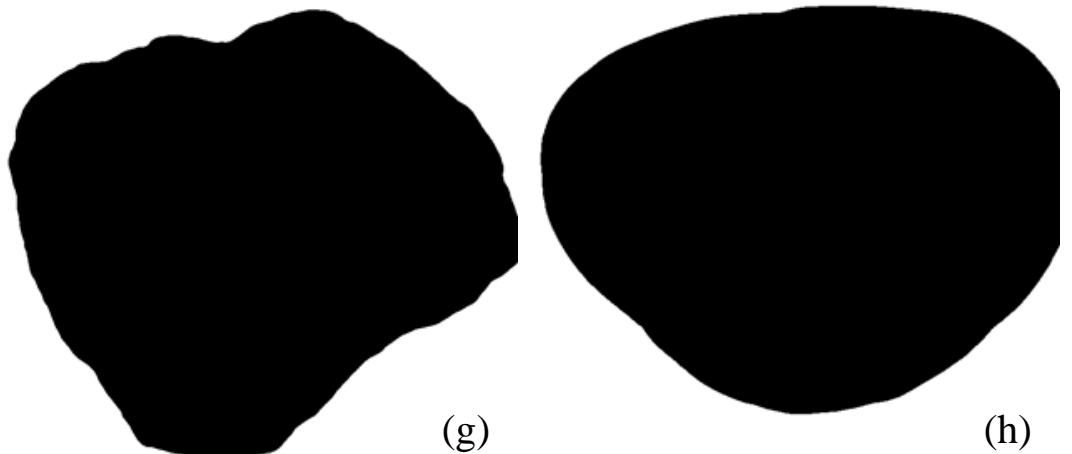

(h)
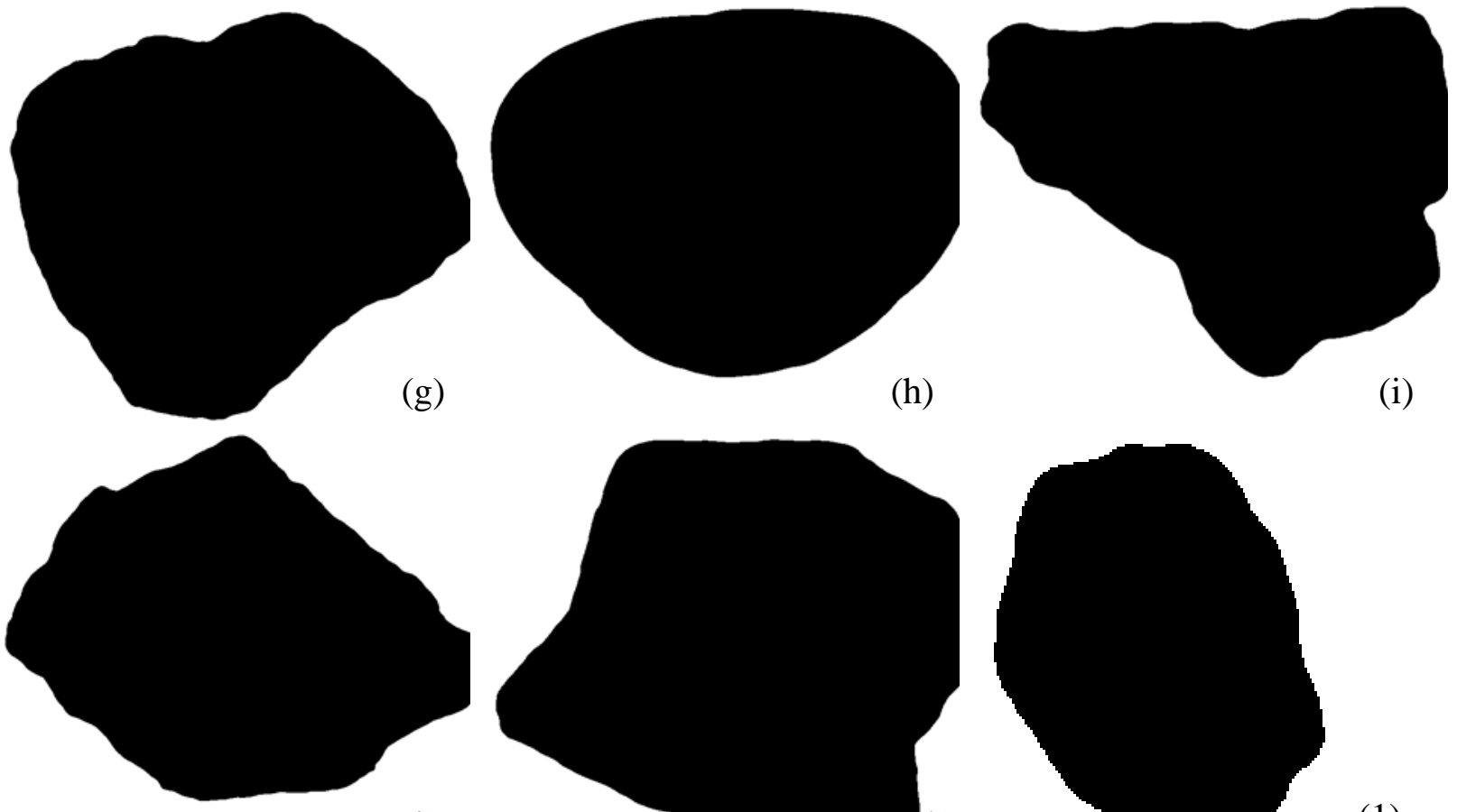

(j)
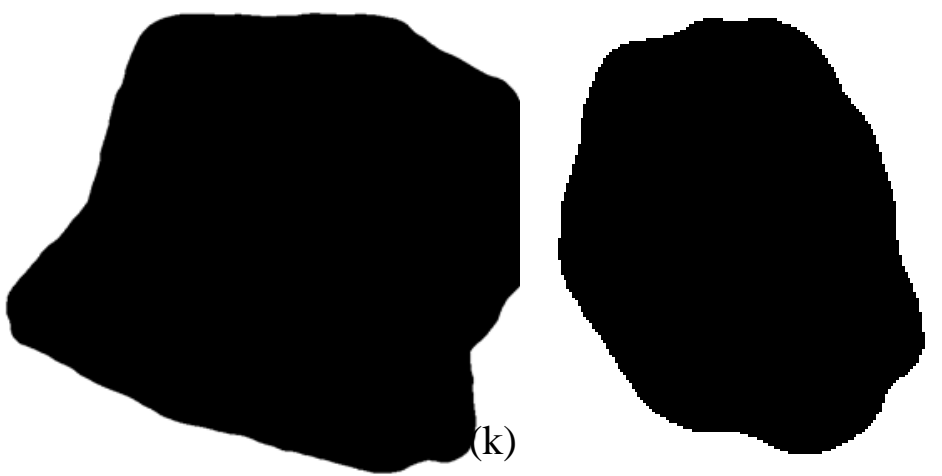

(1)

Figure 7. Angularity pictures of representative particles retained on the $19.0 \mathrm{~mm}$ sieve. (a) Diabase, (b) Dolomite, (c) Dolomitic limestone, (d) High absorption limestone, (e) Micritic limestone, (f) Granite, (g) Granitic gneiss, (h) Siliceous gravel, (i) Marble, (j) Meta-basalt and (k) Quartzite \& Sandstone. (l) Angularity picture of representative sand particle retained on a $4.75 \mathrm{~mm}$ sieve. 

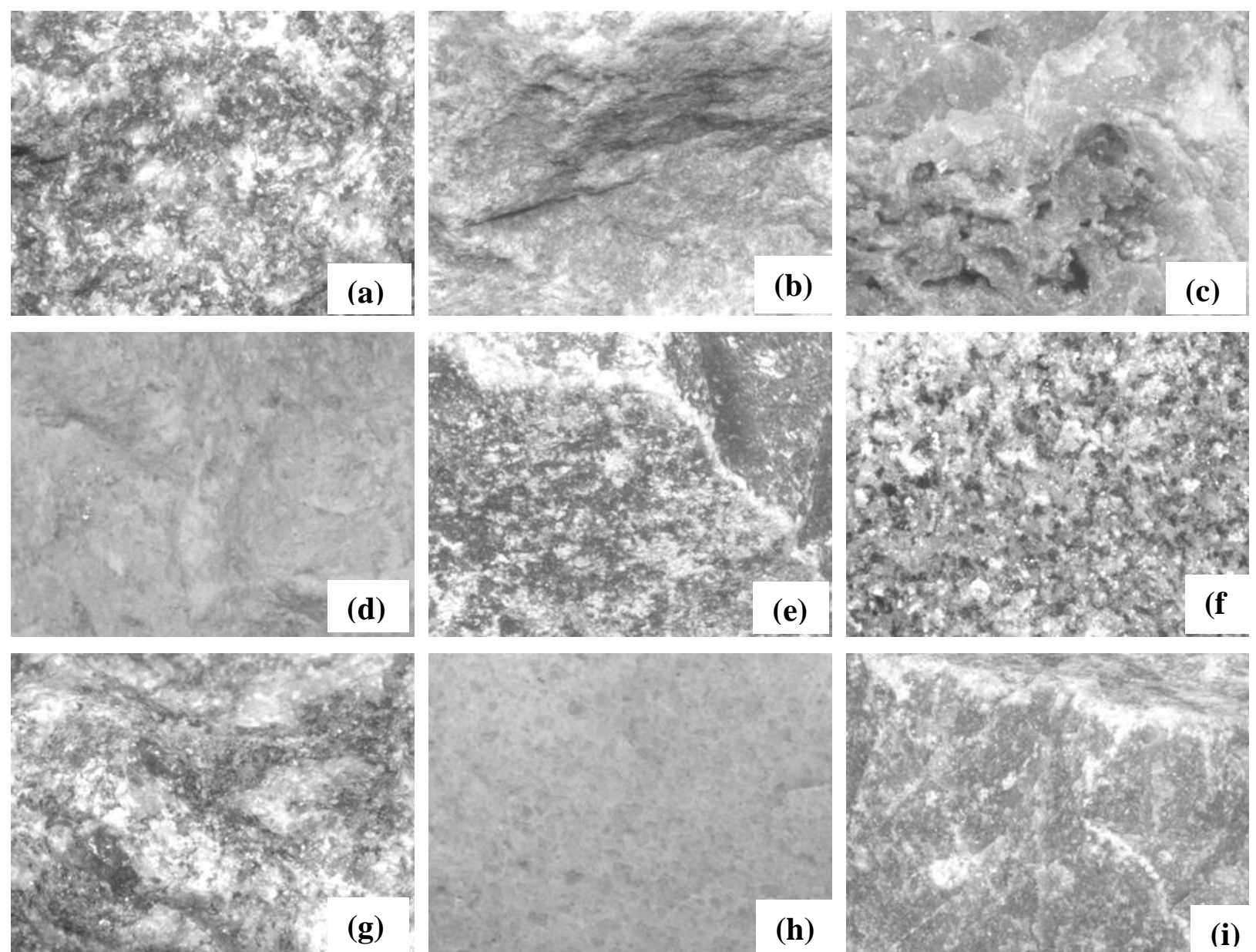

(h)

(i)
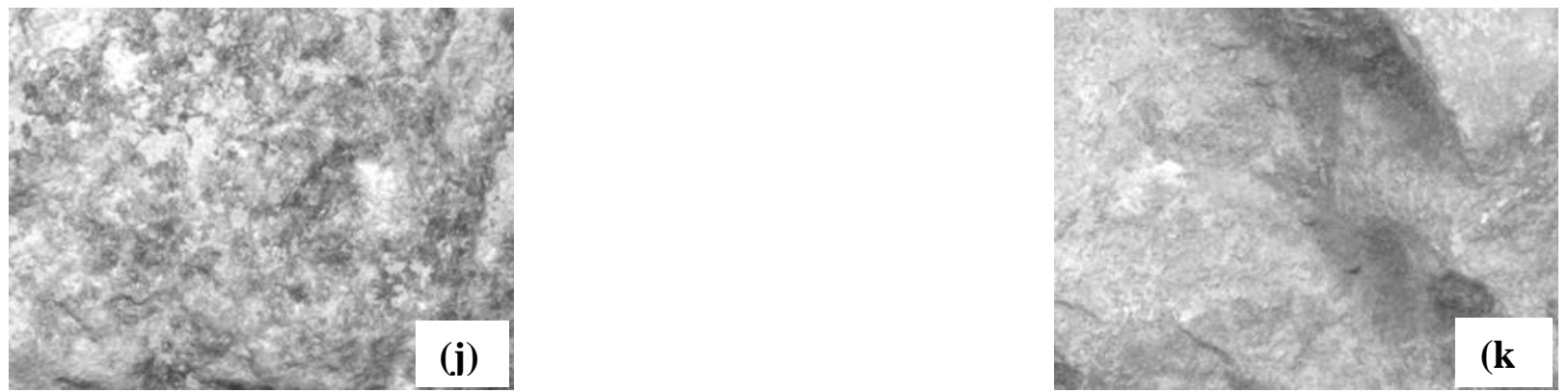

Figure 8. Texture pictures of representative particles retained on the $19.0 \mathrm{~mm}$ sieve. (a) Diabase, (b)

Dolomite, (c) Dolomitic limestone, (d) High absorption limestone, (e) Micritic limestone, (f) Granite, (g) Granitic gneiss, (h) Siliceous gravel, (i) Marble, (j) Meta-basalt and (k) Quartzite \& Sandstone. 


\section{ROCK (CORE) PROPERTIES}

The measured properties of selected rocks, measured on cores obtained from large-sized quarried rocks are presented in Tables 7 and 8. The properties that varied the most were the compressive strength and the longitudinal dynamic modulus of elasticity. Most of the properties measured on the cores did not correlate well with one another, except for what is shown in Figure 9. From Figure 9a and 9b, it appears that the data for the micritic limestone CTE may not be accurate, since once this rock is excluded, good correlations are obtained between CTE and density or CTE and rock modulus of elasticity, with an estimated standard error of $0.59 \mu /{ }^{\circ} \mathrm{C}(7.7 \%)$ and $0.24 \mu /{ }^{\circ} \mathrm{C}(3.2 \%)$, respectively. Figure $9 \mathrm{c}$ shows a promising correlation between modulus of elasticity obtained by static and dynamic measurements (standard error of $4.7 \mathrm{GPa}$ or $4.8 \%$ ), although static tests consistently yielded lower values than the dynamic ones. Although a good correlation was not found between rock density and compressive strength (Figure $9 \mathrm{~d}$ - standard error of $33.9 \mathrm{MPa}$ or $19.6 \%$ ), there is a definite trend between these two rock properties.

Table 7. Density, static modulus of elasticity, compressive and tensile strengths, and CTE of rock cores ${ }^{\mathrm{G}}$

\begin{tabular}{|c|c|c|c|c|c|c|}
\hline \multirow[b]{2}{*}{ Rock Type } & \multirow[b]{2}{*}{$\begin{array}{l}\text { Density } \\
\left(\mathrm{kg} / \mathbf{m}^{3}\right)\end{array}$} & \multicolumn{2}{|c|}{ Static } & \multirow[b]{2}{*}{$\begin{array}{l}\text { Compressive } \\
\text { strength } \\
\text { (MPa) }\end{array}$} & \multirow[b]{2}{*}{$\begin{array}{c}\text { Tensile } \\
\text { strength } \\
\text { (MPa) }\end{array}$} & \multirow[b]{2}{*}{$\begin{array}{c}\mathrm{CTE} \\
\left(\mu \varepsilon /{ }^{\circ} \mathbf{C}\right)\end{array}$} \\
\hline & & $\begin{array}{l}\text { Modulus of } \\
\text { elasticity } \\
(\mathrm{GPa})\end{array}$ & $\begin{array}{l}\text { Poisson } \\
\text { ratio }\end{array}$ & & & \\
\hline Diabase & 3010 & 87 & 0.24 & 265 & 21 & 5.9 \\
\hline $\begin{array}{l}\text { Micritic } \\
\text { limestone }\end{array}$ & 2710 & 70 & 0.28 & 112 & 14 & 4.5 \\
\hline Granite & 2650 & 56 & 0.22 & 163 & 19 & 8.6 \\
\hline Granitic gneiss & 2810 & 48 & 0.23 & 116 & 13 & 8.7 \\
\hline Marble & 2830 & 81 & 0.26 & 182 & 18 & 8.1 \\
\hline Meta-basalt & 2980 & 74 & 0.34 & 191 & 14 & 7.1 \\
\hline $\begin{array}{c}\text { Range/Average } \\
(\%)\end{array}$ & 12.7 & 56.0 & 46.5 & 89.4 & 48.8 & 58.8 \\
\hline
\end{tabular}

${ }^{\mathrm{G}}$ For density, static modulus of elasticity, Poisson ratio, compressive strength, tensile strength, and CTE, the average $\mathrm{CoV}$ was $0.2 \%, 1.1 \%, 2.2 \%, 7.9 \%, 6.3 \%$, and $0.9 \%$, respectively.

Table 8. Dynamic transverse and longitudinal modulus of elasticity of rock cores ${ }^{\mathrm{H}}$

\begin{tabular}{|c|c|c|}
\hline \multirow{2}{*}{ Rock Type } & \multicolumn{2}{|c|}{ Dynamic modulus of elasticity } \\
\hline & Transverse (GPa) & Longitudinal (GPa) \\
\hline Diabase & 97.9 & 7.0 \\
\hline Micritic limestone & 78.8 & 9.1 \\
\hline Granite & 70.6 & 11.0 \\
\hline Granitic gneiss & 59.2 & 16.9 \\
\hline Marble & 88.4 & - \\
\hline Meta-basalt & 93.2 & 7.1 \\
\hline Range/Average (\%) & 47.6 & 96.6 \\
\hline
\end{tabular}

${ }^{\mathrm{H}}$ For transverse dynamic modulus of elasticity and longitudinal dynamic modulus of elasticity, the average CoV was $1.8 \%$ and $5.2 \%$, respectively. 

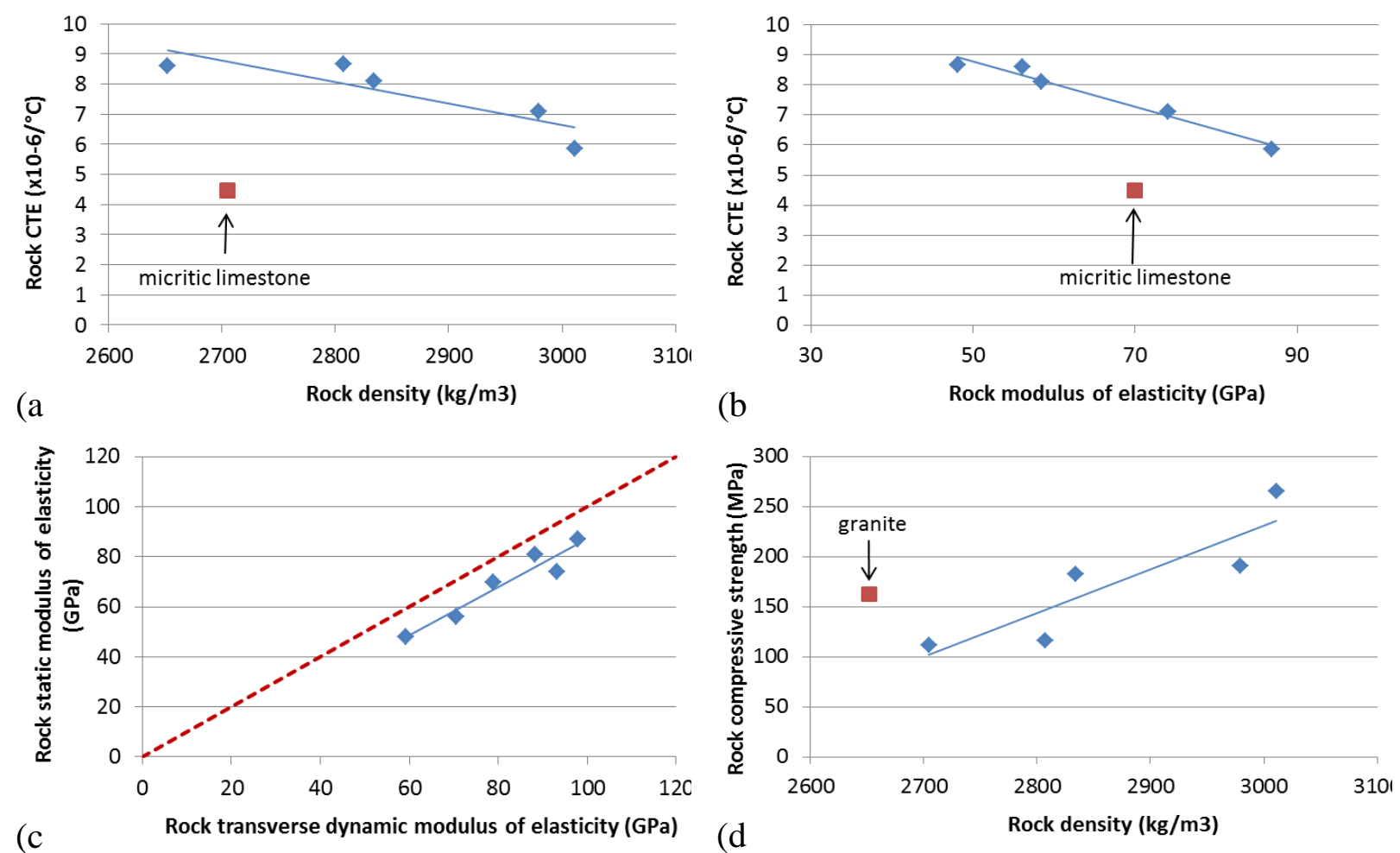

Figure 9. Correlation of measured rock properties. Dashed line in (c) indicates line of equality. Average $\mathrm{CoV}$ can be found in Tables 7 and 8 .

Figure 10 shows that some of the rock properties can be estimated from aggregate testing. As seen in Figure 10a, when the average aggregate dynamic modulus is used for all aggregates, two aggregates (diabase and marble) seem not to follow the same trends as the others. From the limited available data presented in Figure 10b, it does appear that the compressive strengths of the rocks can be estimated from their apparent specific gravities, with an estimated standard error of $33.9 \mathrm{MPa}$ or $19.8 \%$. Out of the 6 rocks tested, granite was the only one that did not follow the same trend as the others and was therefore eliminated from the correlation analysis, confirming that some problems may have occurred when determining the granite's compressive strength, as already suggested in Figure 9d.

Regarding CTE, Figure 10c shows a good agreement between the results obtained in aggregate testing and those on cores, with an estimated standard error of $0.33 \mu \varepsilon /{ }^{\circ} \mathrm{C}$ or $4.3 \%$, when the micritic limestone is excluded. Micritic limestone (rock) CTE testing may have also presented problems since both in Figures 9a and $9 \mathrm{~b}$ and in Figure 10c, it does not follow the expected trends. It is important to point out that the CTE is dependent on the testing temperature range [60] and since the aggregates were tested between $0{ }^{\circ} \mathrm{C}$ and $100{ }^{\circ} \mathrm{C}$, while the cores were evaluated between $10{ }^{\circ} \mathrm{C}$ to $50{ }^{\circ} \mathrm{C}$, a $1: 1$ correlation was not necessarily expected. Still, a generally good agreement is observed between the values obtained on the bulk cores and the small cylinders using the two different measurement techniques, considering the average $\mathrm{CoV}$ of $18 \%$ for the NIST CTE data. Conversely, for the CTE measurements performed at TFHRC on the cores removed from the large-sized quarried rocks, the maximum $\mathrm{CoV}$ was only $0.9 \%$. 

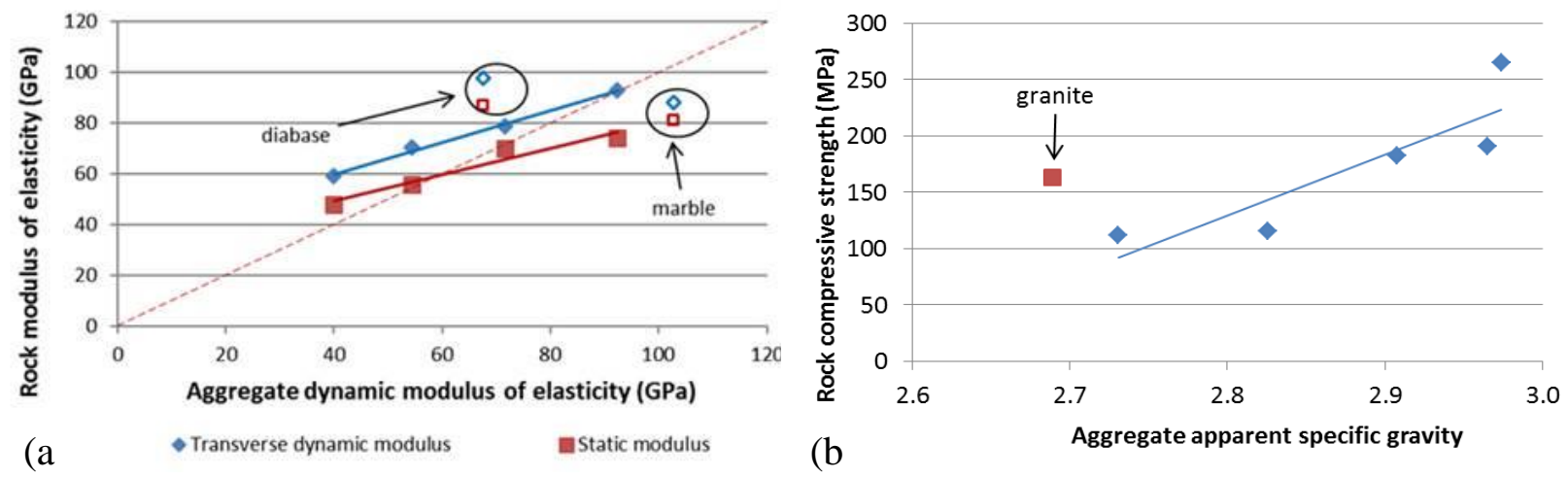

(c

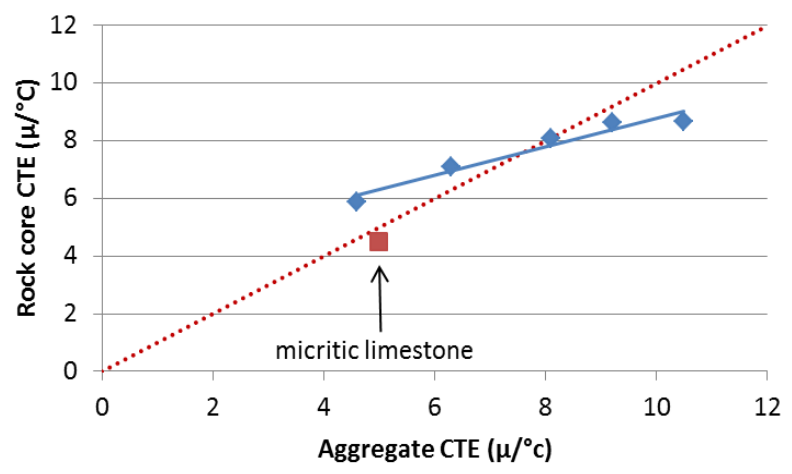

Figure 10. Correlation between aggregate tests and tests on rock cores. (a) aggregate dynamic modulus carried out at NIST and either transverse dynamic modulus or static modulus carried out on rock cores at TFHRC. Dashed line indicates line of equality. (b) apparent specific gravity carried out on aggregates and compressive strength carried out on rock cores. (c) aggregate CTE versus rock core CTE. Average $\mathrm{CoV}$ can be found in Tables 7 and 8 . 


\section{CONCRETE Properties}

\section{FRESH CONCRETE PROPERTIES}

As the concretes were cast over a more than six-month period, the fresh concrete temperature exhibited some variation due to changes in the environment of the rooms where material storage and casting took place. Specifically, the minimum and maximum fresh temperatures were $19.9{ }^{\circ} \mathrm{C}$ and $23.0^{\circ} \mathrm{C}$, respectively. The measured temperature rises for the OPC and ternary concrete mixture semi-adiabatic specimens are provided in Figure 11. To reduce any dispersion in the data due to the variable starting temperatures and exposure environments (curing), the data are plotted as the temperature rise relative to the minimum temperature experienced by each individual mixture. With this correction, data for many of the mixtures appears quite similar, particularly for the ternary blend concretes. Both concretes based on granite appear as outliers in Figure 11, as the starting temperature (by the time the semi-adiabatic cylinder was prepared from the fresh mixture) of the OPC granite-based concrete was only $19.1^{\circ} \mathrm{C}$, while that of the ternary blend was $19.4{ }^{\circ} \mathrm{C}$ but quickly rose to about $21.5^{\circ} \mathrm{C}$ when placed in its curing environment. By comparison, the initial temperature of the semi-adiabatic specimen for the OPC quartzite \& sandstonebased concrete was $23.1^{\circ} \mathrm{C}$.

The measured electrical resistance (impedance) for a subset of the fresh concrete mixtures is provided in Figure 12. While most of the mixtures exhibit a similar response, for both the OPC and ternary blend concretes, those mixtures prepared with the quartzite $\&$ sandstone coarse aggregate produce results that are somewhat different, as was also the case for their semi-adiabatic temperature responses in Figure 11. For the OPC mixtures in Figure 12, the granite also appears somewhat distinct from most of the mixtures (as was again the case for its semi-adiabatic response in Figure 11 as discussed above). When comparing the semi-adiabatic temperature rise results to the measured electrical resistance of the fresh concrete mixtures, a reasonable correlation (standard errors of $0.1 \mathrm{~h}$ to $0.2 \mathrm{~h}$ ) is observed between the time required to reach $80 \%$ (OPC mixtures except for siliceous gravel and granite) to $90 \%$ (ternary blends except for siliceous gravel) of the peak temperature and the inflection point in the electrical resistance response, with both occurring in the $9 \mathrm{~h}$ to $12 \mathrm{~h}$ time range. Previously, the first local minimum in the electrical resistance response has been used to successfully anticipate the initial setting time of both concrete [53] and paste [62] mixtures.

The variation in air content among the concrete mixtures was minimal with an average air content of $2.8 \%$, with individual mixtures ranging from $2.1 \%$ to $3.8 \%$. Similarly, the average slump was $53 \mathrm{~mm}$ with a range of $32 \mathrm{~mm}$ to $76 \mathrm{~mm}$. No systematic differences were observed when comparing the slumps and air contents of the OPC concretes to their ternary blend counterparts. 

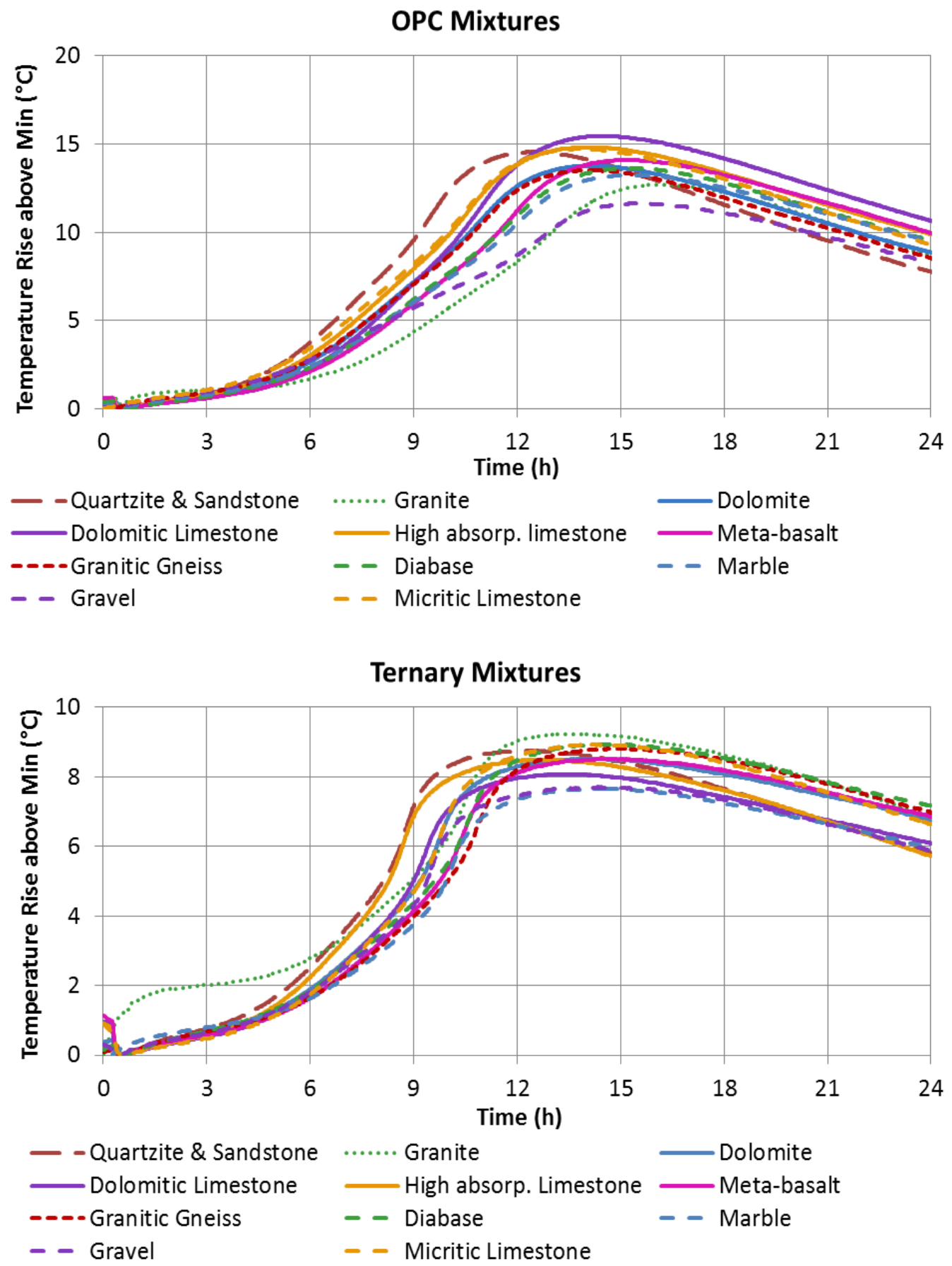

Figure 11. Semi-adiabatic temperature rise (normalized temperatures per initial temperature) plots for the OPC (top) and ternary blend (bottom) concrete mixtures. 

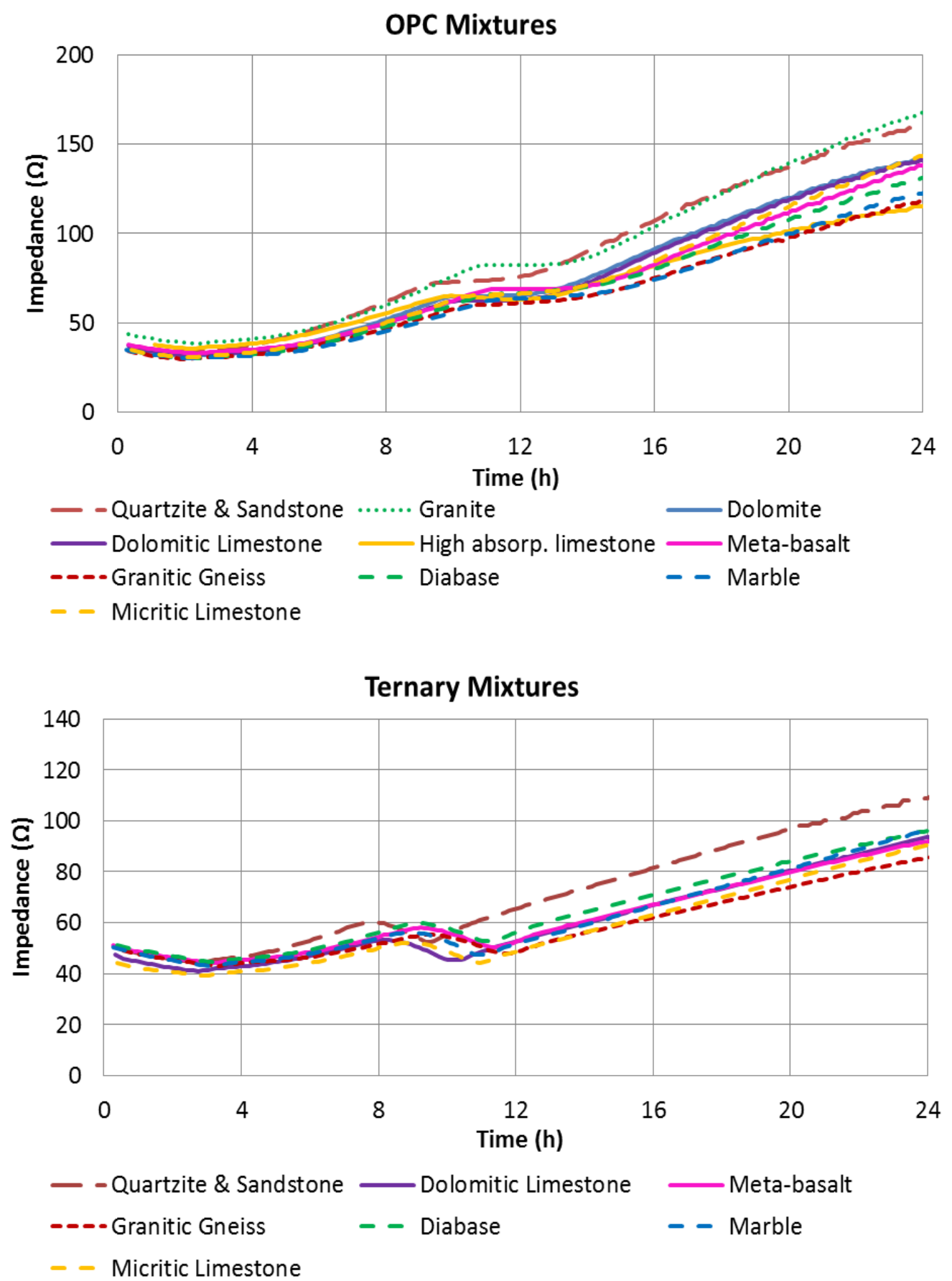

Figure 12. Fresh concrete electrical resistance (impedance) plots for the OPC (top) and ternary blend (bottom) concrete mixtures. 


\section{Concrete Mechanical Properties}

The measured mechanical properties for the OPC and ternary blend concrete mixtures are provided in Tables 9 and 10, respectively, along with the measured variation in each property at each age for each binder type. Aggregate type has the largest influence (range/average) at $1 \mathrm{~d}$, but there is still significant variation in all measured strengths and moduli out to $91 \mathrm{~d}$. At the later ages, the measured variation in strengths is generally greater for the ternary blend concretes than for those based on an OPC binder, in agreement with previous results [63].

The ability to infer later age strength from $1 \mathrm{~d}$ values is illustrated in Figure 13. A reasonable correlation between later ages and $1 \mathrm{~d}$ strength is observed for both the OPC and ternary blend concretes, but the value of the standard error for the linear fit increases progressively from $7 \mathrm{~d}$ through $28 \mathrm{~d}$ to $91 \mathrm{~d}$, exhibiting values of 1.8 MPa, 2.9 MPa, and 3.7 MPa, respectively. Relative to the average strength across all aggregate types at each age, these standard errors correspond to values of $5.4 \%, 6.6 \%$, and $7.0 \%$, respectively. If one considers the component pastes (OPC or ternary) to be nominally of the same strengths in the different aggregate concretes, the variation in strength should be mainly due to the microstructure and bond of the ITZ paste to the much stronger aggregate (Table 7). The relative influence of this microstructural feature on measured strength decreases with specimen age (range values in Tables 9 and 10), so that it is not surprising that the correlation of later age strength with the $1 \mathrm{~d}$ values also decreases at the later ages of $28 \mathrm{~d}$ and $91 \mathrm{~d}$.

It is also informative to compare the strengths of the ternary blend concretes to their corresponding OPC counterparts, as shown in Figure 14 for $28 \mathrm{~d}$ compressive strength. While data from most of the concrete mixtures falls on a straight line, there are two types of exceptions. For most of the carbonate aggregates, the ternary blend exhibits a higher than expected strength, while the opposite is found for the high absorption limestone. While no definitive explanation is provided, the isothermal calorimetry results for the pore solutions with ground aggregate particles (Figure 15) show that marble and micritic limestone appear to be more reactive in ternary pore solution than in OPC pore solution, while high absorption limestone does not show much reaction with the ternary pore solution. More information on aggregate reactivity can be found in appendix A. This additional reactivity could enhance the formation of the hydrated calcium carbonate-calcium hydroxide compounds observed in the interface between carbonate aggregates and cement paste by Monteiro and Mehta [14]. Shannon et al. [63,64] have also observed higher than expected strengths when using portland limestone cements (PLC) instead of OPC for concretes prepared with fly ash or slag (hence ternary blends) and with a variety of aggregates, particularly limestones. Conversely, it is unclear at this time why the ternary blend combined with the high absorption limestone has produced such a low strength concrete.

Figure 16 provides a comparison of the $28 \mathrm{~d}$ and $91 \mathrm{~d}$ splitting tensile strengths to their counterpart compressive strengths. It can be observed that an ACI-type relationship [65], but with a coefficient of 0.62 instead of the expected 0.56 , provides a reasonable description of the relationship between these two measures. However, as shown in the plot, a simple linear relation would provide an equally adequate fitting of the experimental data produced in this study. Similarly, Figure 17 shows three commonly used models to predict modulus of rupture from the measured compressive strength. ACI 363-1 [66] fits the data better, independent of testing age and binder composition, while both ACI 363-2 and ACI 318-14 [65] considerably underestimate the measured modulus of rupture. In addition, the latter two models underestimate the ternary mixtures more than they do the OPC mixtures and the $28 \mathrm{~d}$ specimens more than the $91 \mathrm{~d}$ ones. 
Table 9. Mechanical Properties of OPC Concrete, Mortar, and Paste Mixtures

\begin{tabular}{|c|c|c|c|c|c|c|c|c|c|c|c|c|}
\hline \multirow[t]{2}{*}{ Aggregate } & \multicolumn{4}{|c|}{ Compressive Strength (MPa) } & \multicolumn{4}{|c|}{ Elastic Modulus (GPa) } & \multicolumn{2}{|c|}{$\begin{array}{l}\text { Splitting Tensile } \\
\text { Strength (MPa) }\end{array}$} & \multicolumn{2}{|c|}{$\begin{array}{c}\text { Flexural } \\
\text { Strength (MPa) }\end{array}$} \\
\hline & $1 \mathrm{~d}$ & $7 \mathrm{~d}$ & $28 \mathrm{~d}$ & $91 \mathrm{~d}$ & $1 \mathrm{~d}$ & $7 \mathrm{~d}$ & $28 \mathrm{~d}$ & $91 \mathrm{~d}$ & $28 \mathrm{~d}$ & $91 \mathrm{~d}$ & $28 \mathrm{~d}$ & $91 \mathrm{~d}$ \\
\hline Average $\mathrm{CoV}^{\mathrm{I}}$ & $2.5 \%$ & $1.5 \%$ & $1.9 \%$ & $2.9 \%$ & $5.5 \%$ & $3.3 \%$ & $3.6 \%$ & $1.7 \%$ & $5.3 \%$ & $4.8 \%$ & $3.1 \%$ & $3.7 \%$ \\
\hline Dolomite & 21.0 & 39.4 & 50.3 & 57.7 & 28.4 & 35.8 & 45.8 & 46.3 & 4.18 & 5.06 & 6.19 & 7.25 \\
\hline Dolomitic limestone & 23.1 & 41.9 & 52.5 & 60.1 & 32.9 & 45.2 & 47 & 48.8 & 4.34 & 5.23 & 6.53 & 7.24 \\
\hline Granite & 22.6 & 41.5 & 52.4 & 60.3 & 23.5 & 29.1 & 32.6 & 35.1 & 4.26 & 4.74 & 5.93 & 6.55 \\
\hline Granitic gneiss & 16.3 & 34.5 & 46.3 & 51.4 & 19.6 & 25.5 & 27.6 & 30.7 & 3.99 & 4.31 & 5.75 & 5.83 \\
\hline Siliceous gravel & 9.8 & 31 & 37.9 & 46.4 & 20.6 & 28.9 & 33.6 & 34.8 & 3.72 & 4.19 & 5.89 & 6.01 \\
\hline Marble & 19.3 & 41.8 & 51.1 & 60.7 & 30.9 & 39.9 & 49.3 & 51.6 & 4.66 & 5.12 & 6.37 & 7.14 \\
\hline Paste & & & & & & 12.2 & 13.7 & 15.4 & & & & \\
\hline
\end{tabular}

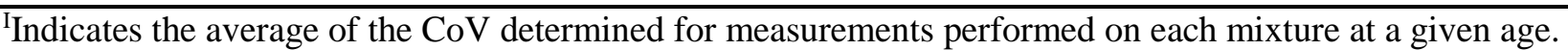


Table 10. Mechanical Properties of Ternary Blend Concrete, Mortar, and Paste Mixtures

\begin{tabular}{|c|c|c|c|c|c|c|c|c|c|c|c|c|}
\hline \multirow[t]{2}{*}{ Aggregate } & \multicolumn{4}{|c|}{ Compressive Strength (MPa) } & \multicolumn{4}{|c|}{ Elastic Modulus (GPa) } & \multicolumn{2}{|c|}{$\begin{array}{l}\text { Splitting Tensile } \\
\text { Strength (MPa) }\end{array}$} & \multicolumn{2}{|c|}{$\begin{array}{c}\text { Flexural } \\
\text { Strength (MPa) }\end{array}$} \\
\hline & $1 \mathrm{~d}$ & $7 \mathrm{~d}$ & $28 \mathrm{~d}$ & $91 \mathrm{~d}$ & $1 \mathrm{~d}$ & $7 \mathrm{~d}$ & $28 \mathrm{~d}$ & $91 \mathrm{~d}$ & $28 \mathrm{~d}$ & $91 \mathrm{~d}$ & $28 \mathrm{~d}$ & $91 \mathrm{~d}$ \\
\hline Average $\mathrm{CoV}$ & $2.8 \%$ & $1.7 \%$ & $2.8 \%$ & $1.9 \%$ & $7.6 \%$ & $3.4 \%$ & $3.3 \%$ & $1.2 \%$ & $5.4 \%$ & $4.2 \%$ & $4.0 \%$ & $3.3 \%$ \\
\hline Diabase & 6.6 & 26.5 & 39.3 & 50.7 & 25.1 & 35.6 & 38.7 & 43.0 & 3.49 & 5.53 & 5.56 & 6.17 \\
\hline Dolomite & 7.9 & 27.7 & 37.7 & 48.0 & 18.3 & 31.4 & 37.9 & 43.7 & 4.30 & 4.59 & 6.62 & 7.18 \\
\hline Dolomitic limestone & 10.6 & 29.6 & 42.3 & 51.1 & 24.3 & 38.6 & 44.3 & 48.9 & 3.73 & 4.14 & 6.37 & 7.11 \\
\hline Micritic limestone & 9.3 & 31.3 & 44.0 & 51.8 & 22.6 & 37.0 & 42.4 & 44.6 & 4.39 & 5.35 & 6.17 & 7.19 \\
\hline Granite & 8.6 & 29.1 & 39.0 & 48.7 & 16.7 & 25.1 & 29.5 & 32.4 & 3.94 & 4.20 & 5.88 & 6.79 \\
\hline Granitic gneiss & 6.6 & 26.0 & 36.7 & 45.9 & 14.4 & 23.6 & 25.0 & 29.3 & 3.41 & 4.45 & 5.08 & 5.34 \\
\hline Siliceous gravel & 6.1 & 22.4 & 29.7 & 40.2 & 17.0 & 26.2 & 30.3 & 34.4 & 3.22 & 4.05 & 4.71 & 5.03 \\
\hline Marble & 8.0 & 31.3 & 43.2 & 56.9 & 22.4 & 37.2 & 42.8 & 47.6 & 4.87 & 5.05 & 6.62 & 7.10 \\
\hline Paste & & & & & & 8.7 & 10.8 & 13.7 & & & & \\
\hline
\end{tabular}




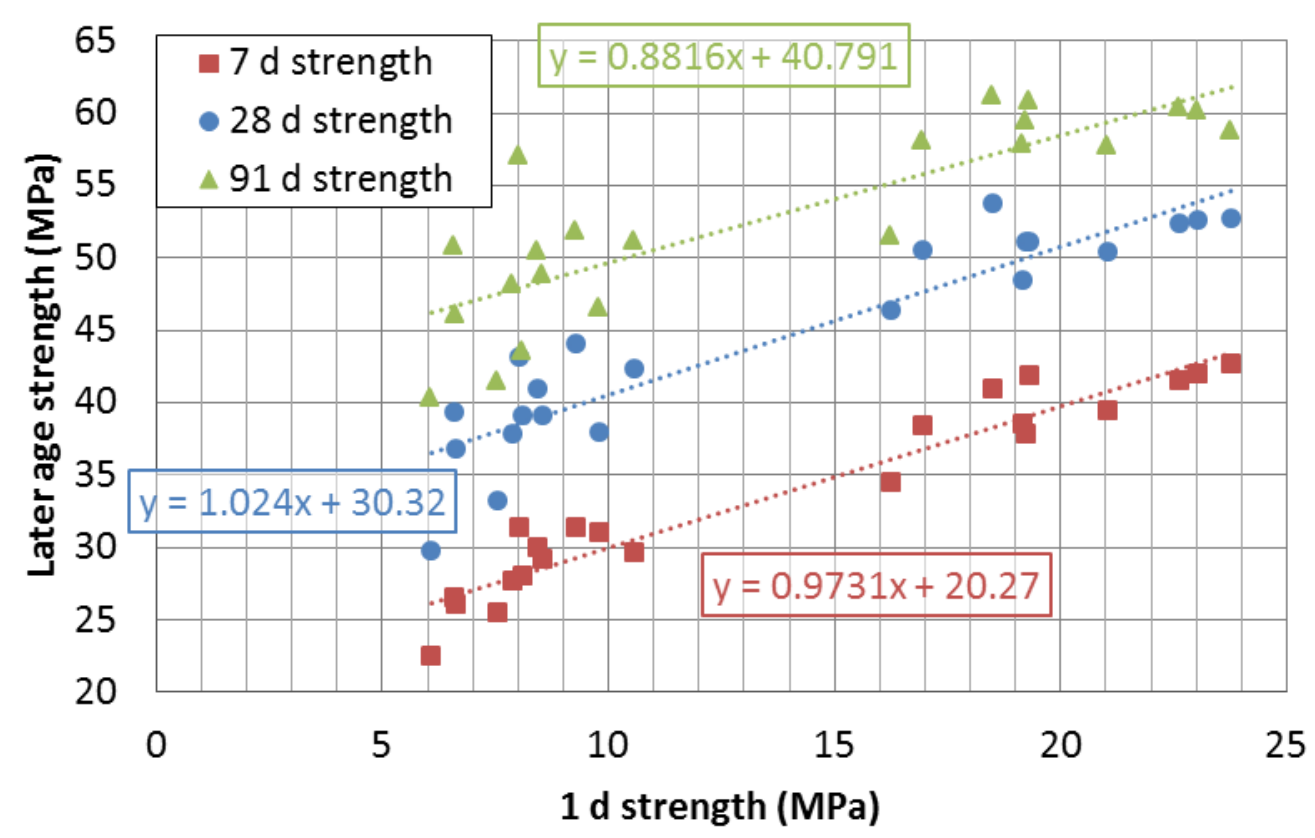

Figure 13. Later age compressive strength vs. 1-d compressive strength for the OPC and ternary blend concretes. Average CoV can be found in Tables 9 and 10.

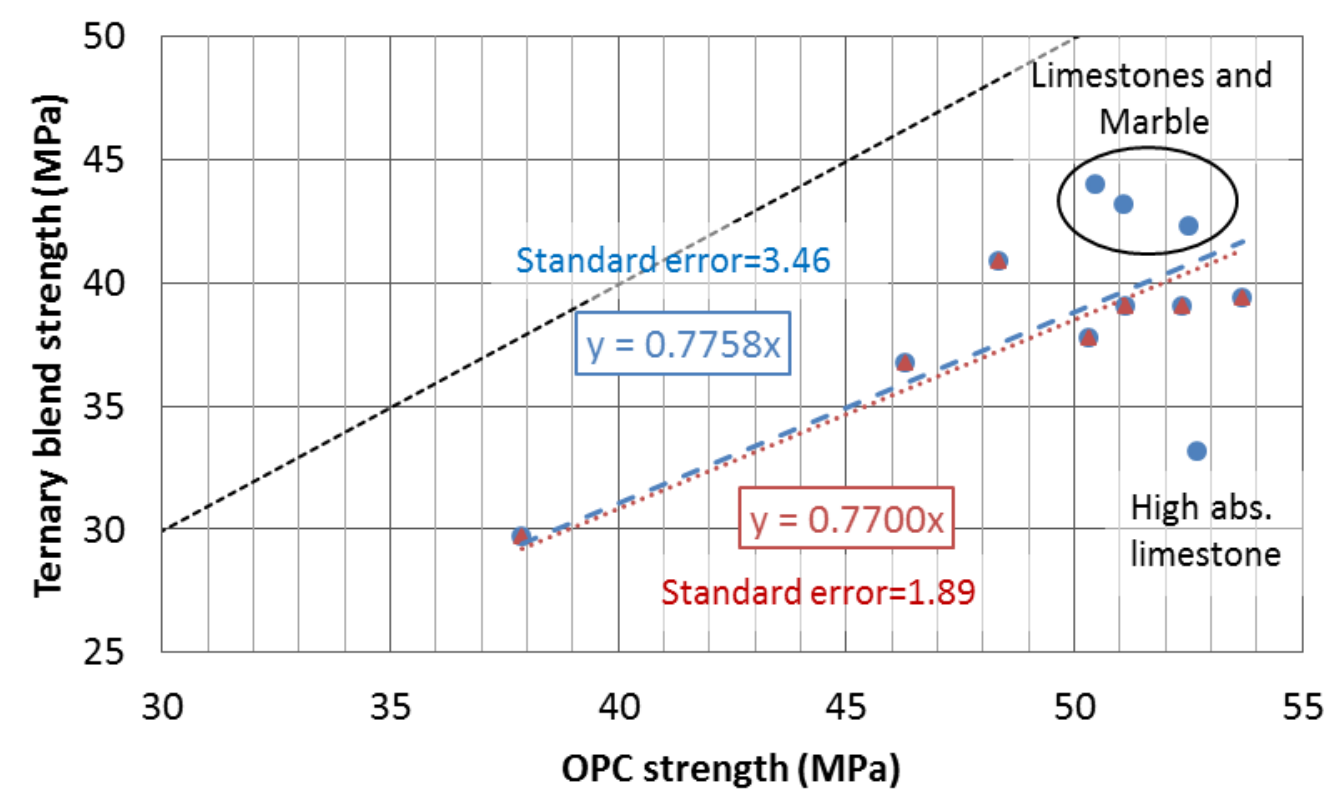

Figure 14. 28-d compressive strength of ternary blend concretes vs. corresponding OPC concrete. Average CoV can be found in Tables 9 and 10. Blue line is fit to all the data, while red line is fit to the seven indicated aggregates, omitting high absorption limestone and three limestones (including marble).

Black dashed line indicates a one-to-one correspondence. 

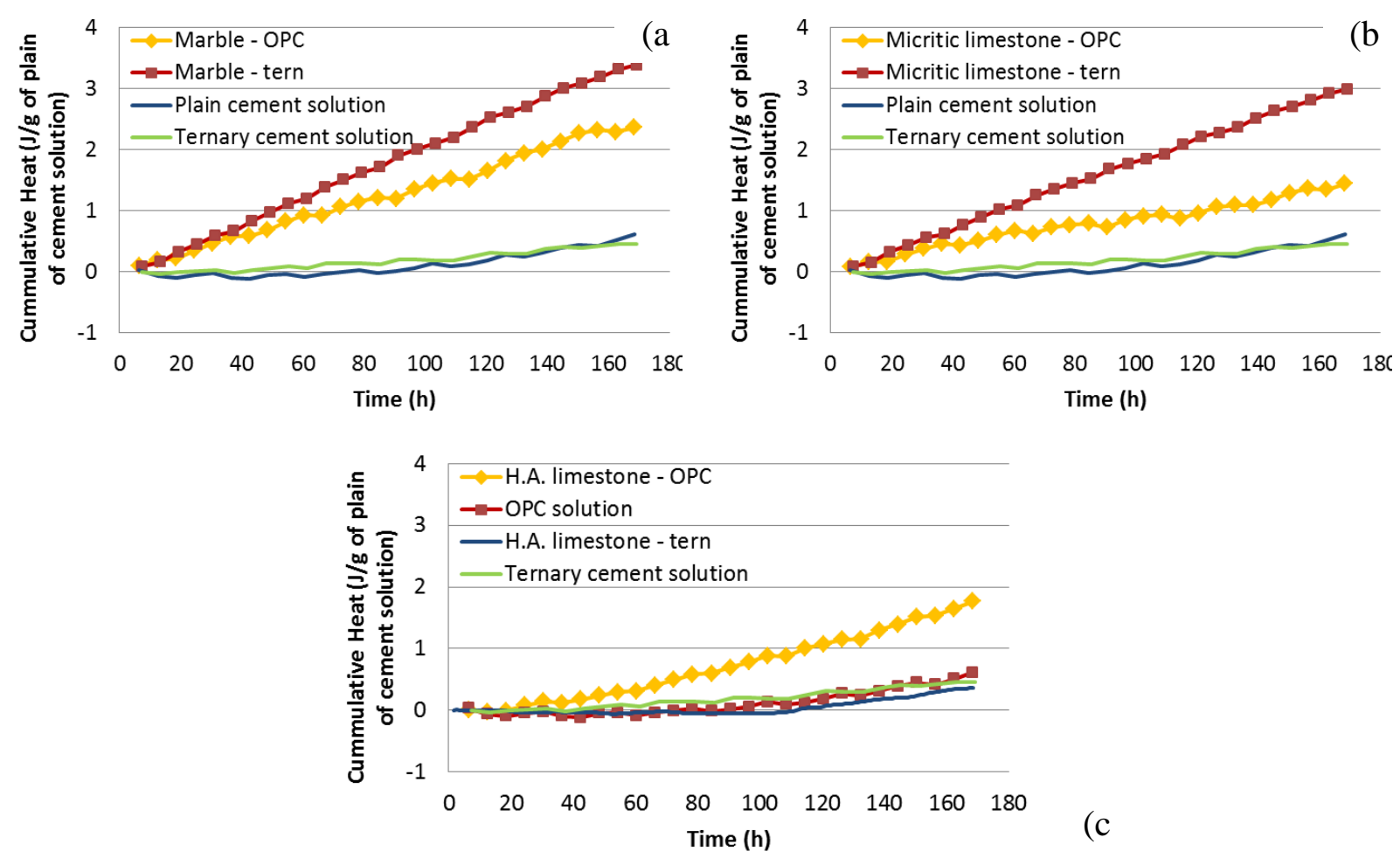

Figure 15. Isothermal calorimetry of aggregates in OPC or ternary pore solution. Cumulative heat over time of (a) marble; (b) micritic limestone and (c) high absorption limestone.

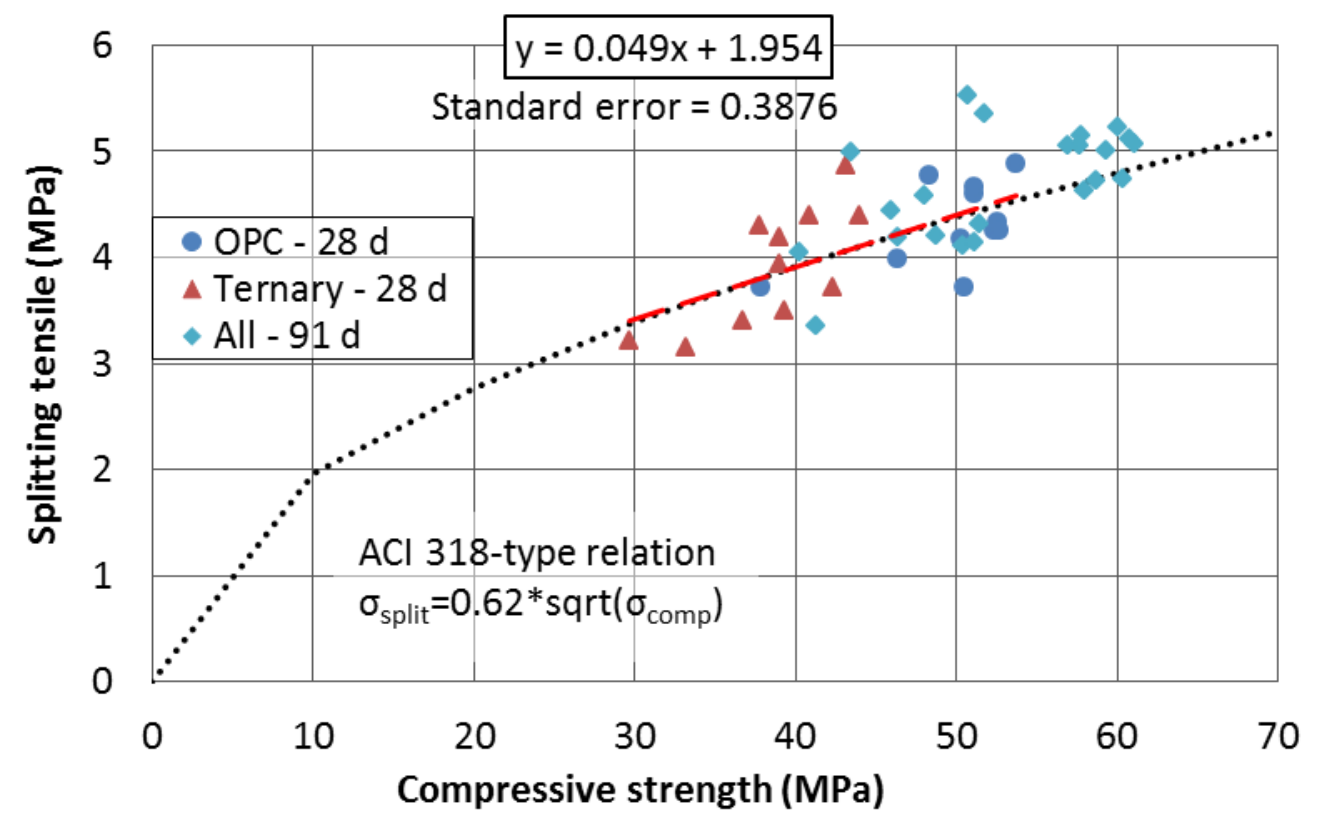

Figure 16. 28-d and 91-d splitting tensile strength vs. compressive strength. Recommended ACI coefficient is 0.56 (instead of 0.62) [65]. Linear relation shown in box is for 28-d data for both ternary and OPC mixtures. Average CoV can be found in Tables 9 and 10. 

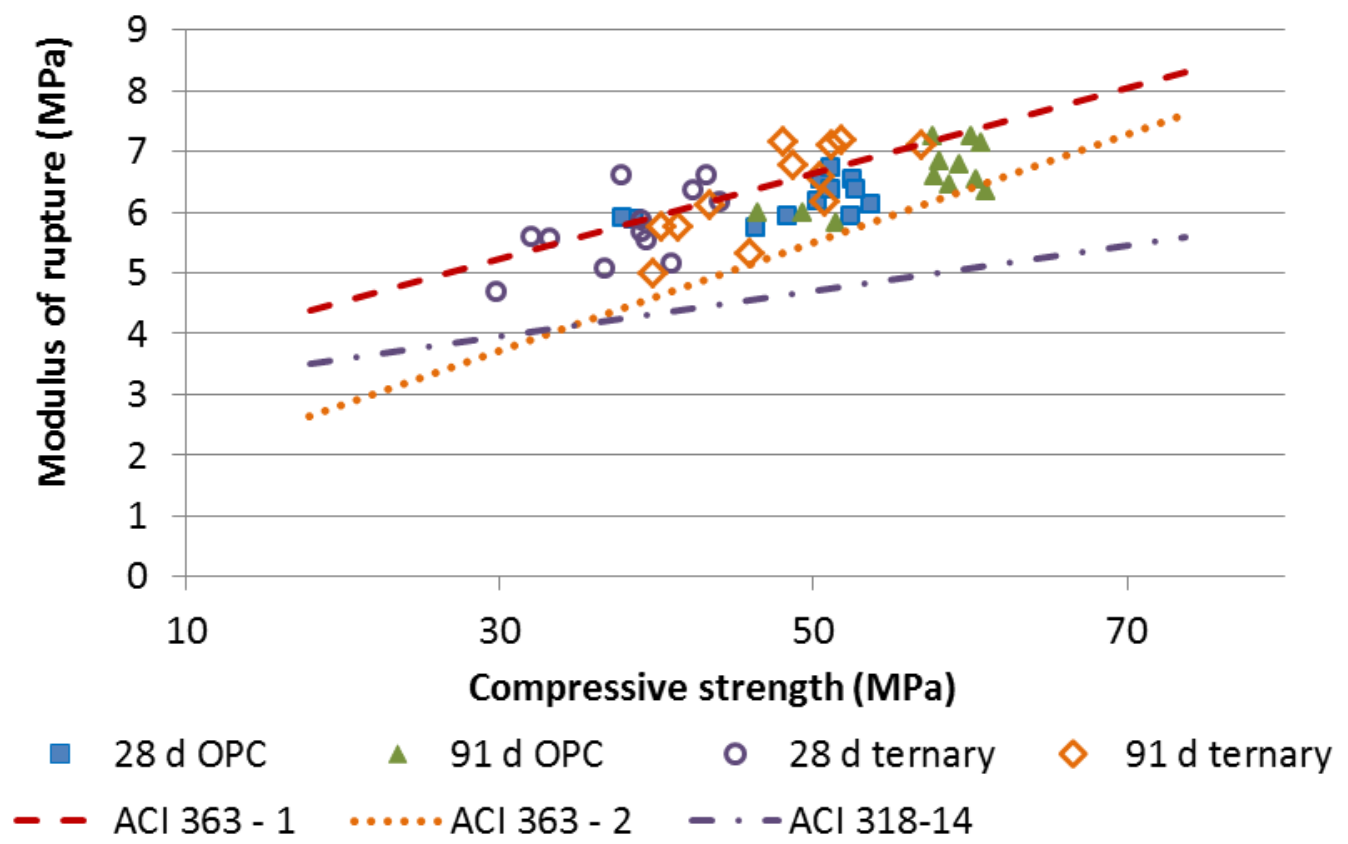

Figure 17. Modulus of rupture vs. compressive strength at $28 \mathrm{~d}$ and $91 \mathrm{~d}$ for the 22 concrete mixtures. Average CoV can be found in Tables 9 and 10 . 


\section{HARDENED CONCRETE RESISTIVITY}

The measured electrical resistivities of the hardened concrete cylinders at ages of $28 \mathrm{~d}$ and $91 \mathrm{~d}$ are provided in Table 11. Both a size correction and the recommended correction for limewater curing $[59,67]$ were applied to the measured data to produce the values shown in the table. Usually, if an aggregate is not prone to alkali-silica reaction (ASR) or freeze-thaw damage and spalling, the aggregate effect on concrete durability is ignored. Nevertheless, the results presented in Table 11 demonstrate the important role that aggregates may play in influencing concrete durability. It is not expected that the concretes produced with the same aggregates but different binders (OPC or ternary) will produce identical resistivity values, due to the significant influence of pore solution resistivity on concrete resistivity $[59,67]$.

Table 11. 28-d and 91-d Electrical Resistivities of the Hardened Concretes

\begin{tabular}{|c|c|c|c|c|}
\hline \multirow[b]{2}{*}{ Aggregate } & \multicolumn{2}{|c|}{ OPC concrete } & \multicolumn{2}{|c|}{ Ternary Blend Concrete } \\
\hline & $\begin{array}{c}28 \mathrm{~d} \\
(\mathrm{k} \Omega \cdot \mathrm{cm})\end{array}$ & $\begin{array}{c}91 \mathrm{~d} \\
(\mathrm{k} \Omega \cdot \mathrm{cm})\end{array}$ & $\begin{array}{c}28 \mathrm{~d} \\
(\mathrm{k} \Omega \cdot \mathrm{cm})\end{array}$ & $\begin{array}{c}91 \mathrm{~d} \\
(\mathrm{k} \Omega \cdot \mathrm{cm})\end{array}$ \\
\hline Average $\mathrm{CoV}$ & $3.7 \%$ & $1.3 \%$ & $3.6 \%$ & $0.7 \%$ \\
\hline Diabase & 6.1 & 8.0 & 5.8 & N.A. \\
\hline Dolomite & 5.2 & 8.1 & 7.2 & 16.2 \\
\hline Dolomitic limestone & 6.3 & 9.3 & 7.6 & 19.1 \\
\hline High absorption limestone & 4.2 & 6.6 & 4.8 & 9.9 \\
\hline Micritic limestone & 6.7 & 9.4 & 9.1 & 22.3 \\
\hline Granite & 5.8 & 7.1 & 6.8 & 16.0 \\
\hline Granitic gneiss & 4.1 & 5.8 & 6.3 & 16.4 \\
\hline Siliceous gravel & 4.6 & 6.7 & 6.0 & 16.4 \\
\hline Marble & 5.4 & 8.0 & 7.3 & 20.6 \\
\hline Meta-basalt & 5.5 & 7.5 & 7.1 & 16.8 \\
\hline Quartzite \& Sandstone & 5.0 & 7.5 & 6.9 & 18.6 \\
\hline Range/Ave (\%) & 48.6 & 47.1 & 63.2 & 72.0 \\
\hline
\end{tabular}

For every aggregate, except for the diabase at $28 \mathrm{~d}$, the measured resistivities for the ternary blend concrete were significantly higher than those for the OPC concrete, particularly at the testing age of $91 \mathrm{~d}$. The combination of a reactive (Class C) fly ash with a fine limestone powder in the ternary blend binder produces concretes with a high degree of pore refinement that therefore exhibit a significantly higher electrical resistivity [20], implying a lower diffusivity for chlorides and other deleterious ions [68], at a similar compressive strength level as that found in the OPC (control) concretes.

There was also a larger variation of electrical resistivity (range/average) amongst the aggregates for the ternary blend concretes at both testing ages. Overall, aggregate selection has a significant influence on the electrical resistivity, especially in ternary mixtures, likely via its influence on the interfacial transition zone microstructure and the established level of bonding between aggregate and paste, as well as the effect of the rock's microstructure and its own resistivity.

In terms of aggregates, the OPC and ternary blend concretes prepared with the micritic limestone provided the highest resistivity at both testing ages, while the lowest resistivities were provided by the granitic gneiss and the high absorption limestone in the OPC and ternary blend concretes, respectively. 
These same two mixtures also produced the second lowest compressive strengths at the ages of $28 \mathrm{~d}$ and $91 \mathrm{~d}$, with only the concretes based on siliceous gravel providing lower values. Weak, porous interfaces should contribute to both reduced strengths and reduced resistivities as they can provide preferential pathways for both crack propagation and electrical (ion) transport. The porous nature of the high absorption limestone may have also contributed to the low resistivity measured for OPC and ternary blend concretes prepared with it.

In practice, more important than the nominal surface resistivity values obtained in tests is the classification of each mixture in terms of their susceptibility to chloride penetration, as presented in AASHTO T358 [59]. Figure 18 shows that, at $28 \mathrm{~d}$, all OPC mixtures, independent of the aggregate employed, were classified as high penetrability mixtures, except for the micritic limestone mixture. At $91 \mathrm{~d}$, all OPC mixtures, except for the mixture based on granitic gneiss, exhibited a moderate chloride penetrability.

Conversely, very few ternary mixtures are classified in the high penetrability range at $28 \mathrm{~d}$ : only the diabase, high absorption limestone, granitic gneiss, and siliceous gravel mixtures. The other 7 mixtures were in the moderate penetrability range. At $91 \mathrm{~d}$, a much wider spread of penetrability classifications was found, depending on the aggregate used: the high absorption limestone mixture was in the moderate range but micritic limestone and marble mixtures were in the very low range, while the remaining 8 mixtures were in the low range.
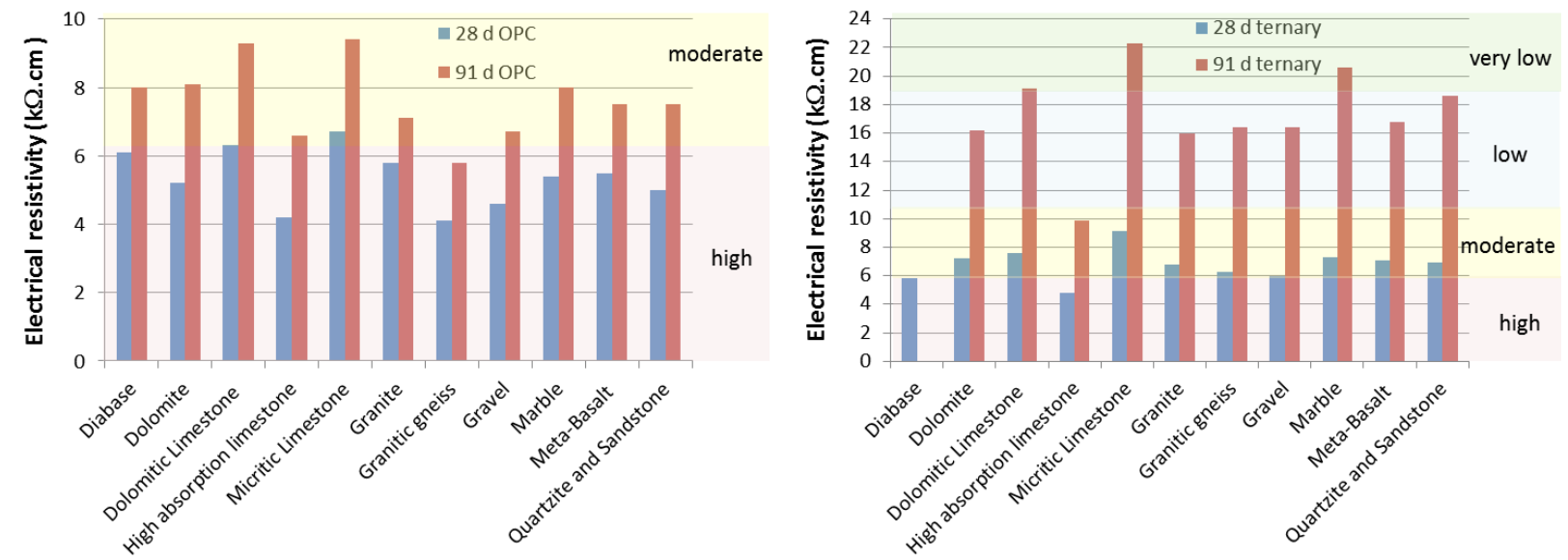

Figure 18. Electrical resistivity and qualitative chloride penetrability classification as per AASHTO T358 [59]. Average CoV can be found in Table 11.

The measured electrical resistivities are plotted against the corresponding measured compressive strengths in Figure 19. No overarching relationship is found between resistivity and strength in agreement with previous results [20], and the relative standard errors are similar for the ternary blends $(0.77 \mathrm{k} \Omega \cdot \mathrm{cm}$ or $11.3 \%$ at $28 \mathrm{~d}$ and $2.33 \mathrm{k} \Omega \cdot \mathrm{cm}$ or $13.5 \%$ at $91 \mathrm{~d})$ and the OPC mixtures $(0.78 \mathrm{k} \Omega \cdot \mathrm{cm}$ or $14.5 \%$ at $28 \mathrm{~d}$ and $0.98 \mathrm{k} \Omega \cdot \mathrm{cm}$ or $12.8 \%$ at $91 \mathrm{~d}$ ). 


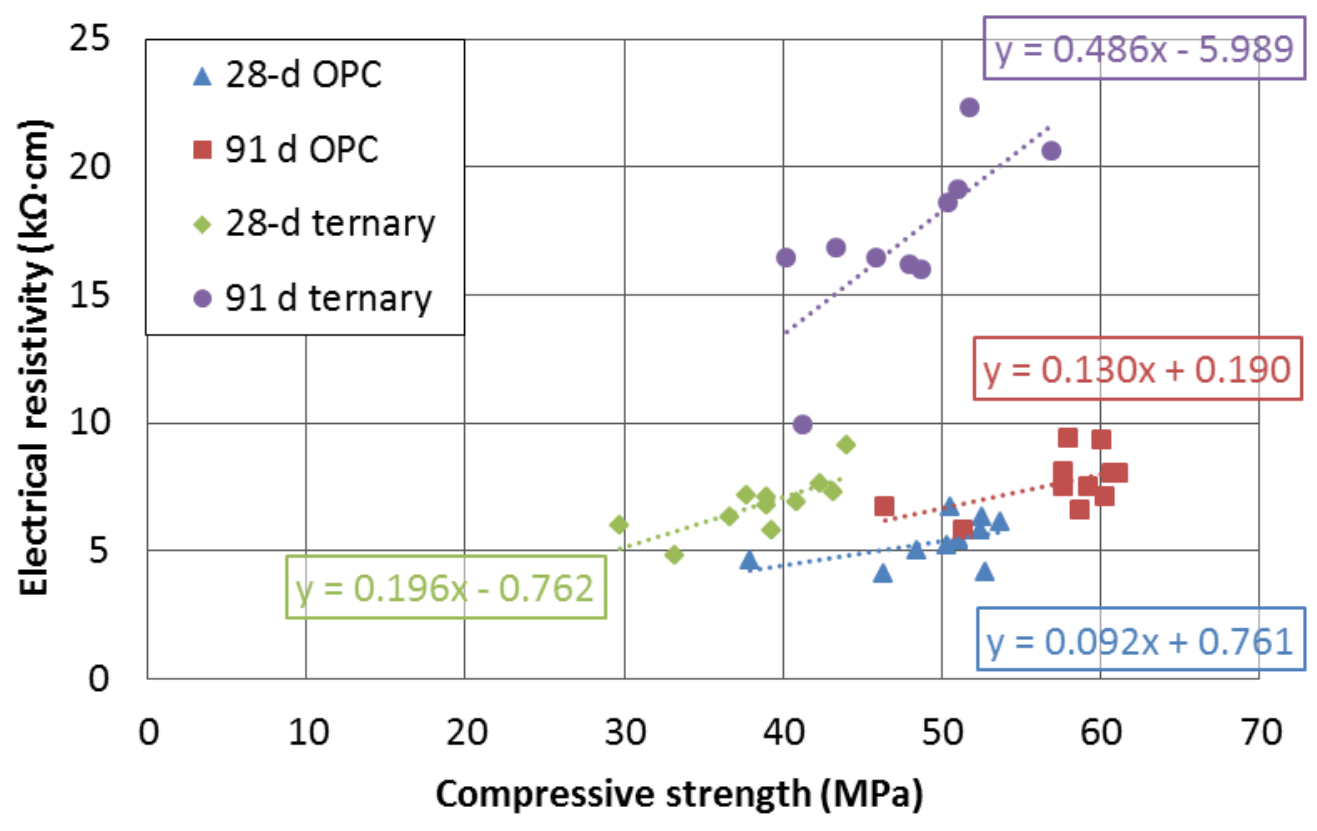

Figure 19. Measured electrical resistivity vs. compressive strength for the OPC and ternary blend concretes at ages of $28 \mathrm{~d}$ and $91 \mathrm{~d}$. Average $\mathrm{CoV}$ can be found in Tables 9, 10, and 11. 


\section{HARDENED CONCRETE COEFFICIENT OF THERMAL EXPANSION}

Finally, the CTE values measured on the OPC and ternary blend concretes at ages of $82 \mathrm{~d}$ to $199 \mathrm{~d}$ (except for the siliceous gravel mixtures that were evaluated at an age between $46 \mathrm{~d}$ and $50 \mathrm{~d}$ ) are summarized in Table 12. For every aggregate, the CTE for the ternary blend concrete is higher (about $4 \%$ on average) than the corresponding value for the OPC concrete mixture, consistent with the higher CTE of its component paste (12\% higher) and mortar (3\% higher) in Table 12. Additionally, the CTE measured for the concretes prepared with the siliceous gravel aggregate is a little over $20 \%$ higher than the average obtained for the other 10 aggregates. Similarly, the CTE measured on the siliceous gravel aggregate itself (Table 6) was the highest for any of the aggregates. The more detailed analysis of concrete CTE vs. aggregate CTE provided in Figure 20 indicates a mild correlation between the two, as the range of the former $\left(3.7 \mu \varepsilon /{ }^{\circ} \mathrm{C}\right.$ and $3.8 \mu \varepsilon /{ }^{\circ} \mathrm{C}$ for the OPC and ternary blend concretes, respectively) is quite a bit less than that of the latter $\left(6.7 \mu \varepsilon /{ }^{\circ} \mathrm{C}\right)$. The standard errors of the best fit lines in Figure 20 improve significantly if the high absorption limestone aggregate is excluded, reducing from $0.66 \mu \varepsilon /{ }^{\circ} \mathrm{C}$ to $0.47 \mu \varepsilon /{ }^{\circ} \mathrm{C}$ and $0.72 \mu \varepsilon /{ }^{\circ} \mathrm{C}$ to $0.49 \mu \varepsilon /{ }^{\circ} \mathrm{C}$ for the OPC and ternary mixtures, respectively.

Furthermore, the data in Figure 20 is quite consistent with a simple linear additive model for CTE [69] as the values measured for the concretes are roughly given by the volume fraction of aggregates (using $0.396=0.4 / 1.01$ to account for the measured $3 \%$ air in the concrete vs. the $2 \%$ air used in the design process) multiplied by the aggregate CTE plus the volume fraction of mortar multiplied by the appropriate (OPC or ternary blend) mortar CTE. Specifically, with an assumed mortar volume fraction of 0.574, the projected constant terms in the linear equations in Figure 20 would be 6.79 and 7.00 for the OPC and ternary blend concretes, respectively. These two estimates are in good agreement with the best fit constants of 6.84 and 7.09 in Figure 20, as also indicated by the model lines plotted in Figure 20.

Table 12. Measured CTE for the OPC and Ternary Blend Concretes, Mortars, and Pastes

\begin{tabular}{ccc}
\hline Aggregate & $\begin{array}{c}\text { OPC concrete } \\
\left(\boldsymbol{\mu \varepsilon} /{ }^{\circ} \mathbf{C}\right)\end{array}$ & $\begin{array}{c}\text { Ternary Blend Concrete } \\
\left(\boldsymbol{\mu \varepsilon} /{ }^{\circ} \mathbf{C}\right)\end{array}$ \\
\hline Diabase & 8.97 & 9.27 \\
Dolomite & 10.12 & 10.39 \\
Dolomitic limestone & 10.07 & 10.53 \\
High absorption limestone & 7.97 & 8.09 \\
Micritic limestone & 8.28 & 8.63 \\
Granite & 9.98 & 10.64 \\
Granitic gneiss & 10.13 & 10.66 \\
Siliceous gravel & 11.62 & 11.92 \\
Marble & 9.77 & 10.13 \\
Meta-basalt & 9.57 & 10.09 \\
Quartzite \& Sandstone & 9.72 & 10.05 \\
Range/Ave $(\%)$ & $38 \%$ & $38 \%$ \\
\hline Mortar & 11.83 & 12.19 \\
Paste & 14.78 & 16.54 \\
\hline
\end{tabular}




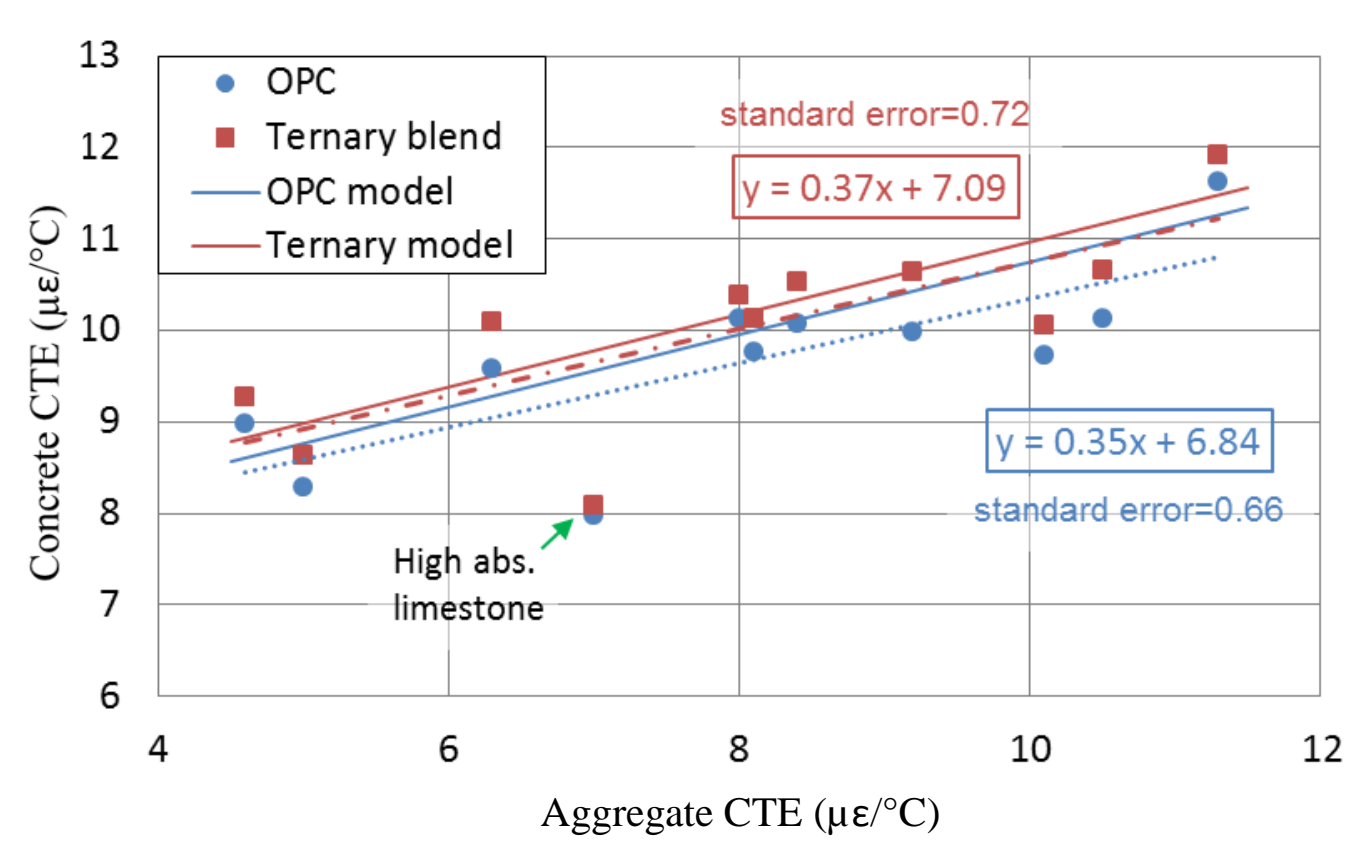

Figure 20. Concrete CTE vs. aggregate CTE for the OPC and ternary blend concrete mixtures. Average $\mathrm{CoV}$ can be found in Tables 6 and 12. Model lines correspond to a simple additive model, assuming aggregate and mortar volume fractions of 0.39 and 0.58 . Dashed lines indicate best linear fits.

When considering the limited CTE data available for six of the rock cores (Table 7), there is a good correlation between the concrete CTE and the rock core CTE (Figure 21), with quite low standard errors. One of the reasons for the better correlation may have been due to the much lower CoV of the rock core CTE tests than the ones performed on the extracted aggregates. Once again, the coefficients determined for the linear fits are consistent with a simple additive model relating concrete CTE to those of the component materials (aggregate and mortar). Another important aspect to point out is that the models in Figures 20 and 21 would be applicable only to mixtures using the same materials and volumetric proportions as in this study, but are important to show the clear role of the aggregate on the concrete CTE for a specific mixture design. 


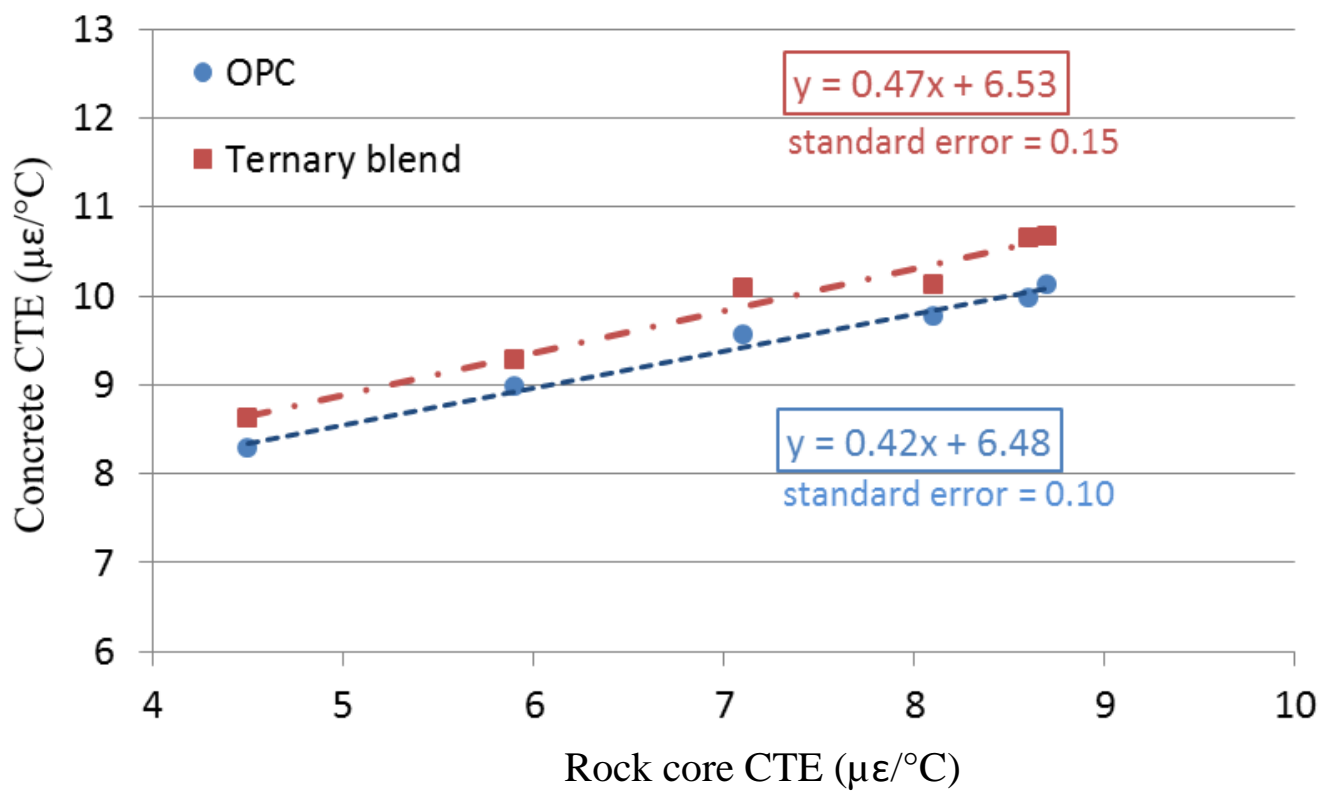

Figure 21. Concrete CTE vs. rock core CTE for the OPC and ternary blend concrete mixtures. Average CoV can be found in Tables 7 and 12 . 


\section{Concrete Mechanical Properties in Relation to Aggregate Characteristics}

It was envisioned that some reasonable correlations would be found between measured aggregate characteristics and concrete mechanical properties for the concretes prepared with the different source aggregates, providing a better understanding of which aggregate characteristics have an impact on the concrete mechanical performance and, in particular, on the bond between aggregate and paste. For example, the bond between ITZ and aggregate is, for normal strength concretes, the weakest link of the composite and where failure usually initiates but, on the other hand, proper bond is essential for a composite, heterogeneous material, such as concrete, to act in a monolithic manner [24]. This bond is affected by aggregate properties, such as texture (Figure 8), modulus of elasticity, CTE, porosity, absorption, and possibly surface energy, as well as by matrix (and ITZ) properties, such as modulus of elasticity, possible chemical affinity/reactivity with the aggregate, porosity, strength and preferential alignment of hydration products at the interface with the aggregate [2,12,22-25]. As an example, significant differences in the measured bond strength in mixtures with different aggregates were observed by Tasong et al. [3-5] which they attributed to the roughness of the aggregate surface (texture), as well as the physical-chemical bond between the hydrating cement paste and the aggregate, due to chemical reactions.

A physical bond or mechanical adhesion is provided, for example, by the shape characteristics of the aggregate through a physical "lock and key" effect, redistribution of stresses and increased surface area [17], and also by the surface texture and porosity that promote an interlock effect [18], but these contributions depend on the applied stress magnitude [70].

Since CAAT combines shape and texture, it is interesting to examine the results in Table 5. If only shape and texture played a role, the lowest compressive strengths should be found in the siliceous gravel and high absorption limestone mixtures, while the highest strengths should be found with micritic limestone and diabase. While siliceous gravel did indeed present the lowest strengths at all ages and for the two different binders, high absorption limestone presented one of the highest strengths among the OPC mixtures. In terms of high strengths, micritic limestone presented one of the highest strengths only in ternary mixtures and diabase only in OPC mixtures after $28 \mathrm{~d}$. So, clearly aggregate characteristics other than shape and texture contribute to contribute to concrete performance.

Of course, adhesion is also influenced by chemical bonding and it has been previously proposed that surface energy could be used as one means to assess this bonding [18,71-73]. Natural aggregates contain active sites (chemical surface energy components) where sorption occurs, which are dependent on the individual minerals at the surface. These sites are either non-polar or polar. Non-polar surfaces bond via dispersion forces, the weakest of van der Waals' three forces, while polar surfaces may also provide bonding via dipole-dipole and hydrogen bonding interactions.

In this study, the non-polar surface energies of siliceous gravel, granitic gneiss, diabase, granite and dolomite were lower than the values typically found in the literature [71-73]. Comparing the different aggregates, siliceous gravel was significantly lower than the other 10 aggregates, indicating a lower affinity to bond with paste through dispersion forces. Most of the other aggregates, except for the meta-basalt, presented similar non-polar surface energies, while meta-basalt showed a much higher one. The non-polar component of the carbonate aggregates (marble, dolomite, and limestones) varied from $32.5 \mathrm{~mJ} / \mathrm{m}^{2}$ to $38.3 \mathrm{~mJ} / \mathrm{m}^{2}$, so considering the $\mathrm{CoV}$ of the measurement, they should behave differently in terms of dispersion forces. 
Besides the non-polar sites, there may also be polar sites that react with the paste, forming a stronger bond. Some of these sites are $\mathrm{pH}$ dependent, such as the ones found in some silicates, clays, micas and carbonates. Among the aggregates studied, the polar surface energy varied much more than the non-polar one, from $2.5 \mathrm{~mJ} / \mathrm{m}^{2}$, for micritic limestone, to $27.3 \mathrm{~mJ} / \mathrm{m}^{2}$, for quartzite \& sandstone. Dolomitic limestone also presented a very low polar surface energy $\left(3.3 \mathrm{~mJ} / \mathrm{m}^{2}\right)$. Considering only the carbonate aggregates, the polar component varied from $2.5 \mathrm{~mJ} / \mathrm{m}^{2}$ to $13.3 \mathrm{~mJ} / \mathrm{m}^{2}$. Among the limestones, micritic limestone and dolomitic limestone presented similar values, while the high absorption limestone presented the highest. For all 11 aggregates, the non-polar surface energy component was larger than the polar one. However, since the non-polar one did not vary as much as the polar one amongst the aggregates (range/average in Table 6), the latter is expected to be more important when comparing aggregates and their influence on concrete performance.

Considering surface energy (total including non-polar and polar components), micritic and dolomitic limestone, siliceous gravel, and marble would be expected to present the poorest mechanical behavior among the aggregates, while meta-basalt and quartzite \& sandstone the highest. Nevertheless, this hypothesis was not strictly confirmed. While siliceous gravel mixtures underperformed the other mixtures in all strength tests (compressive, splitting and flexural), micritic and dolomitic limestones, as well as marble, performed very well and outperformed meta-basalt in most cases. Moreover, quartzite \& sandstone did not show the best mechanical behavior either. Surface energy only assesses the potential contribution of (weak) van der Waals forces to bonding. If an actual chemical reaction is occurring between the aggregates and the binder or if the binder reaction products are precipitating directly on the aggregate surface, the potentially larger contribution of these two mechanisms to bonding will not be indicated by surface energy measurements. This may help explain that while surface energy measurements have proven useful for predicting performance of asphaltic (less reactive binder) concretes [18,70] and bonding of asphalt-coated particles to cementitious materials [74,75], they did not provide useful predictions of mechanical performance in the present study.

Thus, while it was envisioned that some reasonable correlations would be found between measured aggregate characteristics and mechanical properties for the concretes prepared with the different source aggregates, the complexity of the bonding between aggregate and paste generally precluded such identification. Instead, few such correlations were found, the lack of which is exemplified by the plots in Appendix B that show 28-d compressive strength plotted vs. individual aggregate characteristics, with little if any correlation observed in nearly all cases (slopes near 0 in many cases). However, as shown in Figure 22, when the siliceous gravel and meta-basalt data were omitted from the analysis, a reasonable linear correlation was observed between the measured elastic modulus of the concrete $\left(E_{\text {conc }}\right)$ and that of the corresponding coarse aggregate $\left(E_{a g g}\right)$, for modulus measurements conducted after either $28 \mathrm{~d}$ (standard error of $3.6 \mathrm{GPa}$ or $9.5 \%$ ) or $91 \mathrm{~d}$ (standard error of $2.9 \mathrm{GPa}$ or $7.1 \%$ ) of curing. There are two data points for each age and aggregate modulus in Figure 22, corresponding to the OPC and ternary blend mixtures, with the elastic modulus of the OPC mixture generally exceeding that of the one based on the ternary blend binder (by an average of $9 \%$ at $28 \mathrm{~d}$, but only $4 \%$ at $91 \mathrm{~d}$ ). In comparison, on average, the 28 -d compressive strengths of the OPC mixtures were $29 \%$ higher than those of the corresponding ternary blend mixtures (Figure 14). The coefficients for the best linear fits in Figure 22 can again be compared to those from a simple linear additive model for concrete modulus. However, the agreement between the best linear fit and the additive model would not be as good as in the case of CTE, as the slopes of 0.358 and 0.344 are a bit lower than the coarse aggregate fraction and the constant terms of 14.80 and 17.49 are also lower than the mortar fraction (0.58) times the measured mortar moduli of about $27 \mathrm{GPa}$ and $31 \mathrm{GPa}$ at $28 \mathrm{~d}$ and $91 \mathrm{~d}$, respectively. 


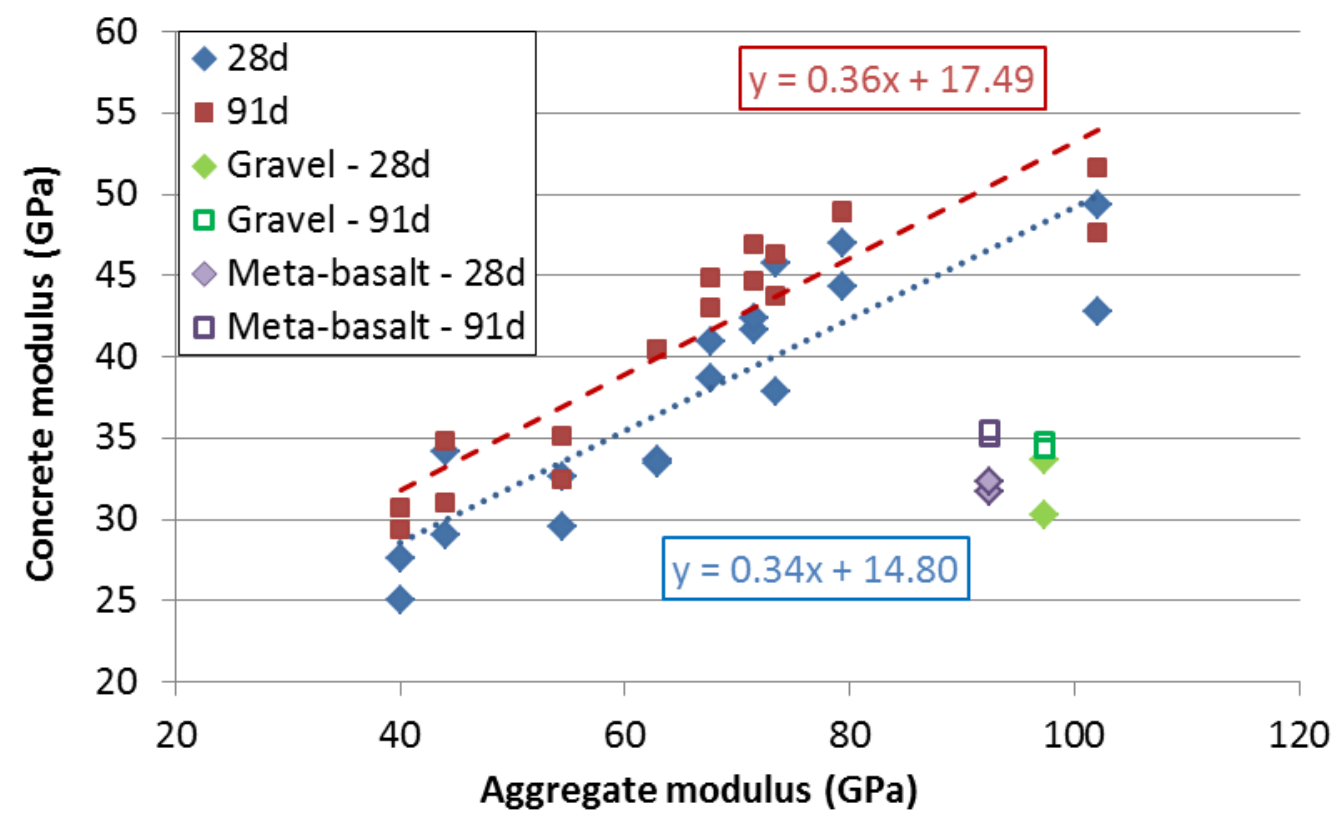

Figure 22. Concrete 28-d and 91-d elastic modulus vs. aggregate elastic modulus for all the aggregates. Fitted lines include all the data at a given age, except for the siliceous gravel and meta-basalt. Average CoV can be found Tables 6, 9, and 10.

For the data in Figure 22, the standard errors would be reduced to $2.7 \mathrm{GPa}$ (with $y=0.45 x+8.53$ ) and $1.8 \mathrm{GPa}$ (with $y=0.48 x+10.36$ ) for the 28 - $\mathrm{d}$ and $91-\mathrm{d}$ elastic moduli, respectively, if the data for the marble were also omitted from the analysis, effectively omitting the three highest modulus aggregates. Specifically, these three aggregates exhibited an elastic modulus greater than $90 \mathrm{GPa}$ and their tendency not to follow the linear trend observed for the lower modulus aggregates may be due to elastic mismatch between the aggregate and the paste components of the OPC and ternary blend concretes. Previous research has pointed out the importance of the elastic mismatch between the aggregate and the matrix in determining mechanical performance [12,22-25]. When stresses are applied to the concrete, the higher the difference between the moduli of elasticity of the aggregate and the paste, the higher the stress concentration at the interface between the two phases. This stress concentration causes microcracking, as well as loss of bond. Such microcracking may occur due to stresses resulting from volume changes during hydration, even before the concrete specimen is subjected to any external load, affecting its measured strength [2,12,22-25].

As mentioned above, both concretes prepared with siliceous gravel not only presented low $\mathrm{E}_{\text {conc, }}$ but also exhibited the lowest measured compressive strengths at all 4 testing ages. This is likely due not only to the moduli mismatch between aggregate and paste, but also this aggregate's smooth surface (Table 5) resulting in a weaker bond between this aggregate and the binders (see images in Appendix C for supporting data). As noted previously, the siliceous gravel also exhibited a significantly higher CTE than any of the other aggregates. Thus, it appears that this gravel may be deficient on nearly all counts in terms of producing a strong concrete.

The remainder of this section will focus in turn on various individual concrete properties and observations concerning their relation to aggregate characteristics. 


\section{CONCRETE COMPRESSIVE STRENGTH}

\section{MODUlus MisMATCH $\left(E_{A G G} / E_{P A S T E}\right)$ AND COMPRESSIVE STRENGTH}

Several studies $[2,23,25,26]$ have shown the importance of the difference between moduli of elasticity of aggregate and of the matrix and how it affects the microcracking within the ITZ. Bremner and Holm [22] calculated both radial and tangential stresses around a spherical particle when a unit of compressive stress is applied to the composite and concluded that when the $E_{\text {agg }}$ is 5 times that of the paste $\left(E_{\text {paste }}\right)$, the matrix is subjected to tension of 1.67 , while the aggregate is subjected to compression of 0.33 . As the ratio between $E_{a g g}$ and $E_{\text {paste }}$ approaches 1, the stresses in the paste approach zero and the stresses in the aggregate decrease considerably to about half. Tensile stresses on the paste may cause microcracking and decrease strength. Figure 23a shows that at $28 \mathrm{~d}, E_{a g g} / E_{\text {paste }}$ is significantly high, varying from 3 to 10 (apart from the high absorption limestone and the granitic gneiss mixtures), and thus very high tensile stresses are expected within the ITZ. In the concrete mixtures with siliceous gravel, marble or meta-basalt, this ratio exceeds 7 at $28 \mathrm{~d}$, while in the high absorption limestone mixtures, the ratio is around 4 or below.

While $E_{\text {agg }}$ does not change with time, $E_{\text {paste }}$ increases with hydration (age) as shown in Tables 9 and 10 , consequently decreasing the ratio $E_{a g g} / E_{\text {paste }}$ (Figure 23a). This explains why the effect of the aggregate type on compressive strength decreases with the concrete age (Tables 9 and 10). Additionally, since the ternary mixtures' hydration is slower than that of the OPC mixtures, their modulus of elasticity also presents a relatively slower increase, explaining why, at later ages, the aggregate effect on ternary mixtures is greater than on OPC mixtures, as seen in Figure 23, where the slope of the ratio vs. strength of ternary mixtures is higher than the one for OPC.

In Figures $23 \mathrm{~b}$ and 23c, mixtures with diabase, dolomite and micritic limestone have similar strengths for the same $E_{a g g} / E_{\text {paste }}$ ratio. In addition, the slope of this ratio vs. strength is similar for these mixtures in both OPC and ternary blends. These aggregates not only have similar moduli of elasticity, but their texture is not very different (Figures $8 \mathrm{a}, 8 \mathrm{~b}$, and 8e). In terms of absorption, diabase and dolomite are similar, while the micritic limestone presents a slightly lower value. Micritic limestone also presents a lower surface energy. Interestingly, diabase and micritic limestone concrete mixtures yielded similar strengths, although the diabase rock presented much higher compressive and tensile strengths than the micritic limestone rock (Table 7), indicating that, in this case, the concrete strength was mostly controlled by aggregate properties other than their strength. For the ternary blends in Figure 23c, the mixture containing quartzite $\&$ sandstone aggregate also behaved similarly, but showed lower strength than the other 3 mixtures, despite having lower modulus, higher absorption, and a much higher surface energy. The main difference of this aggregate is its texture (Figure 8k), which is less than half of those of the micritic limestone and the diabase. In addition, it is important to point out that based on the pore solution calorimetry experiments, both diabase and quartzite $\&$ sandstone aggregates seem to present some reactivity with the paste (Figure 24).

In addition, petrographic analysis of the quartzite $\&$ sandstone aggregate showed the presence of some metasandstone coarse aggregate particles containing weak zones in the rock (Figure $6 \mathrm{~m}$ and 61 and Figure 25a), as well as the presence of what appears to be relatively weak, matrix-supported metasandstone and sandstone particles. Failure during testing may have been initiated in some of these inherently weak aggregates (Figure 25b). Moreover, the bond between carbonate aggregates, such as dolomite and limestones, is expected to be enhanced by potential reactions with cement hydration products, leading to a stronger adhesion and contributing to the improvement of the compressive strength $[10,14,19]$. Monteiro and Mehta [14] have demonstrated that calcite crystals tend to react with $\mathrm{CH}$, forming a hydrated calcium carbonate-calcium hydroxide compound $\left(\mathrm{CaCO}_{3}-\mathrm{Ca}(\mathrm{OH})_{2}-\mathrm{H}_{2} \mathrm{O}\right)$ and creating a good bond between 
aggregate and paste. Figure 26 shows that some chemical interaction between paste and aggregate may have occurred with the micritic limestone, marble and dolomite, but no reaction seemed to occur between dolomitic limestone and either OPC or ternary pastes.
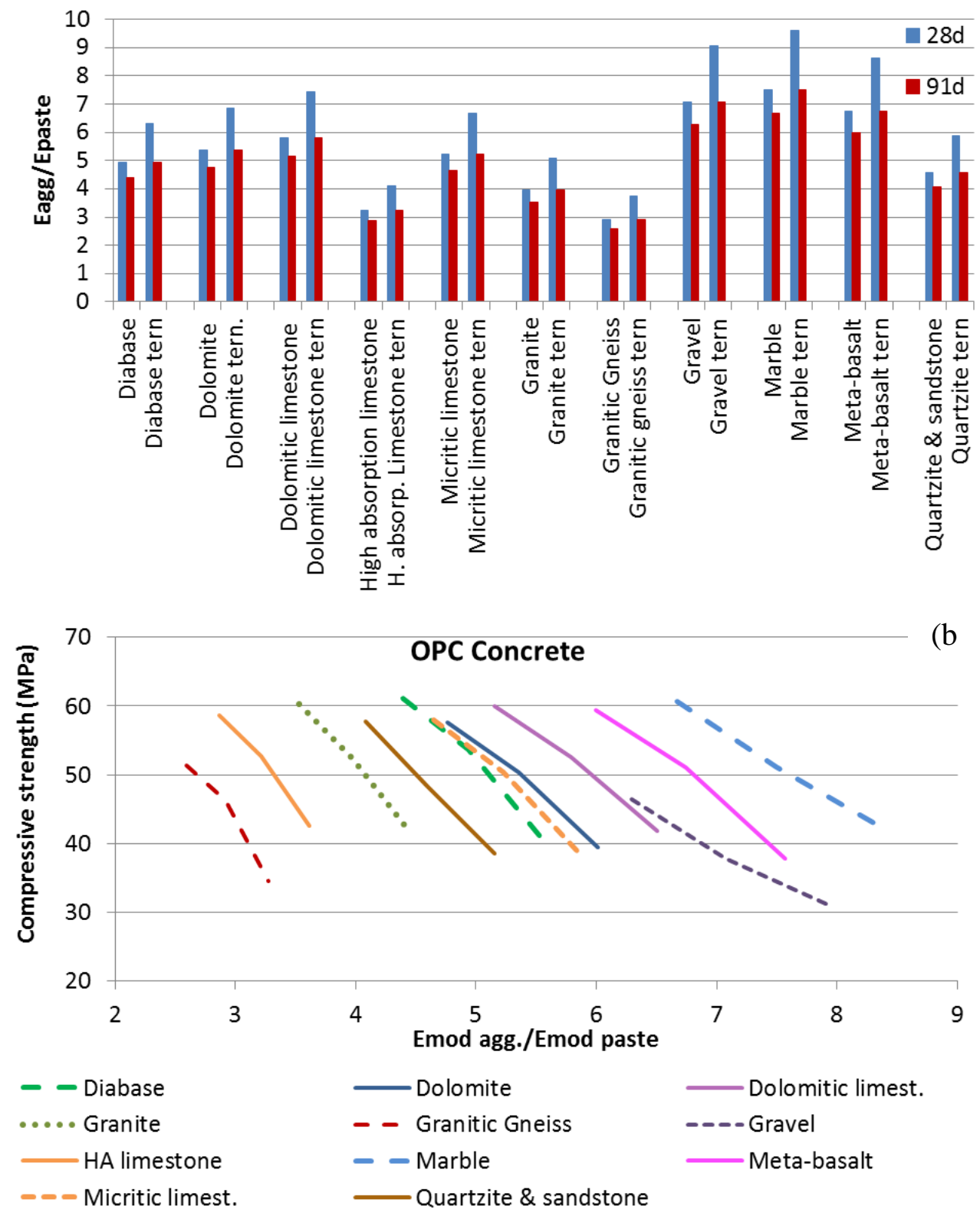


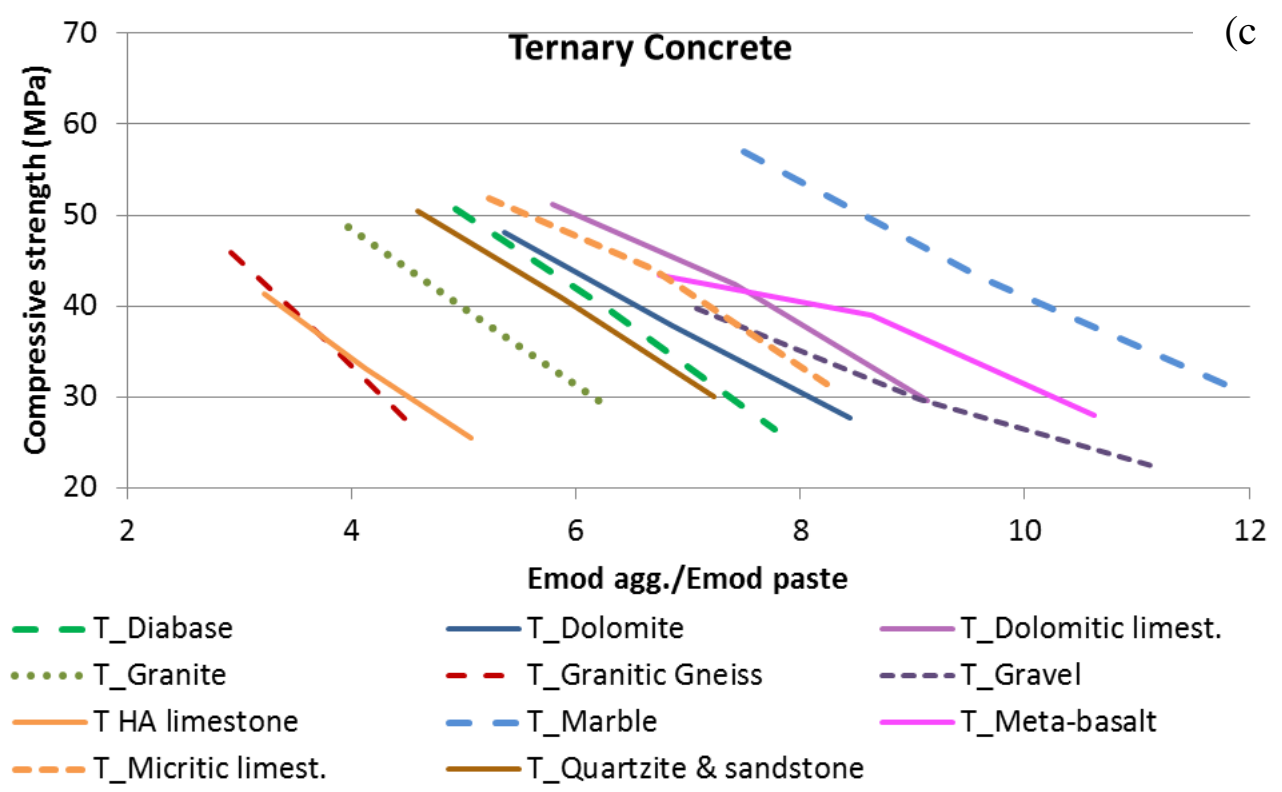

Figure 23. (a) Ratio of aggregate and paste moduli of elasticity at $28 \mathrm{~d}$ and $91 \mathrm{~d}$, (b) effect of $\mathrm{E}_{\text {agg }} / \mathrm{E}_{\text {paste }}$ on compressive strength of OPC mixtures at $7 \mathrm{~d}, 28 \mathrm{~d}$, and $91 \mathrm{~d}$ and (c) effect of $\mathrm{E}_{\text {agg }} / \mathrm{E}_{\text {paste }}$ on compressive strength of ternary blend mixtures at $7 \mathrm{~d}, 28 \mathrm{~d}$, and $91 \mathrm{~d}$. Average CoV can be found in Tables 9 and 10 .

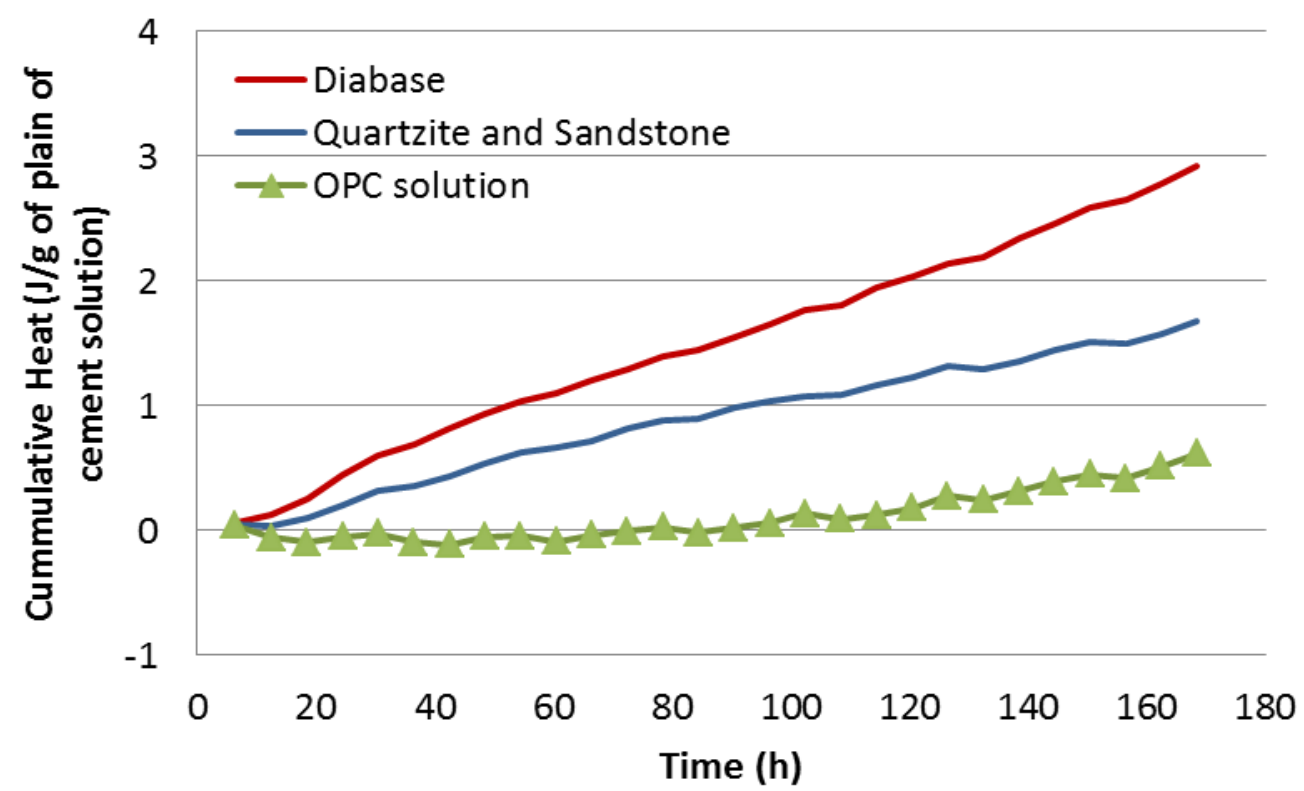

Figure 24. Cumulative heat over time of diabase and quartzite $\&$ sandstone aggregates in OPC pore solution. Information on uncertainty is provided at the bottom of page 4 . 

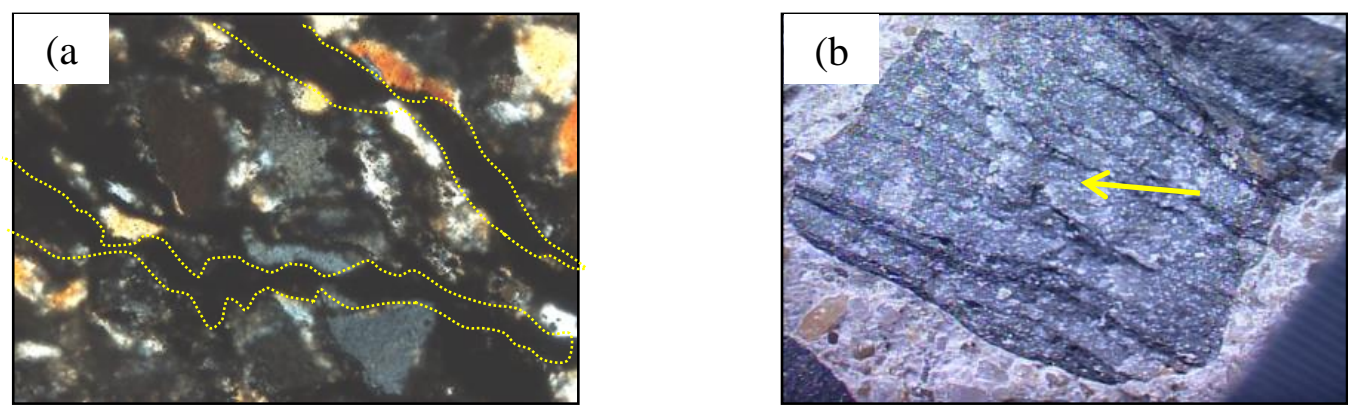

Figure 25. (a) Transmitted light thin section photomicrographs of weakly metamorphosed sandstone. The darker laminations appear developed parallel to the bedding plane (shown by dashed lines). Length of field of view is $1 \mathrm{~mm}$. (b) Stereo-photomicrographs showing example of dominant fracture patterns (both through and around coarse aggregates) in the 28-d cylinders. Length of field of view is $61 \mathrm{~mm}$.
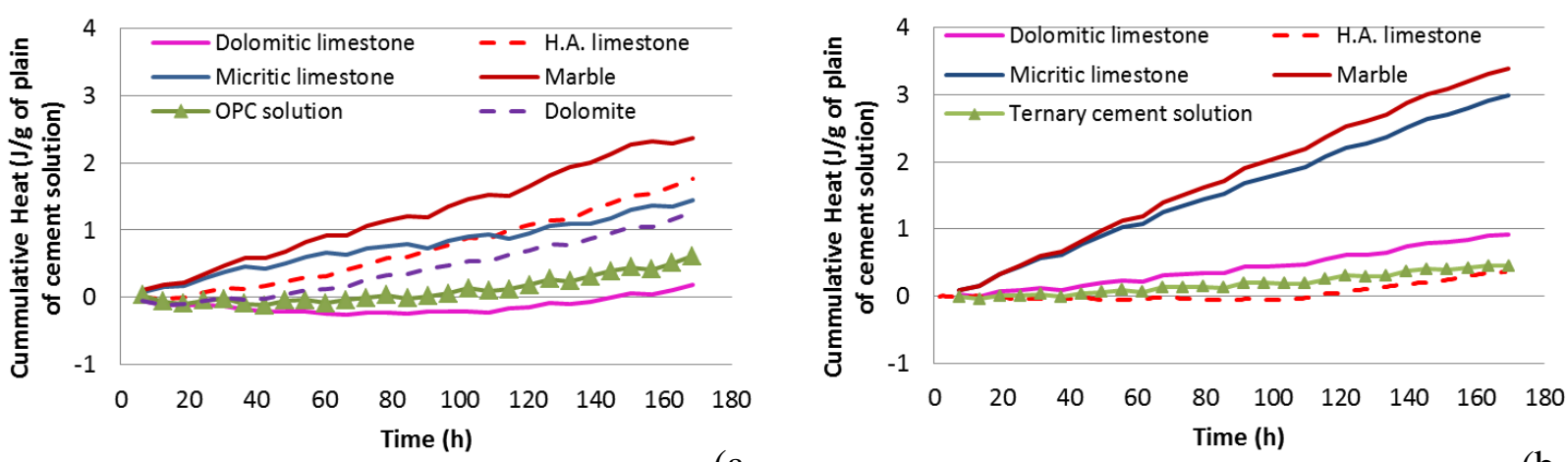

(a

Figure 26. Cumulative heat over time of carbonate aggregates in (a) OPC pore solution and (b) ternary pore solution.

As bond is affected by both $E_{a g g} / E_{\text {paste }}$ and chemical interaction of the aggregate with the paste, it is not surprising that it is a time-dependent property. In most mixtures from this study, at $1 \mathrm{~d}$ and $7 \mathrm{~d}$, cracking occurred predominantly around the aggregates, but once a better bonding developed, cracking started to pass through the aggregate particles and then the strength of the aggregate particle becomes a limiting factor.

Figure 27 shows some examples of this pattern change over time for selected OPC mixtures. The micritic limestone mixture presented a considerable amount of cracking passing through the aggregate even at $1 \mathrm{~d}$, and by $91 \mathrm{~d}$ most of the failure occurred in the aggregate (Figure 27a), while siliceous gravel shows a very different behavior, where most of the failure, even at $91 \mathrm{~d}$ occurred around the aggregate, as if the aggregate had been debonded from the paste (Figure 27d). The high absorption limestone and the granite mixtures presented a similar behavior as the micritic limestone mixture, with the exception that the amount of cracking through the aggregates at $7 \mathrm{~d}$ is like that found in the micritic limestone mixture at $1 \mathrm{~d}$, since the granite rock strength was higher than that of the micritic limestone (Table 7).

On the other hand, it is interesting to observe that aggregates with the same general classification, such as limestone (dolomitic limestone, micritic limestone and high absorption limestone), still present different levels of compressive strength (Tables 9 and 10). This is because, although these three aggregates have the same overall classification, they do present different characteristics in Tables 4, 5, and 6. While the modulus of elasticity of dolomitic and micritic limestones are similar, they are much higher than that of 
the high absorption limestone. In terms of the angularity index, high absorption limestone presented the lowest value, followed by micritic limestone, while dolomitic limestone showed the highest index of all three aggregates. High absorption limestone presented a higher polar surface energy, and is thus expected to have more affinity to interact with the paste via van der Waals forces. On the other hand, in terms of texture index, while the high absorption limestone remained the lowest, the highest index was found in the micritic limestone. In addition, the absorption of dolomitic limestone was significantly higher than that of the micritic limestone.

The high absorption limestone presented one of the highest strengths among all mixtures, but only when OPC was used, even though this aggregate is not expected to have high strength (unfortunately, cores were not available to measure its strength). On the other hand, when a ternary blend was used, the same aggregate presented one of the lowest strengths. The difference in behavior due to the cementitious materials may have been because the improved bond between the high absorption limestone and the paste is a result of the chemical interaction between the calcite from the aggregate and the $\mathrm{CH}$ from the paste [14]. Aggregates in this study presented different reactivity for OPC and ternary pore solution (Figure 26). Figure $26 \mathrm{~b}$ shows no reaction between high absorption limestone and the ternary pore solution, while Figure 26a shows that high absorption limestone reacted well with the OPC solution, which is expected to have higher amounts of $\mathrm{CH}$ than the ternary solution. The thin section photomicrographs of the OPC tested specimens (Figure 28c and 28e) show a high quality, dense ITZ for the OPC mixture (see also Figure 60 in Appendix C). At $1 \mathrm{~d}$ (Figure 28a), only local cracks/gaps around the aggregate can be found. In contrast, thin section photomicrographs of ternary blend tested specimens (Figures 28b, 28d, and 28f) show much more porous, variable quality and less dense ITZ (see also Figure 62 in Appendix C). Large gaps between aggregate and paste were found at all ages, but they became narrower and more discontinuous with time. Even at $91 \mathrm{~d}$, cracks/gaps around the aggregate can still be observed (Figure 28f). The ternary blend bond with this specific aggregate may have been adversely affected for at least three reasons:

1. A previous study [76] using the same materials showed that ternary blends had much less $\mathrm{CH}$ available to react with the aggregates than OPC mixtures (in that study on pastes with $w / c=0.35$, $\mathrm{CH}$ was quantified as $18.7 \%$ and $26.0 \%$ at $7 \mathrm{~d}$ for the ternary blend and $\mathrm{OPC}$, respectively).

2. The kinetics of such reaction depends on the surface area of the carbonate and the diffusion paths for other species, such as alumina [77]. Thus, in the ternary mixture, $\mathrm{CH}$ is expected to react preferentially with the much higher surface area fine limestone and the reaction with the coarse aggregate may be reduced, if not eliminated.

3. Adhesion between aggregate and paste depends not only on the aggregate surface energy, but also on the interfacial energy between paste and aggregate and the affinity between them. 


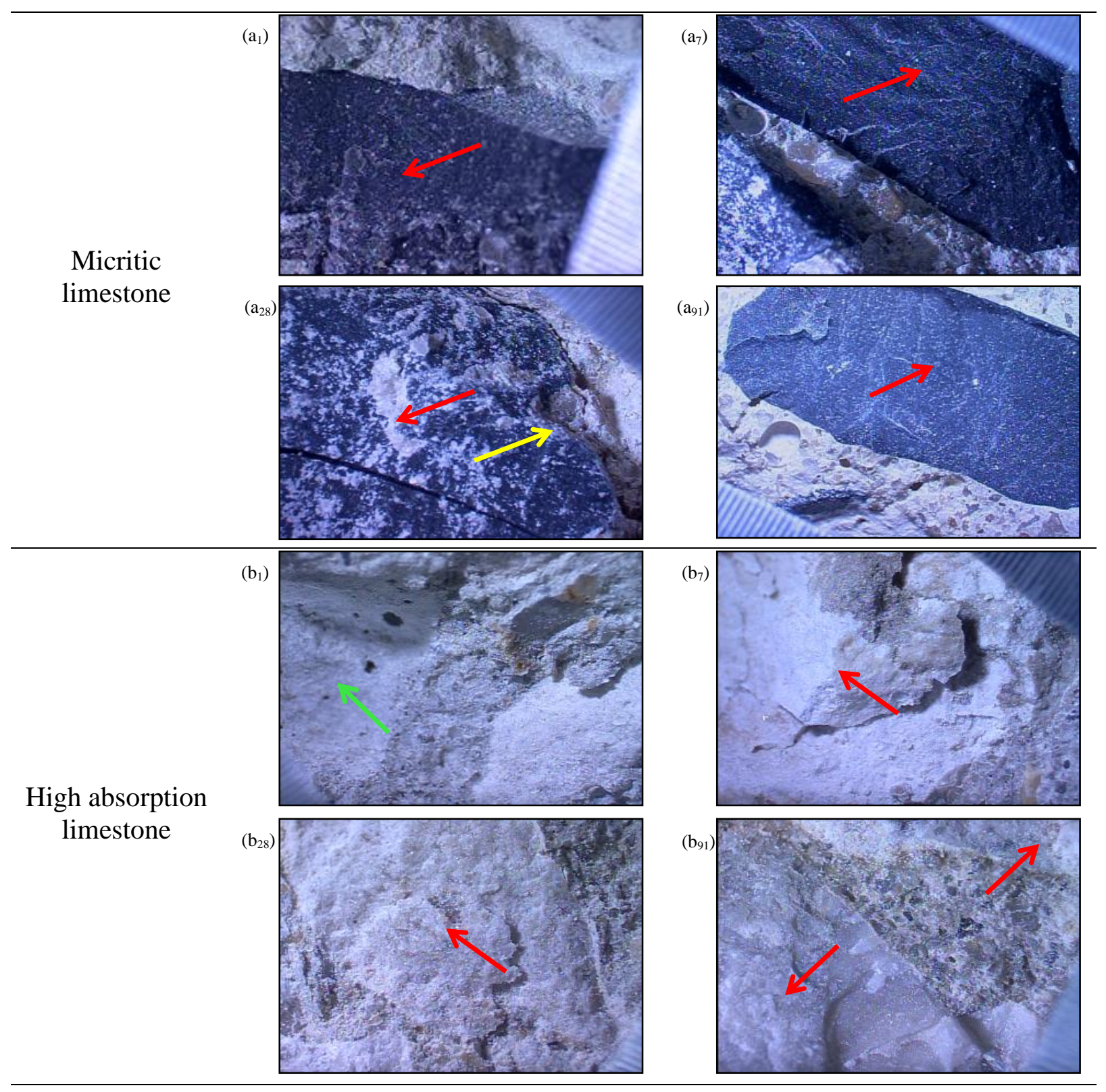

Granite

(c)

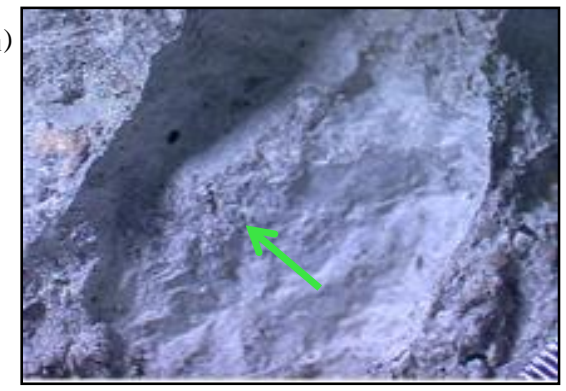

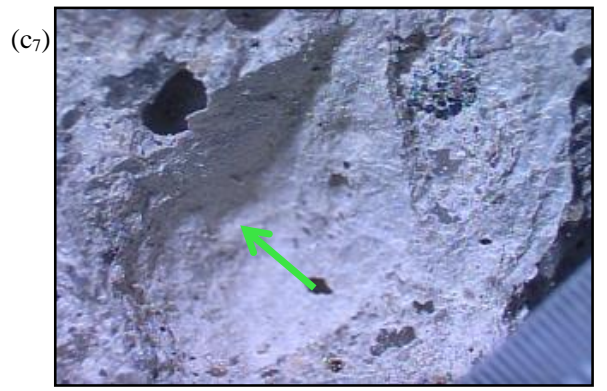



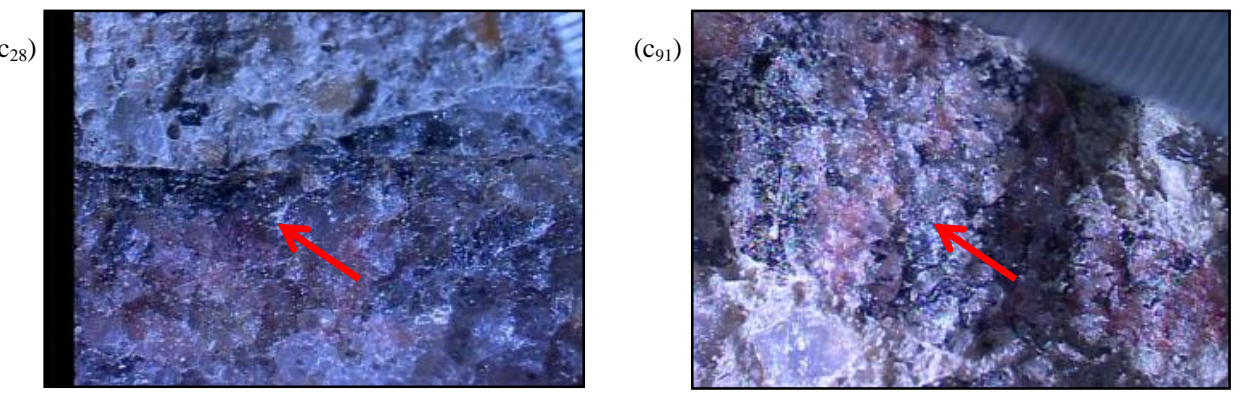

$\left(\mathrm{d}_{1}\right)$

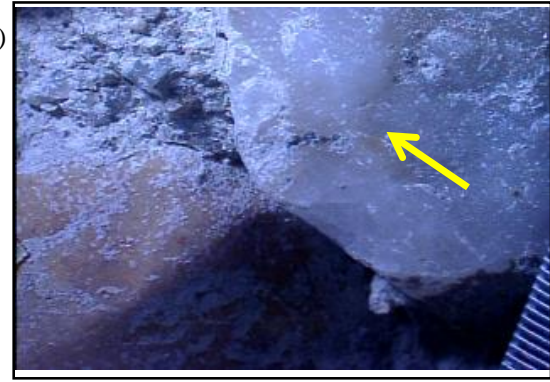

Siliceous gravel

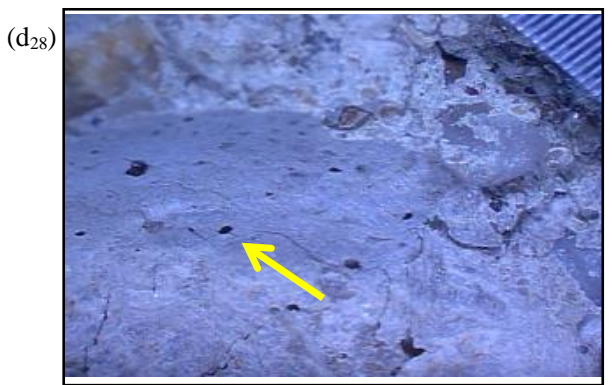

$\left(\mathrm{d}_{7}\right.$

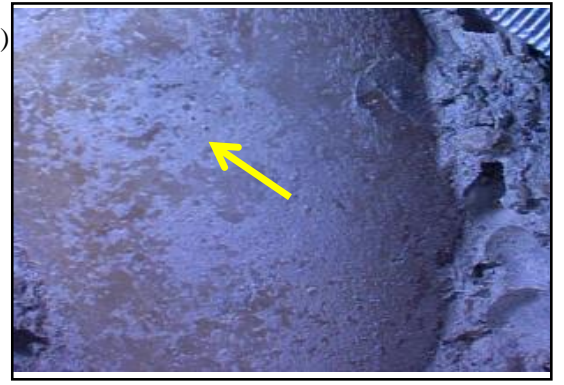

(d $d_{91}$

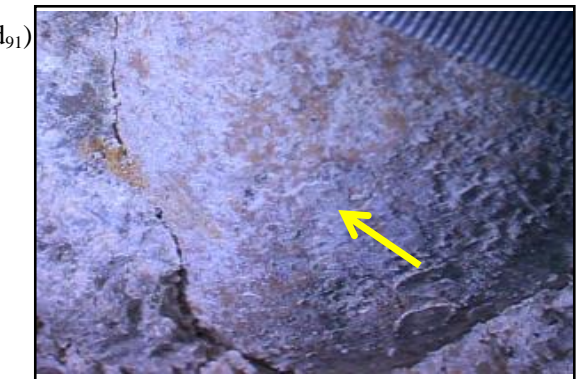

Figure 27. Stereo-photomicrographs showing examples of dominant fracture patterns, after compressive strength testing. Yellow arrows indicate fracture around aggregate, green indicate socket of aggregate (aggregate was completely detached from paste) and red indicate fracture through the aggregate. Scale shown at the corner is in $0.25 \mathrm{~mm}$ increments. Underscore values indicate testing ages of $1 \mathrm{~d}, 7 \mathrm{~d}, 28 \mathrm{~d}$, or

$91 \mathrm{~d}$ of mixtures containing: (a) micritic limestone, (b) high absorption limestone, (c) granite and (d) siliceous gravel.

The dolomitic limestone mixtures had one of the highest strengths among all mixtures (including OPC, ternary blends and all aggregates), even though isothermal calorimetry up to $7 \mathrm{~d}$ did not show any signs of chemical reaction between aggregate and paste (Figure 26). Figures 52 and 54 in Appendix C show a high quality, dense ITZ at the coarse aggregate surface, for both OPC and ternary mixtures. This was confirmed by stereomicroscopic examination which showed that, at later ages, failure in the dolomitic limestone mixtures occurred mostly through aggregates, with evidence of good bond between paste and aggregates (Figure 29a).

The micritic limestone OPC mixture showed a lower compressive strength than the dolomitic limestone one at all ages, despite showing some evidence of chemical reaction with paste (Figure 26), whereas when a ternary binder was used, the mixtures with these two aggregates presented comparable strengths. In the micritic limestone, especially in the OPC mixture, where the binder strength may have surpassed the aggregate strength, it was observed that failure occurred through the aggregate (Figures 29b and 29c), in areas of relatively weak non-durable argillaceous dolomitic limestone particles locally containing relatively thin dark laminations (Figure 29d). On the other hand, in the ternary blend, the strength of the binder was not as high as for the OPC concrete, so the micritic limestone mixture could reach a 
similar strength as the dolomitic limestone mixture. From this analysis, it is evident that a general aggregate description is insufficiently precise to predict the mechanical behavior of the concrete, even when a dense ITZ is observed microscopically.

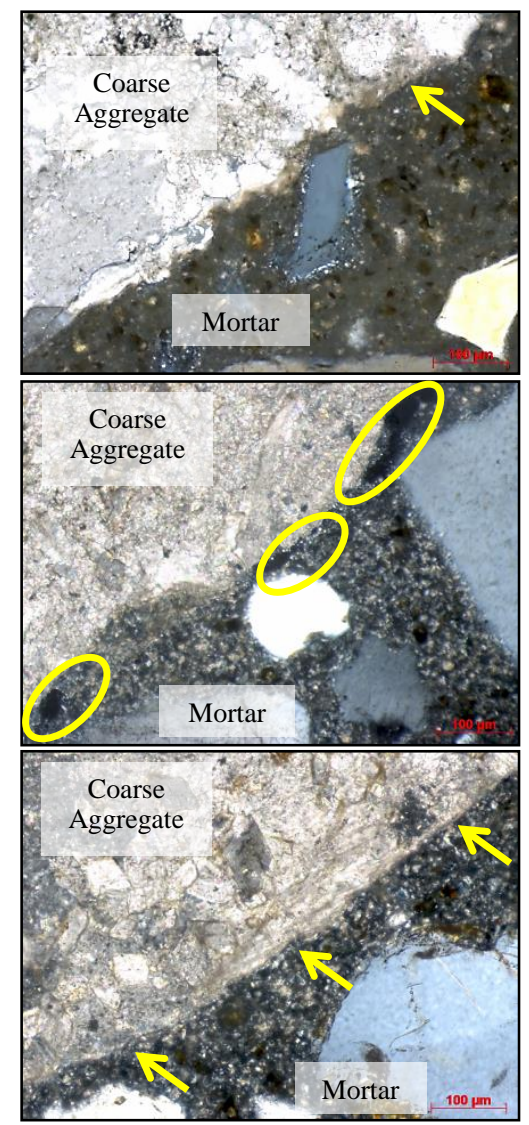

(a)

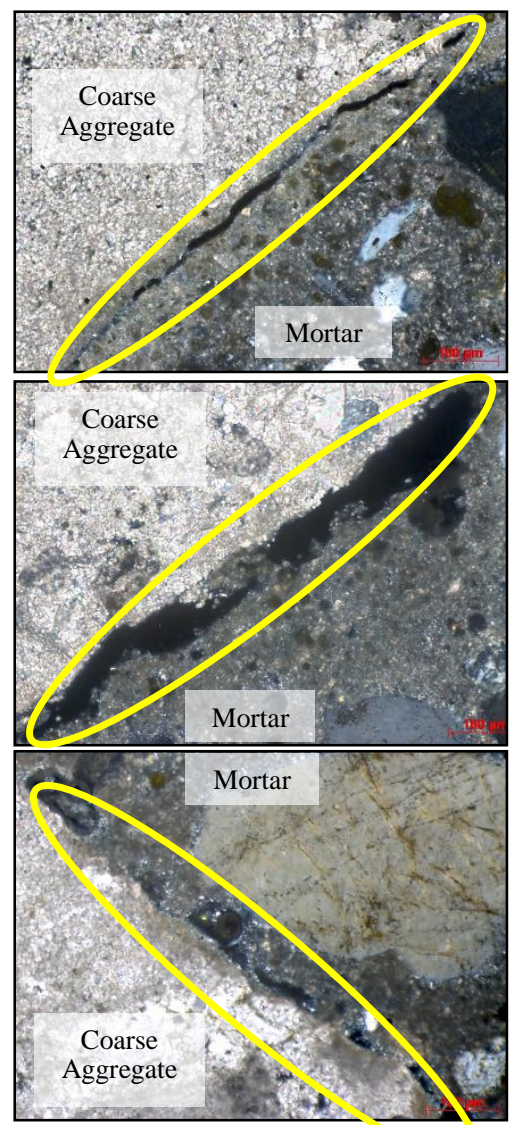

(b)

(d)

(c)

(e)

Figure 28. Thin section photomicrographs showing of high absorption limestone concrei sar aples tested at different ages (a) OPC mixture tested at $1 \mathrm{~d}$. Locally discontinuous cracks/gaps at the ITZ (b) ternary mixture tested at $1 \mathrm{~d}$. Extensive areas with gaps between aggregate and paste, (c) OPC mixture tested at $28 \mathrm{~d}$. Locally discontinuous cracks/gaps at the ITZ (d) ternary mixture tested at $28 \mathrm{~d}$. Gaps/cracks at the ITZ, (e) OPC mixture tested at $91 \mathrm{~d}$. Good bond between aggregate and paste, (f) ternary mixture tested at $91 \mathrm{~d}$. Gaps/cracks still present at ITZ. Gaps/Cracks at ITZ are circled in yellow or indicated by arrows.

A previous study [23] has shown that mixtures with granite aggregate presented a significantly lower compressive strength than mixtures with limestone or diabase, attributed to the low strength of the granite. However, in the present study, the granite OPC mixture had a compressive strength comparable to those of the diabase and dolomitic and high absorption limestone mixtures (Table 9). In contrast, the granite ternary mixture presented a much lower compressive strength than the dolomitic and micritic limestones mixtures, even though the granite aggregate had a lower modulus of elasticity, higher surface energy, and lower texture index than the other two aggregates. The diabase ternary mixture also presented a much lower strength than the dolomitic and micritic limestones mixtures, even though the diabase and the granite rocks had a higher strength than the micritic limestone (Table 7). Stereomicroscope observation showed a good bond between granite and the OPC matrix with through the aggregate and some around the aggregate failures (Figure 30a), while the granite ternary mixture failed mostly due to lack of bond (Figures 30b, 30c, and 30d). This confirms that the rock strength may not always be the limiting aggregate property for concrete strength. If the aggregate strength were the aggregate property governing the concrete strength, 
strengths should increase in the following order: micritic limestone, granitic gneiss, granite, marble, metabasalt and diabase, but the results in Tables 9 and 10 and Figure 31 do not confirm this trend.

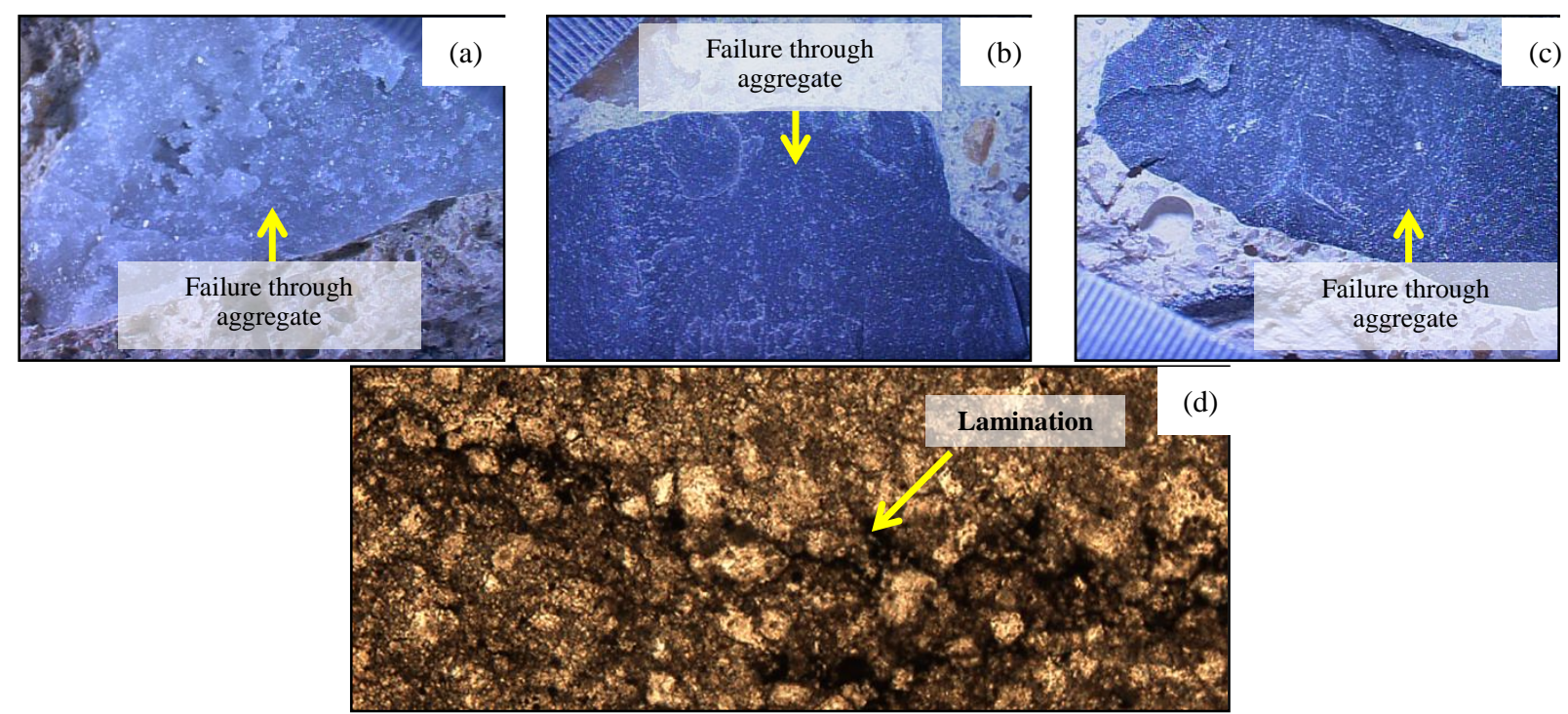

Figure 29. Stereo-photomicrographs of samples, showing fractures surfaces through the aggregate. Scale shown at the corner is in $0.25 \mathrm{~mm}$ increments: (a) dolomitic limestone ternary mixture tested at $91 \mathrm{~d}$ and

(b) and (c) micritic limestone OPC mixture and ternary mixtures, respectively, tested at $28 \mathrm{~d}$. (d)

Transmitted light thin section photomicrographs of argillaceous dolomitic limestone containing thin darker lamination. Length of field of view in image (d) is $1 \mathrm{~mm}$.

Research conducted by Özturan and Çeçen [2] showed that concretes made with meta-basalt presented a higher strength, compared to a limestone concrete, when the designed concrete strength was $60 \mathrm{MPa}$ or above, while the limestone concrete had a higher compressive strength when the designed strength was $30 \mathrm{MPa}$. A similar trend was observed in the present study, since the ternary dolomitic and micritic limestone mixtures had higher strengths than the meta-basalt ternary mixture at all ages. In the case of the OPC mixtures, the meta-basalt mixture had lower strength at $1 \mathrm{~d}$ and $7 \mathrm{~d}$ and similar strength to the micritic limestone mixture at $28 \mathrm{~d}$ and $91 \mathrm{~d}$, when the strength reached about $50 \mathrm{MPa}$. It is important to take into consideration that the strength of the meta-basalt rock was higher than that of the micritic limestone (Table 7), which appears to be an important factor for the different behavior of OPC and ternary mixtures. SEM analysis showed that despite the good quality ITZ, cracks were present at the interface between metabasalt and paste (Figures 56 and 58 in Appendix C). SEM analysis showed a better bond at $28 \mathrm{~d}$ of the mixtures containing dolomitic limestone (Figures 52 and 54 in Appendix C) than those with meta-basalt, also confirmed by stereoscopic examination (Figure 29a and Figures 32a, 32b, and 32c). Micritic limestone mixtures (Figures 29b and 29c) also showed a better bond between aggregate and paste than those containing meta-basalt. This may be due to the high modulus of elasticity of meta-basalt in comparison with those of the limestones and the pastes (OPC and ternary). 


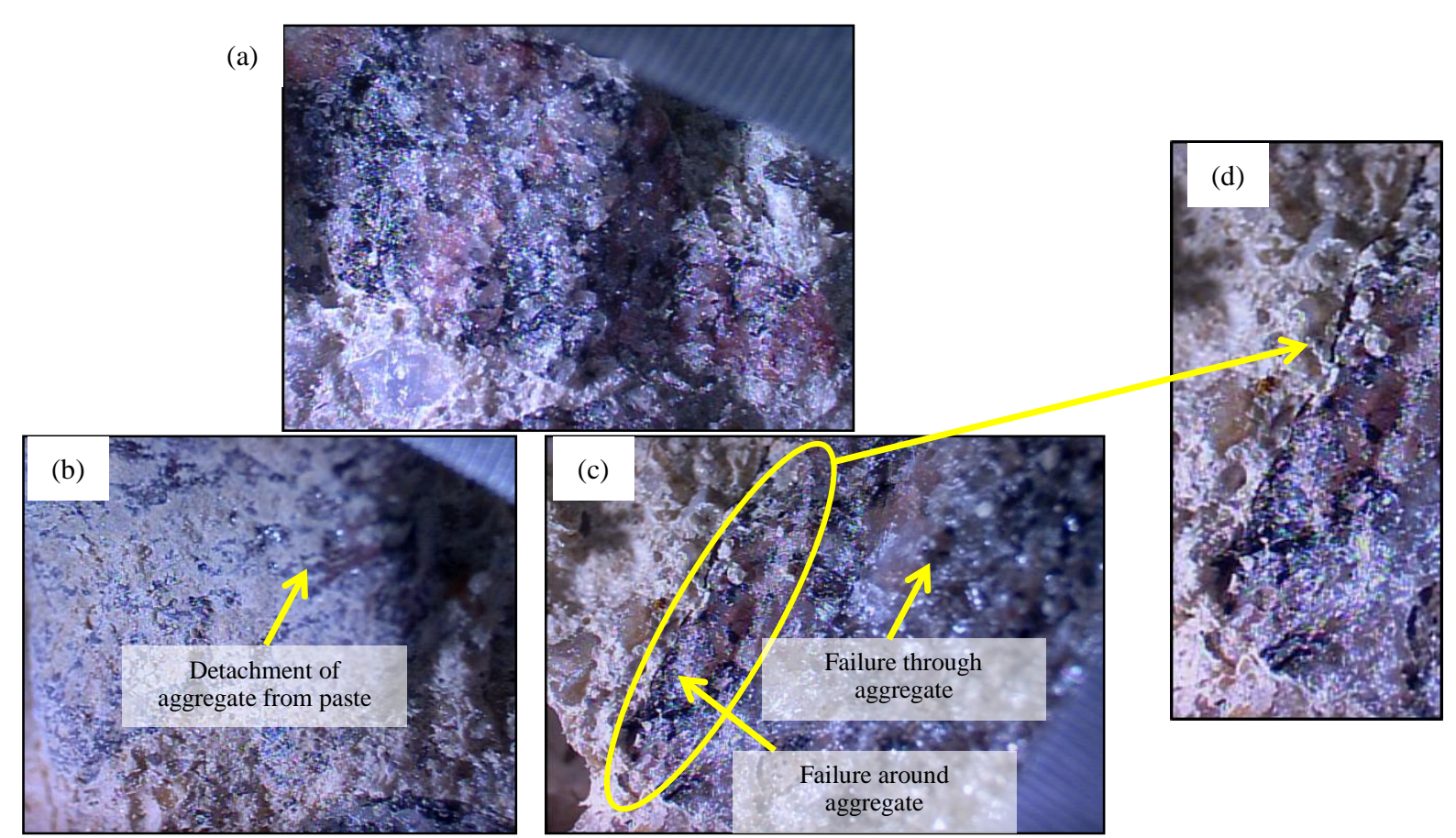

Figure 30. Stereo-photomicrographs showing fracture surfaces of granite mixtures tested at $91 \mathrm{~d}$ (a) OPC mixture (failure through the aggregate), (b) ternary mixture (failure around the aggregate), (c) ternary mixture (failure around and through the aggregate) and (d) zoom in of image in (c). Scale shown at the corners in images (a), (b), and (c) is in $0.25 \mathrm{~mm}$ increments.

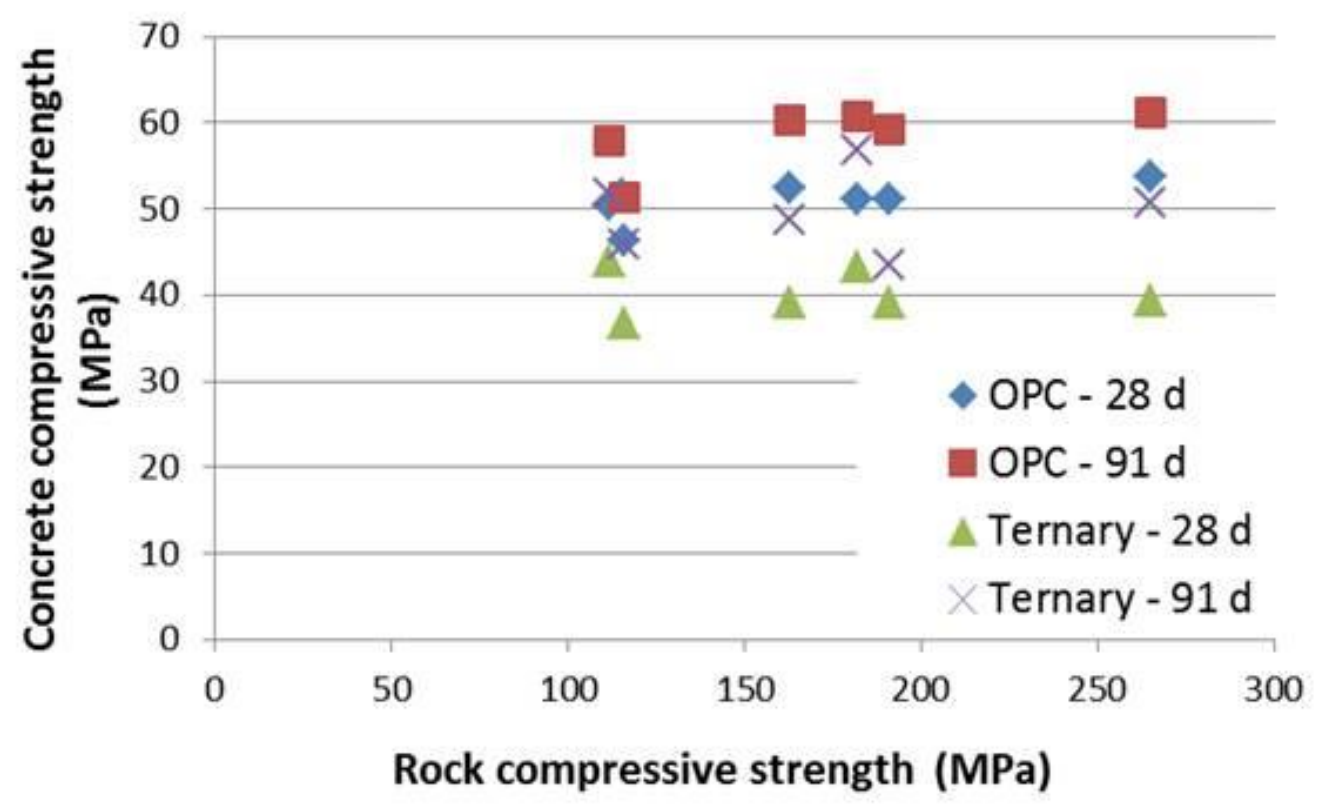

Figure 31. Relation between rock compressive strength and concrete compressive strength. 

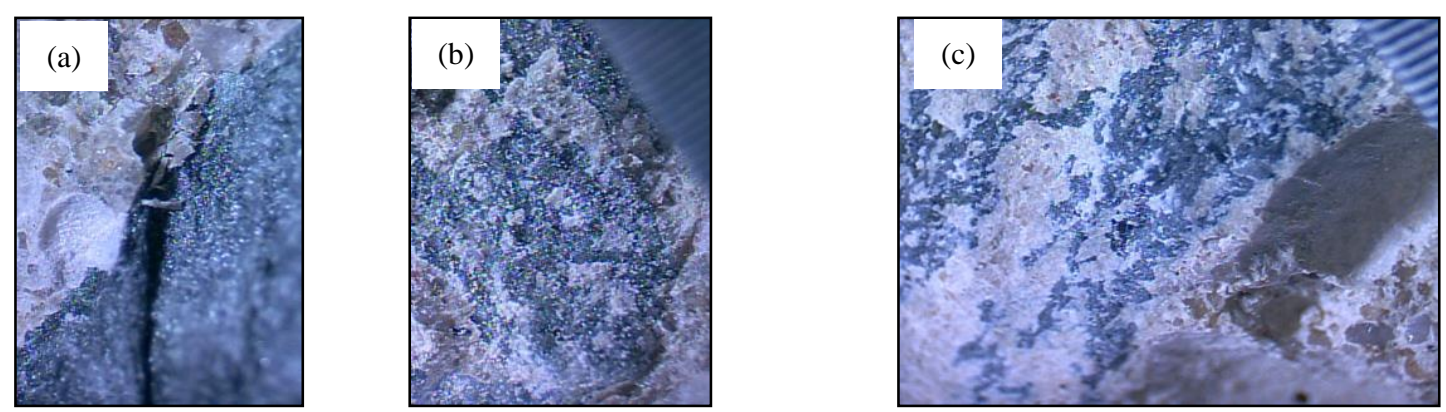

Figure 32. Stereo-photomicrographs of samples tested at $91 \mathrm{~d}$ : (a) meta-basalt OPC mixture with failure through the aggregate, (b) meta-basalt OPC mixture with failure around the aggregate and lack of bond and (c) meta-basalt ternary mixture with failure around the aggregate and lack of bond. Scale shown at the corner is in $0.25 \mathrm{~mm}$ increments.

Siliceous gravel mixtures always provided the lowest compressive strengths, attributable to the deficient bond between aggregate and paste. No sign of chemical interaction between siliceous gravel and paste was found (Figure 33). After strength testing, stereomicroscope observation of specimens showed signs of lack of bond at all ages (Figure $27 \mathrm{~d}_{1}, \mathrm{~d}_{7}, \mathrm{~d}_{28}, \mathrm{~d}_{91}$ ). In addition, SEM analyses of specimens tested at $28 \mathrm{~d}$ indicated localized layers of $\mathrm{CH}$ at the aggregate surface and a porous ITZ (Figures 48 and 50 in Appendix C), confirming this poor bond. This deficient bond was due to two main factors: siliceous gravel's high modulus of elasticity and CTE (Table 6) and low texture index, or smooth surface (Table 5 and Figure $8 \mathrm{~h}$ ). This is agreement with other studies $[2,19,23]$ in which gravel has also shown lower strengths in comparison to other aggregate types.

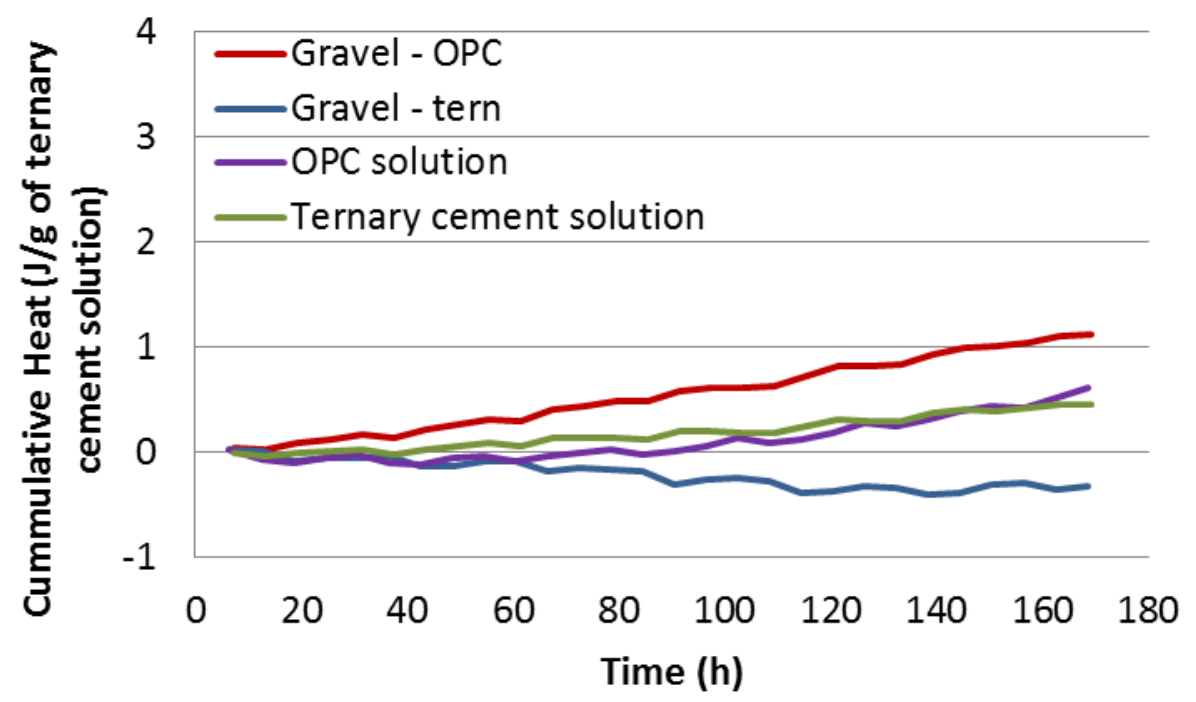

Figure 33. Cumulative heat over time of siliceous gravel in OPC pore solution or ternary pore solution.

Low strengths were also noted in the granitic gneiss mixtures, but not due to a deficient bond, since this aggregate has a low modulus of elasticity and a high texture index (Figure 8g), but more likely due to the aggregate's low strength (Table 7) and high CTE (Table 6). This was confirmed by the stereomicroscope observation of the specimens after testing that showed failure through the aggregates (Figures 34a and 34b), due to the granitic gneiss' low strength attributed to the presence of weak planes, in the form of alternating bands of micaceous minerals and feldspar and quartz (Figure 6h). 

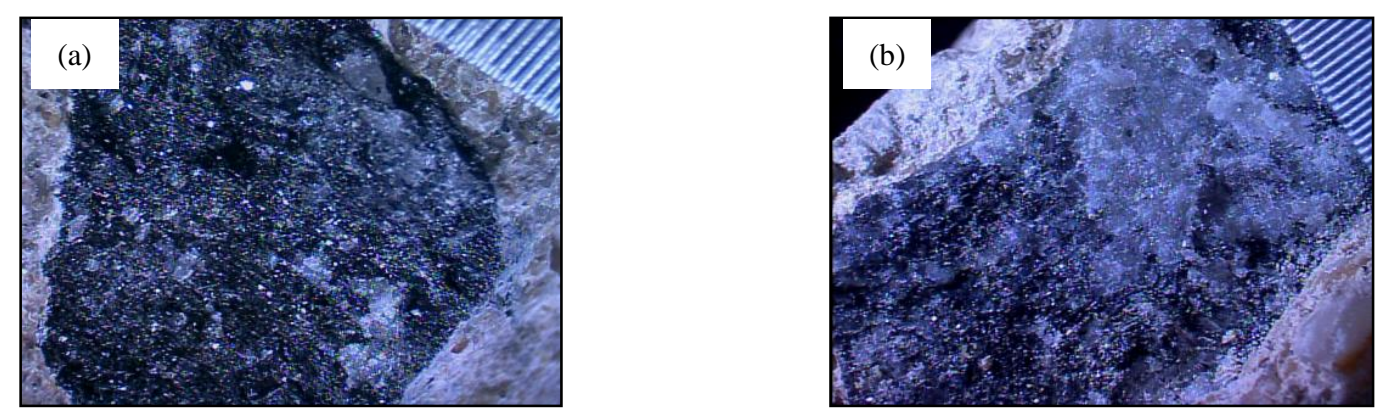

Figure 34. Stereo-photomicrographs of granitic gneiss samples tested at $91 \mathrm{~d}$ (a) OPC mixture and (b) ternary mixture. Scale shown at the corner is in $0.25 \mathrm{~mm}$ increments. 


\section{CTE MiSMATCH $\left(C T E_{A G G} / C T E_{P A S T E}\right)$ AND COMPRESSIVE STRENGTH}

While the modulus mismatch may, in some cases, play a predominant role in bonding (especially in laboratory conditions where the concrete temperature gradients are low), the mismatch between the CTE of the aggregate and that of the paste can affect bonding in the same way and therefore cannot be ignored. Nevertheless, the relationship between aggregate CTE and concrete strength is not so simple to quantify. Firstly, this is because aggregate characteristics, such as morphology of the rock, i.e. density of grains and lamination, not only affect CTE of an aggregate, but also its modulus of elasticity and strength, which ultimately also have an impact on concrete strength. Zunino et al. [9] proposed a model that quantifies the stresses developed at the ITZ based on both the CTE and the modulus of elasticity mismatch. According to this model, the higher the temperature gradient and the CTE mismatch, the higher the stresses and consequently the risk of microcracking that would likely reduce measured strength as well.

In the current study, for the OPC mixtures, the difference between the CTE of aggregate and paste ranged from about $3.5 \mu \varepsilon /{ }^{\circ} \mathrm{C}$ to $10.2 \mu \varepsilon /{ }^{\circ} \mathrm{C}$ at $7 \mathrm{~d}$. However, between the time of concrete maximum temperature (as measured by semi-adiabatic calorimetry and shown in Figure 11) and the time specimens were placed in the water tank, this CTE mismatch is expected to be significantly higher than these estimates, because the paste CTE around setting time can be up to twice that of the hardened material (Tables 9 and 10) [78]. On the other hand, the temperature gradients of these mixtures during the first $24 \mathrm{~h}$ varied between $9{ }^{\circ} \mathrm{C}$ to $15{ }^{\circ} \mathrm{C}$, which are considered relatively low, but could still potentially produce strains registering several hundred microstrains (which of course could be significantly reduced by the high creep/compliance of the young material). Because of this temperature gradient and the higher paste CTE, as temperature rises from its initial value, stresses in the radial direction of the aggregate paste interface will develop, while the paste strength is still very low, potentially leading to microcracks within the mortar phase surrounding the coarse aggregate particles. Later when the concrete cools, the paste will shrink more than the aggregates, again generating substantial stresses within the ITZ regions. Among the OPC mixtures, the highest strains due to the temperature history were likely developed by the high absorption, diabase and micritic limestone mixtures. On the other hand, these thermally induced strains were partially counteracted by the lower mismatch between the $E_{a g g}$ and the $E_{\text {paste }}$ values for these aggregates, in comparison to the other mixtures, which may explain why their strength was not severely affected. 


\section{LINEAR MODELS FOR COMPRESSIVE STRENGTH}

In developing models for the 28-d compressive strength, it should be kept in mind that the standard errors for the OPC and ternary blend mixtures are 4.7 MPa and 4.5 MPa, respectively, if a model based on a single (constant) value, e.g., the average measured compressive strength across all aggregate types, were to be employed. For the OPC concrete mixtures, as shown in Figure 35, the "best" linear model for 28-d compressive strength was found when the values were regressed against the measured CTEs of the component aggregates. The standard error for this model is $3.4 \mathrm{MPa}$, which would decrease to $1.8 \mathrm{MPa}$ if the data to the far lower right (siliceous gravel aggregate data point) were excluded from the analysis. For the ternary blends, the linear model included both aggregate absorption and CTE as variables, resulting in the following equation to predict 28-d compressive strength for all 11 aggregates (see Figure 36):

$$
\sigma(28-\mathrm{d}, \mathrm{MPa})=46.81-3.59 * \text { Absorption }-0.632 * C T E
$$

where Absorption is given in percent and the $C T E$ is given in $\mu \varepsilon /{ }^{\circ} \mathrm{C}$, with a standard error of $2.9 \mathrm{MPa}$. For both types of concrete, aggregates with a higher CTE produce lower strengths. With relative standard errors (standard error divided by average strength) of $6.8 \%$ and $7.5 \%$ for the OPC and ternary blend models, respectively, both are moderately successful in predicting the resultant compressive strength of the concrete from the measured characteristics of the coarse aggregates, as also seen by comparing their standard errors to the value of about $4.5 \mathrm{MPa}$ obtained by simply assuming the average compressive strength to be the predicted response for all aggregate types. The presented models do offer some improvement in this regard, but are still far from ideal.

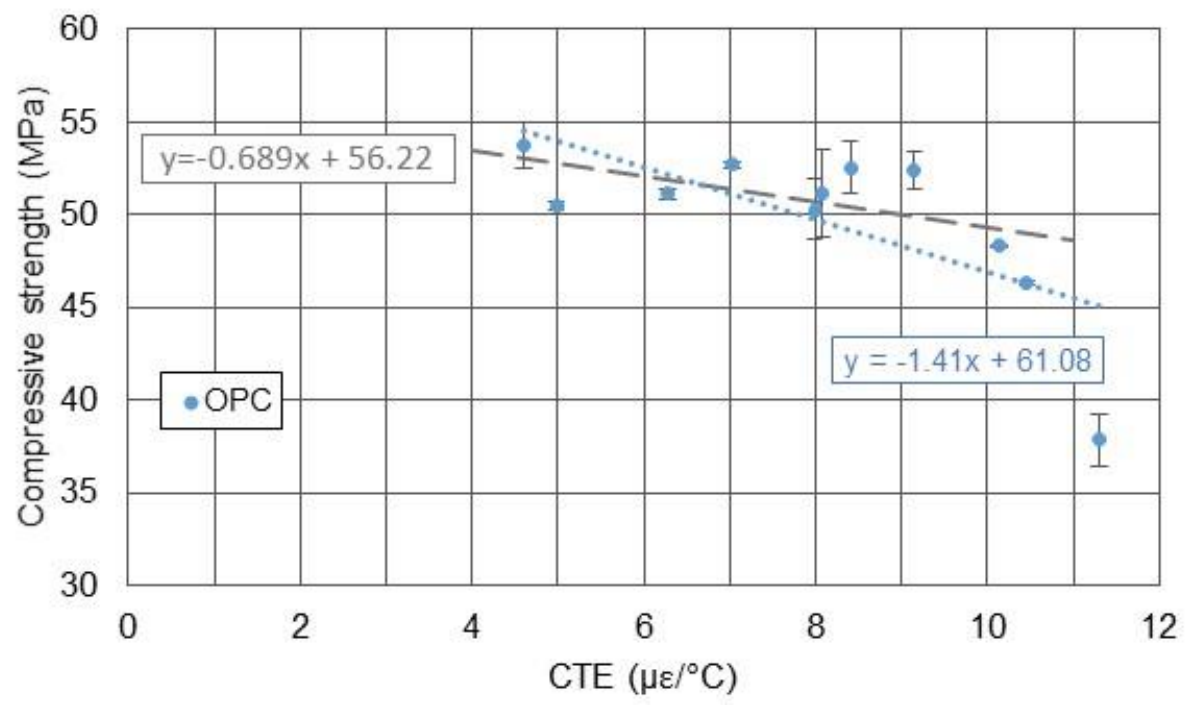

Figure 35. 28-d compressive strength vs. CTE for the OPC concrete mixtures. Dotted blue line indicates best linear fit for all the data. Dashed grey line indicates best linear fit when siliceous gravel data (lower right point) is excluded from the analysis. Error bars indicate one standard deviation for two cylinders broken from each mixture. CoV for CTE can be found in Testing section on page 8.

Model development has first focused on 28-d compressive strength as that is the benchmark measure by which concrete is normally evaluated. As illustrated in Table 13, the other measured mechanical properties of the OPC concretes were even less well described by aggregate characteristics such as CTE. In most cases, minimal improvement over the default model of assuming a single (constant) value for the measured property (e.g., equal to its average value) is obtained when including the aggregate CTE as an 
independent variable in a univariate linear model, particularly in the cases of splitting tensile and 91-d flexural strengths.

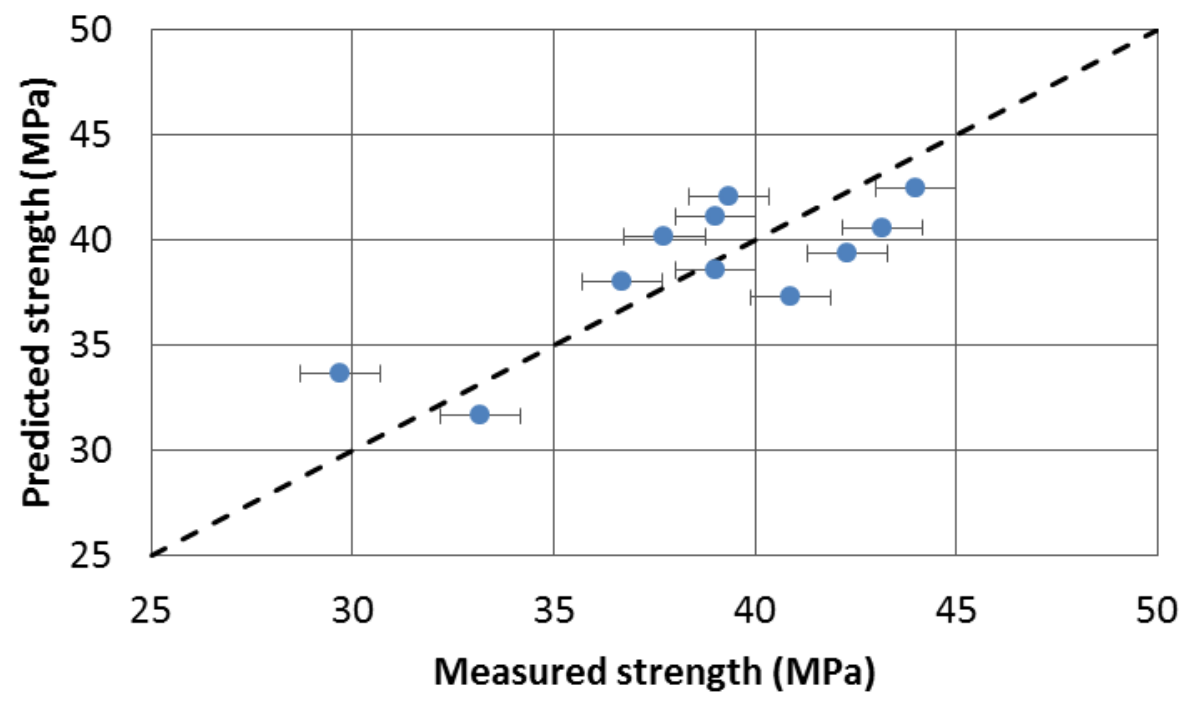

Figure 36. Predicted 28-d compressive strength vs. measured values for the ternary blend concrete mixtures. The dashed line indicates what would be a one-to-one relationship between measured and predicted values.

Table 13. Fitting of OPC concrete mechanical properties to linear model based on aggregate CTE.

\begin{tabular}{ccc}
\hline \multicolumn{1}{c}{ Property } & Standard error vs. CTE & Standard error for Y=mean \\
\hline 1-d compressive strength & $3.9 \mathrm{MPa}$ & $4.1 \mathrm{MPa}$ \\
7-d compressive strength & $3.2 \mathrm{MPa}$ & $3.7 \mathrm{MPa}$ \\
91-d compressive strength & $3.6 \mathrm{MPa}$ & $4.8 \mathrm{MPa}$ \\
28-d splitting tensile strength & $0.40 \mathrm{MPa}$ & $0.42 \mathrm{MPa}$ \\
91-d splitting tensile strength & $0.34 \mathrm{MPa}$ & $0.37 \mathrm{MPa}$ \\
28-d flexural strength & $0.25 \mathrm{MPa}$ & $0.34 \mathrm{MPa}$ \\
91-d flexural strength & $0.47 \mathrm{MPa}$ & $0.50 \mathrm{MPa}$ \\
\hline
\end{tabular}

Further analysis of compressive strength data measured at 3 ages ( $7 \mathrm{~d}, 28 \mathrm{~d}$, and $91 \mathrm{~d}$ ) was conducted using principal components analysis and including the elastic modulus of the cement paste (OPC or ternary blend) as a function of age (Tables 9 and 10) as an independent variable. Here, it was decided to exclude the siliceous gravel aggregate from the analysis due to its unique response in comparison to the other ten aggregates. This resulted in the elastic moduli of the aggregates and the paste being the only two significant variables and the following equation that provides a standard error of 3.2 MPa for predicting strength of either concrete binder at any of the three ages:

$$
\sigma(\mathrm{MPa})=-13.95+0.07 * E_{a g g}+4.30 * E_{\text {paste }}
$$


In equation (3), both linear coefficients are positive, indicating that an increase in either aggregate modulus or paste modulus will increase measured compressive strength at the 3 ages, but significantly more so $(61 \mathrm{x})$ for an increase in paste modulus. This implies that the mechanical properties of the paste component of the concrete are paramount to its mechanical performance, with those of the aggregates being a secondary, but nonetheless significant, contributor, particularly at a given age for a given binder, when the value of $E_{\text {paste }}$ is fixed. 


\section{Concrete Splitting TensiLe StREngth}

The splitting tensile strengths of OPC mixtures varied from $3.7 \mathrm{MPa}$ to $4.9 \mathrm{MPa}$ at $28 \mathrm{~d}$ and from 4.2 MPa to 5.2 MPa at $91 \mathrm{~d}$ (Table 9), with ranges equivalent to $27 \%$ and $22 \%$ of the average value at each age. The splitting tensile strength of the ternary mixtures at $28 \mathrm{~d}$ ranged from $3.2 \mathrm{MPa}$ to $4.9 \mathrm{MPa}$ and at $91 \mathrm{~d}$, they varied from $3.4 \mathrm{MPa}$ to $5.5 \mathrm{MPa}$ (Table 10), with ranges equivalent to $44 \%$ and $48 \%$ of the average value at each age, again confirming that the ternary mixtures are more sensitive to the aggregate type. While the same level of aggregate effect was observed on compressive and splitting tensile strengths of OPC at the same ages, the effect of aggregate type on the ternary mixtures' splitting tensile strength was more pronounced than on their compressive strength.

Stereoscopic examination showed that fracture patterns change depending on how the specimens are loaded (compressive strength, splitting tensile strength, or flexural strength). Part of these differences are due to the loading direction in relation to the casting direction [79]. In compressive strength testing, the load is applied in the same direction as the specimen's casting, while in splitting tensile strength testing, the load is applied perpendicularly to the casting direction. In addition, the effect of the ITZ and the bond between paste and aggregate depends on the loading mode. This was evidenced by the fact that the fracture patterns (through aggregate or around the aggregates) changed with age and the type of cementitious materials used (OPC or ternary blend binder), that is, the paste strength.

High absorption limestone presented one of the lowest splitting tensile strengths among the ternary mixtures, just as with compressive strength. On the other hand, the strength of the OPC high absorption limestone mixture was medium range and like that of the dolomitic limestone mixture. The splitting tensile strength of the micritic limestone mixture followed the same trend as the compressive strength: the strength of the OPC micritic limestone mixture was much lower than those of the high absorption and dolomitic limestone mixtures, while that of the ternary micritic limestone mixture was higher than the ones with the other two limestones. This suggests that the optimization of aggregate type will depend on the binder type as well. Siliceous gravel or granitic gneiss mixtures always provided the lowest splitting tensile strengths, as was observed with their compressive strengths.

At the age of $28 \mathrm{~d}$, the following equation was identified for splitting tensile strength $\left(\sigma_{t}\right)$ for both binder types via principal components analysis, once again excluding the siliceous gravel data:

$$
\sigma_{\mathrm{t}}(\mathrm{MPa})=1.26-0.012 * \text { Absorption }+0.047 * C T E+0.015^{*} E_{\text {agg }}+0.126^{*} E_{\text {paste }}
$$

with a standard error of $0.34 \mathrm{MPa}$. This represents a minor improvement over the previously presented models (Table 13) for OPC mixtures only, that included siliceous gravel and were based on the overall average value at $28 \mathrm{~d}$ (standard error of $0.42 \mathrm{MPa}$ ) or the measured CTE of the aggregates (standard error of 0.40 , for $\sigma_{\mathrm{t}}=4.71-0.050^{*} C T E$ ). As with the 28 -d compressive strength, the most significant variables were identified as aggregate absorption, CTE, and modulus, along with the modulus of the binder (paste) component of the concrete. 


\section{CONCRETE FLEXURAL STRENGTH}

The flexural strengths of OPC mixtures varied from 5.8 MPa to 6.7 MPa at $28 \mathrm{~d}$ and from $5.8 \mathrm{MPa}$ to $7.2 \mathrm{MPa}$ at $91 \mathrm{~d}$. These ranges, in relation to the average value, were lower than what was obtained for the compressive strength and the splitting tensile strength. The ternary blends' flexural strengths varied from 4.7 $\mathrm{MPa}$ to $6.6 \mathrm{MPa}$ at $28 \mathrm{~d}$ and from 5.0 $\mathrm{MPa}$ to $7.2 \mathrm{MPa}$ at $91 \mathrm{~d}$. These ranges, in relation to the average value, were about the same as the compressive strength and lower than the splitting tensile strength. Thus, it appears that flexural strength is less sensitive to the different aggregates than the splitting tensile strength, which was expected since the load in flexural strength testing is applied parallel to the casting direction, as in the case of compressive strength testing [79].

The lowest flexural strengths were also found in mixtures containing siliceous gravel and granitic gneiss, as occurred with compressive and splitting tensile strengths (Tables 9 and 10). The dolomitic limestone and marble mixtures showed high strengths in both OPC and ternary blend mixtures, even though these aggregates presented a low texture index (Figures 8c and 8i) and a medium to high modulus of elasticity. A factor that may have contributed to their high strength is a better bond due to the chemical reaction between the calcite in the aggregate and components of the hydrated cement, as reported by others $[2,10,23,25,26]$. Figure 37 shows that most of the fracture occurred through the aggregates, indicating a good bond between aggregate and paste. Other carbonate aggregates, such as dolomite and micritic limestone, presented high strengths as well, as they had not only the contribution of the possible chemical reaction, but also higher texture indices (Figures $8 \mathrm{~b}$ and $8 \mathrm{e}$ ).
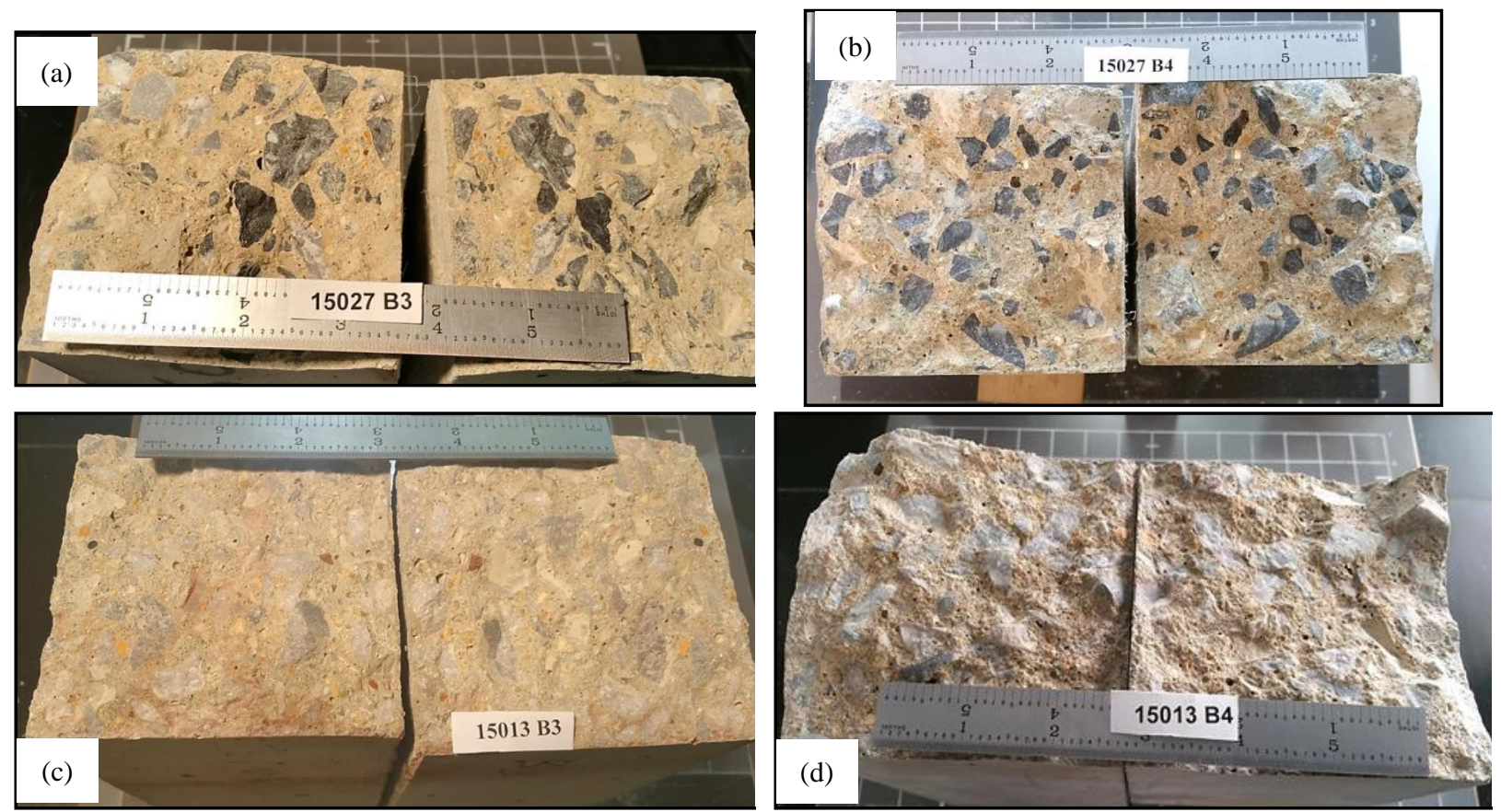

Figure 37. Photographs of OPC beam specimens tested for flexural strength at $28 \mathrm{~d}$ (left) and $91 \mathrm{~d}$ (right), respectively. (a) and (b) with marble aggregate, (c) and (d) with dolomitic limestone aggregate. 


\section{Summary AND Prospectus}

The objectives of this exploratory project were to examine the impact of aggregate type on concrete performance and to identify aggregate characteristics that have the largest impact on this performance. The results have demonstrated that for similar mixture proportions, the selection of coarse aggregates can have a measurable influence on concrete performance, in terms of both mechanical and transport (i.e., electrical resistivity) properties. For example, for 28 -d compressive strength, the range over the average value was on the order of $35 \%$ for both the OPC and ternary blend concrete mixtures for the 11 aggregate types examined in the present study.

Associating a single aggregate characteristic with these performance variations was less successful. Concrete modulus was one exception to this rule as a reasonable prediction of concrete modulus could be obtained based on the aggregate modulus, particularly when two specific aggregates (siliceous gravel and meta-basalt) were excluded from this analysis. Linear models were developed to predict 28-d compressive strength, based on CTE for the OPC concretes and on CTE and absorption for the ternary blend concretes, but the quality of their predictions was far from ideal. Predictions for splitting tensile and flexural strengths offered only slight improvements over a single value (average) model. Each measured concrete property is influenced in a unique manner by a different combination of aggregate characteristics.

Nonetheless, a great deal of data was generated in this study and noteworthy observations that should be highlighted include:

1) The incompatibility of certain paste and aggregate properties, namely modulus of elasticity and CTE, likely promote the development of interfacial stresses, potentially causing microcracking, weakening the bond between the two phases, and lowering the measured concrete strength.

2) For both binders, the siliceous gravel aggregate produced low strength concretes, which exhibited a low electrical resistivity as well. This is likely due to weaker bonding between paste/mortar and coarse aggregate in this composite material.

3) The high absorption limestone produced unexpectedly low strengths (and resistivities) in the ternary blend concrete mixture, for reasons unknown at the present time.

4) Similarly, in the OPC concretes, the granitic gneiss produced the lowest electrical resistivities and the second lowest compressive strengths at $28 \mathrm{~d}$ and $91 \mathrm{~d}$ (after the siliceous gravel).

5) For three of the other concretes based on carbonate aggregates (limestones and marble), the strengths exhibited by the ternary blends were unexpectedly high relative to those exhibited by the OPC mixtures, in agreement with results from a previous study $[63,64]$.

6) The micritic limestone produced OPC and ternary blend concretes with the highest measured electrical resistivities, suggestive of a low diffusivity, potentially high durability concrete. These concretes had strengths that were in the upper quartile for the ternary blend but in the lower one for OPC, illustrating that strength should not be used to infer resistivity (durability) and vice versa.

7) These results demonstrate that selection of an optimum aggregate for a specific concrete application will also require knowledge of the binder to be used, as some aggregates performed better with the OPC concrete than they did in the ternary blends, and vice versa.

The present study did not provide any direct assessments of the level of bond between aggregates and paste/mortar and it is likely this parameter that greatly influences mechanical (and to a lesser extent transport) properties of the produced concrete. Clearly, both aggregate and binder characteristics will 
influence this bonding level. In the future, it is planned to assess the bonding level in some of the remaining cylinders from each concrete mixture using non-linear ultrasonic techniques, in the hopes that such measurements on these concretes can be related to the established database (Tables 9 and 10) of their measured mechanical properties. 


\section{REFERENCES}

1) French, C.W., and Mokhtarzadeh, A., "High Strength Concrete: Effects of Materials, Curing and Test Procedures on Short-Term Compressive Strength,” PCI Journal, 38 (3), 76-87, 1993.

2) Özturan, T., and Çeçen, C., "Effect of Coarse Aggregate Type on Mechanical Properties of Concrete with Different Strengths," Cement and Concrete Research, 27 (2), 165-170, 1997.

3) Tasong, W.A., Cripps, J.C., and Lynsdale, C.J., "Aggregate-Cement Chemical Interactions," Cement and Concrete Research, 28 (7), 1037-1048, 1998.

4) Tasong, W.A., Lynsdale, C.J., and Cripps, J.C., "Aggregate-Cement Paste Interface Part I. Influence of Aggregate Geochemistry," Cement and Concrete Research, 29, 1019-1025, 1999.

5) Tasong, W.A., Lynsdale, C.J., and Cripps, J.C., "Aggregate-Cement Paste Interface. II: Influence of Aggregate Physical Properties," Cement and Concrete Research, 28 (10), 1453-1465, 1998.

6) Quiroga, P.N., and Fowler, D.W., "The Effects of Aggregates Characteristics on the Performance of Portland Cement Concrete," Report ICAR 104-1F, August 2004.

7) Al-Oraimi, S.K., Taha, R., and Hassan, H.F., "The Effect of the Mineralogy of Coarse Aggregate on the Mechanical Properties of High-Strength Concrete," Construction and Building Materials, 20, 499-503, 2006.

8) Rocco, C., and Elices, M., "Effect of Aggregate Shape on the Mechanical Properties of a Simple Concrete," Engineering Fracture Mechanics, 76 (2), 286-298, 2008.

9) Zunino, F., Castro, J., and Lopez, M., "Thermo-mechanical Assessment of Concrete Microcracking Damage Due to Early-Age Temperature Rise," Construction and Building Materials, 81, 140-153, 2015.

10) Kamali-Bernard, S., Keinde, D., and Bernard, F., "Effect of Aggregate Type on the Concrete Matrix/Aggregates Interface and Its Influence on the Overall Mechanical Behavior. A Numerical Study," Key Engineering Materials, 617, 14-17, 2014.

11) Liu, Y., and Presuel-Moreno, F., "Effect of Elevated Temperature Curing on Compressive Strength and Electrical Resistivity of Concrete with Fly Ash and Ground-Granulated Blast-Furnace Slag," ACI Materials Journal, 111 (5), 531-541, 2014.

12) Beushausen, H., and Dittmer, T., "The Influence of Aggregate Type of the Strength and Elastic Modulus of High Strength Concrete," Construction and Building Materials, 74, 132-139, 2015.

13) Grandet, J., and Ollivier, J.P., "Etude de la Formation du Monocarboaluminate de Calcium Hydrate au Contact d'un Granulat Calcaire dans une Pate de Ciment Portland," Cement and Concrete Research, 10, 759-770, 1980.

14) Monteiro, P.J.M., and Mehta, P.K., "Interaction between Carbonate Rock and Cement Paste," Cement and Concrete Research, Vol. 16 (2), 127-134, 1986.

15) Bentz, D.P., Stutzman, P.E., and Garboczi, E.J., "Experimental and Simulation Studies of the Interfacial Zone in Concrete," Cement and Concrete Research, 22 (5), 891-902, 1992.

16) Hussin, A., and Poole, C., "Petrography Evidence of the Interfacial Transition Zone (ITZ) in the Normal Strength Concrete Containing Granitic and Limestone Aggregates," Construction and Building Materials, 25, 2298-2303, 2011.

17) Pocius, A.V., Adhesion and Adhesives Technology: An Introduction. Carl Hanser Verlag GmbH Co KG, 2012. 
18) Miller, C., Vasconcelos, K., Little, D., and Bhasin, A., "Investigating Aspects of Aggregate Properties that Influence Asphalt Mixtures Performance," Research Report for DTFH61-06-C-00021, Texas A\&M University at College Station and The University of Texas at Austin, Texas, 2011.

19) Bentz, D.P., Ardani, A., Barrett, T., Jones, S.Z., Lootens, D., Peltz, M.A., Sato, T., Stutzman, P.E., Tanesi, J., and Weiss, W.J., "Multi-Scale Investigation of the Performance of Limestone in Concrete," Construction and Building Materials, 75, 1-10, 2015.

20) Bentz, D.P., Tanesi, J., and Ardani, A., "Ternary Blends for Controlling Cost and Carbon Content," Concrete International, 35 (8), 51-59, 2013.

21) Bentz, D.P., Barrett, T., de la Varga, I., and Weiss, W.J., "Relating Compressive Strength to Heat Release in Mortars," Advanced Civil Engineering Materials, 1 (1), 1-14, 2012, doi:10.1520/ACEM20120002.

22) Bremner, T., and Holm, T., "Elastic Compatibility and the Behavior of Concrete," ACI Materials Journal, 83 (2), 244-250, 1986.

23) Aitcin, P.-C., and Mehta, P., "Effect of Coarse Aggregate Characteristics on Mechanical Properties of High-Strength Concrete," ACI Materials Journal, 87 (2), 103-107, 1990.

24) Neville, A., "Aggregate Bond and Modulus of Elasticity of Concrete," ACI Materials Journal, 94 (1), 71-74, 1997.

25) Sengul, O., Tasdemir, C., and Tasdemir, M., "Influence of Aggregate Type of Mechanical Behavior of Normal- and High-Strength Concretes," ACI Materials Journal, 99 (6), 528-533, 2002.

26) Swamy, R., "Aggregate-Matrix Interaction in Concrete Systems," Solids Mechanics and Engineering Design in Civil Engineering Materials, 301-315, 1969.

27) Bloem, D.L. and Gaynor, R.D., "Effects of Aggregate Properties on Strength of Concrete," ACI Journal, Proceedings, 60 (10), 1429-1456, 1963.

28) ASTM International, ASTM C29-09 Standard Test Method for Bulk Density ("Unit Weight") and Voids in Aggregate, ASTM International, West Conshohocken, PA, 5 pp., 2009.

29) ASTM International, ASTM C127-12 Standard Test Method for Relative Density, Relative Density (Specific Gravity), and Absorption of Coarse Aggregate, ASTM International, West Conshohocken, PA, 6 pp., 2012.

30) Masad, E., “Aggregate Imaging System (AIMS): Basics and Applications,” Report FHWA/TX-05/51707-01-1, Department of Transportation, 2005.

31) Gates, L., Masad, E., Pyle, R., and Bushee, F., “Aggregate Imaging Measurements System 2 (AIMS2): Final Report,” FHWA-HIG-11-030, FHWA, Department of Transportation, 2011.

32) AASHTO, AASHTO TP81-12 Determining Aggregate Shape Properties by Means of Digital Image Analysis, American Association of State and Highway Transportation Officials, 2012.

33) ASTM International, ASTM C295/C295M-12 Standard Guide for Petrographic Examination of Aggregates for Concrete, ASTM International, West Conshohocken, PA, 9 pp., 2012.

34) ASTM International, ASTM C1679-14 Standard Practice for Measuring Hydration Kinetics of Hydraulic Cementitious Mixtures Using Isothermal Calorimetry, ASTM International, West Conshohocken, PA, 15 pp., 2014.

35) Lawrence, C.D., "Changes in Composition of Aqueous Phase during Hydration of Cement Pastes and Suspensions," in Proceedings of a Symposium on the Structure of Portland Cement Paste and Concrete, Highway Research Board, Special Report 90, Washington, D.C., 378-391, 1966. 
36) AASHTO, AASHTO T22-14 Standard Method of Test for Compressive Strength of Cylindrical Concrete Specimens, American Association of State and Highway Transportation Officials, 2014.

37) AASHTO, AASHTO T336-15 Standard Method of Test for Coefficient of Thermal Expansion of Hydraulic Cement Concrete, American Association of State and Highway Transportation Officials, 2015.

38) ASTM International, ASTM D7012-14 Standard Test Methods for Compressive Strength and Elastic Moduli of Intact Rock Core Specimens under Varying States of Stress and Temperatures, ASTM International, West Conshohocken, PA, 9 pp., 2014.

39) ASTM International, ASTM D3967-08 Standard Test Method for Splitting Tensile Strength of Intact Rock Core Specimens, ASTM International, West Conshohocken, PA, 4 pp., 2008.

40) ASTM International, ASTM C215-14 Standard Test Method for Fundamental Transverse, Longitudinal, and Torsional Resonant Frequencies of Concrete Specimens, ASTM International, West Conshohocken, PA, 7 pp., 2014.

41) ASTM International, ASTM C1259-14 Standard Test Method for Dynamic Young's Modulus, Shear Modulus, and Poisson's Ratio for Advanced Ceramics by Impulse Excitation of Vibration, ASTM International, West Conshohocken, PA, 17 pp. 2014.

42) Boulange, L., and Sterczynskia, F., "Study of the Interaction between Bitumen and Various Aggregates Used in Road Construction," Journal of Adhesion Science and Technology, Vol. 26 (1-3), 163-173, 2012.

43) National Institute of Standards and Technology, Certificate of Analysis, Standard Reference Material 738, Stainless Steel (AISI 446), Thermal Expansion, 1993 (revision of certificate dated 11-17-86).

44) National Institute of Standards and Technology, Certificate, Standard Reference Material 731, Borosilicate Glass, Thermal Expansion, 1993 (revision of certificate dated 7-31-72).

45) ASTM International, ASTM C150/C150M-15 Standard Specification for Portland Cement, ASTM International, West Conshohocken, PA, 9 pp., 2015.

46) ASTM International, ASTM C618-15 Standard Specification for Coal Fly Ash and Raw or Calcined Natural Pozzolan for Use in Concrete, ASTM International, West Conshohocken, PA, 5 pp., 2015.

47) ACI, ACI 211.1-91: Standard Practice for Selecting Proportions for Normal, Heavyweight, and Mass Concrete (Reapproved 2009), American Concrete Institute, Farmington Hills, MI, 2009.

48) ASTM International, ASTM C192/C192M-15 Standard Practice for Making and Curing Concrete Test Specimens in the Laboratory, ASTM International, West Conshohocken, PA, 8 pp. 2015.

49) ASTM International, ASTM C1064/C1064M-12 Standard Test Method for Temperature of Freshly Mixed Hydraulic-Cement Concrete, ASTM International, West Conshohocken, PA, 3 pp., 2012.

50) ASTM International, ASTM C143/C143M-15 Standard Test Method for Slump of Hydraulic-Cement Concrete, ASTM International, West Conshohocken, PA, 4 pp., 2015.

51) ASTM International, ASTM C231/C231M-14 Standard Test Method for Air Content of Freshly Mixed Concrete by the Pressure Method, ASTM International, West Conshohocken, PA, 9 pp., 2014.

52) ASTM International, ASTM C138/C138M-14 Standard Test Method for Density (Unit Weight), Yield, and Air Content (Gravimetric) of Concrete, ASTM International, West Conshohocken, PA, 4 pp., 2014.

53) Bentz, D.P., Jones, S.Z., and Snyder, K.A., "Design and Performance of Ternary Blend High-Volume Fly Ash Concretes of Moderate Slump," Construction and Building Materials, 84, 409-415, 2015.

54) ASTM International, ASTM C1753-15 Standard Practice for Evaluating Early Hydration of Hydraulic Cementitious Mixtures Using Thermal Measurements, ASTM International, West Conshohocken, PA, 19 pp., 2015. 
55) ASTM International, ASTM C39/C39M-15 Standard Test Method for Compressive Strength of Cylindrical Concrete Specimens, ASTM International, West Conshohocken, PA, 7 pp., 2015.

56) ASTM International, ASTM C469/C469M-14 Standard Test Method for Static Modulus of Elasticity and Poisson's Ratio of Concrete in Compression, ASTM International, West Conshohocken, PA, 5 pp., 2014.

57) ASTM International, ASTM C496/C496M-11 Standard Test Method for Splitting Tensile Strength of Cylindrical Concrete Specimens, ASTM International, West Conshohocken, PA, 5 pp., 2011.

58) ASTM International, ASTM C78/C78M-15b Standard Test Method for Flexural Strength of Concrete (Using Simple Beam with Third-Point Loading), ASTM International, West Conshohocken, PA, 4 pp., 2015.

59) AASHTO, AASHTO T-358 Standard Method of Test for Surface Resistivity Indication of Concrete's Ability to Resist Chloride Ion Penetration, American Association of State Highway Transportation Officials, 2015.

60) Blattner, T., et. al., "A Hybrid CPU-GPU System for Stitching of Large Scale Optical Microscopy Images," 2014 International Conference on Parallel Processing, Minneapolis, MN, 2014.

61) Tanesi, J., Crawford, G., Nicolaescu, M., Meininger, R., and Gudimettla, J., "New AASHTO 336-09 Coefficient of Thermal Expansion Test Method: How Will It Affect You?" Transportation Research Record: Journal of the Transportation Research Board, No. 2164, Transportation Research Board of National Academies, Washington, D.C., 2010.

62) Bentz, D.P., Snyder, K.A., and Ahmed, A., "Anticipating the Setting Time of High-Volume Fly Ash Concretes Using Electrical Measurements: Feasibility Studies Using Pastes," Journal of Materials in Civil Engineering, 27 (3), 04014129-1-6, 2015.

63) Shannon, J., Howard, I., and Cost, V., "Potential of Portland-Limestone Cement to Improve Performance of Concrete Made with High Slag Cement and Fly Ash Replacement Rates," ASTM Journal of Testing and Evaluation, 45 (3), 1-17, 2017.

64) Shannon, J., Howard, I., Cost, V., and Wilson, W., "Benefits of Portland-Limestone Cement for Concrete with Round Gravel Aggregates and Higher Fly Ash Replacement Rates," TRB 94 ${ }^{\text {th }}$ Annual Meeting Compendium of Papers, Report \#15-4049, 17 pp., 2015.

65) American Concrete Institute and International Organization for Standardization, ACI 318-14: Building Code Requirements for Structural Concrete and Commentary, ACI, Farmington Hills, MI, 2014.

66) American Concrete Institute and International Organization for Standardization, ACI 363R-10: Report on High-Strength Concrete, ACI, Farmington Hills, MI, 2010.

67) Morris, W., Moreno, E.I., and Sagüés, A.A., "Practical Evaluation of Resistivity of Concrete in Test Cylinders Using a Wenner Array Probe," Cement and Concrete Research, 26 (12), 1779-1787, 1996.

68) Jones, S.Z., Bentz, D.P., Snyder, K.A., Martys, N.S., Hussey, D.S., and Jacobson, D.L., "Service Life Modeling of Reinforced High Volume Fly Ash (HVFA) Concrete Structures Containing Cracks," Proceedings International Concrete Sustainability Conference, Miami, FL, 15 pp., May 2015.

69) Vegard, L., "Die Konstitution der Mischkristalle und die Raumfüllung der Atome," Zeitschrift für Physik, 5, 17-26, 1921.

70) Hefer, A., and Little, D., "Adhesion in Bitumen-Aggregate Systems and Quantification of the Effects of Water on the Adhesive Bond," Research Report ICAR-505-1, 205 p., 2005.

71) Miller, C.M., "Adhesion and the Surface Energy Components of Natural Minerals and Aggregates," Ph.D., Texas A\&M University, 2010. 
72) Lyne, Å.L., Krivosheeva, O., and Birgisson, B., "Adhesion Between Bitumen and Aggregate: Implementation of Spectroscopic Ellipsometry Characterization and Estimation of Hamaker's Constant," Materials and Structures, 46 (10), 1737-1745, 2013.

73) Jones, D.R., SHRP Materials Reference Library: Asphalt Cements: A Concise Data Compilation. Vol. 1. Washington, D.C.: Strategic Highway Research Program, National Research Council, 1993.

74) Brand, A.S., and Roesler, J.R., "Bonding in Cementitious Materials with Asphalt-Coated Particles: Part I - The Interfacial Transition Zone," Construction and Building Materials, 130, 171-181, 2017.

75) Brand, A.S., and Roesler, J.R., "Bonding in Cementitious Materials with Asphalt-Coated Particles: Part II - Cement-Asphalt Chemical Interactions," Construction and Building Materials, 130, 182-182, 2017.

76) Bentz, D.P., "Activation Energies of High-Volume Fly Ash Ternary Blends: Hydration and Setting," Cement and Concrete Composites, 53, 214-223, 2014.

77) Matschei, T., Lothenbach, B., and Glasser, F.P., "The Role of Calcium Carbonate in Cement Hydration," Cement and Concrete Research, 37 (4), 551-558, 2007.

78) Loser, R., Münch, B., and Lura, P., "A Volumetric Technique for Measuring the Coefficient of Thermal Expansion of Hardening Cement Paste and Mortar," Cement and Concrete Research, 40 (7), 1138-1147, 2010.

79) Mindess, S., Young, J.F., and Darwin, D., Concrete, $2^{\text {nd }}$ edition, Pearson, New York, 2002. 


\section{Appendix A. Aggregate Reactivity as AsSesSed by ISOTHERMAL CALORIMETRY AND ICP-AES ANALYSIS}

Al

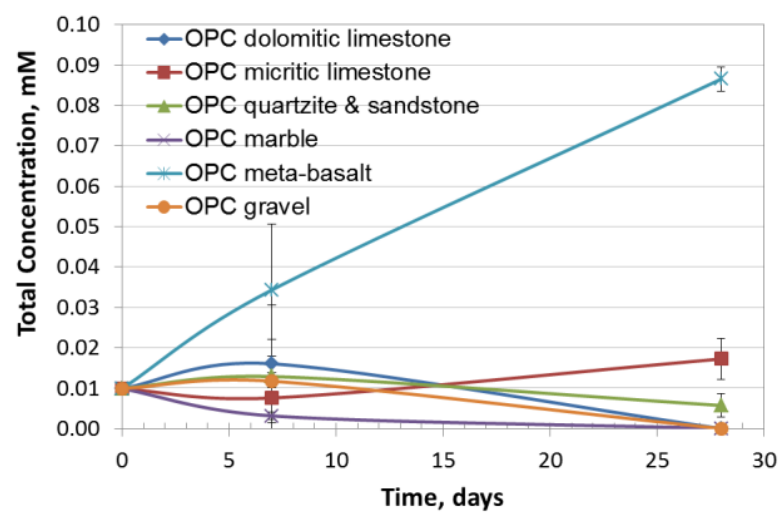

$\mathrm{Ca}$

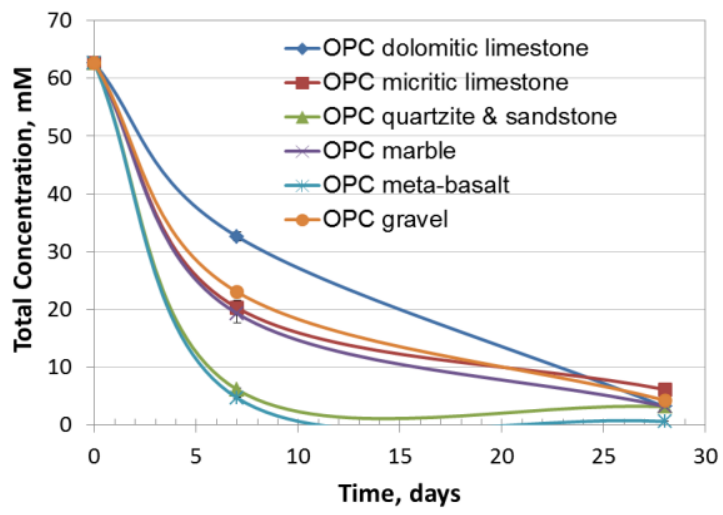

K

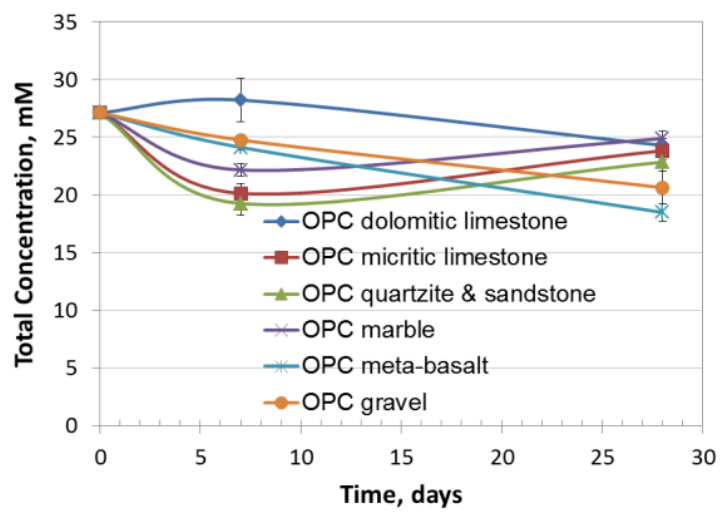

Al

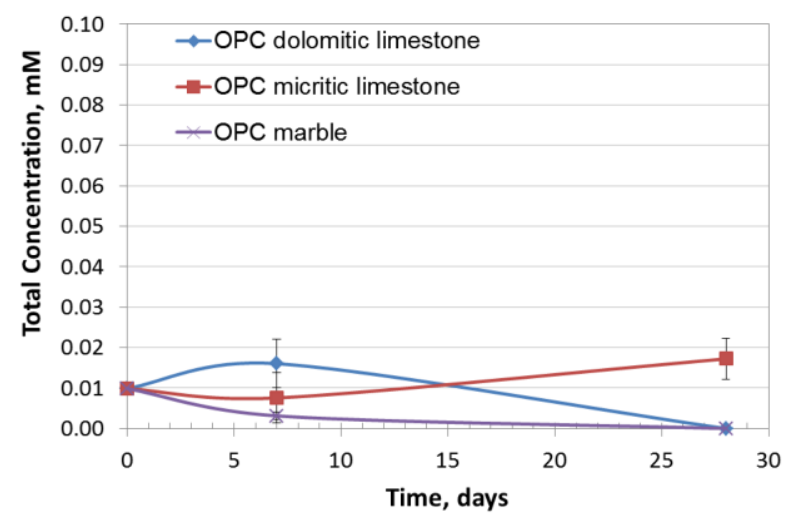

$\mathrm{Ca}$

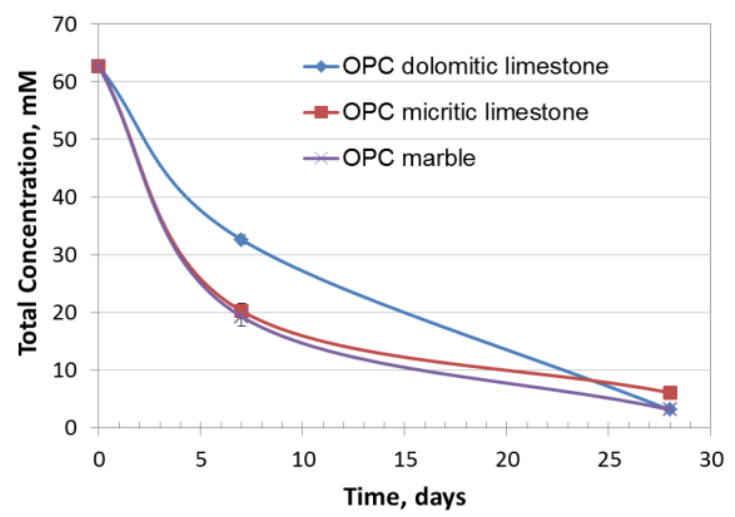

K

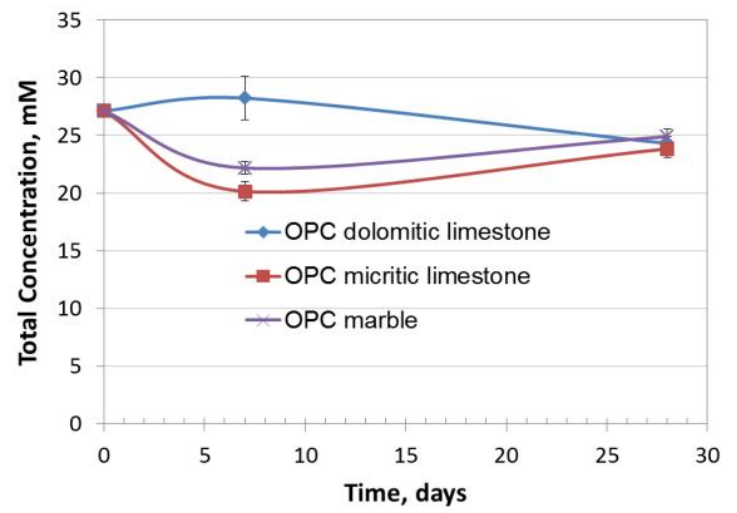


$\mathrm{Na}$

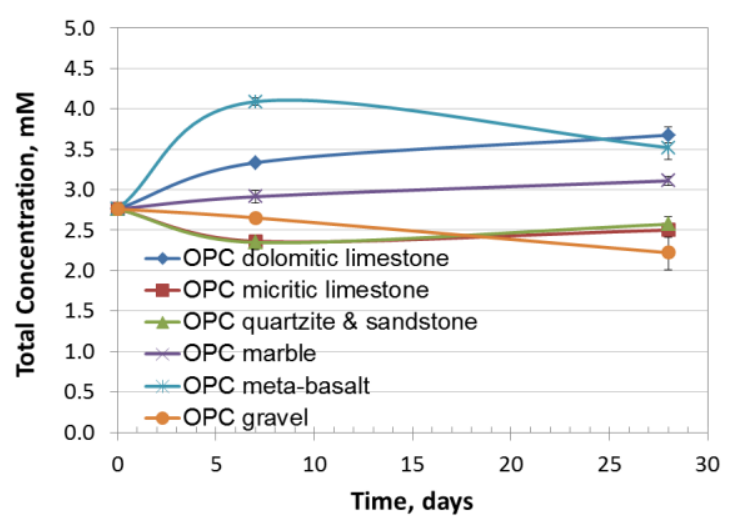

S

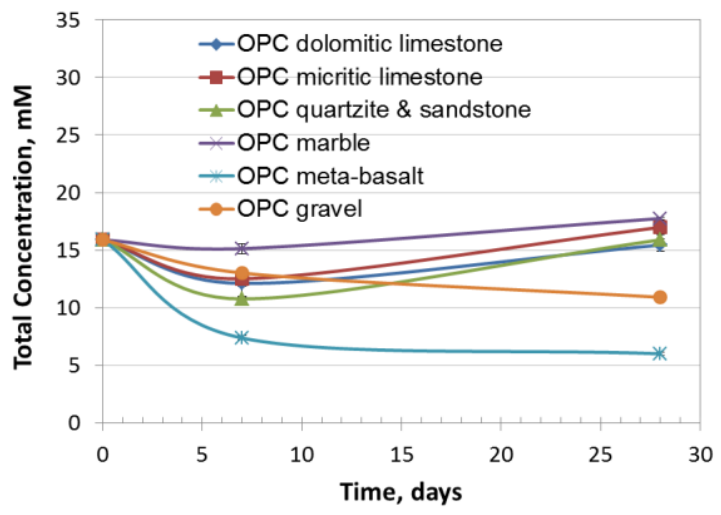

Si

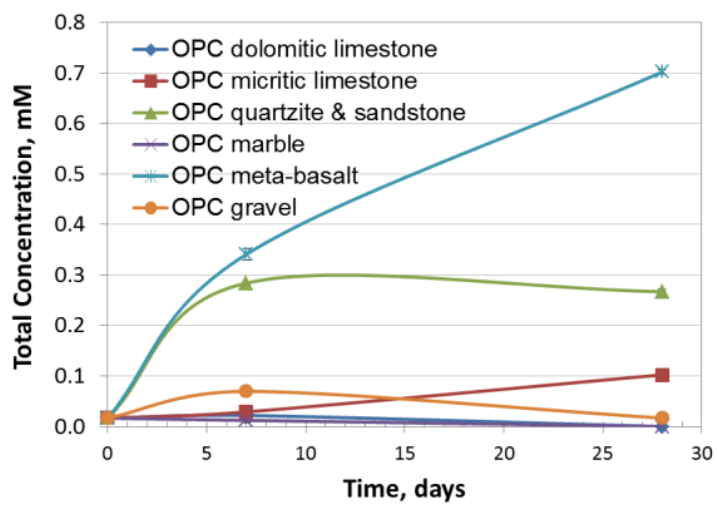

$\mathrm{Na}$

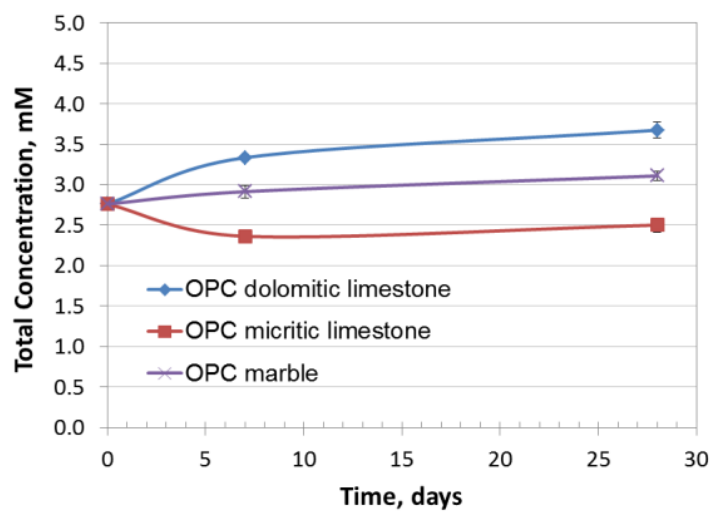

S

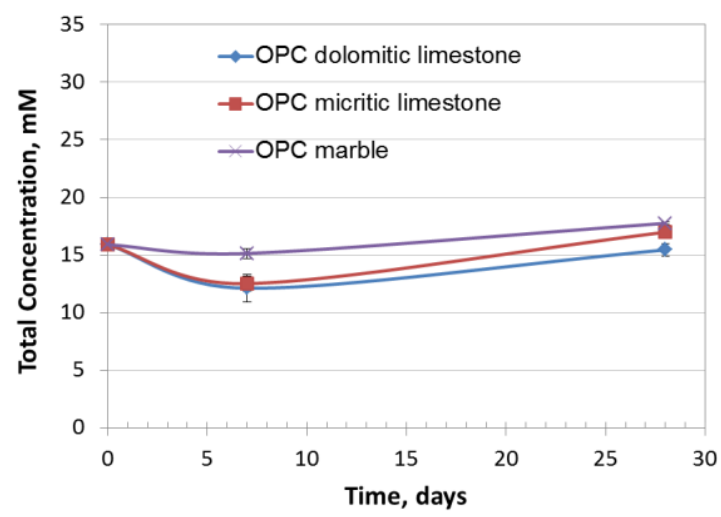

Si

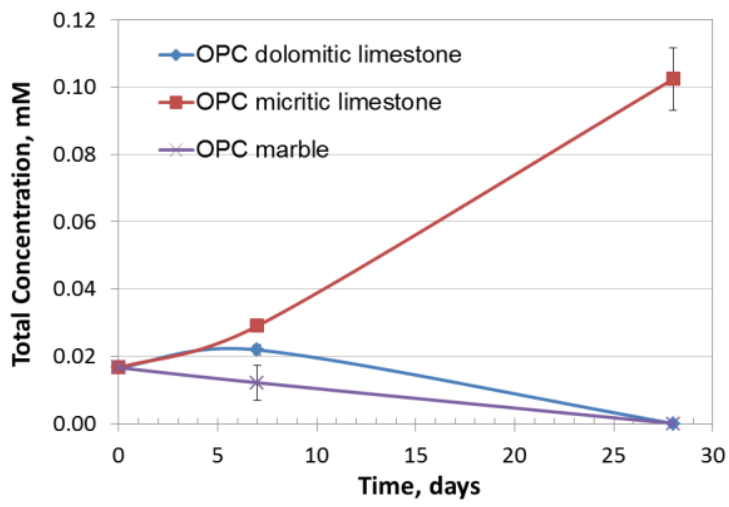

Figure 38. Ion concentrations in solutions exposed to aggregates over time. Charts on the left show all the OPC mixtures tested, while charts on the right show only the carbonate aggregates exposed to OPC solutions. Error bars indicate one standard deviation for three replicate specimens. 
Al

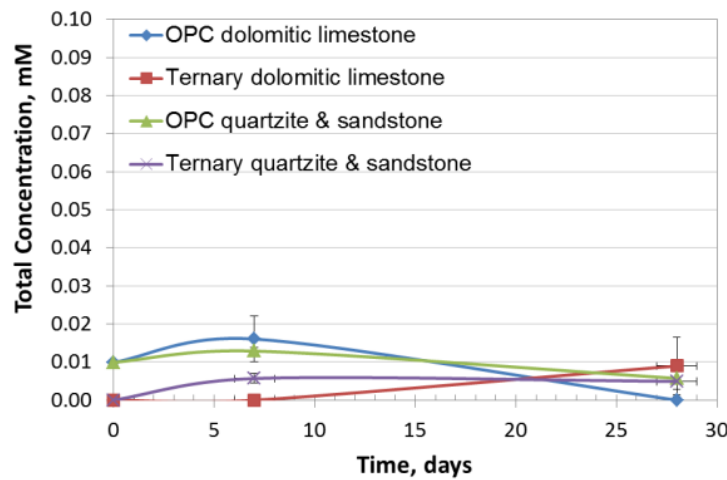

$\mathbf{K}$

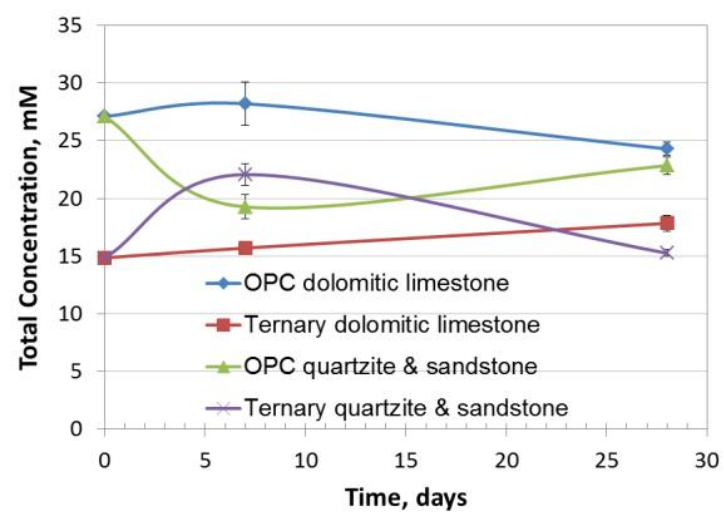

S

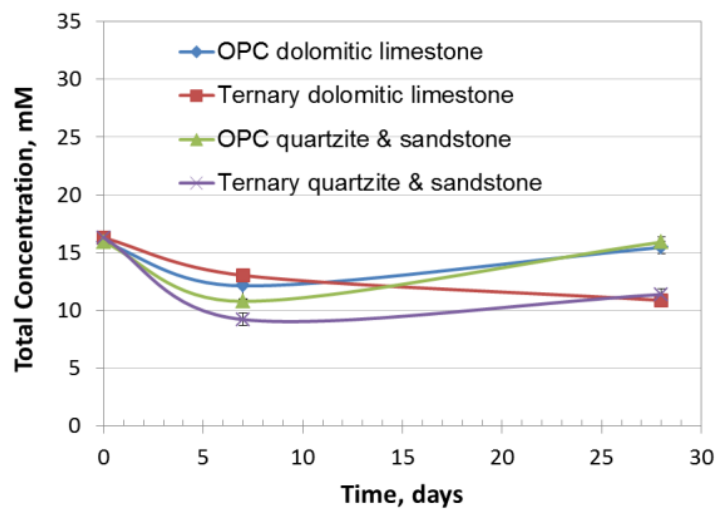

Ca

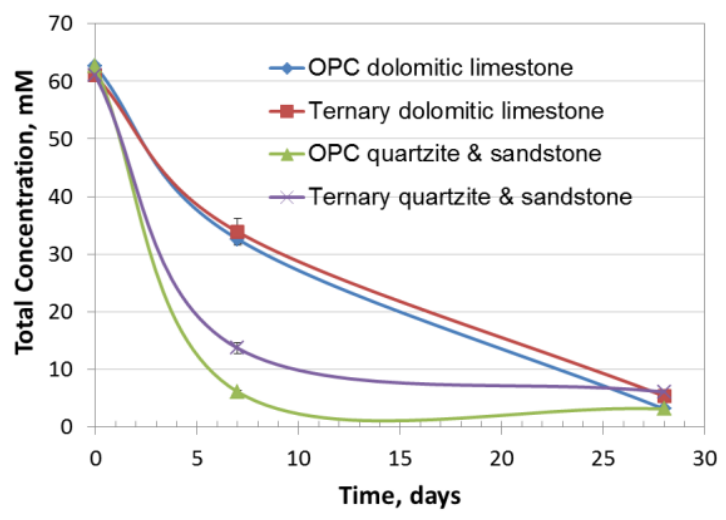

$\mathrm{Na}$

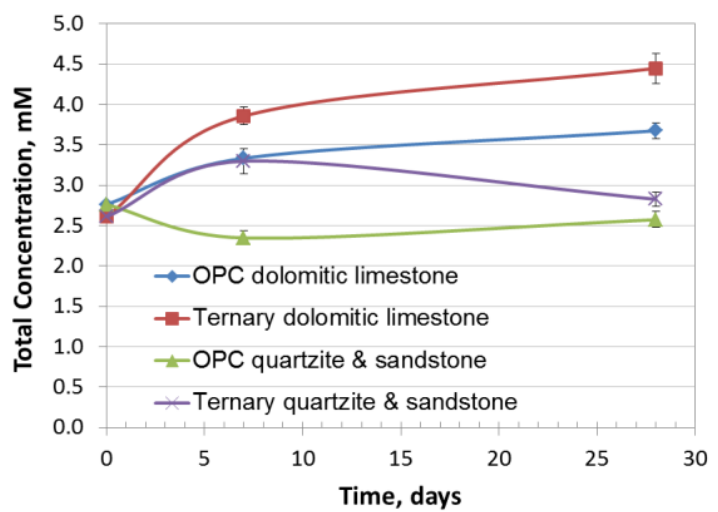

Si

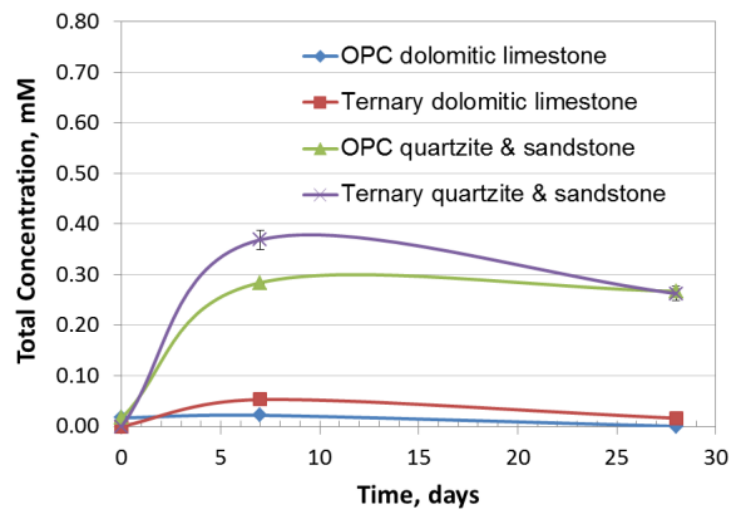

Figure 39. Ion concentrations in OPC and ternary solutions that have been exposed to aggregates over time. Error bars indicate one standard deviation for three replicate specimens. 
(a)

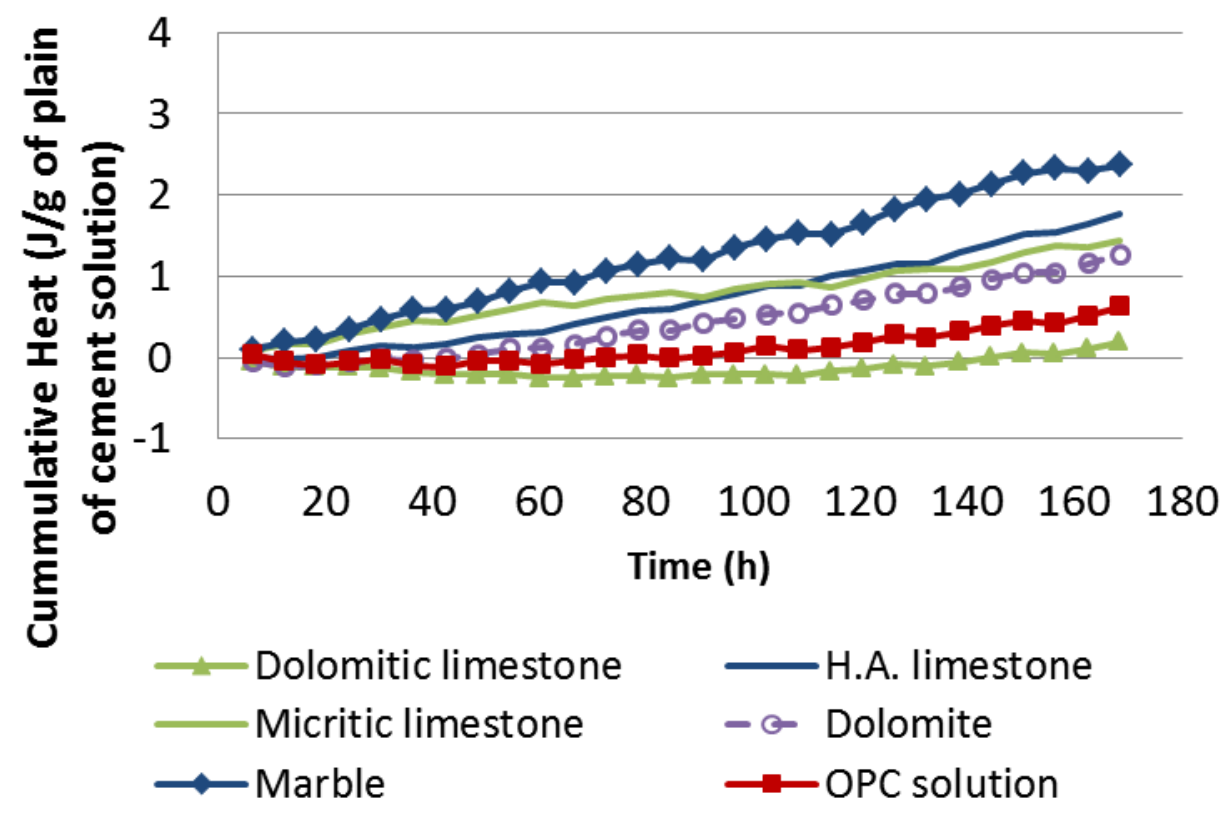

(b)

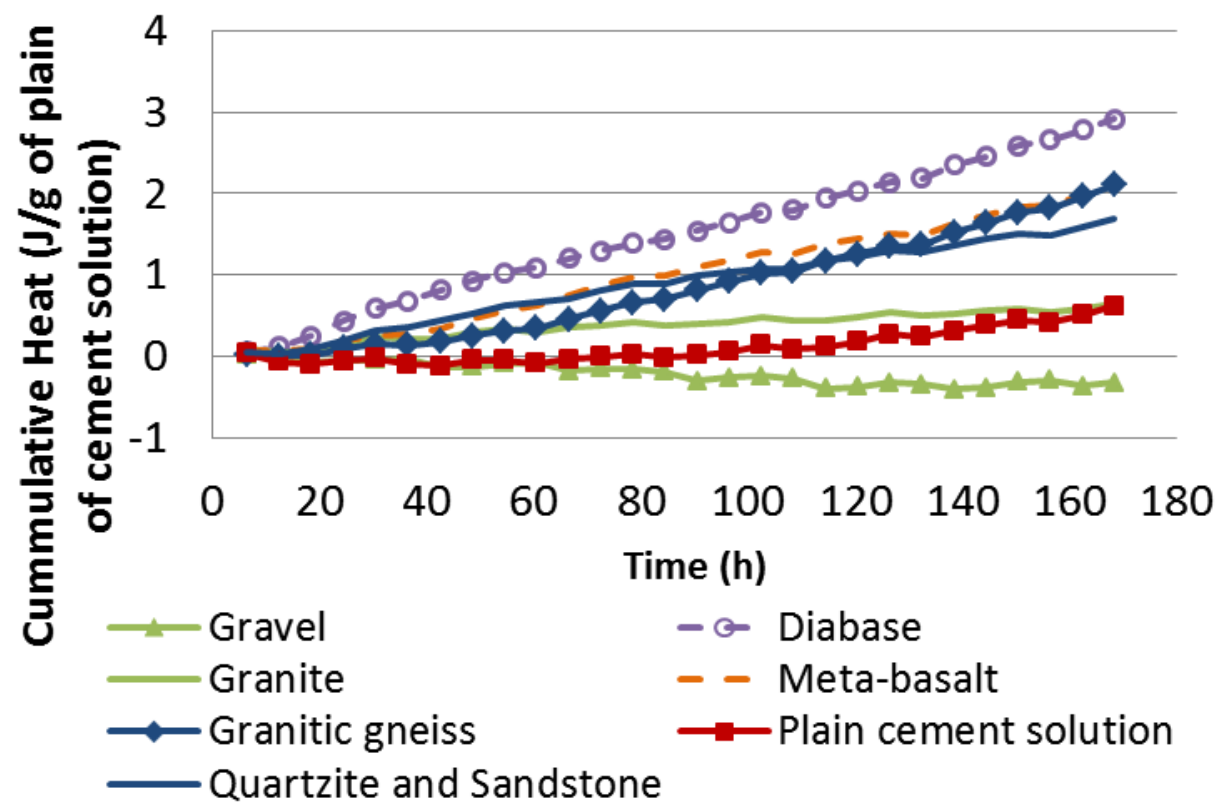

Figure 40. Cumulative heat over time of aggregates in OPC pore solution (a) carbonate aggregates and (b) non-carbonate aggregates. 
(a)
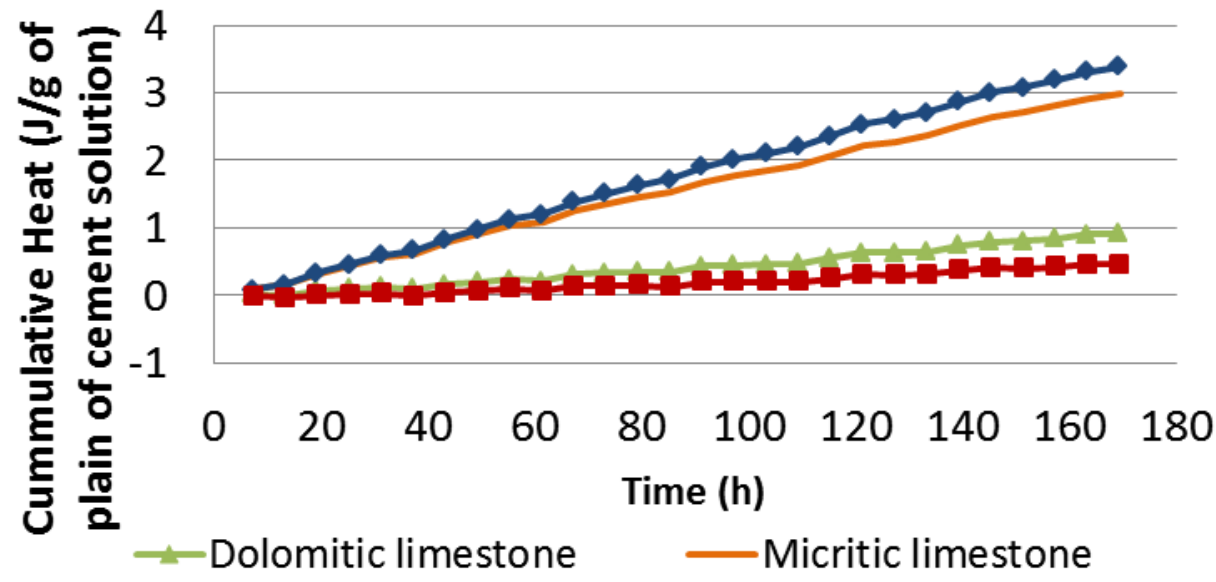

Micritic limestone

$\rightarrow$ Marble

$\rightarrow-T e r n a r y$ cement solution

(b)

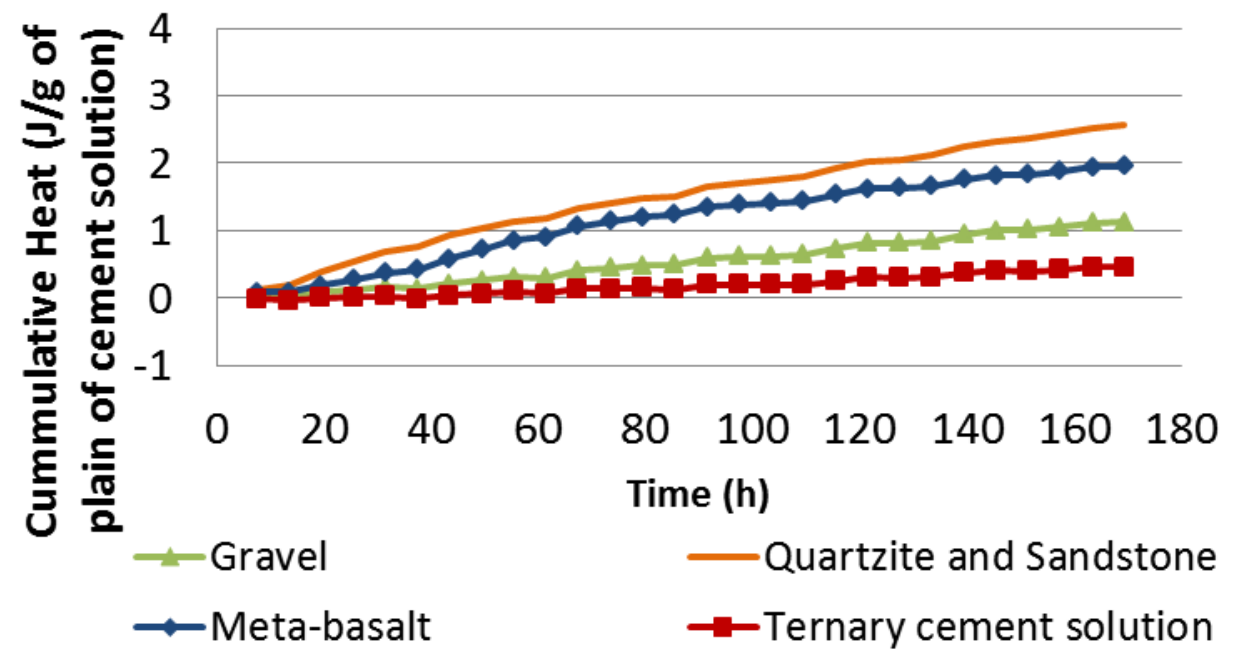

Figure 41. Cumulative heat over time of aggregates in ternary pore solution (a) carbonate aggregates and (b) non-carbonate aggregates. 


\section{APPENDix B. Plots OF 28-D COMPRESSive Strength VS. Individual Aggregate Characteristics}

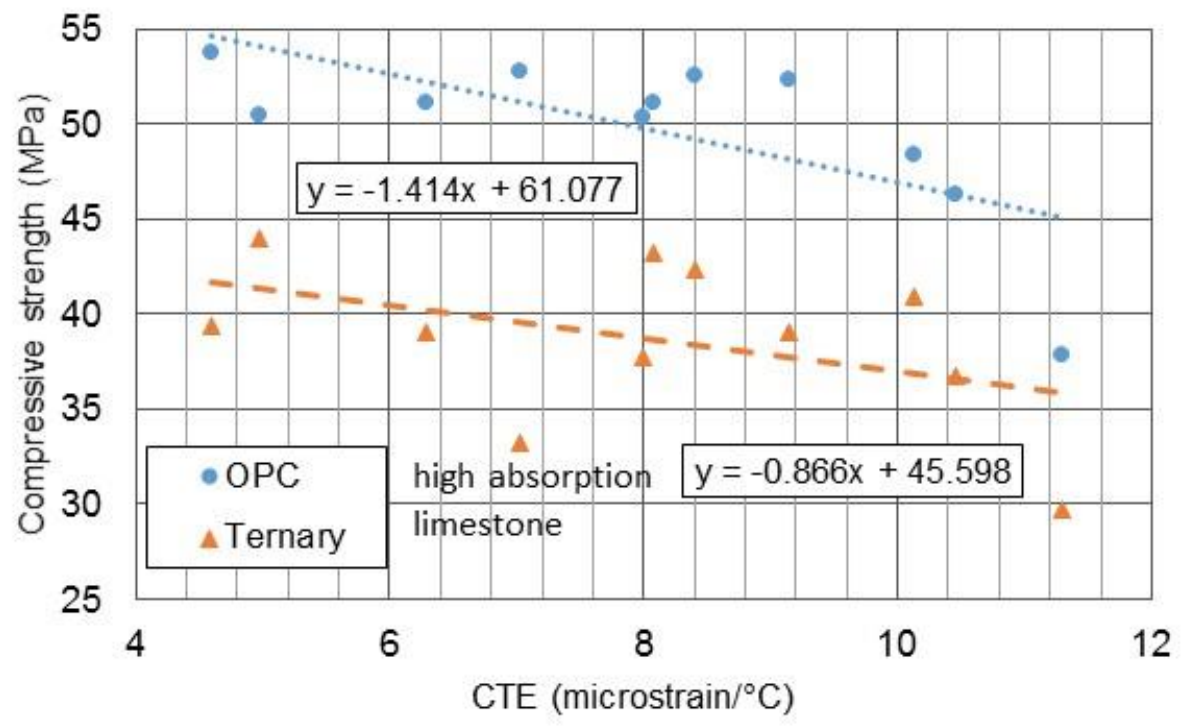

Figure 42. 28-d compressive strength vs. aggregate coefficient of thermal expansion (CTE) of the 11 aggregates for the OPC and ternary blend concretes.

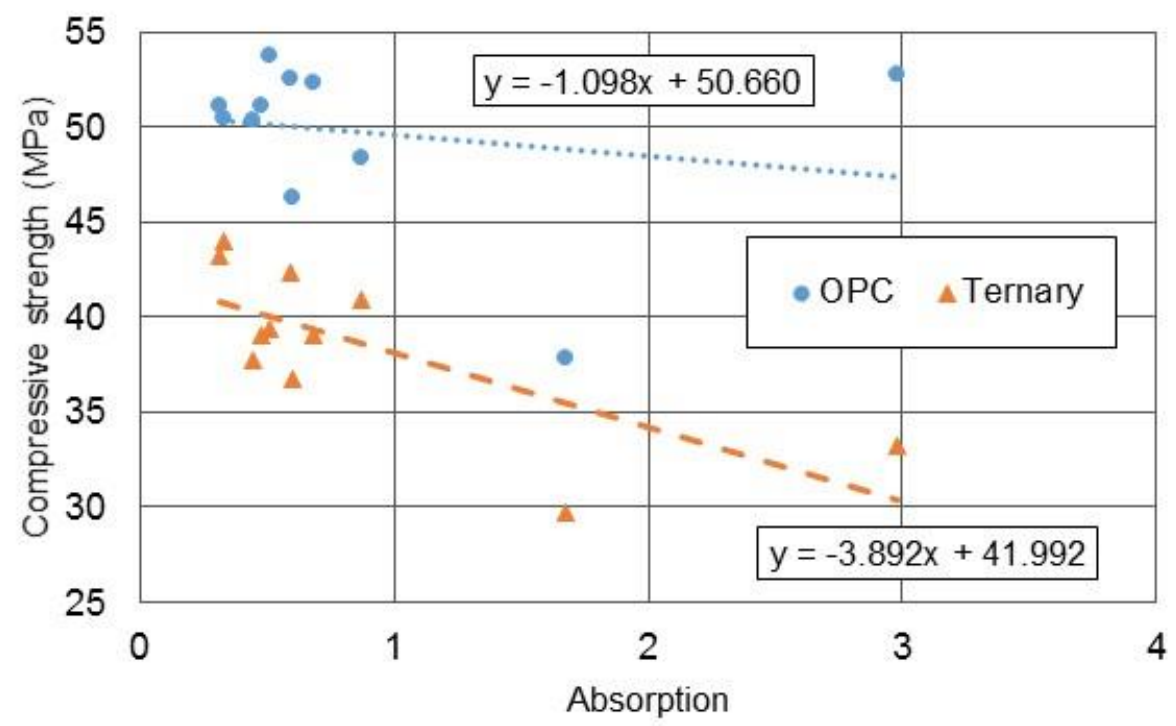

Figure 43. 28-d compressive strength vs. absorption of the 11 aggregates for the OPC and ternary blend concretes. 


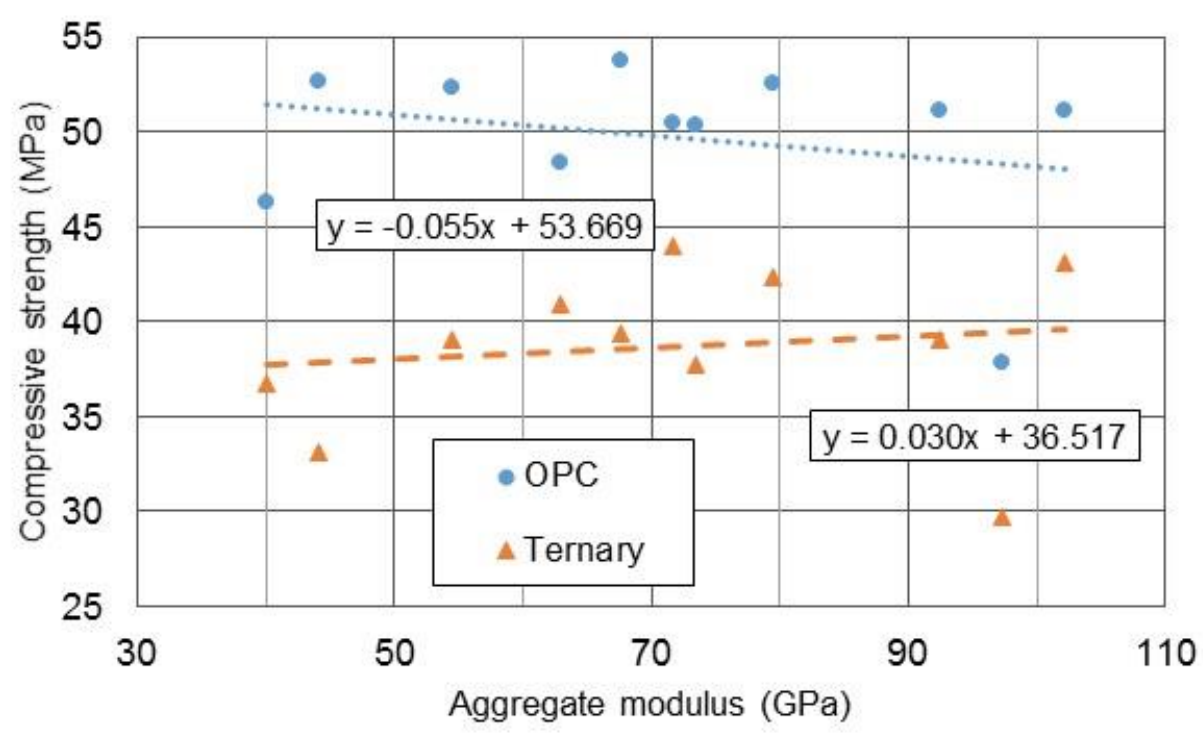

Figure 44. 28-d compressive strength vs. aggregate elastic modulus of the 11 aggregates for the OPC and ternary blend concretes.

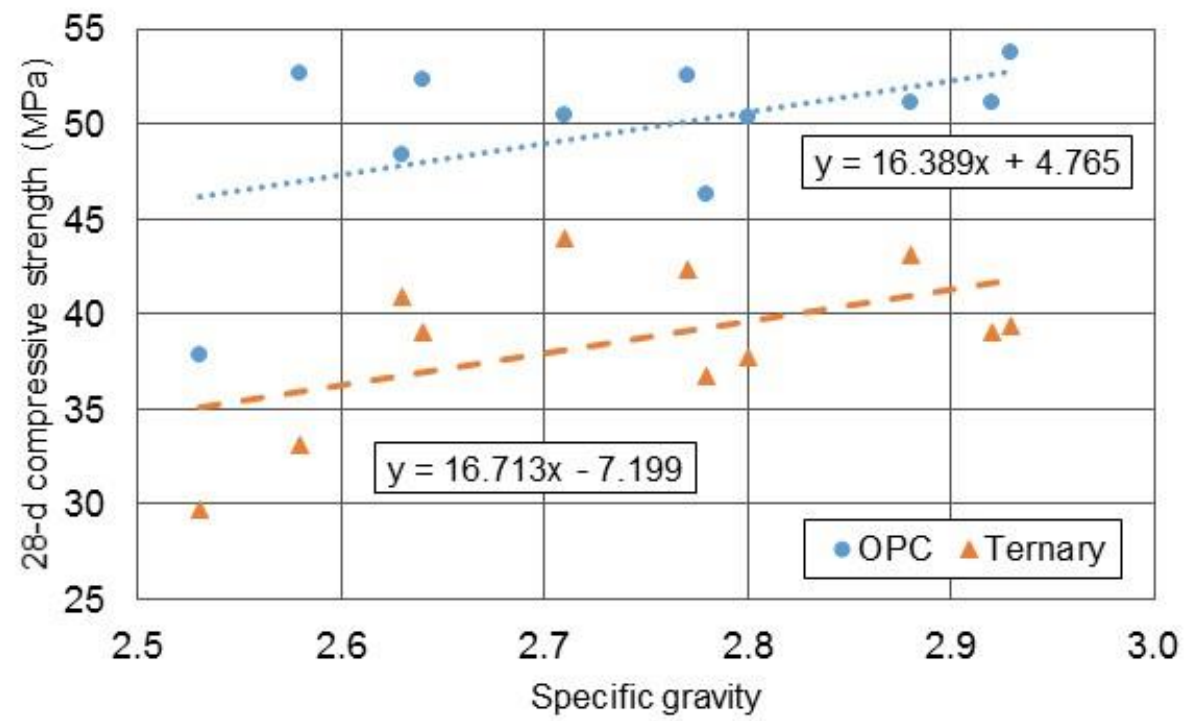

Figure 45. 28-d compressive strength vs. specific gravity of the 11 aggregates for the OPC and ternary blend concretes. Standard errors are 4.06 MPa and 3.81 MPa for OPC and ternary blends, respectively. 

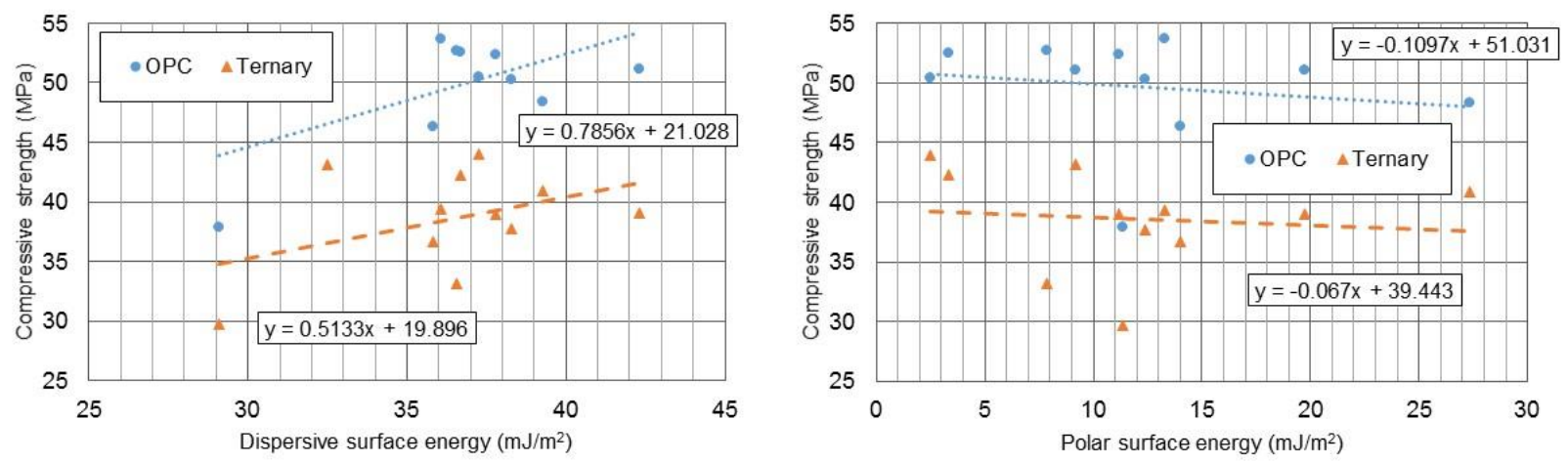

Figure 46. 28-d compressive strength vs. aggregate surface energy, dispersive (left) and polar (right) components, for the OPC and ternary blend concretes. Standard errors for linear fits in the case of dispersive surface energy are $3.73 \mathrm{MPa}$ and $4.1 \mathrm{MPa}$ for the OPC and ternary blends, respectively.
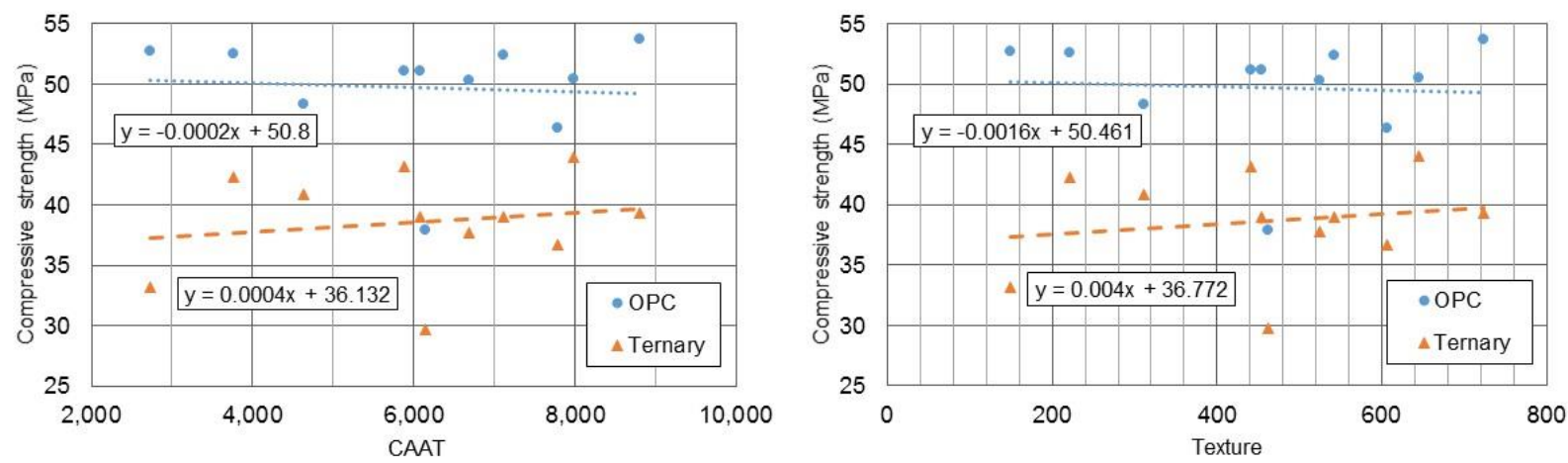

Figure 47. 28-d compressive strength vs. CAAT (left) and Texture (right) parameters from the AIMS analysis of each of the 11 aggregates for the OPC and ternary blend concretes. 


\section{APPENDIX C. REPRESENTATIVE SEM IMAgES FROM CONCRETE MiXTURES}

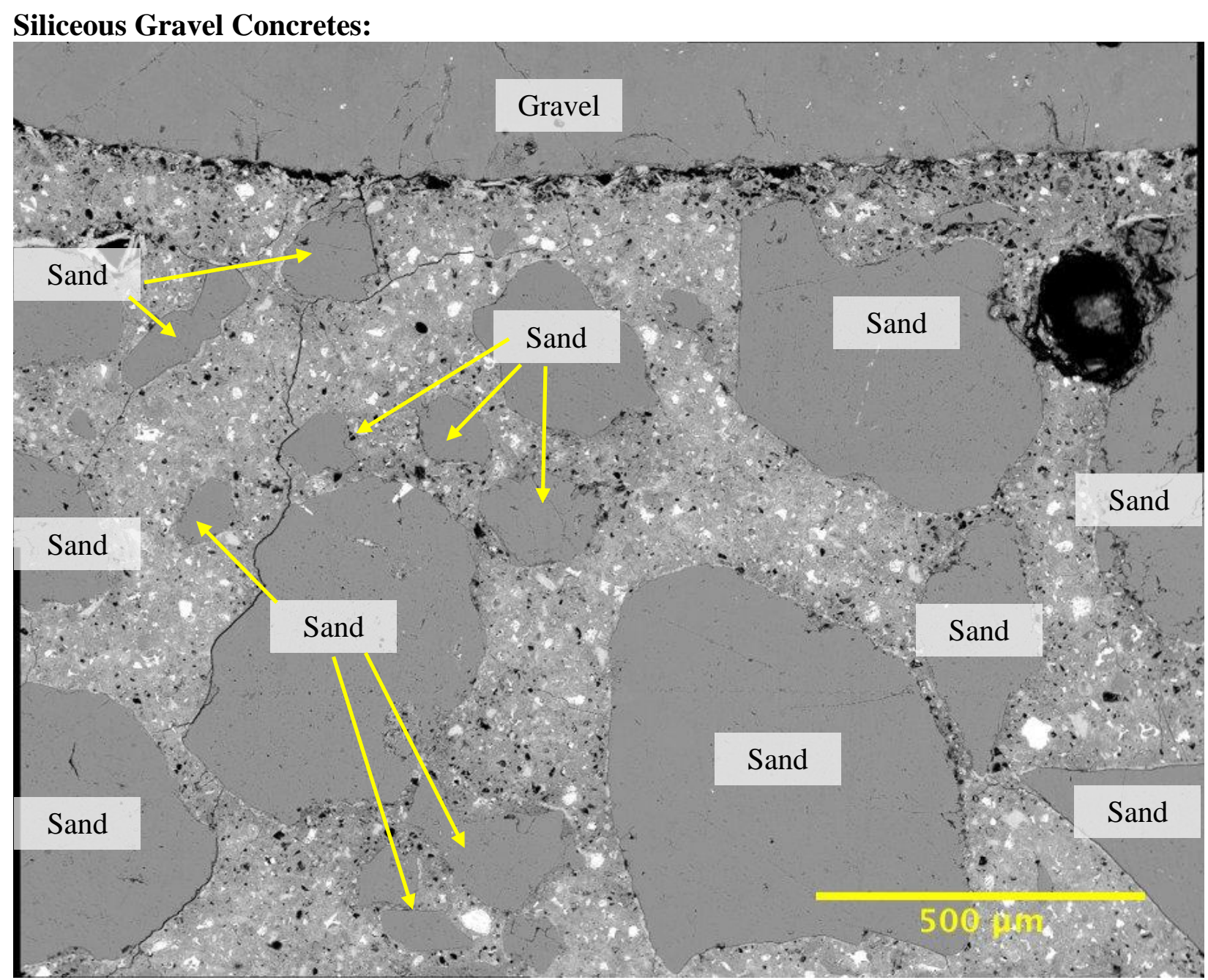

Figure 48. BE image for siliceous gravel concrete prepared with OPC.

Some localized "layers" of CH can be seen at the aggregate and sand grain surfaces, with a generally porous ITZ at the coarse aggregate surface (top). 


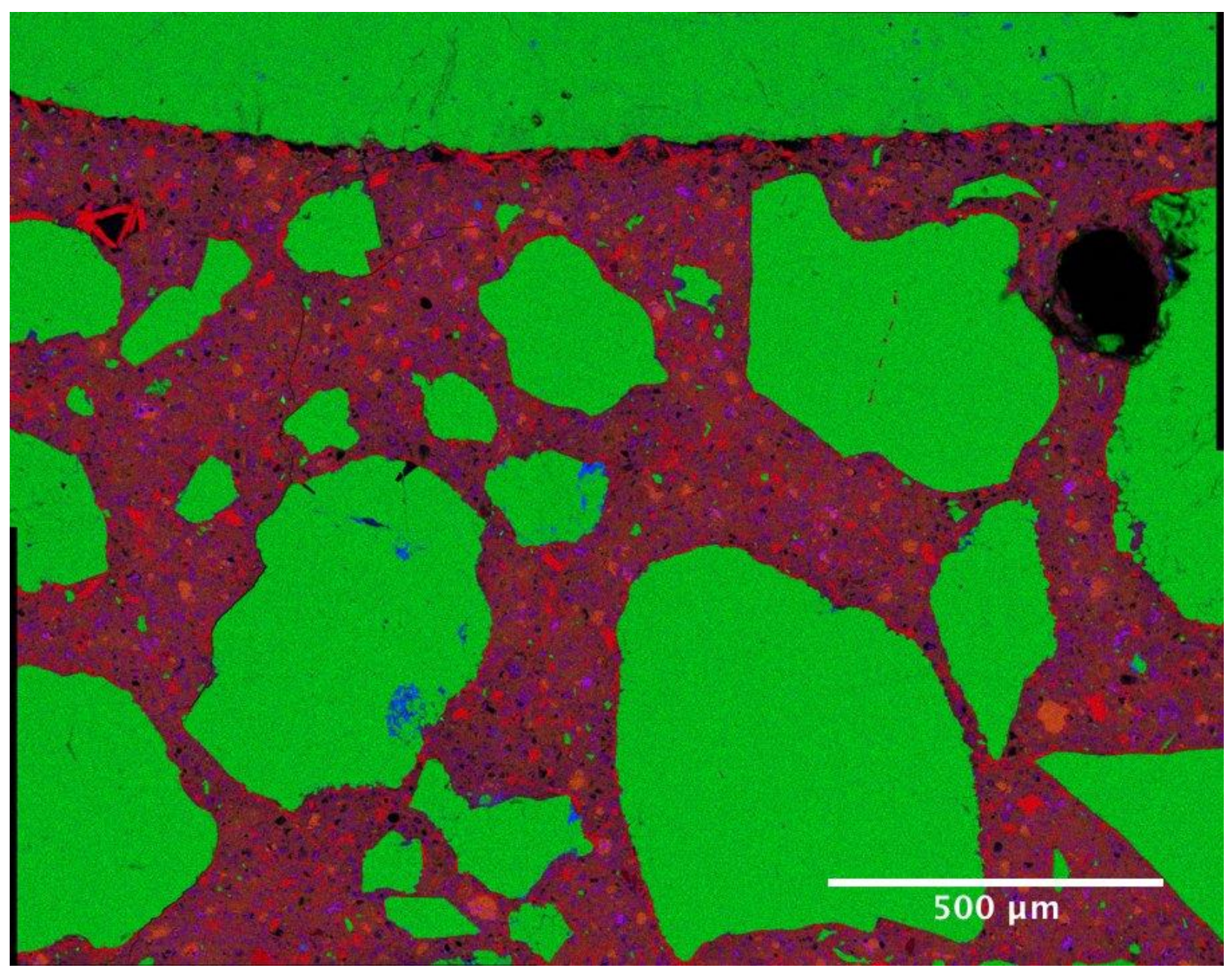

Figure 49. Ca-Si-Al RGB pseudo-color image for OPC siliceous gravel concrete.

$\mathrm{CH}$ is apparent as bright red inclusions within the paste, some localized at aggregate surfaces. 


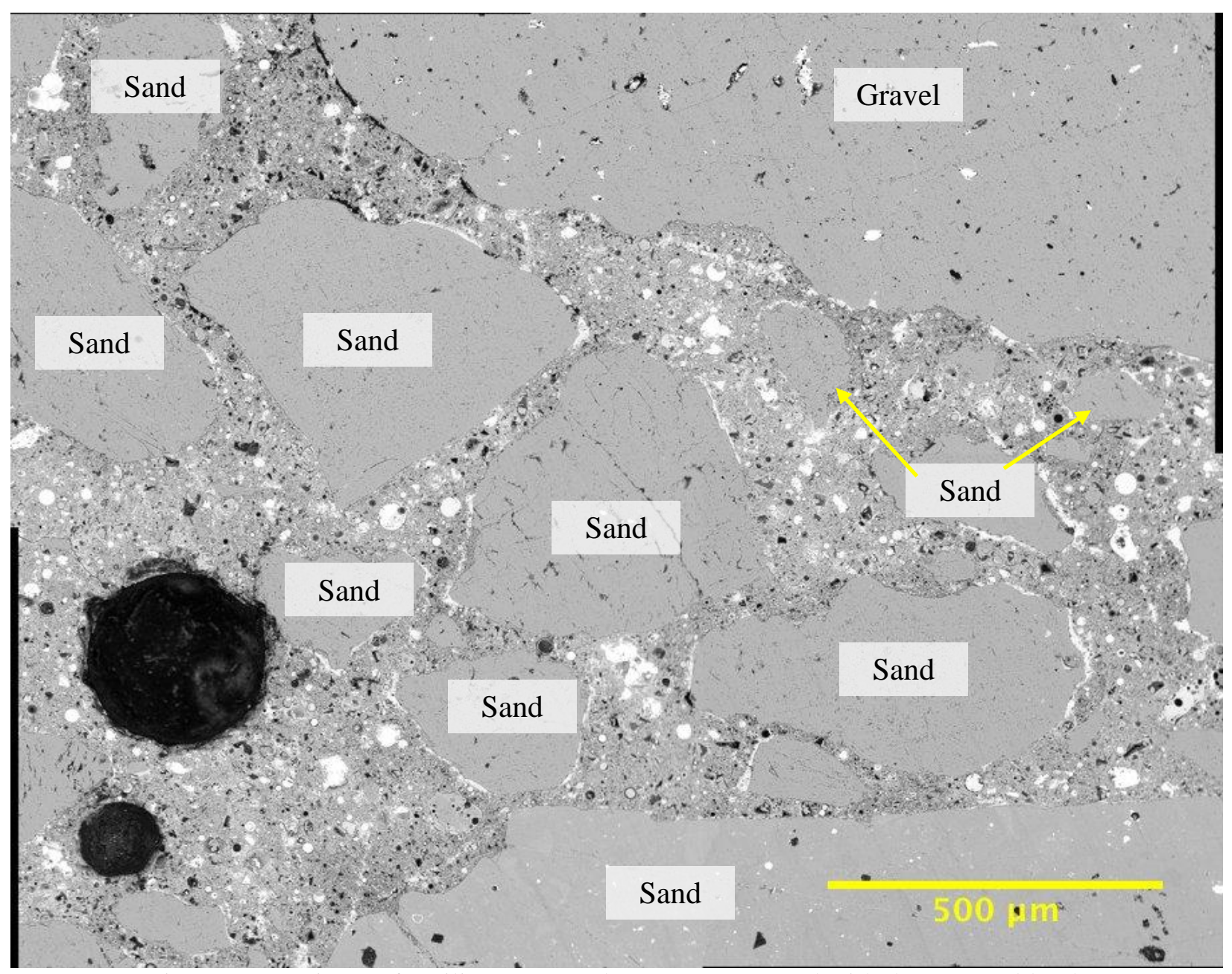

Figure 50. BE image for siliceous gravel concrete prepared with the ternary blend.

Many localized "layers" of $\mathrm{CH}$ are present at the aggregate surfaces, with some porous ITZ regions. 


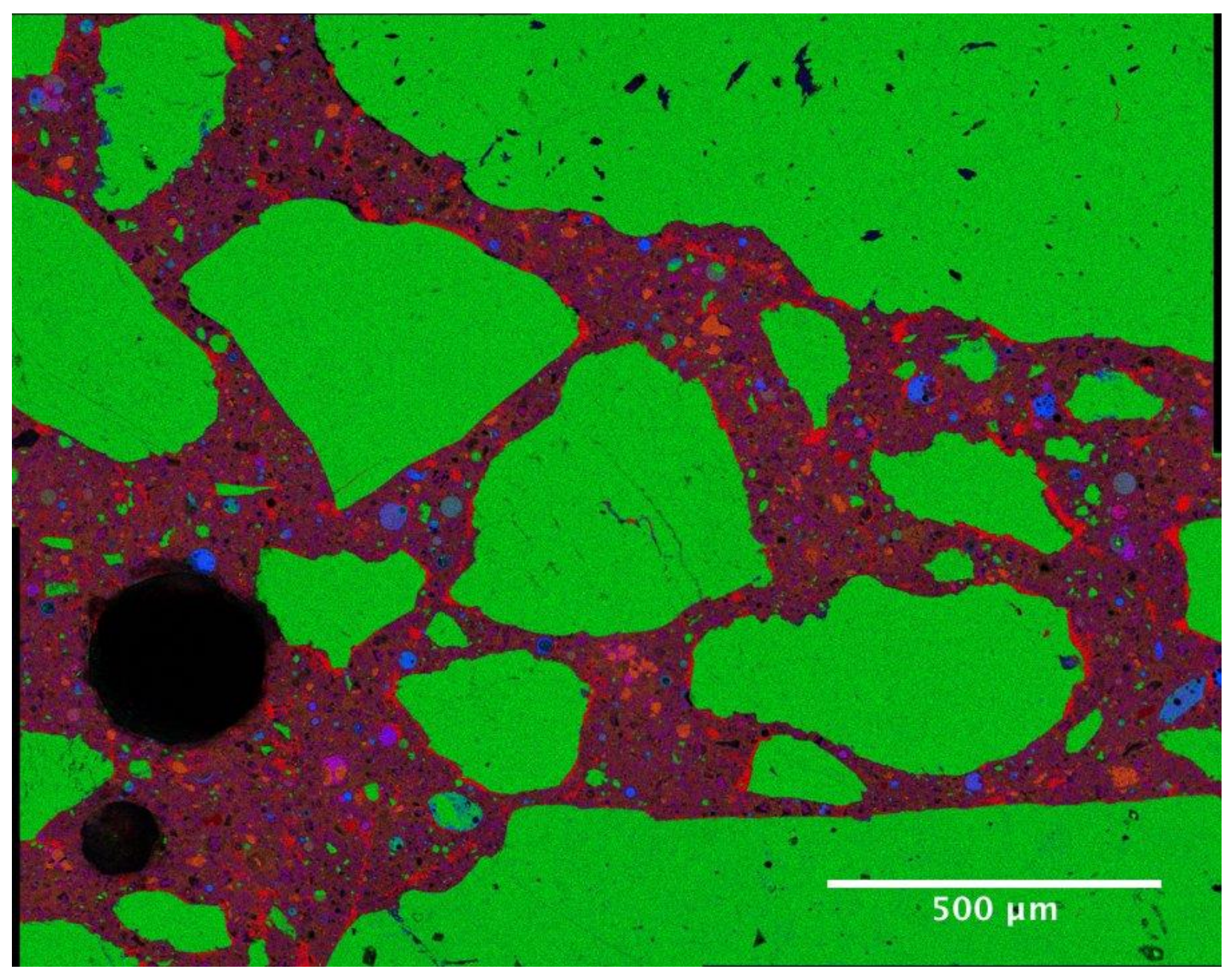

Figure 51. Ca-Si-Al RGB pseudo-color image for ternary blend siliceous gravel concrete.

$\mathrm{CH}$ is apparent as bright red inclusions in the paste, some localized at aggregate surfaces. Calcium aluminosilicate and aluminosilicate fly ash phases are visible as rounded purple and blue/green particles within the paste. 


\section{Dolomitic Limestone Concretes:}

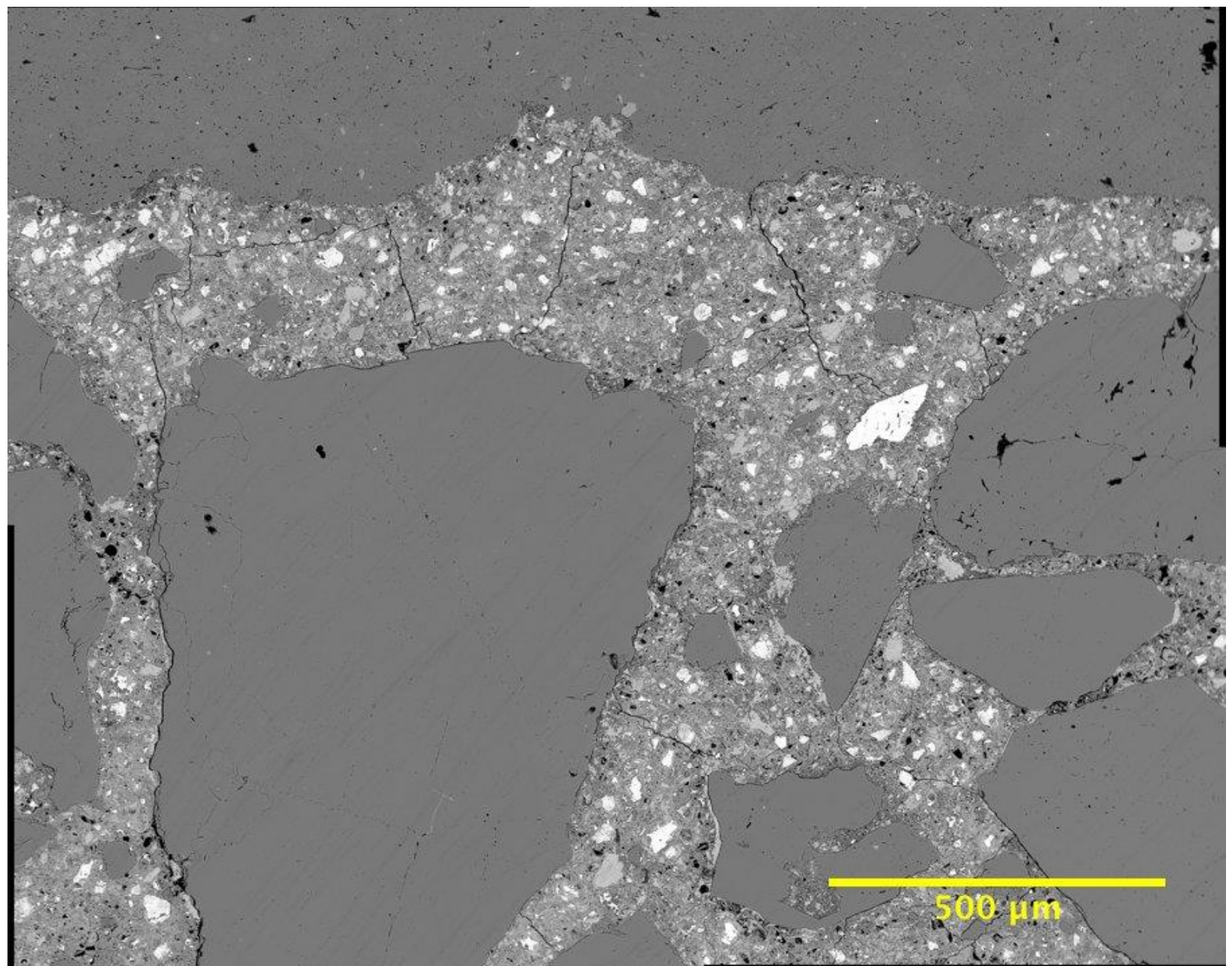

Figure 52. BE image for dolomitic limestone concrete prepared with OPC.

There is a high quality ITZ at the coarse aggregate surface, but there are still some $\mathrm{CH}$ regions around sand grains. Cracks are present as specimen was taken from a broken compressive strength cylinder. 


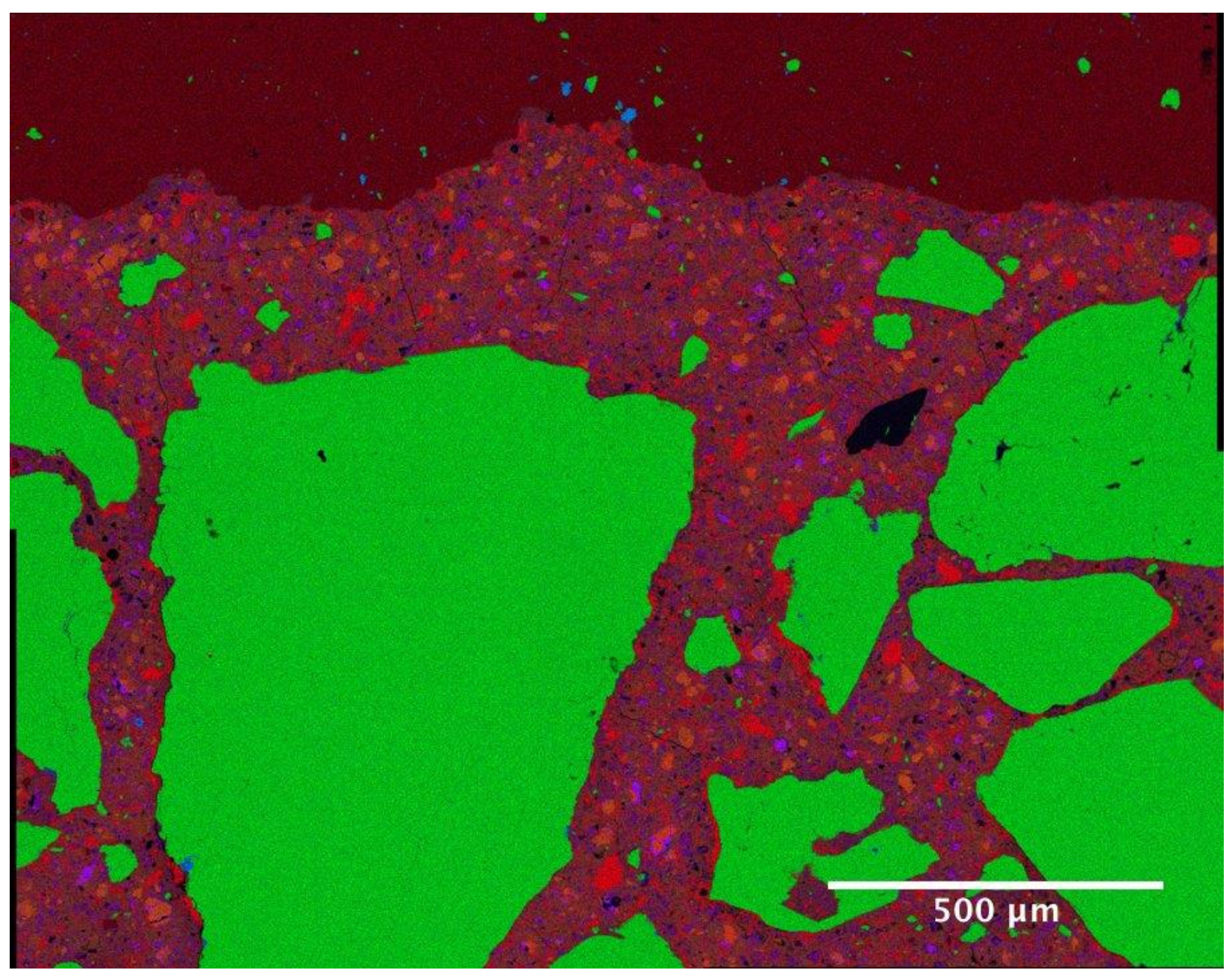

Figure 53. Ca-Si-Al RGB pseudo-color image for OPC dolomitic limestone concrete.

There is a dense, high quality ITZ region at the coarse aggregate surface (top in burgundy). Some quartz inclusions are easily identifiable within the limestone (dolomite) aggregate. Sand particles are shown in green. 


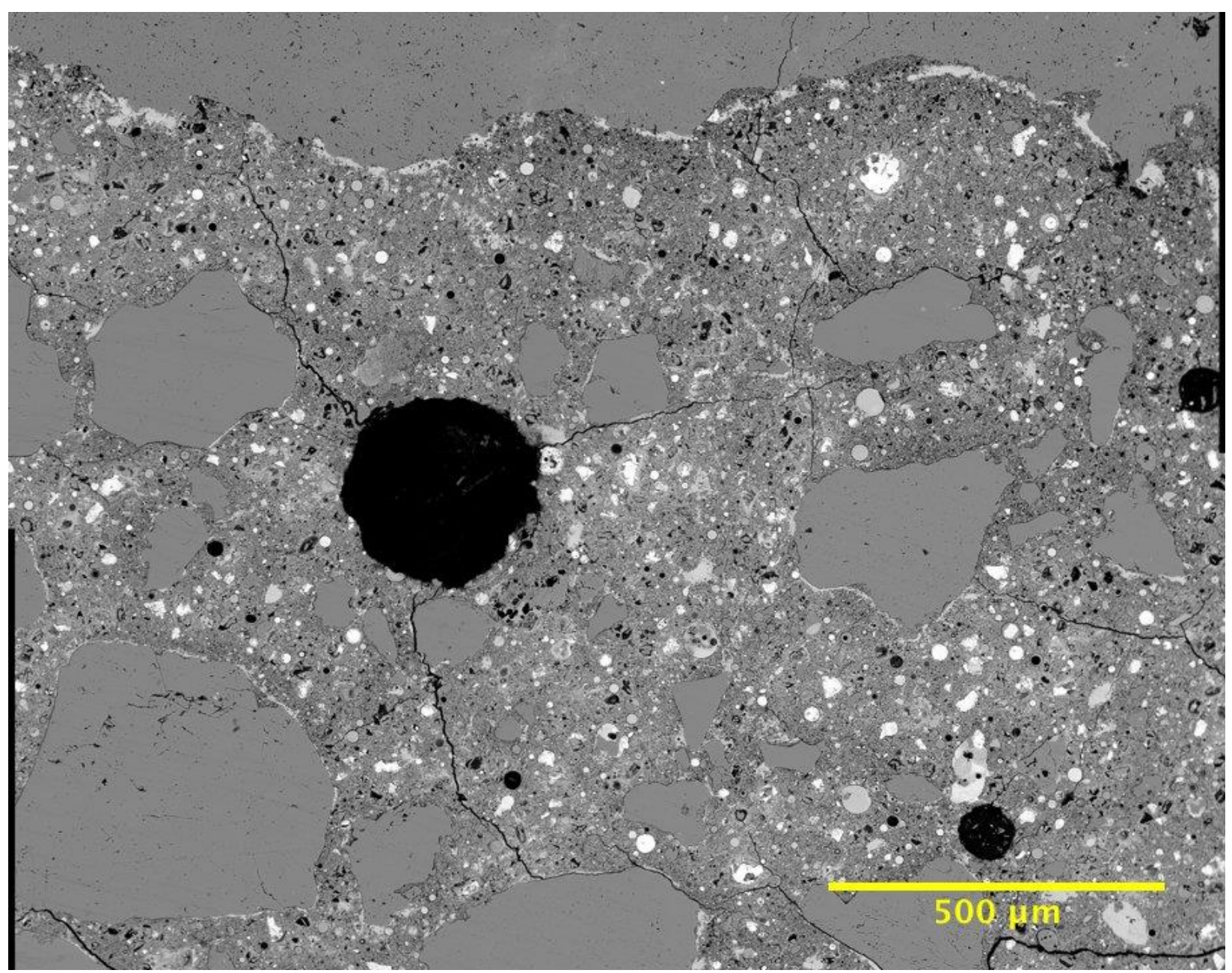

Figure 54. BE image for dolomitic limestone concrete prepared with the ternary blend.

There is a generally dense ITZ, but with localized $\mathrm{CH}$ formation; some $\mathrm{CH}$ regions are present around sand grains as well. Cracks are present as specimen was taken from a broken compressive strength cylinder. 


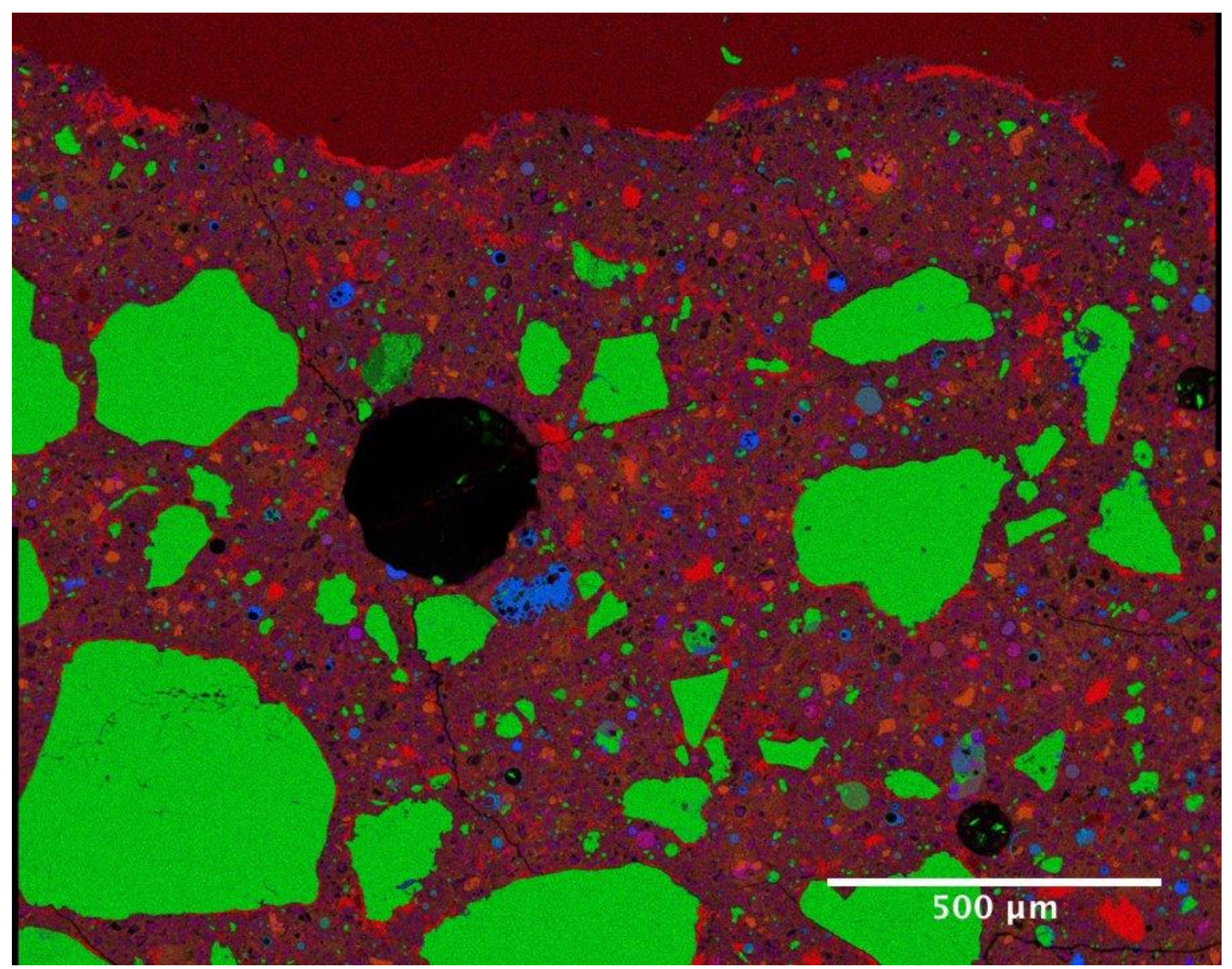

Figure 55. Ca-Si-Al RGB pseudo-color image for ternary blend dolomitic limestone concrete.

$\mathrm{CH}$ is apparent as bright red inclusions in the paste, some localized at aggregate surfaces. Calcium aluminosilicate and aluminosilicate fly ash phases are visible as rounded purple and blue/green particles within the paste. Sand is shown in green and dolomitic limestone in burgundy (at top). 


\section{Meta-Basalt Concretes:}

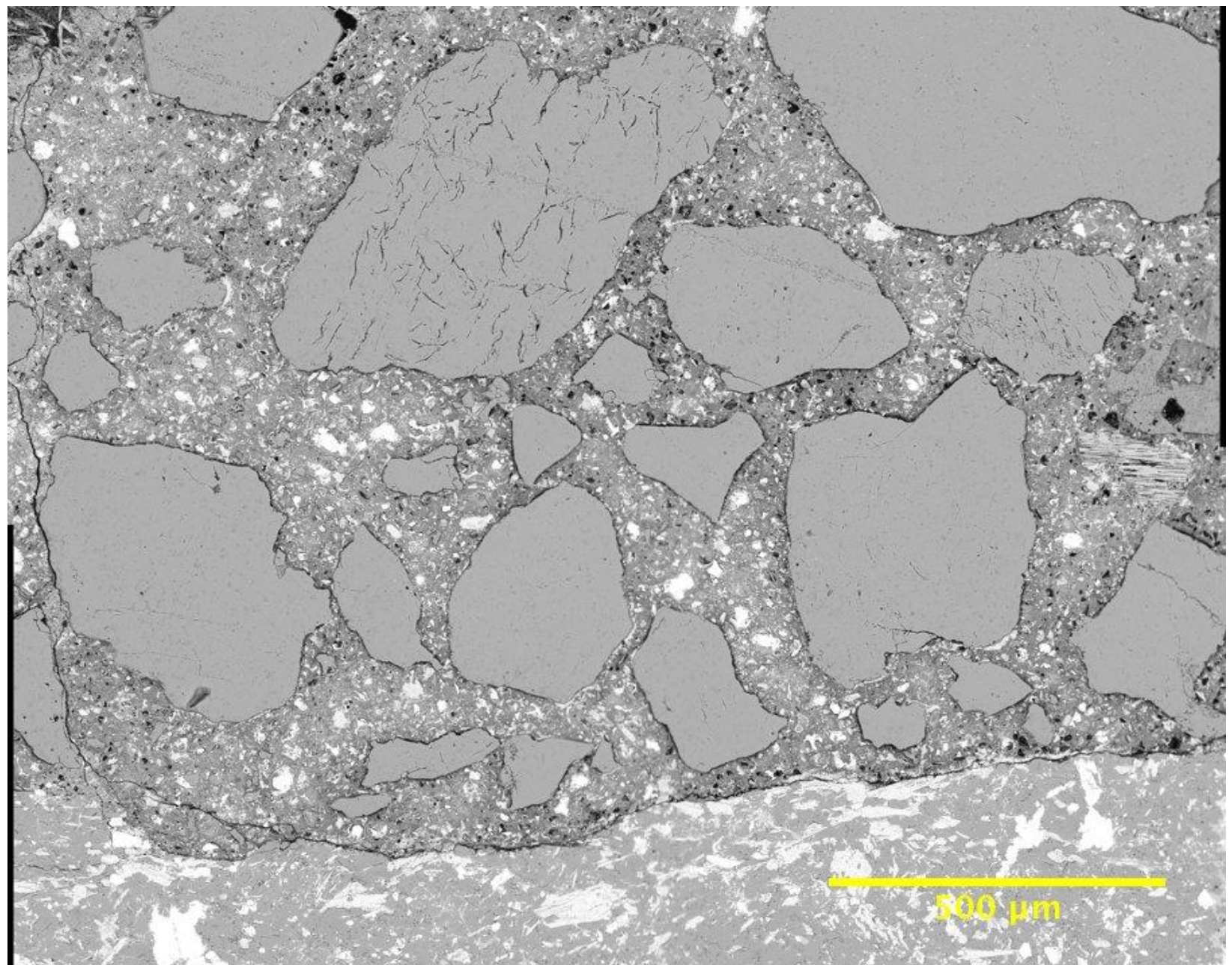

Figure 56. BE image for meta-basalt concrete prepared with OPC.

There is a generally high quality ITZ at the coarse aggregate surface, but with a crack running along that interface. There are still some $\mathrm{CH}$ regions around sand grains. Cracks are present as specimen was taken from a broken compressive strength cylinder. 


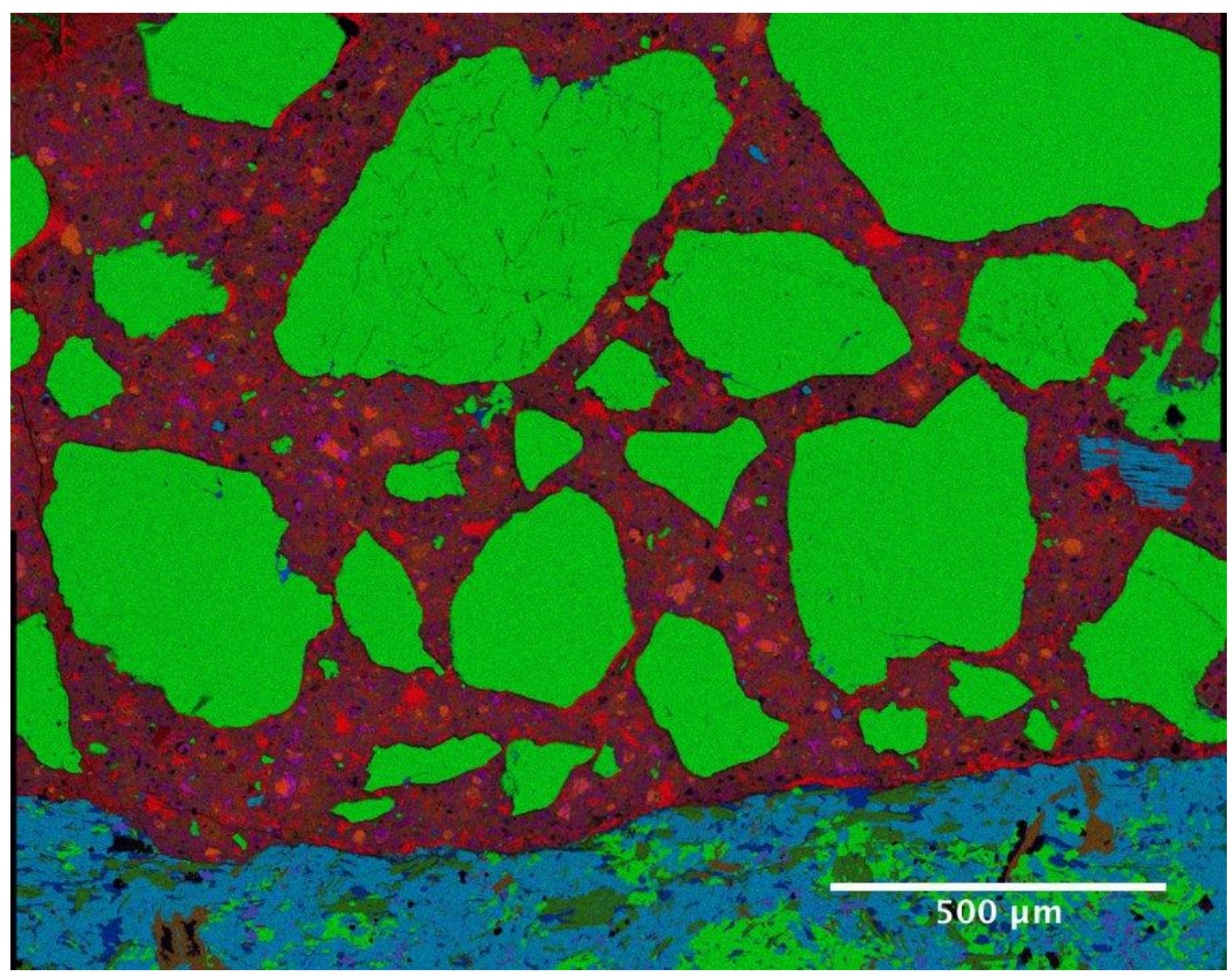

Figure 57. Ca-Si-Al RGB pseudo-color image for OPC meta-basalt concrete.

There is a generally dense, high quality ITZ region at the coarse aggregate surface (bottom in blue/green). Multi-phase nature of basalt aggregate is clear. Sand particles are shown in green. 


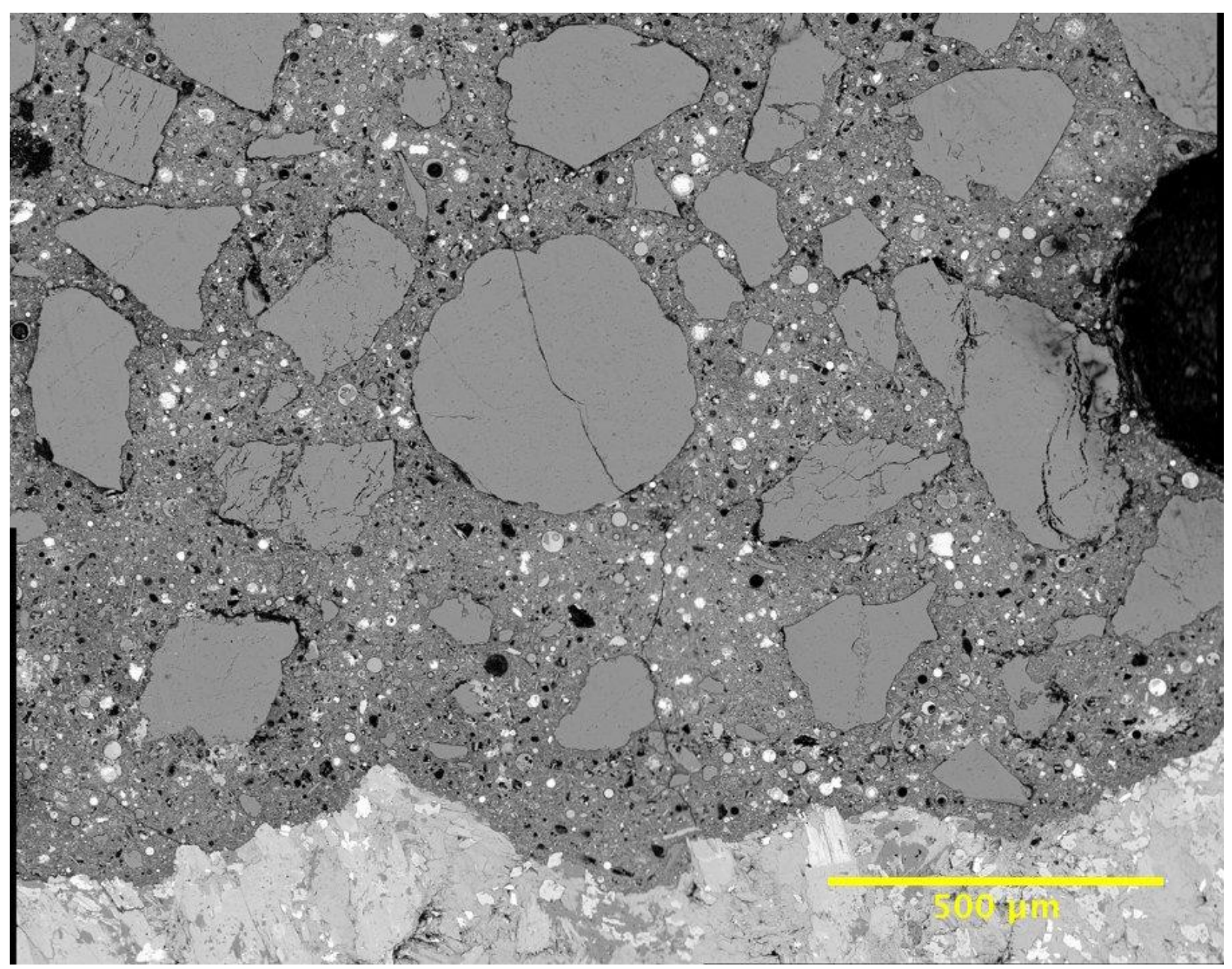

Figure 58. BE image for meta-basalt concrete prepared with the ternary blend.

There is a very high quality ITZ at the coarse aggregate surface (bottom). Cracks are present as specimen was taken from a broken compressive strength cylinder. 


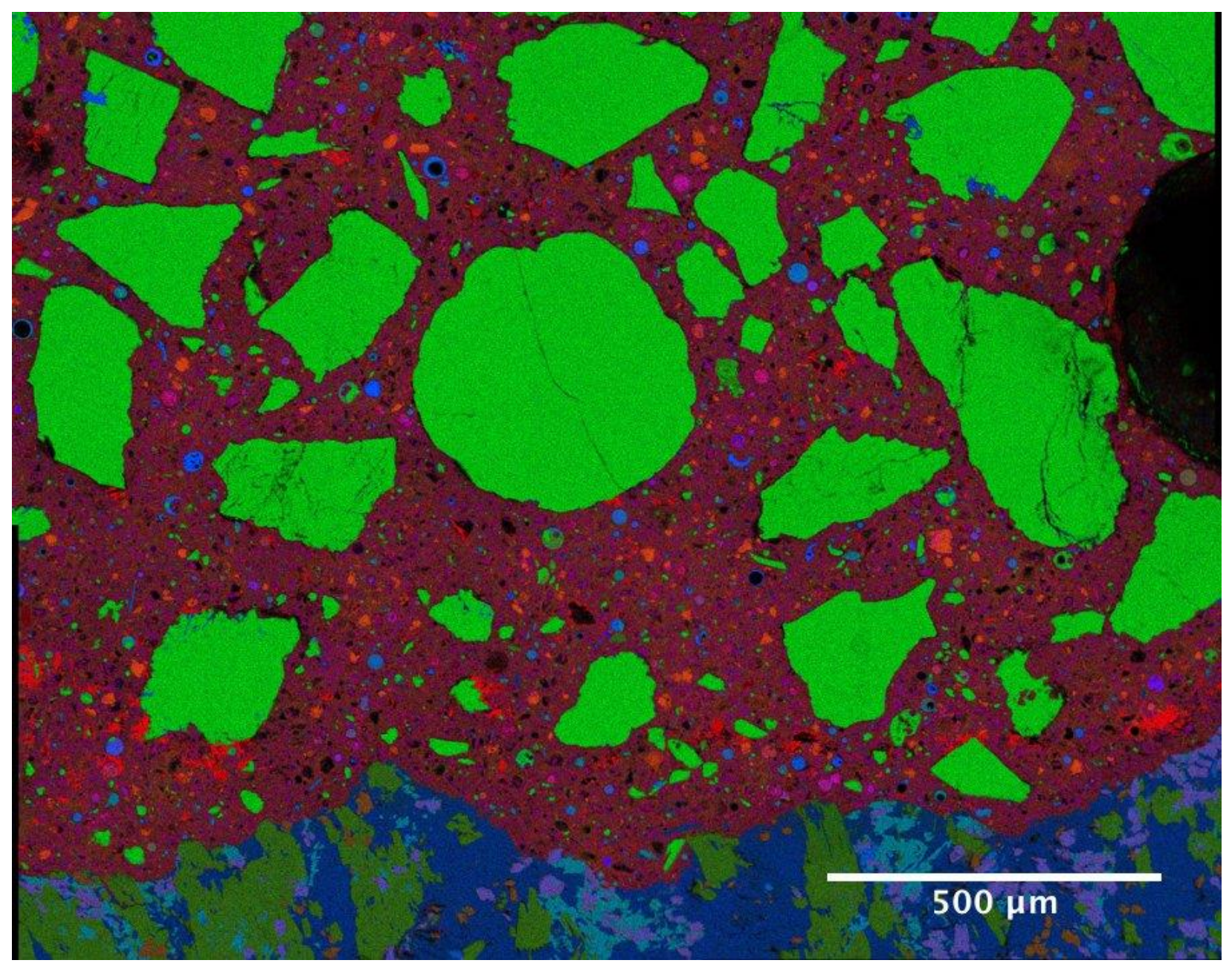

Figure 59. Ca-Si-Al RGB pseudo-color image for ternary blend meta-basalt concrete.

There is a very high quality ITZ region at the coarse aggregate surface (bottom). Multi-phase nature of basalt aggregate is clear. Calcium aluminosilicate and aluminosilicate fly ash phases are visible as rounded purple and blue/green particles within the paste. Sand particles are shown in green and meta-basalt in navy/dark green (at bottom). 


\section{High Absorption Limestone Concretes:}

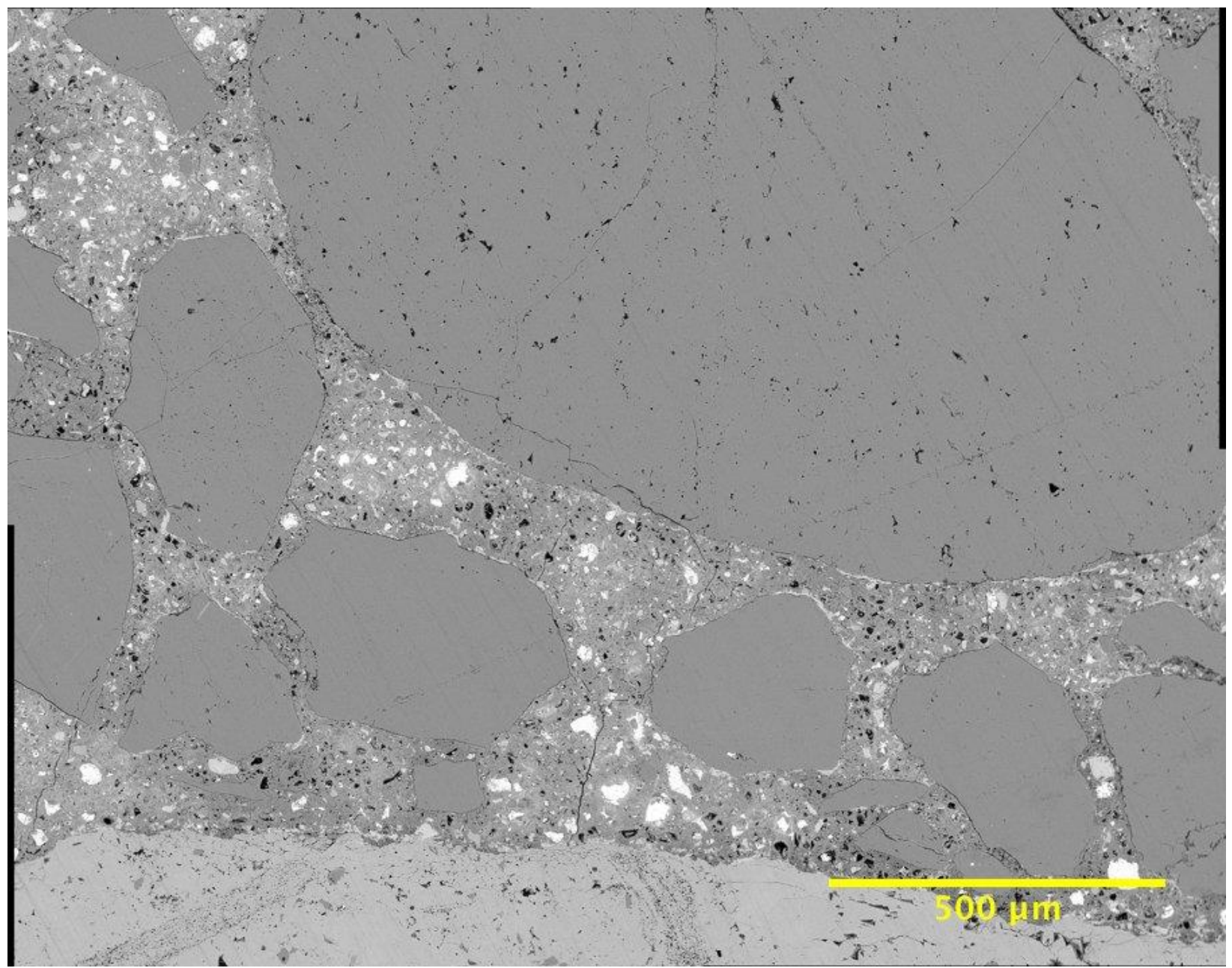

Figure 60. BE image for high absorption limestone concrete prepared with OPC.

There is a high quality ITZ at the coarse aggregate surface (bottom), but there are still some $\mathrm{CH}$ regions around sand grains. Minor cracking is present as specimen was taken from a broken compressive strength cylinder. 


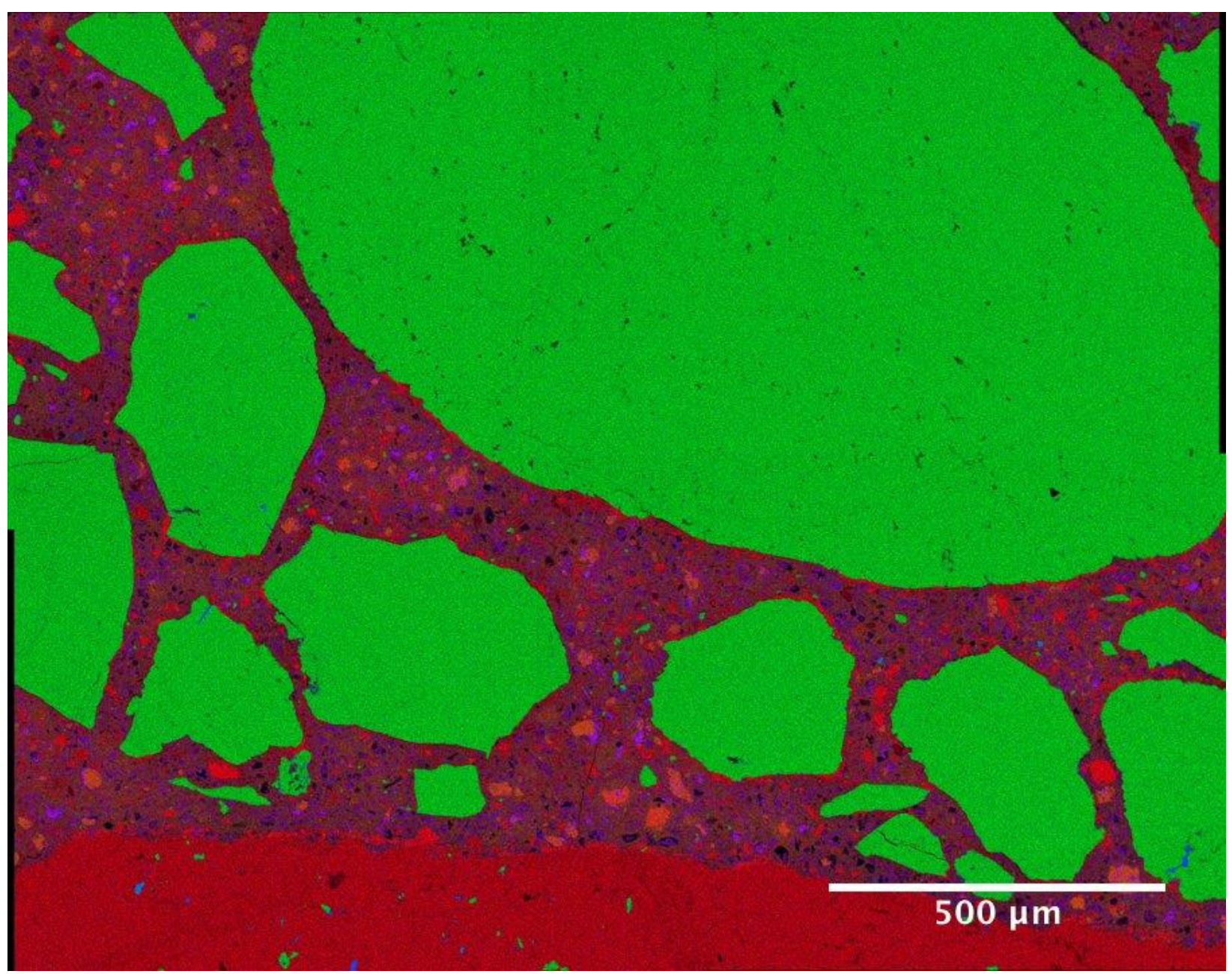

Figure 61. Ca-Si-Al RGB pseudo-color image for OPC high absorption limestone concrete.

There is a dense, high quality ITZ region at the coarse aggregate surface (bottom in scarlet red). Calcite (calcium carbonate) aggregate is easily identified by its bright red color, with very small quartz inclusions. Sand particles are shown in green. 


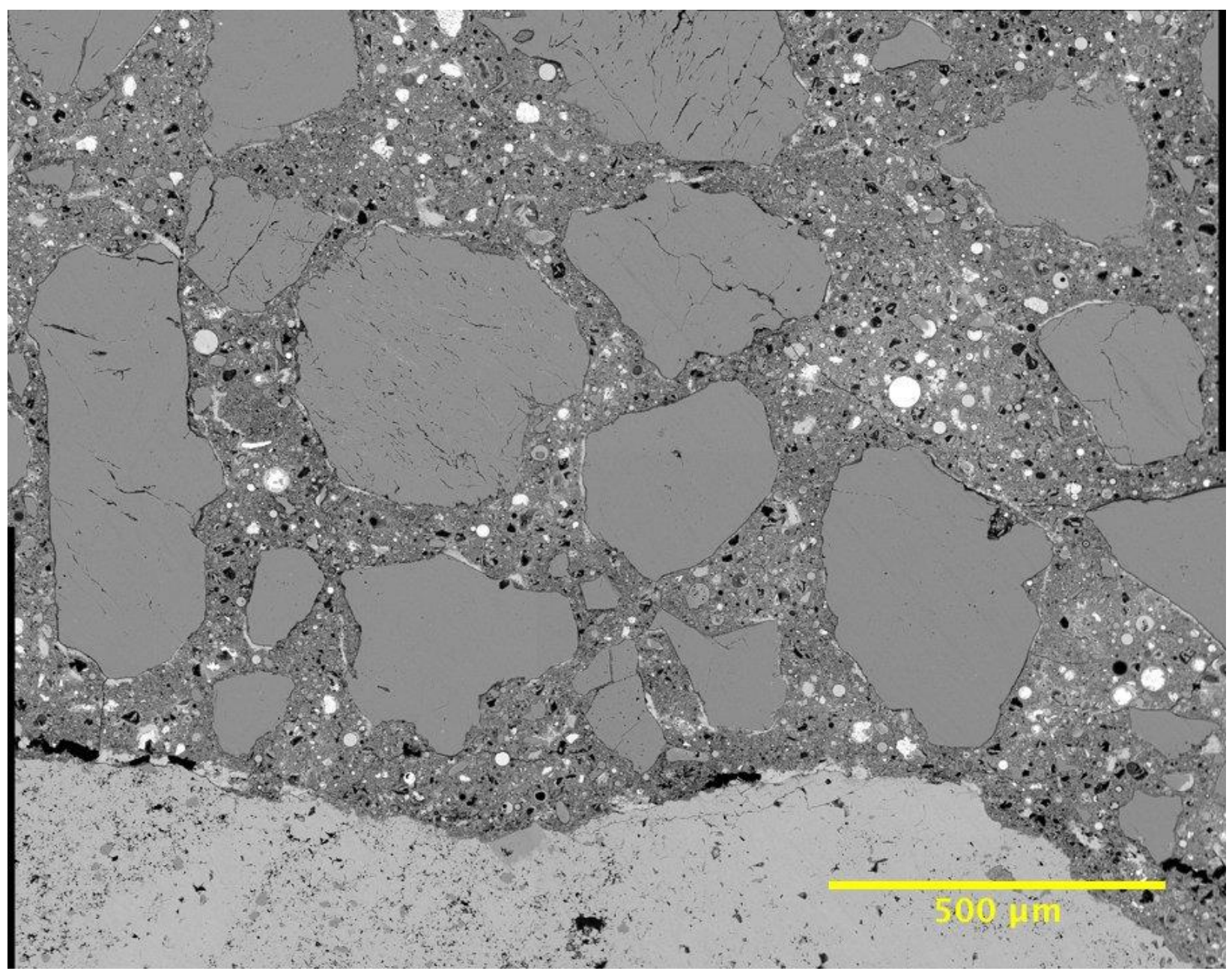

Figure 62. BE image for high absorption limestone concrete prepared with the ternary blend.

There are many localized "layers" of $\mathrm{CH}$ at aggregate and sand grain surfaces, along with some porous ITZ regions. 


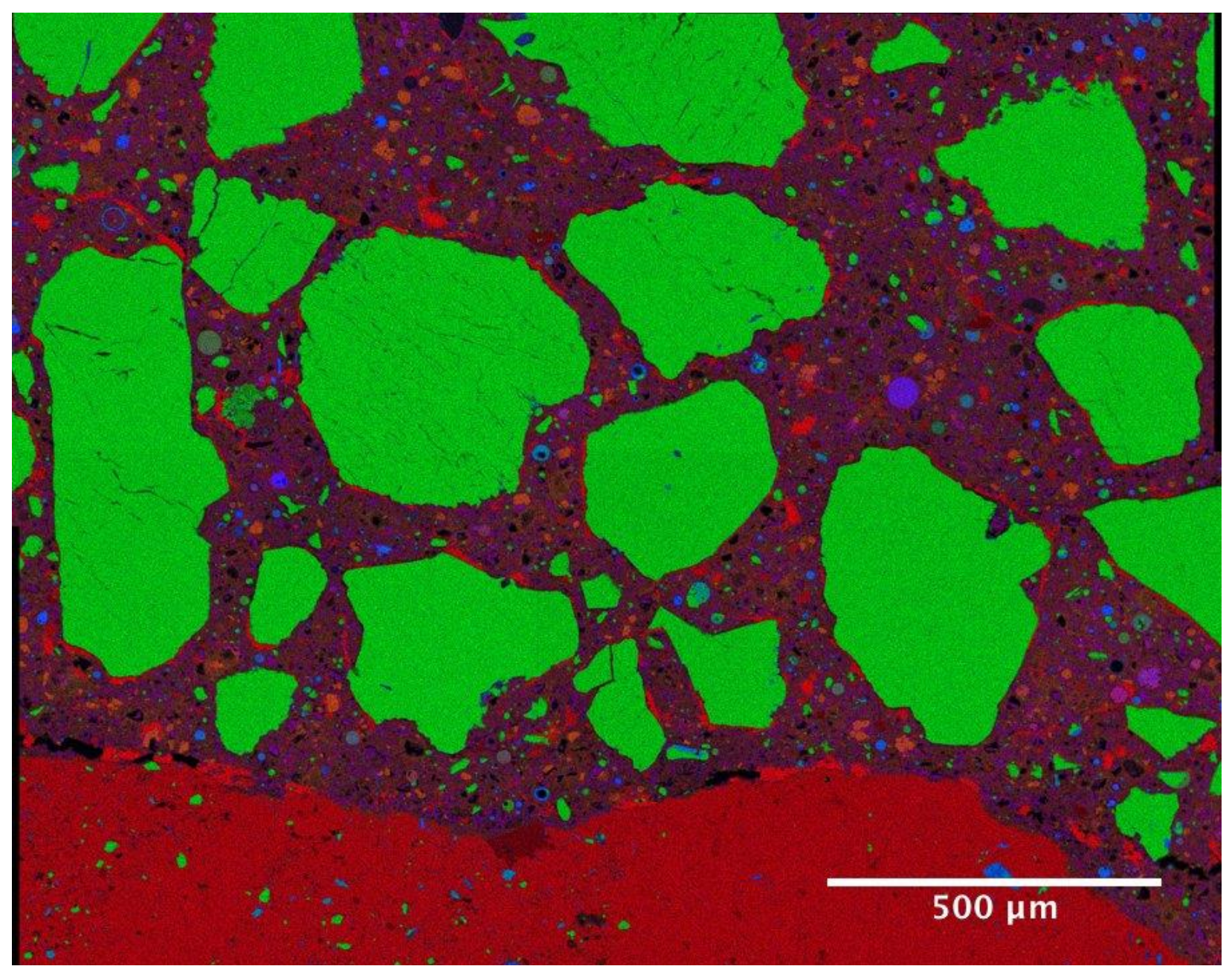

Figure 63. Ca-Si-Al RGB pseudo-color image for ternary blend high absorption limestone concrete.

There is a variable quality ITZ region at the coarse aggregate surface (bottom in scarlet red). Calcite (calcium carbonate) aggregate is easily identified by its bright red color, with very small quartz inclusions. Calcium aluminosilicate and aluminosilicate fly ash phases are visible as rounded purple and blue/green particles within the paste. Sand particles are shown in green. 


\section{APPEndix D. X-RAY Diffraction Scans of SElEcted AggregateS}

Gravel:

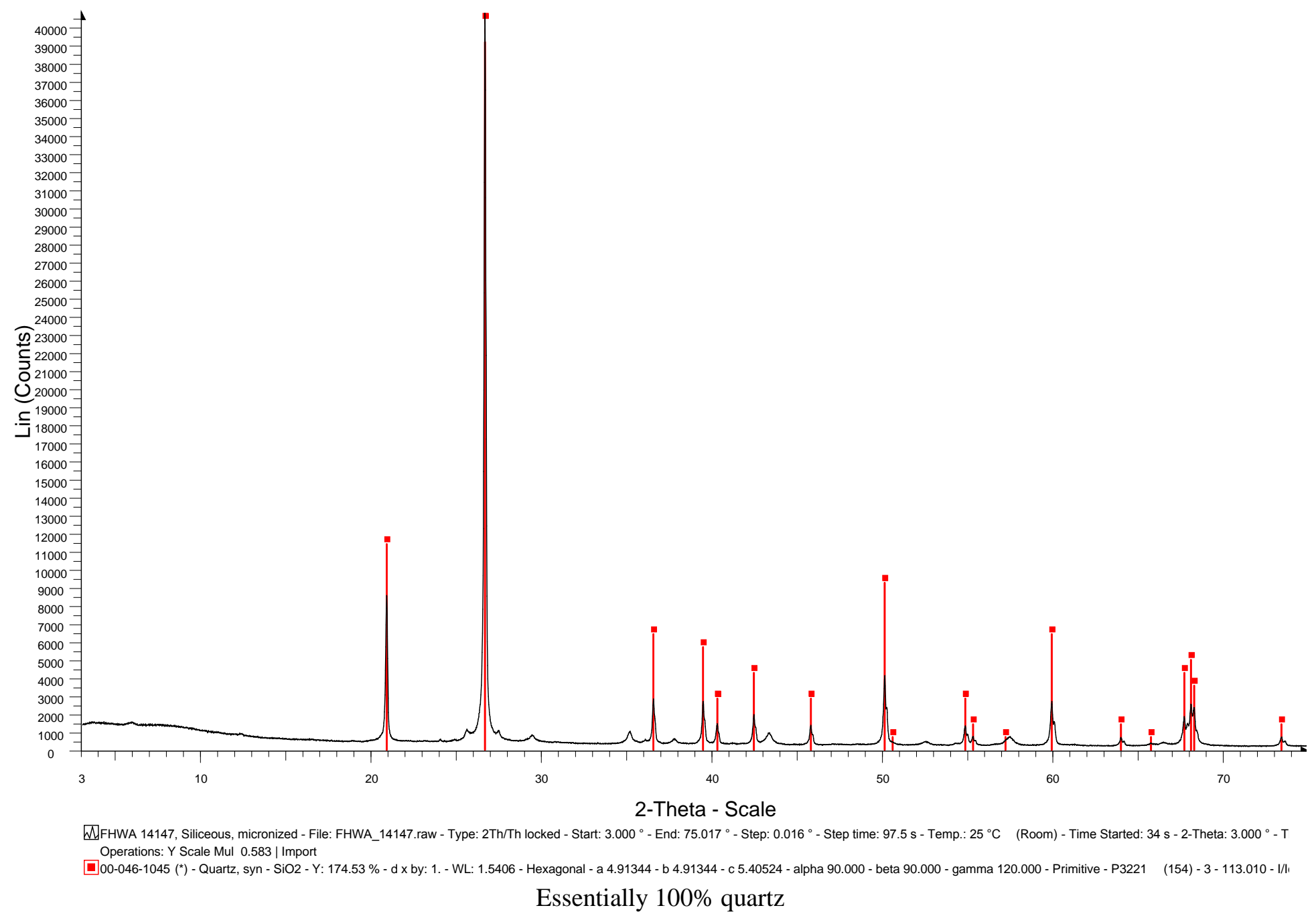




\section{Dolomitic Limestone:}

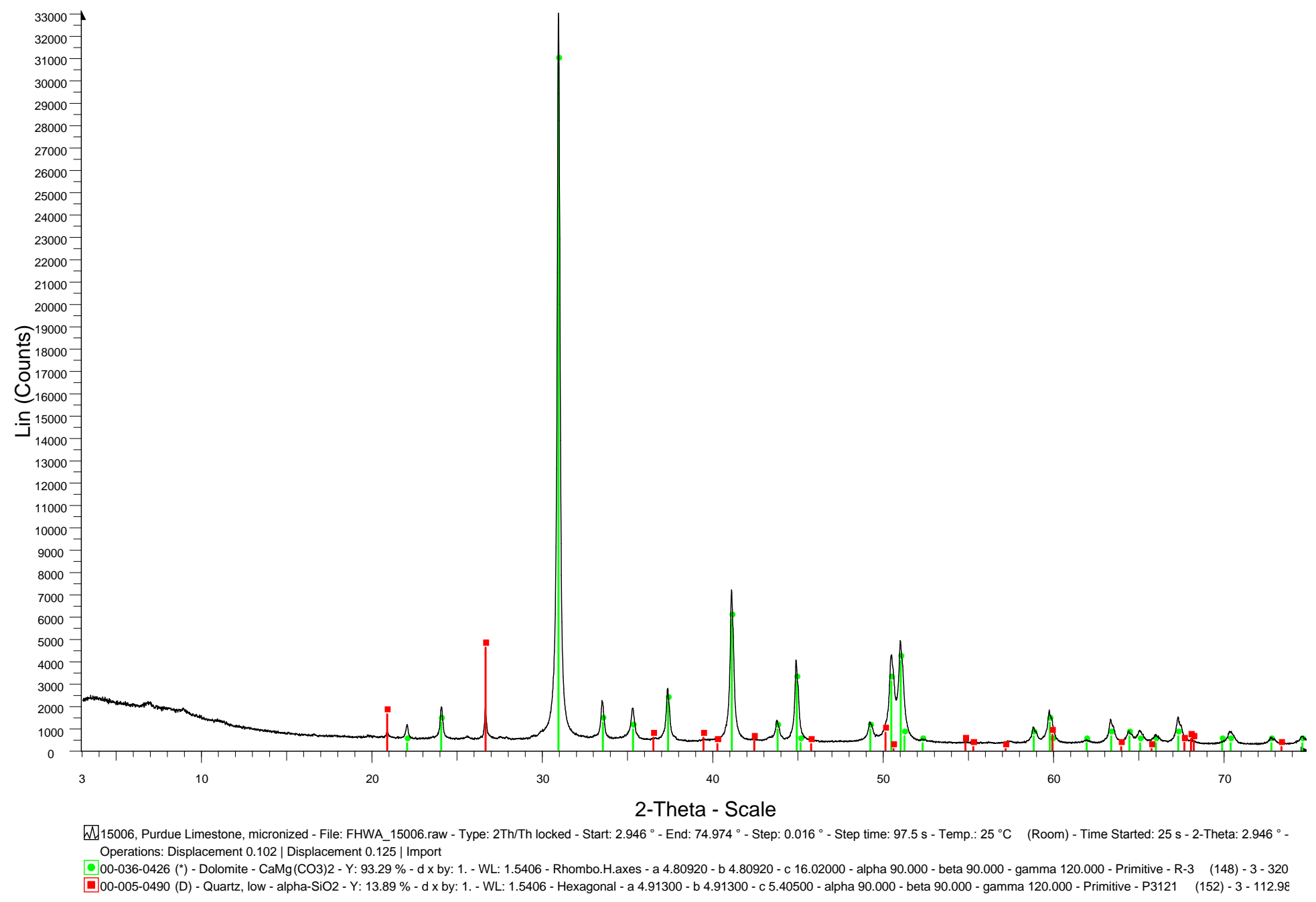

Primarily dolomite with minor quartz inclusions 


\section{Meta-Basalt:}

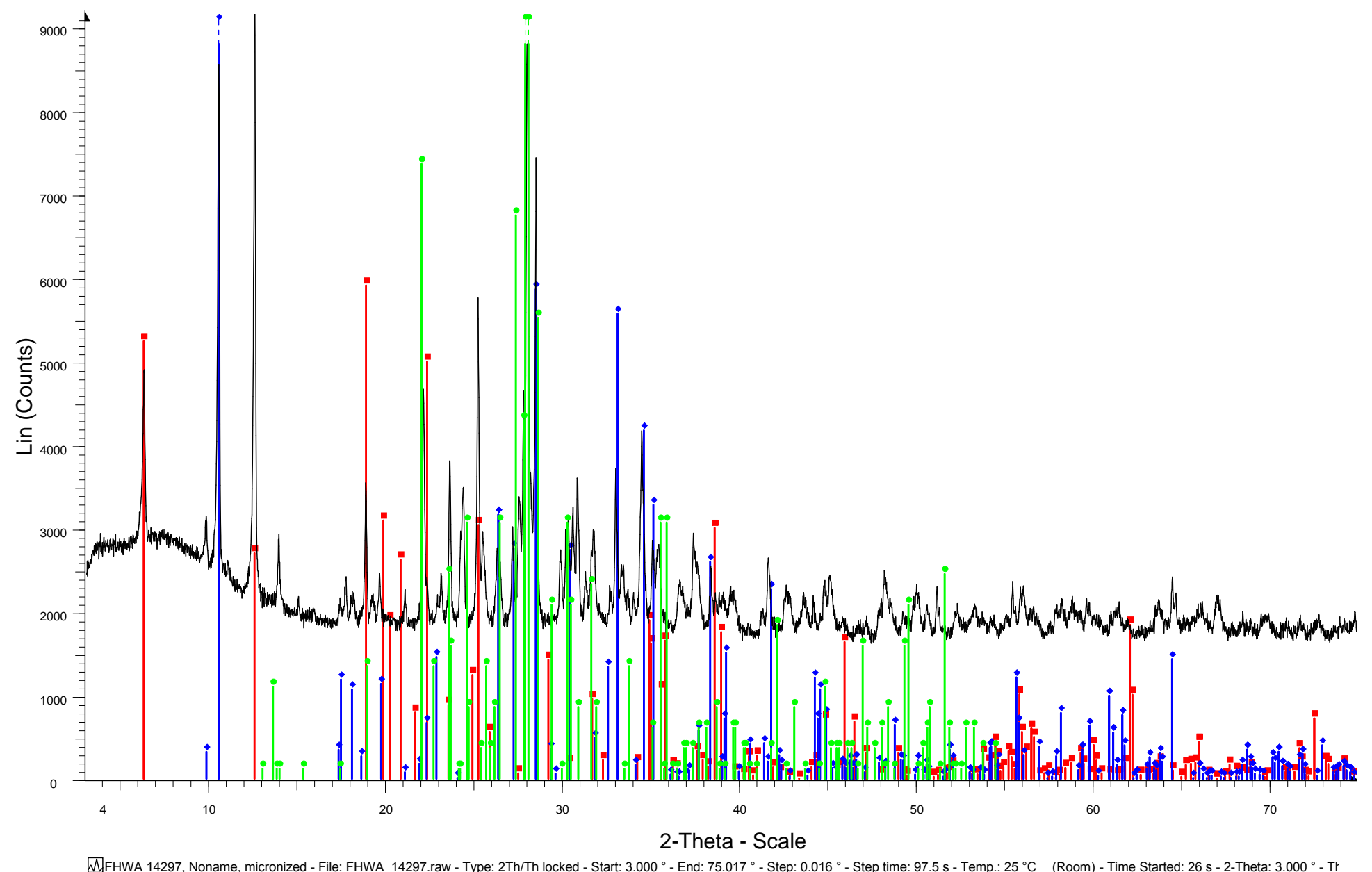

WFFHA 14297, Noname, micronized - File: FHWA_14297.raw - Type: 2 Th/Th locked - Start: $3.000^{\circ}$ - End: $75.017^{\circ}$ - Step: $0.016^{\circ}$ - Step time: $97.5 \mathrm{~s}$ - Temp.: $25^{\circ} \mathrm{C}$ (Room) - Time Started: $26 \mathrm{~s}-2$-Theta: $3.000^{\circ}$ - Tr

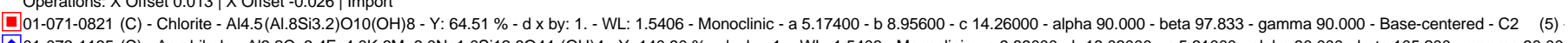

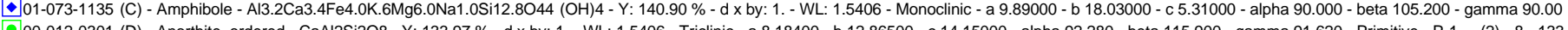

Anorthite (plagioclase feldspar) with chlorite and amphibole 


\section{High Absorption Limestone:}

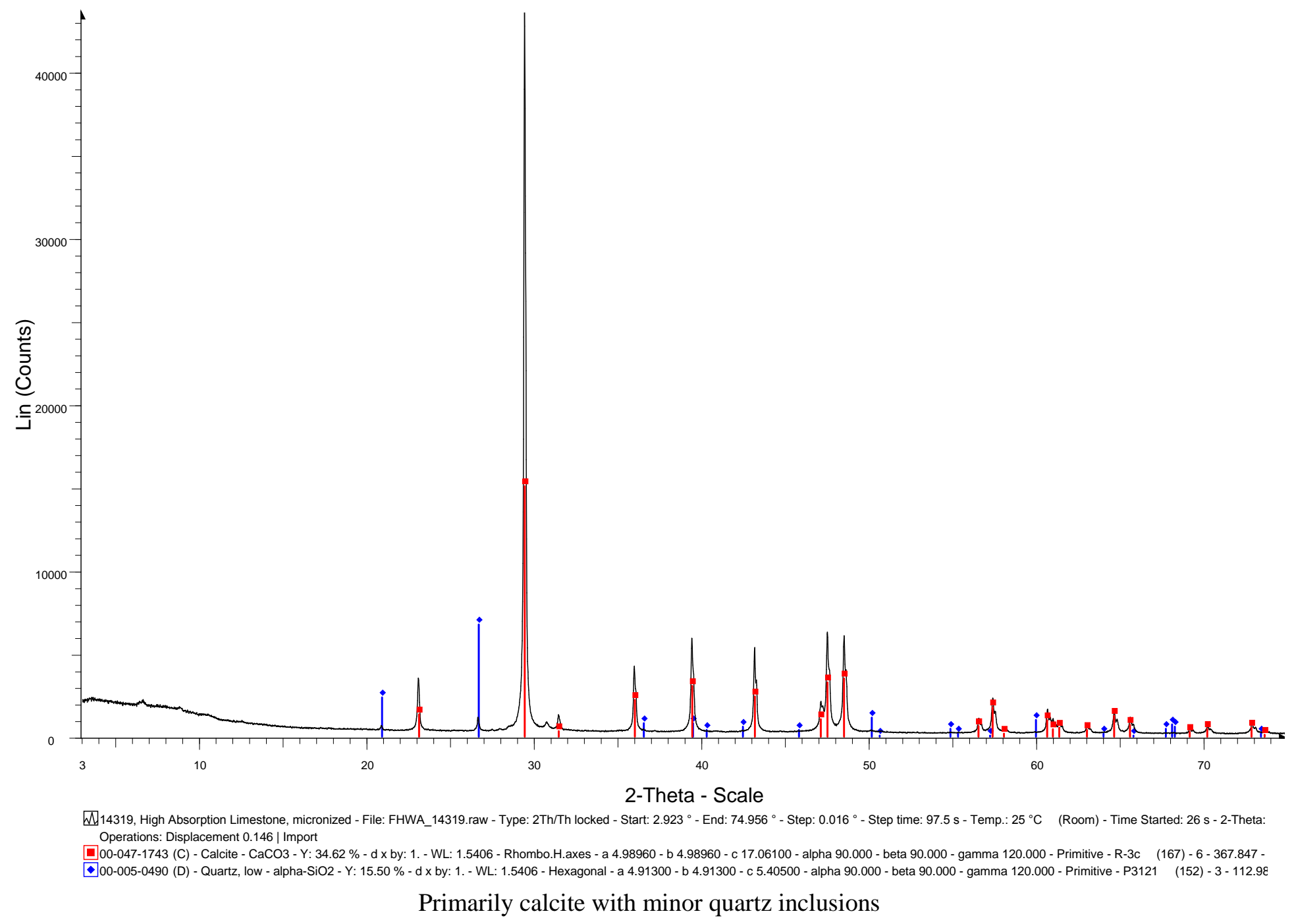

